\title{
INSTRUMENTATION METHODS FOR INTERCHANNEL COOLANT MIXING STUDIES IN WIRE-WRAP SPACED NUCLEAR FUEL ASSEMBLIES
}

by

Thomas E. Eaton and Neil E: Todreas

\author{
June 1974
}
Massachusetts Institute of Technology
Department of Nuclear Engineering
Cambridge, Massachusetts 02139

Prepared for the U.S. Atomic Energy Commission Under Contract No. AT(11-1)-2245

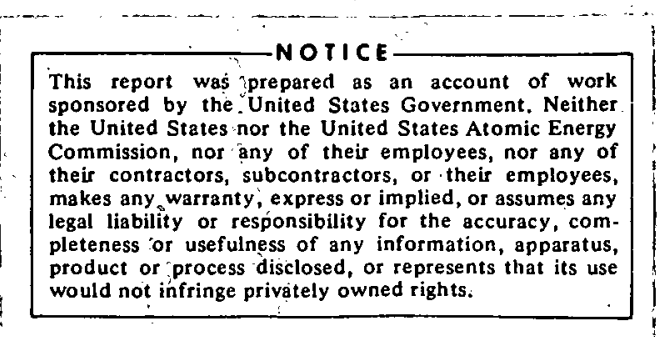




\section{DISCLAIMER}

This report was prepared as an account of work sponsored by an agency of the United States Government. Neither the United States Government nor any agency Thereof, nor any of their employees, makes any warranty, express or implied, or assumes any legal liability or responsibility for the accuracy, completeness, or usefulness of any information, apparatus, product, or process disclosed, or represents that its use would not infringe privately owned rights. Reference herein to any specific commercial product, process, or service by trade name, trademark, manufacturer, or otherwise does not necessarily constitute or imply its endorsement, recommendation, or favoring by the United States Government or any agency thereof. The views and opinions of authors expressed herein do not necessarily state or reflect those of the United States Government or any agency thereof. 


\section{DISCLAIMER}

Portions of this document may be illegible in electronic image products. Images are produced from the best available original document. 


\section{ABSTRACT}

A wire-wrap spaced, rhombus shaped, 25-pin experimental rod array was constructed with parameters typical of LMFBR's: $D=0.25$ in., $P / D=1.25$, Lead=12 in. Instrumentation design for coolant mixing experiments was discussed in deta1l. Salt $(\mathrm{NaCl})$ solution tracers offered Inherent advantages in detection. Experiments revealed no influence of salt type or injection solution concentration on results. Transverse infection caused more flow perturbation than a hypodermic tube mounted at $20^{\circ}$ from the tube centerline. Injection velocity influenced the flow perturbations; for this work, injection at the average subchannel velocity was used with water for the flow media.

Using an infector moving over the upper thirty inches of the rod array, tracer dispersion was detected at the outlet. The instrumentation was evaluated by comparing the tracer injected to that detected. Inherent loss of tracer due to concentration Inhomogeneities occurred over the last four inches of infector-detector separation with no serious effects. An unexpected loss of mass occurred at separations greater than twelve inches due to mechanical difficulties in the design.

The axial behavior of interchannel coolant mixing with tracer injection into an interior and a peripheral subchannel was established for both turbulent and laminar flow and required more than four data points per inch for its complete determination. With interior subchannel injection, the tracer dispersion pattern was dominated by flow sweeping effects with separations less than twelve inches; at greater separations, natural turbulent interchange dominated the dispersion. In laminar flow, the results were similar; however, the amount of tracer transferred by flow sweeping was markedly increased, apparently due to the change in wire-wrap drag coefficient and the absence of turbulence. The laminar flow signal fluctuated due to wire-wrap vortex shedding or injection instabilities.

Peripheral infection, mixing results were similar except the results were dominated by flow sweeping over the entire injector travel. A swirl flow around the bundle periphery was determined to be $4.9^{\circ} \pm 1.4^{\circ}$ using salt tracer data and $5.5^{\circ} \pm 1.0^{\circ}$ via flow visualization. The swirl flow remained away from the rod gaps and did not $\mathrm{mix}$ with adjacent interior subchannels in either flow regime. 
TITLE PAGE • . . . . . . . . . . . . . . . . 1

ABSTRACT.. . . . . . . . . . . . . . . . . 2

TABLE OF CONTENTS . . . . . . . . . . . . . . 3

IIST OF FIGURES . . . . . . . . . . . . . . 6

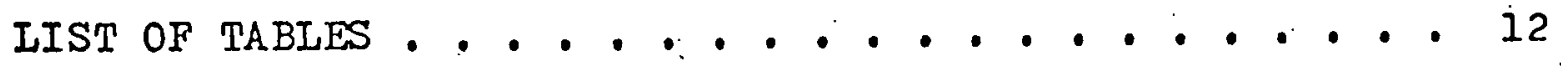

ACKNOWLEDGEIEINTS • . . . . . . . . . . . . . 14

Chapter 1 - INTRODUCTION - . . . . . . . . - 16

1.1 Mixing in Nuclear Fuel Assemblies . . . . 16

1.2 Natural Mixing Effects........... 17

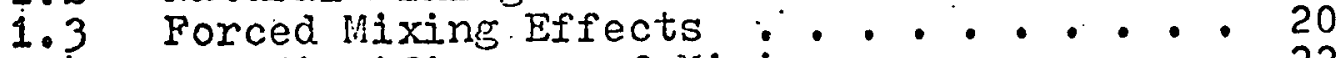

1.4 The Significance of lifixing . . . . . . . 22

1.5 Work Scope................ 24

Chapter 2 - INSTRUMENTING COOLANT MIXING EXPERIMENTS - 27

2.1. Tracer Instrumentation Techniques . • . 27

2.2 Tracers for Coolant inixing Experiments . 28

2.3 Injection System Design . . . . . . 31

2.4 . Detection System Design . . . : . . 35

2.5 The Significance of Tracer Diffusivity . . 37

2.6 The Advantages of Salt Soiution Tracers, 39

2.7 A Review of Instrumentation inethods Used

in other Interchannel Coolant Mixing.

Experiments . . . . . . . . . 42

Chapter 3 - SAIT SOLUTION TRACER EXPERIMENTS - . . - 56

3.1 Water Solutions and Tacotrolytic

Conductance - . - - . . . . 56

3.2 Electrolytic Conductance Hechanisms . . 58

3.3 Electrolytic Solutions as lracers . . . 59

3.4 Conductance Measurement Networks . . . . 62

3.5 The Conductivity Cell . . . . . . . 64

3.6 Accurate Conductance Measurements . • . 69

Chapter 4 - EXPERIMENT DESIGN $\Lambda N D$ CONSTRUCTION - - 72

4.1 Experiment Design Criteria . . . . . . 72

4.2 Experimental objectives $\because \because \because \because 2$

4.3 The History of NITF, The Mixing Instrumentation Test Facility . . . . 73

4.4 The First Experiment.......... 83

4.5 Facility Redesign and Reconstruction . . 87 
TABLE OF CONTENTS (Continued)

4.6 Test Section Redesion Page

4.7 Instrumentation Redesign . . .... 88

4.8 The EPI-EEL-2 Mixing Instrumentation Test Facility . . . . . . . . . 997

4.9 Design Nioditications of the Injector Rod . 99

4.10 Design and Modification of the Conductivity

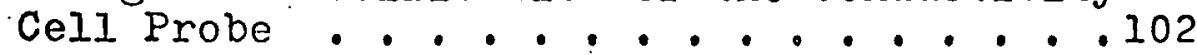

Chapter 5 - EXPERINENTAL RESULTS . . . . . . .105

5.1 A Summary of the Experimental Results. . .105

5.2 Data Collection and Processing . : :108

5.3 The Influence of Experimental Operating

. Parameters on Coolant lixing Results . . .120

5.4 Interchannel Coolant lixing Experiments . .128

5.5 Comments on the liass Balance Results : . 168

5.6 Flow Visualization Experiments ......172

Chapter 6 - RECONIENDATIONS FOR FUTURE MORK . . . . . 176

6.1 Influence of Rod Bundle Geometrical

Parameters on Coolant rixing . . . . . .176

6.2 Influence of the ivinber of Array Rods: : : 178

6.3 Influence of Subchannel Location ... . . 179

6.4 Miscellaneous Rod Bundle Nixing

Experiments ..............181

6.5 The Role of Diffusivity in Computer Code

6.6 Data Analysis . . . . . . . . . 182

6.6 Data Analysis . . . . . . . . . . 185

6.7 Integral Experiments .......... 187

6.8 Flow Visualization . : : : : 187

6.9 Recommendations for Future Experiment Design and Operation . . . . . . . 188

Chapter 7 - CONCLUSIONS .............. 192

7.1 Instrumentation Design ........ . 192

7.2. The Influence of Dperating Parameters on Experimental Resuits ......... 193

7.3 Interchannel Coolant Mixing Resuits - Interior

7 Subchannel Injection : . . . . . . 194

7.4 Interchannel Coolant ining Results - Peripheral

7.5 Instrumentation Perfomiance $\cdot . \cdot 0.196$

7.6 Flow Visualization Results : : : : : 197

REFERENCES . . . . . . . . . . . . . 198

NOMENCLATURE . . . . . . . . . . . . . 202 
TABLE OF CONTENTS (Concluded)

Page :

Appendix 1 - HYDRAULIC ANALYSIS OF THE EXPERIMENTAL FACILITY . . . . . . . . . . 205

Append1x 2 - CONDUCTANCE MEASUREMENT METHODS AND EQUIPMENT. . . . . . . . . . . . . . 212

Appendix 3 - MITMIX - A DATA REDUCTION PROGRAM FOR THE MIT MIXING PROJECT EXPERIMENTST . . . . .221

Appendix 4 - EQUIPMENT LIST . . . . . . . . . .*.

Appendix 5 - NOTES FOR THE EXPERIMENTER . . . . . .**

Appendix 6 - A DISCUSSION OF EXPERIMENTAL ERRORS. • . .226

Appendix 7. - ANALOG-TO-DIGITAL CONVERSION . . . . . 23I

Appendix 8 - FLOW VISUALIZATION PHOTOGRAPHS . . . .**

Appendix 9 - GRAPHICAL RESULTS OF THE PARAMETRIC EXPERIMENTS. . . . . . . . . . . . . 235

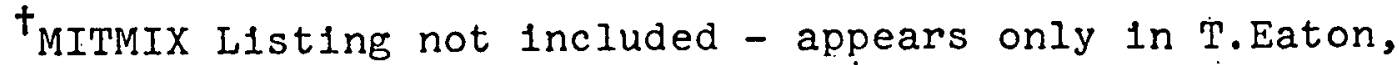
Engineer's Thesis, MIT, June 1974.

*Not included - appears only in T. Eaton Engineer's Thes1s, MIT, June 1974 . 


\section{IIST OF FIGURES}

Fig.

Page

1.1 - INFLUENCE OF INTERCHANNEL COOLANT AND ENERGY MIXING ON THE TRAINSVERSE BUNDIE TEIIPERATURE PROFILE ARISIIN FRONI RADIAI POWER GRADIENTS. - 23

1.2 - A CROSS SECTION VIEW OF $\Lambda 217$ PIN, HEXAGONAL FUEI ASSEMELY CHARAC'LERISTIC OF LRFBR'S. • . 26

3.1 - SPECIFIC RESISTANCE VS CONCENITRATION OF SODIUM CHLORIDE DISSOLVED IN DISTILLED $\mathrm{H}_{2} \mathrm{O}$ AT $140 \mathrm{~F}$............... . . 57

3.2 - ELECTRICAL NETWORK EOUIVAIEINT OF A CONDUCTIVITY. CELI USING AC MEASURING TECHNIQUES . . . . 65

4.1 - SCHEMATIC OF HYDRAUIIC LOOP NO. 1 USED FOR MIXING EXPERIMENTS ......... 74

4.2 - CROSS SECTION OF EXPERIMENTAI TEST SECTION NO. $1 . \cdot$. . . . . . . . . . 75

4.3 - ROD MOUNTED ELECTRODE DESIGN . . . . . 82

4.4 - SALT CONCENTRATION VERSUS INJEC'TOR TRAVEU RUN 2, 16 April 1972 (See Text for Details). . 84

4.5 - SCHEMATIC OF MIT MIXING PROJECT PUNP FACIIIMY. 89

4.6 - CROSS SECTION VIEN OF THE TEST SECTION FLOW CHANNEL NO. 2 . . . . . . . . 90

4.7 - ARRAY ROD END DETAILS . . . . . . . 92

4.8 - INJECTOR DETAILS , . . . . . . . . 93

4.9 - UPPER ROD SUPPORT PLATE DRAWING • • • • . 95

4.10 - UPPER ROD SUPPORT AND IINSTRUMENTATION PROBE DETAILS . . . . . . 96

4.11 - SCHEIATC DIAGRAM OF THE EPL-EEU-2 MIXING INSTRUNENTATION TEST FACIIITY . . . . . 98 
IIST OF FIGURES (Continued)

Fig.

Page

5.1 - PRESSURE DROP VERSUS FLOH RATE P VS. Q FOR THE TEST SECTION . . . . . . . . . . 112

5.2 - SUBCHANNET $A R R U N G$ MIENT OF THE EXPERIMENTAL TEST SECTION SHOWIING SUBCHANNEI IDENTIFICATION NUMBERS AND INJECTOR ROD LOCATIONS . . . .

5.3 - THE INFLUENCE OF WHEATSTONE BRIDGE, RESISTANCE SETTING ON UNBALANCED BRIDGE VOITAGE WIEASURED SHOWING THE KARIATION WITH SOLUTION CONCENIRATION . . . . . . . . . . . . . . . .

5.3.1 - TYPICAI CAIIBRATION CURVE OF SALT CONCENTRATION VS. UNBAIANCED BRIDGE VOLTAGE, IOW SCALE . . . 118

5.3.2 - TYPICAI CALIBRA TION CURVE OF' SALT CONCENTRATION VS. UNBALANCED BRIDGE VOITAGE: HIGH SCALE • • •

5.4 .1 - INTERCHANNEL COOLANT MIXING EXPERIMENTAL RESULTS FOR INTERIOR. SUBCHANNEL INJECTION AND TURBULINT FLOW CONDITIONS, RUN 1 - IT: SUBCHANNEL NOS. 1 ,

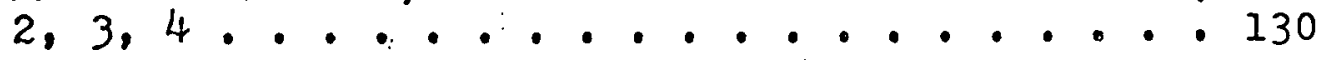

5.4.2 - INTERIOR SUBCHANNEL INJECTION, TURBULEIYT FLOW, RUN 1 - IT: SUBCHANNEL NOS. $1,5,6,7: . .131$

5.4 .3 - INTERIOR SUBCHANNEL INJECTION, TURBULENT FIOW, RUN 1 - IT: SUBCHANNEI NOS. $1,8,9,10 . . .132$

5.4.4 - INTERIOR SUBCHANNEL INJECTION, TURBULENT FLOW, RUN 1 - IT: SUBCHANNEL NOS. 1, 11, 12, 13... 133

5.4 .5 - INTERIOR SUBCHANNET INTECMION; MUPBUIENT FIOW, RUN 1 - IT: SUBCHANNEJ NOS. 1, 14, 15, 16... 134

5.4 .6 - INTERIOR SUBCHANNEI INJECTION, TURRUTEIST FIOW, RUN 1 - IT: SUBCHANNEI NOS $1,27,33,34 \ldots . .135$

5.4 .7 - INTERIOR SUBCHANNEL INJECIION, TURBULENT FLOW, RUN 1 - IT: SUBCHANNEI NOS. 1, 35, 50,51 .. 136

5.4 .8 - INTERIOR SUBCHANNEI INJECTION, TUREUI,ENT FLOW, RUN 1 - IT: MISS BALANCE VS. INJECTOR TRAVEJ . 137

5.4.9 - TEST SECTION CROSS SECTION SHOWING SUBCHANNELS MONITORED WITH INJECTION INTO INTERIOR

SUBCHANNEL NO. $1 . . . . . . . .138$ 
LIST OF FIGURES (Continued)

Fig.

Page

5.5.1 - INTERCHANNEL COOLANT. MIXING EXPERIMENTAL RESULTS

FOR INTERIOR SUBCHANNEJ INJECTION AND LAMINAR

FLOW COINDITIONS, RUN 2 - IL: SUBCHANNEI NUS. 1 ,

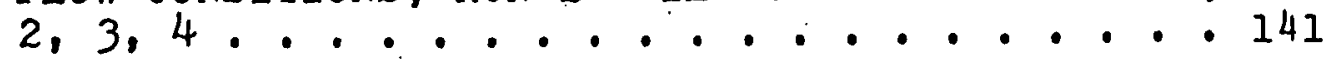

5.5 .2 - INTERIOR SUBCHANNEI INJECTION, IAMINAR FIOW, RUN 2 - IL: SUBCHANNEL NOS. 1, 5, 6, 7 . . 142

5.5 .3 - INTERIOR SUBCHANNEE INJECTION, LAMINAR FLOW, RUN 2 - IL: SUBCHANNEU NOS. 1, 8, 9, 10.... 143

5.5 .4 - INTERIOR SUBCHANNEL INJECTION, IMMINAR FIOW, RUN 2 - II : SUBCHANNEI NOS. 1, 11, 12, 13.. . 144

5.5.5 - INTERIOR SUBCHANNEL INJECTION, IAAIINAR FLOW: RUN 2 - II: SUBCHANNEL NOS. 1; 14, 15, 16.. 145

5.5.6 - INTERIOR SUBCHANNEL INJECTION, IAMINAR FLOW, RUN 2 - II: SUBCHANNEI NOS. 1, 17, 18, 19!. . 146

5.5.7 - INMERIOR SUBCHANNEL INJECTION, LAMINAR FIOW, RUN 2 - II: SUBCHANNEJ NOS. 1, 21, 26, 27. . . 147

5.5 .8 - IN'SERIOR SUBCHANNEL INJECTION, IAMINAR FIOW, RUN 2 - II: SUBCHANNEL NOS. 1, 33, 34,50.. . 148

5.5 .9 - INTERIOR SUBCHANNEI INJECTION, LAMINAR FLOW, RUN 2 - IL: SUBCHANNEL NOS.1,51...... 149

5.5.10- INTERIOR SUBCHANNET INJECTION, IAMINAR FIOW, RUN 2 - IL ? MLASS BAIANCE VS. INJECTOR TRAVEL • 150

5.6.1 - INTERCHANNEL COOLANT MIXING EXPERTMIENTAI RESULTS FOR PERIPHERAI SUBCHANNEI INJECTION AND TURBUIENT FLOW CONDITIONS, RUN 5 - PT, SUBCHANNEU NOS. 50, $27,26,49$. . . . . . . . . . 153

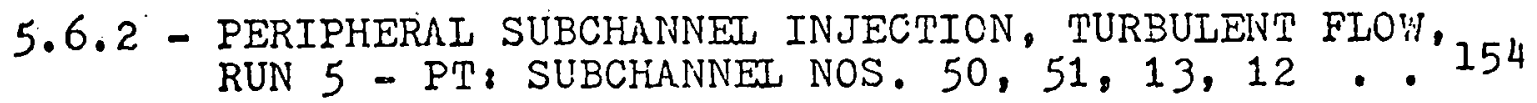

5.6.3 - PERIPHERAI SUBCHANNEL INJECTION, TURBULENT FLOW, RUN 5 - PT: SUBCHANINEU NOS. $50,52,33,14 . .155$

5.6.4 - PERIPHERAI SUBCHANNEI INJECTION, TURBULENT FLOW, RUN 5 - PT: SUBCYANNEL NOS. $50,34,35,18$. 156 


\section{IIST OF FIGURES (Continued)}

Fig.

Page

5.6.5 - PERIPHERAL SUBCHANNEL INJECTION, TURBULENT FLOW, RUN 5 - PT: SUBCHANNET NOS. $50,36,37$. . 157

5.6.6 - PERIPHERAI SUBCHANNEI INJECTIOIN, TURBULENT FLON, RUN 5 - PT: MASS BAIANCE VS. INJECTOR TRAVEL . 158

5.6.7 - TEST SECTION CROSS SECTION SHONING SUBCHANNEIS INONITORED WITH INJECTION INTO PERIPHEKAL SUBCHANNEL NO. 50 . . . . . . . . . 159

5.7 .1 - INTERCILANNEL COOLANT MIXING EXPERIMENTAL RESULTS FOR PERIPHERAI SUBCHANNEI IINJECIION AIND IANIINAR FLOW CONDITIONS, RUN 6 - PI, SUBCHANNEI NOS. 50 , $27,26,51$. . . . . . . . . . . 161

5.7 .2 - PERIPHERAL SUBCHANNEI INJECTION, LAMINAR FLOW, RUN 6 - PI: SUBCHANNET NOS. $50,13,12,52, .162$

5.7 .3 - PERIPHERAL SUBCHANNEL INJECTION, IAMINAR FLOW, RUN 6 - PI: SUBCHANNEI NOS. 50,33, 13, 34. 163

5.7 .4 - PERIPHERAI SUBCHANNET INJECTION, IAMINAR FIOW, RUN 6 - PL: SUBCHANNEL NOS. $50,7,35,18 \ldots .164$

5.7 .5 - PERIPHERAL SUBCHANNEL INJECTION, LAMINAR FLOW, RUN 6 - PI: SUBCHANNEI NOS. $50,16,36,28 \cdot .165$

5.7 .6 - PERIPHERAI SUBCHANNEL INJECTION, LAMINAR FLOW, RUN 6 - PL: SUBCHANNEL NOS. $50,19,37 . . . .166$

5.7 .7 - PERIPHERAI SUBCHANNEL INJECTION, LAMINAR FIOW, RUN 6 - PI: MASS BALANCE VS. INJECTOR TRAVEL . 167

6.1 - VARIATION OF THE RAIIO OF THE NUIIBER OF PERIE PHERAL-TO-INTERIOR TYPE SUBCHAINNEIS FOR HEXIGONAL ROD BUNDLES OF VARIOUS SIZES . . . 180

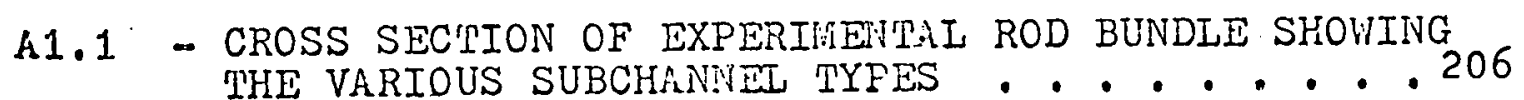

A1.2 - REYNOLDS NUMBER VS. FLOW RATE FOR VARIOUS FLOW AREAS IN THE EXPERIMEIVTAL TEST SECTION . . . . 210

A1.3 - FIOW VELOCIIY VS. TOTAL FIOW RATE FOR VARIOUS FIOW AREAS IN THE EYPERIMENTAL TEST SECTION . . 211

A2.1 - SCHENATIC OF WHEATSTONE BRIDGE CONDUCTANCE MEASITELIENT EQUIPIIENIP . . . . . . . . . . 213 


\section{LIST OF FIGURES (Continued)}

F1g.

Page

A2.2 - MEASURED VOLTAGE VERSUS SOLUTION CONCENTRATION USING UNBALANCED WHEATSTONE BRIDGE METHODS • • 217

A2.3 - MEASURED UNBALANCED BRIDGE VOLTAGE VERSUS BALANCED BRIDGE RESISTANCE . . . . . . . . 218

A2.4 - SCHEMATIC OF THE CONDUCTANCE MEASUREMENT EQUIPMENT . . . . . . . . . . . • • • 219

A7.1 - LOW-PASS FILTER CIRCUIT DIAGRAM . . . . . 233 A9.1.1 - RUN 0/2 - A: SUBCHANNEL NOS. 1, 2, 6, 7 . . 240 A9.1.2 - RUN 0/2 - A: MASS BALANCE VS. INJECTOR TRAVEL . 241 A9.2.1 - RUN 0/2 - A: SUBCHANNEL NOS. 1, 2, 6, 7. . . 242 A9.2.2 - RUN O/I - A: MASS BALANCE VS. INJECTOR TRAVEL . 243 A9.3.1 - RUN $0 / 1$ - B: SUBCHANNEL NOS. 1, 2, 6, 7 . . . 244 A9.3.2 - RUN $0 / 1$ - B: MASS BALANCE VS. INJECTOR TRAVEL . 245 A9.4.I - RUN 0/1 - C: SUBCHANNEL NO: I . . . . . . 246 A9.5.1 - RUN $0 / 1$ - E: SUBChANNEL NO. 1 . . .... 247 A9.6.1 - RUN $0 / 3$ - A: SUBCHANNEL NOS. $1,2,6,7 . . .248$ A9.6.2 - RUN 0/3 - A: MASS BALANCE VS. INJECTOR TRAVEL . 249 A9.7.1 - RUN $0 / 3$ - B: SUBCHANNEL NOS. $1,2,6,7 . \cdots 250$ A9.7.2 - RUN 0/3 - B: MASS BALANCE VS. INJECTOR TRAVEL . 251 A9.8.1 - RUN $0 / 3$ - G: SUbChanNEL NOS. $1,2,6,7 . . .252$ A9.8.2 - RUN $0 / 3$ - G: MASS BALANCE VS. INJECTOR TRAVEL - 253 A9.9.1 - RUN $0 / 3$ - H: SUBCHANNEL NOS. 1, 2, 6, 7 . . 254 A9.9.2 - RUN 0/3 - H: MASS BALANCE VS. INJECTOR TRAVEL . 255 A9.10.1 - RUN 0/2.9-A: SUBCHANNEL NO. 1 . . . . . . 256 
LIST OF FIGURES (Concluded)

Fig.

Page

A9.11.1 - RŨN 3/2 - A: SUBCHANNEL NOS. 1, 2, 6, 7. . . 257 A9.11.2 - RUN 3/2 - A: MASS BALANCE VS. INJECTOR TRAVEL. 258 A9.12.1 - RUN 3/2 - E: SUBCHANNEL NOS. 1, 2, 6, 7. . . 259 A9.12.2 - RUN 3/2 - E: MASS BALANCE VS. INJECTOR TRAVEL. 260 A9.13.1 - RUN 4/2 - A: SUBCHANNEL NOS. 1, 2, 6, 7. . . 261. A9.13.2 - RUN 4/2 - A: MASS BALANCE VS. INJECTOR TRAVEL. 262 A9.14.1 - RUN 4/2 - B: SUBCHANNEL NOS. 1, 2, 6, 7. . . 263 A9.14.2 - RUN 4/2 - B: MASS BALANCE VS: INJECTOR TRAVEL. 264 A9.15.1 - RUN 4/2 - C: SUBCHANNEL NOS. 1, 2, 6, 7. . . 265 A9.15.2 - RUN 4/2 - C: MASS BALANCE VS. INJECTOR. TRAVEL. 266 A9.16.1 - RUN 4/2 - E: SUBCHANNEL NOS. 1, 2, 6,7. . . 267 A9.16.2 - RUN 4/2 - E: MASS BALANCE VS. INJECTOR TRAVEL. 268 A9.17.1 - RUN $1 / 2$ - D: SUBCHANNEL NO. I. . . . . . 269 A9.18.1 - RUN $1 / 2$ - E: SUBCHANNEL NOS. $1,2,3,4$. . . 270 A9.18.2 - RUN $1 / 2$ - E: SUBCHANNEL NOS. 1, 5, 6,7. . . 271 A9.18.3 - RUN $1 / 2$ - E: MASS BALANCE VS. INJECTOR TRAVEL. 272 A9.19.1 - RUN 3/2 - A: SUBCHANNEL NO. 1; THE EFFECT OF INJECTOR MECHANICAL BEHAVIOR AND AXIAL SYNCHRONIZATION ERROR ILLUSTRATED . . . . • 273

A9.20.1 - RUN 1A -- IT: SUBCHANNEL NOS. 1, 2, 3, 4. . . 274 A9.20.2 - RUN IA -- IT: SUBCHANNEL NOS. 1, 5, 6, 7. . . 275 A9.20.3 - RUN IA -- IT: SUBCHANNEL NOS. 1, 8, 12, 13. . 276 A9.20.4 - RUN 1A - IT: SUBCHANNEL NOS. 1, 14, 15, 16. . 277 A9.20.5 - RUN IA - IT: MASS BALANCE VS. INJECTOR TRAVEL. 278 
IIST OF TABLES

Table

Page

1.1 A Summary of Mechanisms for Interchannel Coolant and Energy Mixing Effects Within ivclear Fuei Assemblies ............... 18

2.1 Interchannel Coolant Mixing Experiment Design Options Using Tracer Techniques . . . . . . 29

2.2 A Comparison of Salt Solution and Hot Water Tracers 41

2.3 Instrumentation Viethods Used in Other Wire-irap Spaced Coolant Mixing Experiments ... . . . 44.

2.4 Geometrical Parameters of Wire-Wrap Spaced Rod Arrays Used for Coolant Mixing Experiments . . • 47

2.5 Operating Parameters for Wire-Wrap Spaced Rod Array, Coolant Mixing Experiments . . .... 48

3.1 Characteristics of $\mathrm{AC}$ and $\mathrm{DC}$ Conductance heasuring Circuits............... 63

3.2 Standard Reference Solutions ......... 70

4.1 Geometrical Characteristics of hexagonal and Parallelogram, Triangular Lattice Rod Bundles of Interest . . . . . . . . . . . . . 77

5.1 Experiments to Determine the Influence of Experi. mental Operating Parameters on Results...... 106

5.2 Interchannel Coolant Mixing Experiments with a Wire-Wrap Spaced Rod Array ........... 109

5.3 Subchannel Reynolds Numbers and Flow Velocities for the Experiments ............ 110

5.4 Equal Average Velocity Criterion for Injection Operations . . . . . . . . . . . . . 122

6.1 Recommendations for Future Experimental itork in Interchannel Coolant hixing ... . . . . 177 


\section{LIST OF TABLES (Concluded)}

Table

Page

6.2 Diffusivity Ratios in Experimental Rod Arrays and LMFBR Fuel Assemblies.......... 184.

Al.1 Hydraulic Calculations for the Experimental Facility 209 A3.1 MITMIX (A Program for Data Reduction of Interchannel. Coolant Mixing Experiments at M.I.T.) . . . . . .

A6.1 Sources of Error in the Experimental Results. . . . 227

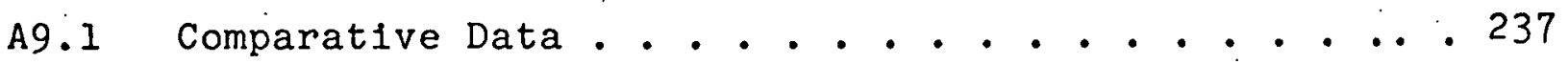




\section{ACKNOWLEDGEMENTS}

The work described in this report has been performed primarily by the principal author, T.E. Eaton, who has submitted essentially the same report to the Department of Nuclear Englneering at M.I.T. in partial fulfillment of the requirements for the degrees of Nuclear Englneer and Master of Sclence in Nuclear Engineering.

The financial support of the principal author during this work by a U.S. Atomic Energy Commission Special Fellowship in Nuclear Science and Englneering is most gratefully acknowledged. The financial support of the experimental program by U.S. Atomic Energy Commission Contract AT(11-1)2245, "Coolant Mixing In LMFBR Rod Bundles," and by the Massachusetts Institute of Technology, Sloan Basic Research Fund is also gratefully acknowledged.

Performance of this investigation has required the soliciting of the technical advice and assistance of many persons, and though this list is rather long, it is certainly appropriate to acknowledge their assistance here. Dr. Jeffery S. Horowitz, Mr. David N. Plummer and Dr. James Lorenz of the MIT Heat Transfer Laboratory, Mr. Lawrence Mandeville, Mr. Frederick Johnson and Mr. J.A. (TIny) Caloggero of the Mechanical Engineering Dept. Engineering Projects Laboratory, 
Mr. Alan S. Hanson and Mr. Walter Kirchner of the M.I.T. Mixing Project, Mr. David Gwinn, Mr. Jon C. Ferguson and Mr. Franc1s L. Woodworth and the machinists of the M.I.T. Reactor Machine Shop, Mr. Paul Sawyer of Balmsbaugh Laboratories, and Mr. James Kirksey of M.I.T. - all have provided much appreclated assistance during the course of the investigation.

A special note of thanks goes to Mrs. Virginia O'Keefe who has typed the first draft of this report. The review of the final manuscript by Professor David D. Lanning was also appreciated.

During the final days of data collection and data processing, the invaluable assistance of Messrs. David Gossard and David Plummer and of Miss Virginia Miethe is greatfully acknowledged.

The financial support of the principal author during the final phases of this project by the General Atomic Company was greatly appreclated.

The final manuscript of this report has been prepared by the author. 


\section{Chapter 1}

INTRODUCTION

\subsection{Mixing in Nuclear Fuel Assemblies}

Many nuclear power reactor cores are made up of fuel assemblies composed of an array of fuel bearing tubes called fuel rods. The fuel rods are arranged into an array and are held in the lattice arrangement by a spacer device, e.g., spacer grids or wire-wraps. The spacer devices serve primarily to maintain the coolant flow passages and to prevent fuel rod vibrations: The fuel rod array may be contained within a box structure to provide support for the rods" and to contain the coolant within the array. The rod array is constructed so as to provide for transverse communication of the coolant as it passes axially through the fuel assembly. The transverse exchange or transfer of coolant and energy within the fuel assembly is the subject of interchannel coolant and energy mixing. The word interchannel is introduced in rod array or rod bundle thermal-hydraulic analysis where the coolant flow passages are divided into unit flow areas called subchannels. 
Transverse coolant and energy transfer or mixing occurs via natural or inherent mechanisms and by forced or mechanical (uesigr) mechanisms. Fluid transfer or coolant mixing inherently gives rise to energy mixing as well; however, thermal conduction within fuel assembly materials and radiation (with gaseous coolants) transfers energy without coolant transfer. The design option of using extended surfaces (fins) to promote energy transfer can be considered a mechanical mechanism to promote energy mixing. The natural coolant and energy mixing effects are turbulent interchange and diversion cross flow while the forced or mechanical coolant (and energy) mixing mechanisms are turbulence promotion (flow scattering) and flow sweeping. These mechanisms of coolant and energy mixing are summarized in Table 1.1. Additional discussion of mixing effects may be found in Rogers and Todreas (1.1), Todreas and Turi (1.2) and Brodkey (1.3).

\subsection{Natural Mixing Effects}

The primary natural mixing effect is turbulent interchange (resulting from transverse eddy transport) of coolant and energy within the gaps between fuel rods where the fluid flowing axially in the rod array communicates transversely (across the artificial subchannel boundaries); turbulent interchange does not involve a 
Table 1.1

A Summary of Mechanisms for Interchannel Coolant and Energy Mixing Effects Within Nuclear Fuel Assembiies +

\begin{tabular}{|c|c|c|}
\hline & NA TURAI & FORCED or MECHANICAI \\
\hline $\begin{array}{l}\text { FLUID AND ENERGY } \\
\text { MIXING EFFECTS }\end{array}$ & $\begin{array}{l}\text { TURBULENT INTERCHANGE } \\
\text { DIVERSION CROSS FLOW* }\end{array}$ & $\begin{array}{l}\text { TURBULENCE PROMOTION } \\
\text { (FlOW Scattering) } \\
\text {. FLOW SWEEPING* }\end{array}$ \\
\hline $\begin{array}{l}\text { ENERGY MIXING } \\
\text { EFFECTS ONIY }\end{array}$ & $\begin{array}{l}\text { THERMAL CONDUCTION } \\
\text { RADIATIVE TRANSFER }\end{array}$ & $\begin{array}{c}\text { THERMAL CONDUCTION } \\
\text { IN EXTENDED SURFACES (FINS) }\end{array}$ \\
\hline
\end{tabular}

+Adapted from Rogers and Todreas (1.1)

*Directional Coolant Mixing Effects 
net fluid transfer but can result in net energy transfer from one flow region to another. Diversion cross flow is a directional inherent mixing mechanism which results from changes ir the differences of hydraulic resistance between flow subchannels. An excellent example of diversion cross flow is the flow development in rod arrays enclosed within a fuel assembly box or can. The flow normaliy enters the rod array from a plenum with a uniform velocity and is redistributed as hydraulic flow: development occurs due to differences in the hydraulic resistances of the various subchannels. That is, because the local hydraulic resistance adjacent to the wall is less, coolant is diverted from the rod array interior toward the array sides in the flow development region (the effect is directional in nature). Another. example of diversion cross flow arises when a gaseous coolant is used in a fuel assembly subjected to radial power gradients; density decreases in higher powered regions result in a transverse or diversion cross flow to the cooler side of the fuel assembly.

Secondary flow occurs naturally whenever the wetted perimeter (hydraulic resistance) is not distributed uniformly around the flow area. These non-circular flow geometries give rise to transverse pressure gradients which generate secondary flows (superimposed on the main axial flow)....Although secondary flows are not 
responsible for the transfer of coolant from one subchannel to another, such internal subchannel flows can be expected to have a significant influence on the transfer of coolant and energy in the vicinity of the subchannel gaps.

\subsection{Forced Mixing Effects}

Forced mixing results from coolant flow interaction with mechanical components. within the assembly. Several types of forced mixing effects are possible - turbulence promotion, which includes flow scattering, and flow sweeping. Turbulence promotion is a non-directional mechanical method of increasing the level of background or natural turbulence; this forced mixing effect is introduced into the fuel assembly by using roughened surfaces of various types. Turbulence promotion (which is used to improve the convective heat transfer coefficient) is desirable only in the active fuel region of the assembly and thus gives rise to diversion cross flow at the start (and termination) of roughening. This is because only the heated surfaces are roughened, and the increase in hydraulic resistance is greater within the rod array than along the smooth edges of the assembly. Flow scattering is a non-directional type of turbulence promotion which results from mechanical protuberances in the flow field, e.g., spacer grids. 
Flow sweeping is a directional forced mixing effect which.is caused by such mechanical devices as wire-wrap or spacer turning vanes that are oriented with an angle to the axially flowing coolant. Swirl flow is a cumulative flow sweeping effect that is discussed next.

It is important to note that no interchannel coolant mixing effect has the capability to transfer coolant over length scales larger than those typical of the fuel rod pitch. It may be speculated that wire-wrap spaced fuel assemblies induce a bulk swirl component, i.e.. a large length scale secondary or swirl flow superimposed on the main axial flow. This swirl flow is speculated to occur because all flow sweeping in wire-wrap spaced fuel assemblies is in the same angular direction at a given axial plane (all wire-wraps are at the same angular orientation on each rod at a given axial location). In the rod array interior the wire-wraps from the three contiguous rods traverse the subchannel in such a manner that over one axial pitch of the wire-wrap, the coolant flowing axially in the subchannel experiences no net flow sweeping. However, as the coolant flows axially in the peripheral subchannels between the outside rods and the channel walls, the wire-wrap spacers always enter and traverse the subchannel with the same rotational direction. Thus, a net flow sweep is experienced in the peripheral subchannels of wire- 
wrap spaced rod arrays, and a peripheral swirl flow might be expected. Such swirl flow has the capability of producing transverse coolant transfer over length scales typical of several rod pitches or perhaps more. Further experimental investigation is required before swirl flow can be assessed quantitatively.

\subsection{The Significance of Mixing}

Interchannel coolant and energy mixing are important in the thermal-hydraulic and thermal-mechanical design. of nuclear fuel assemblies because its mechanisms influence the coolant temperature profile and reduce hot spot temperatures. These considerations of temperature profile are particularly important in fast breeder reactors where coolant and structural temperatures are higher and where structural materials undergo volumetric swelling in a strongly temperature dependent manner. The length scale typical of mixing mechanisms limits the ability of mixing to reduce temperature gradients over lengths greater than a few rod pitches, e.g., the radial assembly temperature tilt occuring in fuel assemblies subjected to steep radial power gradients. Mixing effects can be very effective in reducing local temperature differences in fuel assemblies but cannot be effective in reducing temperature differences across the entire assembly. Figure 1.1 shows typical results of 


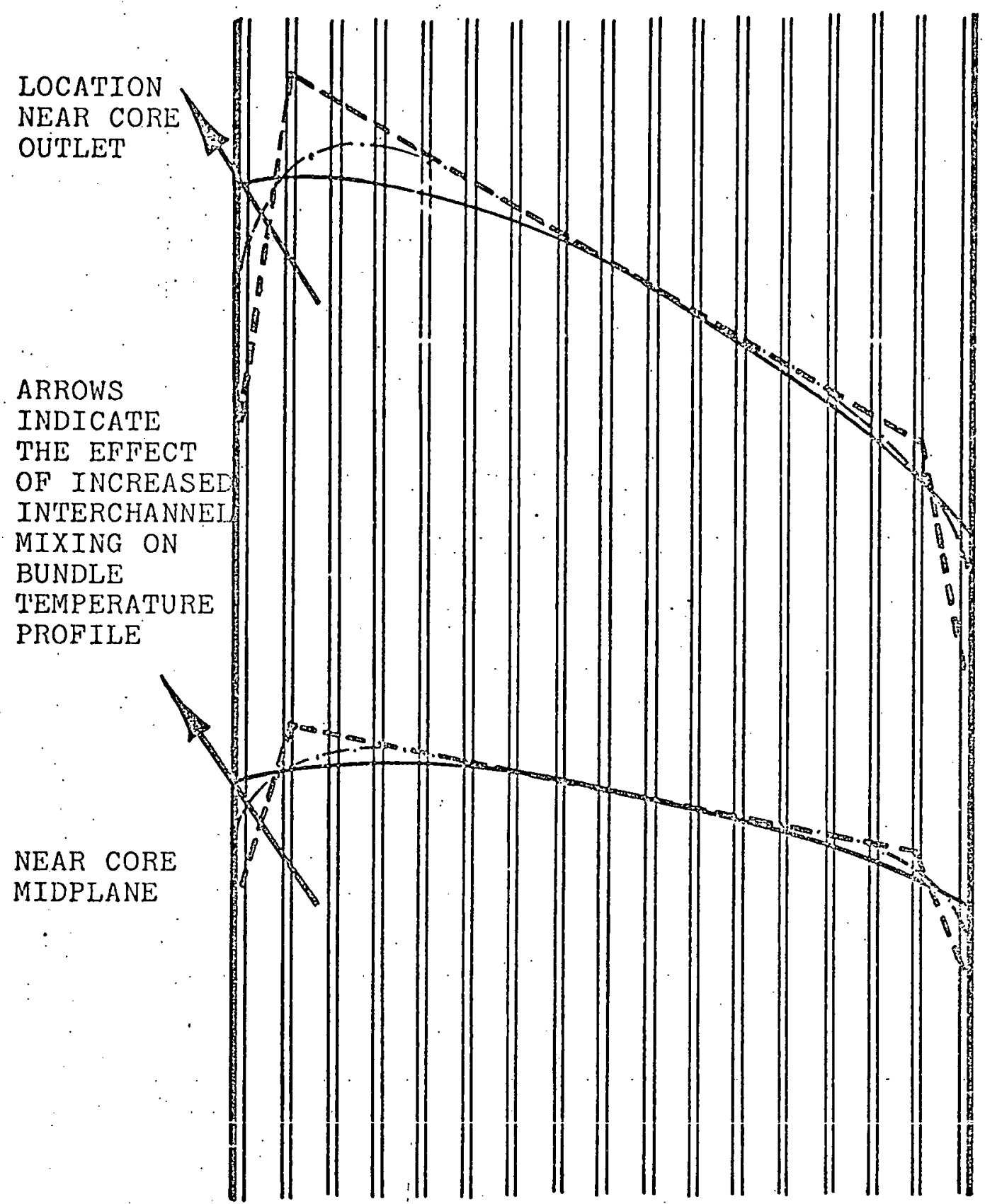

FIGURE 1.1 - INFLUENCE OF INTERCHANNEL COOLANT AND ENERGY MIXING ON THE TRANSVERSE BUNDLE TEMPERATURE PROFILE ARISING FROM RADIAL POWER GRADIENTS*

* Adopted f'rom Markdczy $(1,4)$ 
increasing mixing levels on the temperature tilt across a wire-wrap spaced nuclear fuel assembly characteristic of Liquid Metal-Cooled Fast Breeder Reactors, LMFBR's. The steep temperatur? gradients near the array sides in Figure 1.1 are due to a by-pass flow that over-cools the near-wall region. The by-pass flow results from the mechanical design of the wire-wrapped fuel assembly which has a lower flow resistance at the array edge than in the array interior.

\subsection{Work Scope}

The objective of this investigation is to discuss, compare and develop techniques for instrumenting experimental facilities for determining interchannel coolant mixing in nuclear fuel assemblies and to assinilate experimental mixing data with continuous axial resolution. This information will be used to aid in the development of breeder reactor fuel assemblies. To date, several experimental methods have been used to assess mixing in fuel assemblies; however, little effort has been devoted to discussing and comparing the instrumentation methods of coolant mixing experiments. Also, few of the: experiments reported thus far have had the capability to provide axially detailed information $(\underline{1.1}, \underline{1.2})$.

The balance of this work includes a discussion of mixing experiment instrumentation methods, a description 
of the experiments conducted as part of this work, a presentation of experimental results, and recommendations for further experimental work on interchannel coolant mixing. The experiments mentioned are directed towara rod arrays with geometries typical of the IMFBR with wire-wrap spacers, $i_{0}$ e., a rod diameter $D=1 / 4$ inches arranged with a rod-to-rod pitch $P=5 / 16$ inches $(P / D=$ 1.25) in an equilaterial, triangular lattice rod array. Figure 1.2 shows a true-size cross-section of a 217 pin (rod), hexagonal, LMFBR fuel assembly with these characteristic rod array parameters. Note that the rod-to-wall. gap is set by the wire-wrap diameter on the outer row of fuel rods; designs using the same wire diameters on all rods, e.g., the IMFBR, have the inherent by-pass flow near the assembly walls noted earlier. 


\section{TRUE SIZE}

ROD DIAMETER $=0.250 \mathrm{IN}$.

ROD-TO-ROD PITCH $=0.3125 \mathrm{IN}$.

PITCH/DIAMETER $=1.25$

ROD-TO-WALL GAP $=0$. SS 25 IN.

TRIANGULAR LATTICE ARRAY

WIRE-WRAP NOT SHOWN

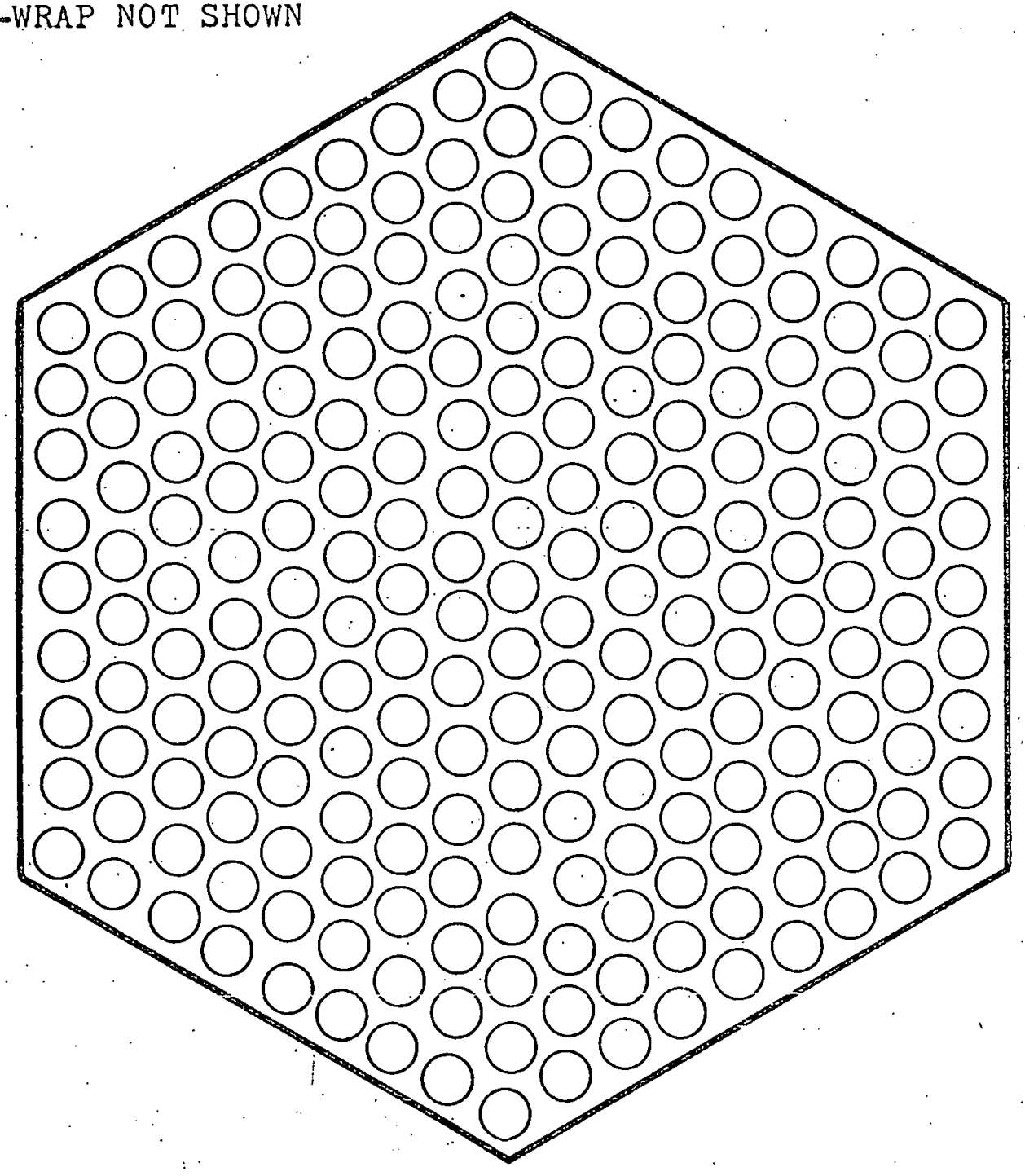

FIGURE 1.2 - A CROSS SECTION VIEW OF A 217 PIN, HEXAGONAL FUEL ASSEMBLY CHARACTERISTIC OF LMFBR'S 


\section{Chapter 2}

\section{INSTRUMENTING COOLANT MIXING EXPERIMENTS}

\subsection{Tracer Instrumentation Techniques}

The purpose of a coolant mixing experiment is to observe transverse fluid motions within the flow passages of a fuel assembly. This may be done by inserting or injecting a small amount of tracer into the fluid flowing axially through the rod bundle geometry of interest. The tracer then travels with this main flow and is dispersed by the various fluid. mixing mechanisms discussed in Chapter 1. Detection. instruments are mounted downstream of the injector. A primary requirement for the experiment is that the injection and detection activities (and apparatus) not interfere with the mixing phenomenon being observed. This requirement is of most concern in the injection activities because the wake from this operation is within the flow region being monitored. Because flow disturbances upstream of a protuberance are small compared to the wake behind, cf, a ship on calm water, the detection activities would appear to be of less concern with respect to main flow perturbations.

The tracer injection technique for coolant mixing experiments has three major areas of concern: (1) tracer 
selection, (2) injection system design and (3) detector system design. The tracer used strongly influences the detection system, whereas the injection system is relatively independent of both tracer and detection systems. The design options arising during experiment design are tabulated in Table 2.1.

Key factors in tracer selection are the diffusivity of the tracer and the influence on detection system design. Key factors in design of the injection system are the location, mobility and geometry of the tracer injection device. Key factors in design of the detection system are the type and design of the measuring instruments and the instrument location relative to the geometry of interest (inside or outside the experimental rod array).

\subsection{Tracers for Coolant Hixing Experiments}

Obviously there are numerous tracers which could be used for mixing experiments. Electrolytic solutions, photoluminescent liquids, radioactive solutions, dye solutions and hot water are examples of the fluid injection type tracers. Also, a heated rod might be included in the experimental array such that heat could be added to the main flow as a tracer.

Photoluminescent, radioactive chemical and dye solutions would be expected to $\mathrm{mix}$ in a manner similar to a salt solution; they were not considered for this 


\section{Table 2.1}

Interchannel Coolant Mixing Experiment Design Options Using Tracer Techniques

\section{TRACER}

Salt Solution

Heated Fluid

Heat Addition (Heated Rod)

Photolumirescent Solution

Radioactive Chemical Solution

Dye Solution

INJECTION SYSTEM

Location Within Rod Array

Axial.

Fixed Inside Array

Fixed At Array Inlet.

Radial

Movable Within Array

Interior Subchannel

Peripheral Subchannel

Corner Subchannel

Injection Geometry

Needle (Jet)

Needle With Diffuser

Transverse (through a hole in the array rod)

Withdrawl

Withdraw a flow equal to that injected

Do not withdraw

Isolated Subchannel

DETECTION SYSTEM

Location

Internal-Inside Array

Instrumentaion Mounting Technique

Mounted on or Inside Array Rods

Mounted on Externally Supoorted Probes

External-outside Array

- Withdrawal Technique

Withdraw Transversely through Array Rods

Withdraw Sample Axially through an

Externaliy Supported Tube

Withdraw Entire Subchannel Flow through

Flow Splitter and Tube Arrangement 
Table 2.1 (Concluded)

INSTRUMENTATION TYPE

(Set by Tracer)

Instrumentation Design

Response Time

Physical Size

Flow Diversion arising from Detection Activities 
work due to instrumentation complications. Local heat additions (either by using heated rods or heated rod sections) has the noteworthy advantage of not distrubing the main filow field as do the injection izacers; however, such devices were dismissed because of hardware complications.

Salt solutions and hot water were the tracers considered best suited for the work at hand. Each of these tracers has inherent advantages and disadvantages; a detailed comparison of these tracer types will be presented after discussion of the injection and detection systems.

\subsection{Injection System Design}

The purpose of the injection system is to insert a tracer into the main flow of the experimental test section with a minimum disturbance to the main Ilow. This minimum disturbance criterion is important because the wake of the injection stream is inside the region being monitored by the detection system. The level of main flow perturbation due to injection is mainly a function of injector design and injection flow rate.

The location and mobility of the injection device are of primary concern and strongly influence the geometry of the injector, see Table 2.1. Injection 
can be done at the array inlet or inside the array and can be either stationary or mobile. Stationary injection often involves detection and/or injection at several axial levels so as is provide additional information on mixing behavior. Fixing the detectors at one axial level and moving the injector within the rod array provides the ability to perform mixing experiments with detailed axial resolution of the coolant mixing phenomenon. The same capability of axial resolution may be obtained by moving the detection devices; however, the detection system with its numerous instruments is much more difficult, if not impossible, to move inside the experimental array.

It should be noted that moving the injector while holding the detectors stationary gives data with notable. - differences from that which would be expected using a fixed injector with moving detectors. This is a consequence of the difference between wire-wrap orientation with respect to the injector for the alternative methods (2.1).

The axially movable, rod-mounted, injection device appears the better option for satisfying the flexible requirements of coolant mixing experiments. (Changing the position and/or mounting angle of the injection rod provides for radial mobility within the experimental array.) The moving injector consists of two concentric 
tubes; the outer tube is slotted, and the inner tube moves axially inside the outer tube. The injector device is mounted to the inside tube through the slot in the outside tube. The geometry of this injection device - could be expected to significantly influence flow perturbations due to tracer injection. Although numerous designs are conceivable, the simplest design has the tracer injected into the main flow through a hole drilled transversely through the inner rod. Alternately, a needle could be inserted into a hole drilled at an angle to the axis of the injector tube, say $15^{\circ}-20^{\circ}$. This injector needle arrangement would reduce the tracer insertion flow perturbation.

With needle injection there is the question, "How much tracer fluid to inject?" Two criteria come to mind; inject with a velocity equal to the average velocity in the subchannel or inject such that the entire flow of the subchannel is displaced. Injecting ai flows greater than required for the equal velocity criterion will result in a turbulent jet (and "jet pump," flow induction effects) in the injection region. The influence of injection flow perturbations on experimental coolant mixing results may be readily assessed by running a series of experiments varing only the injection flow rate. In the case where it is desirable to inject a flow equal to the entire subchannel flow, a diffuser 
should be mounted on the needle so that the turbulent jet is decelerated to reduce jet mixing not characteristic of the rod array. The diffused jet flow rate should be based on the discharge area of the diffuser and should give a discharge velocity approximately equal to the averago relocity characteristic $2 f$ the subchannel. The detailed design of the injector will be discussed in Chapter 4 .

Inserting the tracer into the main flow field unavoidably causes main fiow perturbations. In the case of the needle, the wake from the needle, the slot in the outer tube, and the diversion cross rlow arising from the injection flow, all serve to perturb the normal flow in the test array. With the diffuser type injector, all the effects are increased; there is more. diversion cross flow from injection and a larger wake from the diffuser. Also, with the diffuser it may be necessary to break the wire-wrap across the slot to allow passage of the diffuser (when an axialiy moving injector is used). The advantage of the diffused jet is that the subchannel starts with a uniformly mixed tracer in the injection subchannel (as does an isolated subchannel). For the needle; the tracer.must mix with the subchannel flow before such a uniform concentration can be achieved. In order to achieve a uniform, injection subchannel, tracer concentration, 
it is also possible to isolate the subchannel with real boundaries (e.g., fins) in the injection region. This isolated injection region prevents interchannel mixing until the tracer injected has been mixed with the main flow in the injection subchannel. Nevertheless, the isolated subchannel also causes flow perturbations and is not a flexible technique.

Injecting the tracer Ilow into the injection subchannel causes a diversion cross flow away from the injection region. This flow diversion can be avoided by withdrawing an amount of fluid equal to the injection

- flow just upstream of the injector. This localized source-sink would reduce the diversion flow perturbation; however, the complications associated with design, construction and operation of a withdrawal device more than offset any advantages of reducing the diversion cross flow. Furthermore, the effect of injectioninduced flow diversion can be assessed by varing the injection flow rate holding other experimental parameters constant.

\subsection{Detection System Design}

The primary consideration in detection system design is the tracer used. The tracer determines what type of instrumentation is required, see Table 2.1. Given the tracer, the concern of the detection system design becomes the location of the detectors with 
respect to the experimental array, i.e., inside the array or outside the array - internal or external detection, respectively. The detection system, whether internal or externai, is most conveniently located near the outlet of the test bundle.

Internal instrumentation is prefered if the detectors are amenable to measurements in the main flow field, because the overall detection system is simplified. With internal detectors the major difficulty is locating the instrumentation within the limited space available inside the experimental rod array. The instruments or detectors may be supported either from the rods of the array or from externally supported probes which penetrate into the rod array subchannels axially from the outlet plenum. Internal instruments are also subjected to the turbulent flow field inside the experimental array. Because the properties of a turbulent flow fluctuate rapidly, internal instruments must be capable of dealing with these fluctuations.

With external detectors, the major difficulty is withdrawing the fluid samples from the main flow field. A sample may be withdrawn transversely through passages in the array rods or axially through an externally supported, probe tube. Another sample withdrawal option is to mount sharp-edged, flow separators at the exit of the subchannels of interest and withdraw the entire subcharmel flow. 
Perturbing the main flow is a consideration in detection system design regardless of the instrument location. Placing the instrumentation inside of the array changes the hydraulic resistance in the region of the detectors, but a withdrawal apparatus has a similar effect. The perturbation of the main flow by the instrumentation is important only if the perturbations propagate upstream into the region where mixing behavior is being monitored. The changes in hydraulic resistance arising from detection apparatus can be regulated (by varing the probe size) and distributed (by. using dummy probes) over the array. outlet so as to minimize diversion cross flows due to detection activities.

\subsection{The Significance of Tracer Diffusivity}

In coolant mixing experiments, several factors must be considered in evaluating the observed dispersion of a tracer. Molecular diffusion (with a mass tracer) or thermal. conduction (with a heat tracer) does not represent mixing of the fluid tracer diffusion due to these molecular transport mechanis ms occurs simultareousiy with tracer motion due to any existing coolant (fluid) mixing phenomenon. Tracer diffusion does promote homogenization of the tracer concentration or temperature as the tracer is dispersed within an experimental rod array by fluid mixing mechanisms. Concentration measurement techniques work well for uniformly dispersed tracers. The occurrance of tracer concentration or temperature inhomogeneities can make accurate measurements difficult when utilizing internal detectors. . 
To quantify the significance of tracer diffusivity,

consider the dimensionless groups given below with a description of their meaning ( $\underline{2.18})$ :

Le $=$ Lewis Number $=\frac{O C_{p} C_{D}}{k}=\frac{P r}{S c}=\frac{\text { Mass Diffusivity }}{\text { Thermal Diffusivity }}(2.1 \mathrm{a})$

$\mathrm{Pe}_{\mathrm{h}}=\underset{\text { (heat transfer; }}{\text { Peclet Number }}=\frac{\mathrm{Nc} \mathrm{pd}_{\mathrm{e}}}{\mathrm{k}}=\frac{\text { Heat Convection }}{\text { Heat Corduction }}$

$\mathrm{Pe}_{\mathrm{m}}=\underset{(\text { mass } \text { transfer })}{\text { Peclet Number }}=\frac{\mathrm{d}_{\mathrm{e}} \mathrm{V}}{\mathrm{C}_{\mathrm{D}}}=\frac{\text { Bulk Mass Transfer }}{\text { Diffusive Viass Transfer }}$

$\operatorname{Pr}=$ PrandtI Number $=\frac{\mu c p}{k}=\frac{\text { Momentum Diffusivity }}{\text { Thermal Diffusivity }}$

$\operatorname{Re}=$ Reynolds Number $=\frac{\rho^{V d} \mathrm{e}}{\mu}=\frac{\text { Inertia Force }}{\text { Viscous Force }}$

$S c=$ Schmidt Number $=\frac{\mu}{\rho C_{D}}=\frac{\text { Momentum Diffusivity }}{\text { Viass Diffusivity }}$

For comparing tracer diffusivities of aqueous, sodium chloride solutions and heated water, the following values of the dimensionless variables are established. for the temperature range of experimental interest and for dilute $\mathrm{NaCl}$ solutions (2.16, 2.17):

$$
\begin{aligned}
& \mathrm{T}\left({ }^{\circ} \mathrm{F}\right)=50 \quad-100 \\
& \mathrm{~T}\left({ }^{\circ} \mathrm{C}\right)=20-40 \\
& \mathrm{Le}=0.012-0.015 \\
& \mathrm{Pr} \quad=10 \quad-5 \\
& \mathrm{Sc} \quad=750 \quad-300
\end{aligned}
$$

Note that the Lewis number is low, i.e., the thermal diffusivity is 65 to 85 times the mass diffusivity. For the salt tracer the Schmidt numbers are of the order $500-1000$ (2.16); this indicates that momentum transport 
mechanisms are over two orders of magnitude greater than mass diffusion. When only fluid motions (coolant mixing other than the integrated effects of fluid and enexgy mixing) are of interest, salt solutions are better suited

i for mixing experiment tracers than heated fluids.

Further discussioin of tracer and coolani uiffusivity will be given in Chapter 6 .

\subsection{The Advantages of Salt Solution Tracers}

Salt solution tracers, in addition to low mass diffusivity, enjoy another marked advantage over hot water tracers. With salt solutions, the tracer concentration can be much greater than background concentration thus giving a wider range of tracer dilution during the experiment and reducing experimental error due to instrument sensitivity. The equivalent conductivity of tap water at $140 \mathrm{~F}$ is of the order of $150 \mathrm{ppm}$ of $\mathrm{NaCl}$; tracers can be injected at concentrations of 50,000 ppm or more; this gives a tracer-to-kackground ratio of 300:1. For water at atmospheric pressure and say 60F, the enthalpy. is $28 \mathrm{Btw} / \mathrm{lbm}$, and the practical limit of tracer inthalpy $(212 \mathrm{~F})$ is $180 \mathrm{Btu} / \mathrm{Ibm}$ - a tracer-tobackground ration of about $7: 1$. Without pressurization of the system or cooling the main flow (and increasing pumping power to keep the same Reynolds number), the tracer-to-background enthalpy ratio is limited, Further, 
using high tracer enthalpies leads to significant changes in fluid physical properties, particularly viscosity, in the experimental array. Table 2.2 gives a comparison of salt solution versus hot water tracers fcr interchannel coolant mixing experiments.

Because the tracer nay become highly diluted before being monitored by the detectors, weak signals are common in mixing experiments. Salt solution concuctance measuring equipment is very sensitive to weak signals while temperature measuring equipment is not sensitive. This gives salt solutions another advantage over heated water tracers (more instrumentation details in Chapter 3 ).

For hot water tracers, internal thermocouples are not seriously affected by small inhomogeneties in the fluid temperature field but are affected by conduction within rod array materials. Thermocouples act as integrators and respond to average temperature changes with a characteristic time constant (of the order of seconds). With external temperature measurements, errors are introduced due to heat transfer in the withdrawal apparatus. Hot water tracers are amenable to internal detection only.

Salt solution tracers may or may not be desirable for internal measurements. A primary objective of this report is to experimentally estabilish the compatability, 
Table 2.2

A Comparison of Salt Solution and Hot Water Tracers

Salt Solution Tracer.

++ High injection-to-Backround concentration ratio

+Low mass diffusivity

+Nonlinear relation between conductivity and solution concentration results in. instruments sensitive to weak signals

*Rapidly fluctuating measurements may be difficult to interpret with internal measurements

No storage or diffusion of tracer between injection and detection (except within coolant)

- External detection eliminates internal measurement difficulties without interference

* Internal detection may be inherently impossible due to inhomogeneous solution concentrations within the conductance cells

\section{Hot Water Tracer}

* Low injection-to-backround ratio (high instrument accuracy required)

*High thermal diffusivity

*Linear relationship between enthalpy and temperature requires sensitive instruments to monitor weak signals

+Time integrated signal results with internal instrumentation

Materials within the test section conduct and store heat (the detected tracer)

External detection suffers from heat conduction interference

High temperature injecition influences the fluid viscosity and. therefore interferes slightly with the fl.ow field

+Primary Advantage

* Primary Disadvantage 
feasibility, and reliability of internal measurements of electrolytic conductance. The main concern is the level of inhomogeneity of salt solution concentration in the vicinity of the conductance cell used to measure solution concentration. How variations of solution strength and resistance (in a complex, three dimensional, time-dependent manner) in the region of the conductance cell influences the measurements is not clear. If the solute mass balance criterion is met, i.e.. if the salt detected equals the salt injected (discussed in detail in Chapter 3), this inhomogeneity or unmixied solution consideration will not be of concern. If homogeneous concentrations are serious enough to generate difficulties with internal measurements, the difficulties should reduce with mixing, i.e., as the injector is moved away from the detector and the tracer solution mixes more with the main flow. Nevertheless. inhomogeneous solution problems can be eliminated by using an external detection system, if necessary.

\subsection{A Review of Instrumentation Methods Used in Other Interchanne] Coolant Mixing Experiments}

This section shall discuss the instrumentation methods used in experiments on interchannel coolant mixing in triangular lattice, wire-wrap spaced fuel assemblies. A review of mixing experiment results is given in Rogers and Todreas $(1,3)$ and in Todreas and 
Turi (1.1). The literature cited in these papers may be consulted for instrumentation details of the investigations not discussed here.

Interchannel coolant mixing is currently of interest in light water reactors, gas-cooled reactors and particularly fast breeder reactors. In light water and gas-cooled thermal reactors, mixing is of interest because a better understanding of the mixing phenomenon can lead to improvements in reactor thermal performance. During thermal reactor development, conservatism in thermal design permitted demonstration reactors to safely compensate for lack of thermal-hydraulic development work. In fast breeder reactors, mixing is an import: ant part of core thermal-mechanical as well as thermalhydraulic design; thus for fast breeder reactors, the mixing phenomenon must be understood during reactor development, because it strongly influences core design. The bulk of recent experimental activities in interchannel coolant mixing have been devoted to wirewrap spaced fuel assemblies with geometries characteristic of IMFBR design. Table 2.3 summarizes details regarding the instrumentation methods used in wire-wrap spaced, rod array, coolant mixing experiments. Table 2.4 gives the geometrical parameters for these experimental rod arrays while Table 2.5 summarizes the operating parameters of the experiments. 
Táble 2.3

Instrumentation Methods Used in Wire - Wrap Spaced Coolant Mixing Experiments

\begin{tabular}{|c|c|c|c|c|c|c|}
\hline Group & $\begin{array}{l}\text { Exper. } \\
\text { No. }\end{array}$ & $\begin{array}{l}\text { Main } \\
\text { Flow }\end{array}$ & Tracer & $\begin{array}{l}\text { Injection } \\
\text { Technique }\end{array}$ & $\begin{array}{l}\text { Detection } \\
\text { Technique }\end{array}$ & $\begin{array}{l}\text { Ref. } \\
\text { No. }\end{array}$ \\
\hline $\begin{array}{l}\text { ANL } \\
\text { CT }\end{array}$ & $1-3$ & Water & $\begin{array}{c}\text { Salt } \\
(\mathrm{NaCl})\end{array}$ & $\begin{array}{l}\text { Axial, Low } \\
\text { Velocity into } \\
\text { Peripheral } \\
\text { Channel }\end{array}$ & $\begin{array}{l}\text { External, Full } \\
\text { Subchannel. Flow } \\
\text { Withdrawal }\end{array}$ & $\begin{array}{l}{[2.2]} \\
{[2.3]}\end{array}$ \\
\hline $\begin{array}{l}\text { ANL } \\
\text { CT }\end{array}$ & Planned & Water & $\begin{array}{l}\text { Salt } \\
(\mathrm{NaCl})\end{array}$ & $\begin{array}{l}\text { Axial, Low } \\
\text { Velocity into } \\
\text { Peripherai } \\
\text { Channel. }\end{array}$ & $\begin{array}{l}\text { External: Full } \\
\text { Subchannel Flow } \\
\text { Withdrawal. }\end{array}$ & {$[2.4]$} \\
\hline $\begin{array}{l}\text { ANL } \\
\text { RAS }\end{array}$ & 4 & Water: & $\begin{array}{l}\text { Heated } \\
\text { Water }\end{array}$ & $\begin{array}{l}\text { Transverse } \\
\text { Low Velocity. }\end{array}$ & $\begin{array}{l}\text { Thermocouples } \\
\text { Inside Pins, } \\
4 \text { Contiguous } \\
\text { Subchannels, } \\
\text { Numerous Axial } \\
\text { Locations }\end{array}$ & {$[2.5]$. } \\
\hline $\begin{array}{l}\text { ANL } \\
\text { RAS }\end{array}$ & Planned & Water & $\begin{array}{l}\text { Heated } \\
\text { Water }\end{array}$ & $\begin{array}{l}\text { Transverse } \\
\text { Low Velocity }\end{array}$ & $\begin{array}{l}\text { Transversing } \\
\text { Thermocouples }\end{array}$ & $\begin{array}{l}{[2 \cdot 3]} \\
{[2 \cdot 6]}\end{array}$ \\
\hline$\cdot$ & & Water & $\underset{\left(\mathrm{NaNO}_{3}\right)}{\mathrm{Salt}}$ & $\begin{array}{l}\text { Axially through } \\
\text { Tube, Equal } \\
\text { Velocity }\end{array}$ & $\begin{array}{l}\text { Internal, Flush, } \\
\text { Rod-Mounted } \\
\text { Electrodes }\end{array}$ & {$[2.7]$} \\
\hline$G E$ & $5-6$ & Water & $\begin{array}{l}\text { Heated } \\
\text { Water }\end{array}$ & $\begin{array}{l}\text { Axially into } \\
\text { Six. Interlor } \\
\text { Subchannels, } \\
\text { Six Inches } \\
\text { Above Inlet }\end{array}$ & $\begin{array}{l}\text { Internal, Moving } \\
\text { Thermocouple } \\
\text { Probes Inside } \\
\text { Array Rods. }\end{array}$ & {$[2.8]$} \\
\hline
\end{tabular}


Table 2.3 (Continued)

\begin{tabular}{|c|c|c|c|c|c|c|}
\hline HEDL & 7 & Water & $\underset{\left(\mathrm{NaNO}_{3}\right)}{\mathrm{Salt}}$ & $\begin{array}{l}\text { Needie, Isolated } \\
\text { Subchannel with }\end{array}$ & $\begin{array}{l}\text { Internal, Nickle } \\
\text { Plated Copper } \\
\text { Wire Flush with } \\
\text { Rod }\end{array}$ & {$[2.9]$} \\
\hline $\begin{array}{c}\text { MIT } \\
\text { (Eaton) }\end{array}$ & 8 & Water & $\begin{array}{l}\mathrm{SaIt} \\
(\mathrm{NaCl})\end{array}$ & $\begin{array}{l}\text { Needle, Axially } \\
\text { Moving }\end{array}$ & $\begin{array}{l}\text { Probe Mounted, } \\
\text { Platinized } \\
\text { Conductivity } \\
\text { Cells }\end{array}$ & - \\
\hline $\begin{array}{c}\text { MIT } \\
\text { (Hanson) }\end{array}$ & Planned & Water & $\begin{array}{c}\mathrm{Salt} \\
(\mathrm{NaCl})\end{array}$ & $\begin{array}{l}\text { Needle, Axially } \\
\text { Moving }\end{array}$ & $\begin{array}{l}\text { Probes Mounted, } \\
\text { Platinized } \\
\text { Conductivity } \\
\text { Cells }\end{array}$ & {$[2.10]$} \\
\hline ORNL & 9 & Sodium & $\begin{array}{c}\text { Heat } \\
\text { Addition }\end{array}$ & $\begin{array}{l}\text { Any Rod or } \\
\text { Combination of } \\
\text { Rods may be } \\
\text { Heated Over } 2.1 \\
\text { Inches Length }\end{array}$ & $\begin{array}{l}\text { Thermocouples } \\
\text { Mounted at } \\
\text { Various Loca- } \\
\text { tions within } \\
\text { the Array Rods }\end{array}$ & {$[2.10]$} \\
\hline $\begin{array}{l}\text { France } \\
(\text { Skok) }\end{array}$ & $10-14$ & Water & $\begin{array}{l}\text { Heated } \\
\text { Rod }\end{array}$ & $\begin{array}{l}\text { Traveling In- } \\
\text { jector with } \\
\text { Subchannel } \\
\text { Isolation }\end{array}$ & $\begin{array}{l}\text { Thermocouple } \\
\text { Probes in } \\
\text { Isolated Sub- } \\
\text { channels zt the } \\
\text { Outlet }\end{array}$ & {$[2.11]$} \\
\hline $\begin{array}{l}\text { Germany } \\
\text { (Baumann) }\end{array}$ & $15-17$ & SodLum & $\begin{array}{c}\text { Heat } \\
\text { Addition }\end{array}$ & $\begin{array}{l}\text { Central Array } \\
\text { Rod Heated over } \\
\text { First } 39.4 \\
\text { Inches }\end{array}$ & $\begin{array}{l}\text { Thermocouples } \\
\text { at Subchannel } \\
\text { Outlets }\end{array}$ & {$[2.12]$} \\
\hline
\end{tabular}


Table 2.3 (Concluded)

\begin{tabular}{|c|c|c|c|c|c|}
\hline $\begin{array}{c}\text { Japan } \\
\text { (okamato) }\end{array}$ & 18 & Water & $\begin{array}{c}\text { Salt } \\
(\mathrm{NaCl})\end{array}$ & $\begin{array}{l}\text { Injection Axially } \\
\text { through a Tube at } \\
\text { the Inlet }\end{array}$ & $\begin{array}{l}\text { Conductance } \\
\text { Measuring Probes } \\
\text { in the Center of } \\
\text { the Subchannel at } \\
\text { the Bundle outlet }\end{array}$ \\
\hline $\begin{array}{c}\text { Japan } \\
\text { (okamato) }\end{array}$ & 19 & Water & $\begin{array}{c}\mathrm{Salt} \\
(\mathrm{NaCl})\end{array}$ & $\begin{array}{l}\text { Inection Trans- } \\
\text { versely through } \\
\text { Numerous Holes } \\
\text { Around the Cir- } \\
\text { cumference of an } \\
\text { Arräy Rod }\end{array}$ & $\begin{array}{l}\text { Conductance } \\
\text { Measuring Probe:s } \\
\text { in the Center of } \\
\text { the Subchannel at } \\
\text { the Bundle Outlet }\end{array}$ \\
\hline
\end{tabular}

* See Table 2.4 for Experimental Rod Array Geometrical Details and

Table 2.5 for Experimental Operating Parameter Details 
Table $2.4 *$

Geometrical Parameters of Wire Wrap Spaced Rod Arrays Used for Coolant Mixing Experiments

\begin{tabular}{|c|c|c|c|c|c|c|}
\hline Group & $\begin{array}{l}\text { Exper. } \\
\text { No. }\end{array}$ & $\begin{array}{l}\text { No. } \\
\text { of } \\
\text { Pins }\end{array}$ & $\begin{array}{l}\text { Bundle } \\
\text { Geometry }\end{array}$ & $P / D$ & $\dot{\mathcal{V}}$ & $\ell$ \\
\hline \multirow{3}{*}{$\begin{array}{l}\text { ANL } \\
\text { CT }\end{array}$} & 1 & 7 & Hexagon & 1.20 & 0.25 & 6 \\
\hline & 2 & & & 1.20 & 0.25 & 12 \\
\hline & 3 & & $\cdot$ & 1.20 & 0.25. & 18 \\
\hline $\begin{array}{l}\text { ANL. } \\
\text { RAS }\end{array}$ & 4 & 19 & Hexagon & 1.21 & 0.25 & 12 \\
\hline \multirow[t]{2}{*}{$\mathrm{GE}$} & 5 & 127 & Hexagon & 1.20 & 0.25 & 12 \\
\hline & 6 & & . & 1.28 & 0.25. & 6 \\
\hline HEDL & 7 & 217 & Hexagon & 1.24 & 0.23 & 11.9 \\
\hline $\begin{array}{c}\text { MIT } \\
\text { (Eaton) }\end{array}$ & 8 & 25 & Rhombus & 1.25 & 0.2 .5 & 12 \\
\hline ORNL & 9 & 19 & Hexagon & 1.24 & 0.23 & 12 \\
\hline \multirow{5}{*}{$\begin{array}{l}\text { France } \\
\text { (Skok) }\end{array}$} & 10 & 7 & Hexagon & 1.36 & 0.67 & 17.7 \\
\hline & 11 & & & 1.14 & 0.83. & 11.8 \\
\hline & 12 & & & 1.14 & 0.83 & 17.7 \\
\hline & 13 & 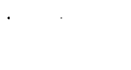 & & 1.14 & 0.83 & 23.6 \\
\hline & 14 & & & $1.07^{\circ}$ & 0.91 & 17.7 \\
\hline \multirow{3}{*}{$\begin{array}{c}\text { Germany } \\
\text { (Baumann) }\end{array}$} & 15 & 61 & Hexagon & 1.32 & 0.24 & 3.94 \\
\hline & 16 & & & & & 7.87 \\
\hline & 17 & & & & & 11.8 \\
\hline \multirow{2}{*}{$\begin{array}{c}\text { Japan } \\
\text { (Okamato) }\end{array}$} & 18 & 91 & Hexagon & 1.19 & 0.25 & 10.6 \\
\hline & 19 & 19 & Hexagon & 1.08 & 0.59 & 12.8 \\
\hline
\end{tabular}


Table 2.5

Operating Parameters for Wire-Vrap Spaced Rod Array,

Coolant Mixing Experiments

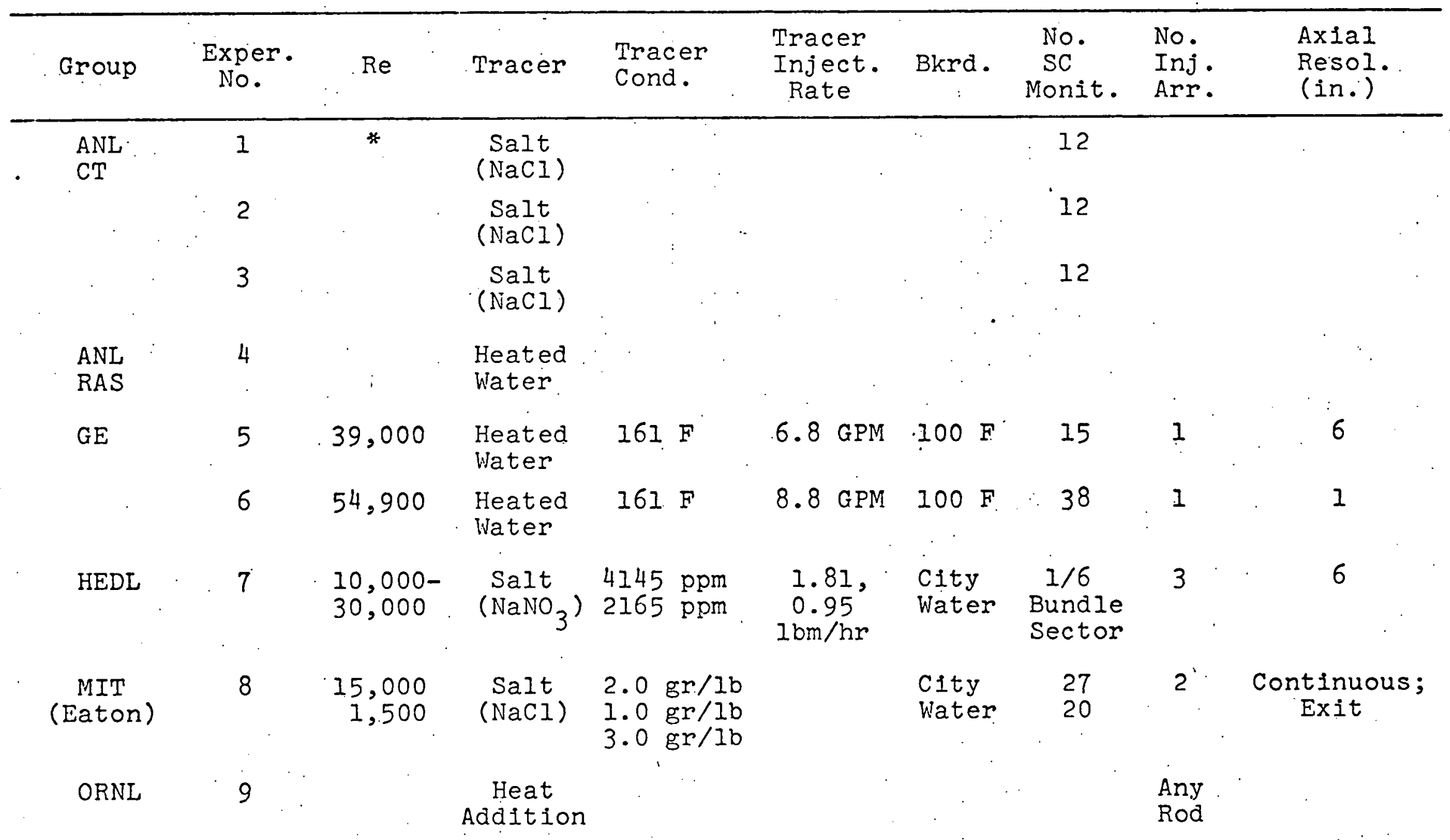


Table 2.5 (Concluded)

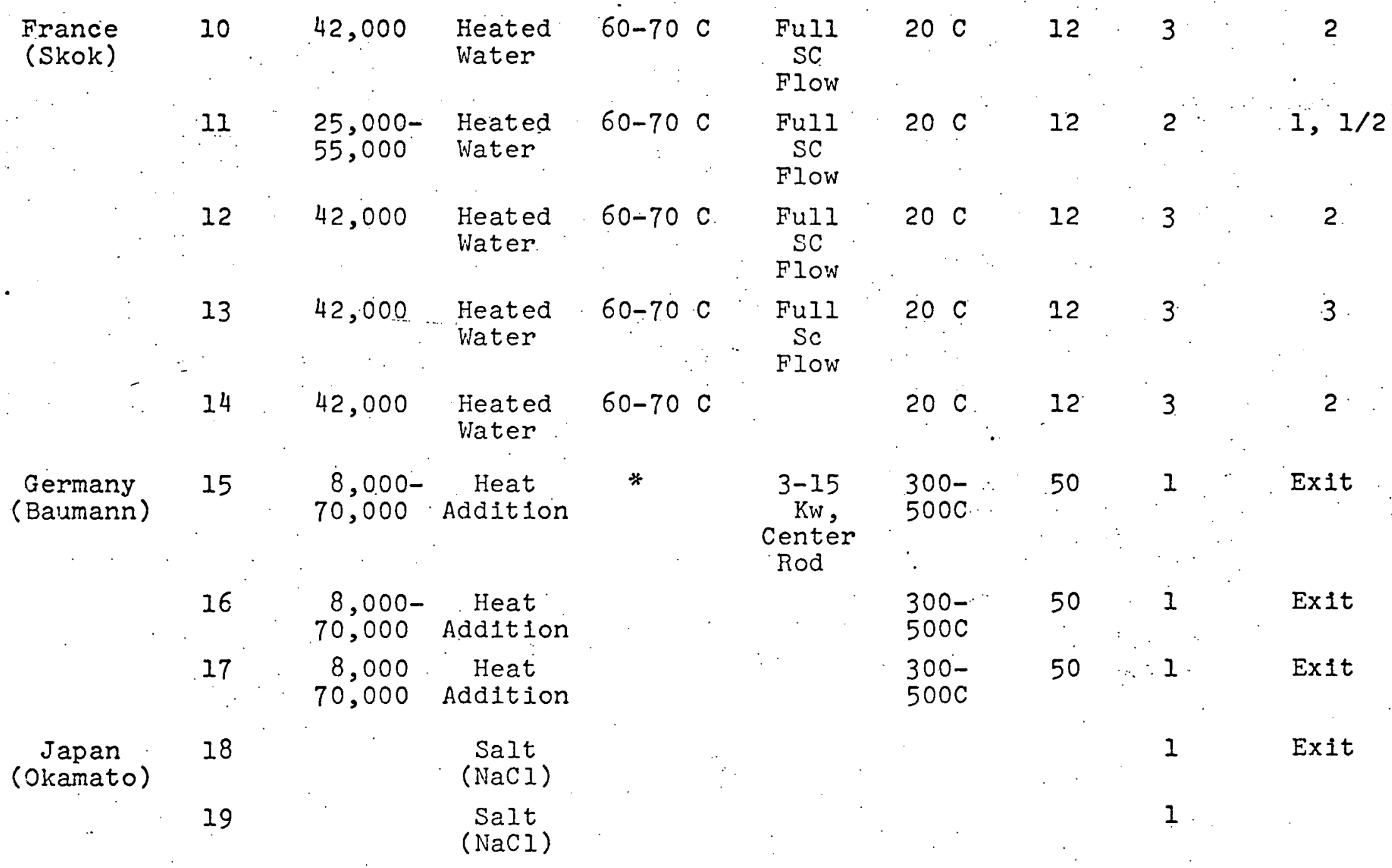

* Information deleted was not reported 
Some experiments have used sodium, the LMFBR coolant, for the main flow, and others have used water to model sodium. Sodium (at LMFBR operating conditions) is hydraulically quite similar to water; so that water is a good fluid for modeling sodium flow (using the equal Reynolds number criterion). Sodium fla: experiments have used heated rods for tracer insertion (heat addition) and internal thermocouple detectors. Water flow experiments have used both heated water (irom injection and heat addition) and electrolytic solution injection and have had both internal and external detection systems. No effort has compared techniques of injection and detection, but instead. each experiment has used one injection design and one detector design. In the literature to date, discussion of the methods: and design of coolant mixing experiment instrumentation has been poor.

The Argonne National Laboratory (ANL) has two coolant mixing investigations underway. Lorenz and Ginsberg $(2.2,2.3)$ of the Components Technology. (CT) Division have run experiments with a ?-pin, hexagonal rod bundle with a pitch-to-diameter $P / D$ ratio of 1.20 and 0.25 inch diameter rods. The experiments used water for the main flow and salt ( $\mathrm{NaCl}$ ) solution as the tracer. The solution was injected into a peripheral subchannel and in the axial direction through a hole 
drilled into a tube penetrating transversely into the subchannel through the flow channel wall. The detection system used a full subchannel flow withdrawal technique with an external conductivity cell. The subchannels were monitored individually giving averaged, outlet, subchannel tracer concentrations. This technigue has been expanded into a 91-pin, hexagonal array (2.4). J. van Erp and T. Chawla $(\underline{2.5}, \underline{2.6})$ of the ANL Reactor Analysis and Safety Division have conducted experiments with a 91-pin hexagonal rod bundle with 0.25 inch diameter rods $(P / D=1.21)$. These experiments used water for the main flow and heated water as the tracer. The tracer was injected at low velocity transversely through a hole in one of the array rods. The detection system used thermocouples mounted inside the. array rods at numerous axial locations. Only four contiguous subchannels were monitored in these experiments. The work has also been extended to a 91-pin, hexagonal geometry $(2.3,2.7)$.

At General Electric, Marian and Hines (2.8)have run a 127-pin bundle with two rod arrays, $P / D=1.20$ and $1.28,1=12$ inches and 6 inches, respectively, and $D=0.25$ inches. A heated water tracer was used and temperatures were measured with transversing thermocouples inside the rod array tubes. The heated water was injected near the inlet into the six interior 
subchannels surrounding the central array rod.

Salt $\left(\mathrm{NaNO}_{3}\right)$. tracer experiments have been run wi.th internal conductivity cell instrumentation at the Hanford Engineering Development Laboratory (HEDI) by Collingham, et al. (2.9): The experimental test section is the only published full-scalo 217-pin, hexagonal array used for mixing studies. The tracer was injected through a stationary needle into a subchannel confined by fins in the injection region; a flow equal to the injection flow rate was withdrawn from near the injector. Nickle plated (not platinized) copper electrodes flush with the rod surface were mounted in several axial detection Iocations.

The details of the MIT 25-pin rhombus experiments by Eaton and Todreas are discussed within this report. Briefly, a salt solution tracer was injected from a continuously moving injection device. The tracer dispersion in the wire-wrapped rod array ( $I=12$ inches, $P / D=1.25, D=0.25$ inches) was monitored by intemal conductivity-measuring probes near the bundle outlet. The details of the experimental design shall be discussed in Chapter 4.

Hanson and Todreas (2.10) shall be using methods developed as part of this work to do a series of investigations of 61-pin, hexagonal wire-wrapped rod arrays. The objective of this work shall be to examine the 
influence of geometrical parameters, e.g., pitch-todiameter ratio, rod diameter, and lead length on interchannel coolant mixing in rod bundles of typical LMFBR geometries.

A. 19-pin, hexagonal bundle has been used for coolant mixing studies at the Oak Ridge National Labnratory ORNL (2.10). The main flow for this work was sodium and heat addition was used as a tracer. Any one of the array rods could be heated individually (or in any combination) over a 21 inch (approximate) length. Thermocouples were mounted at various locations within the rod array and in the flow channel walls to monitor temperatures.

Foreign interchannel coolant mixing studies have been reported in France, Germany and Japan. Skok (2.11) in France has run a series of 5 different rod bundles in a 7-pin, hexagonal geometry. The rod size was about 3 times ( $3 X)$ nominal size $(D=0.83 \mathrm{in})$, and the effect of lead length on mixing behavior was examined. The experiments used water for the main flow and heated water injection for the tracer. The tracer was injected at variable levels into subchannels isolated by fins in the gaps between the rods (in the axial region near the injection point). Fluid temperatures were detected by thermocouples in the subchannels near the bundle outlet. 
Baumann and Hoffmann in Germany (2.12) have done coolant mixing experiments in a 61-pin, hexagonal assembly $(D=0.24$ in., $P / D=1.32)$ using a sodium flow. A heated central rod was used for tracer insertion, and temperatures were measured internally with thermocouples mounted in the subchannels near the array outlet. Included as part of these experiments was a parametric study of the influence of lead length 1 on interchannel coolant mixing.

In Japan, Okamoto, et al. (2.13, 2.14) have run experiments in a 91-pin, hexagonal assembly typical of LMFBR's, and also, an experiment was run with a 19-pin, hexagonal rod bundle typical of a LMFBR blanket assembly. Both experiments used water for the main flow with internal, probe-type (externally supported) conductivity . cells mounted in the center of the flow subchannels and located at the outlet of the bundle. The salt ( $\mathrm{NaCl}$ ) solution tracer was injected into the inlet of the injection subchannel through a tube in the case of the 91-pin experiment. In the 19-pin experiment, the tracer was injected transversely around the periphery of the circumference of the injection rod.

Davidson (2.15) has reported results of salt tracer instrumentation development work in a single (unwrapped) subchannel. This work was done to assess 
the influence of boundary layers on conductivity cell detectors mounted flush against an array rod (internal. detection). Because the tracer ( $\mathrm{NaNO}_{3}$ ) was injected into the center of the subchannel, j.t was found that a. 4 to 6 inch development length was required for the tracer to penetrate to the rod surface, i.e.. to be properly detected. For this work, the conductivity detectors were located directly in the flow of the subchannel so that these results may not be applicable. 


\section{Chapter 3}

\section{SALT SOLUTION TRACER EXPERIMEITS}

\subsection{Water Solutions and Electrolytic Conductance}

When electrolytic salts are dissolved in water, the dissolved salt disassociates (to a certain degree) into ions. These dissociated ions serve as electrical charge carriers within the solution and thus decrease the resistance to the flow of electrical charge below that resistance characterized by the pure solvent. The conductance, the inverse of electrical resistance, of an electrolytic solution depends quite strongly on solution strength; as solution concentration is increased, the electrolytic conductance rapidly rises. It then saturates quickly and approaches a limit monotonically as the solution strength approaches saturation. A solution resistance versus salt concentration curve is given in Figure 3.1, and well illustrates this conductance behavior in the case of sodium chloride dissolved in $140 \mathrm{~F}$ distilled water. Notice the resistance drops from well over 300,000 ohms-cm for the pure water to around 500 Ohms-cm for a $\mathrm{NaCl}$ solution of $113 \mathrm{ppm}$ (parts per million) but has dropped to only $100 \mathrm{Ohms-cm}$ when the solution concentration is further increased six-fold.

Some familiar water solutions include saltwater which is greater than $15,000 \mathrm{ppm}$ dissolved solids by 


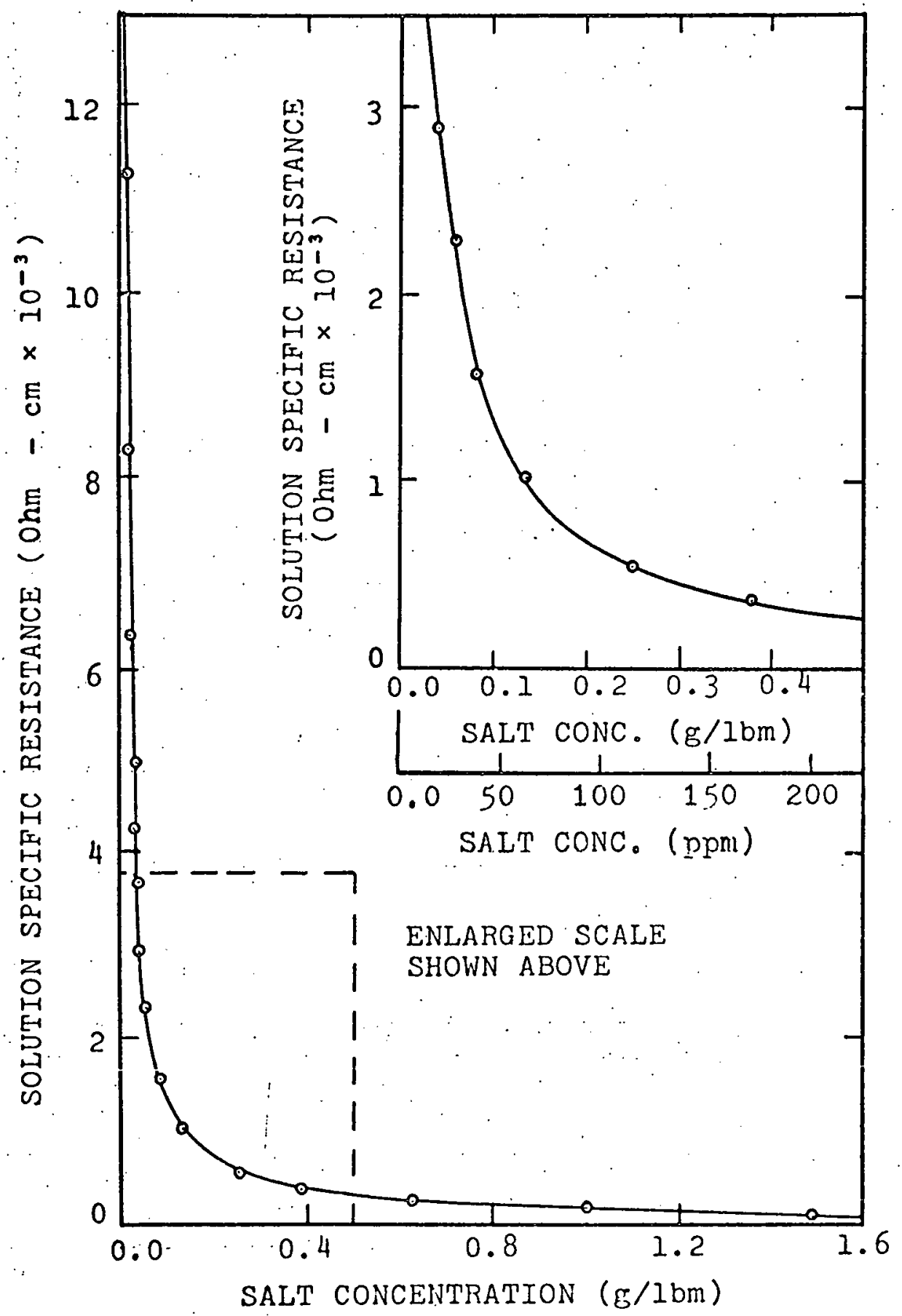

FIGURE 3.1 - SPECIFIC RESISTANCE vS. CONCENTRATION OF SODIUM CHLORIDE DISSOLVED IN DISTILLED $\mathrm{H}_{2} \mathrm{O}$ AT $140 \mathrm{~F}$ 
weight, seawater which is about $35,000 \mathrm{ppm}$, and brackish which is from 1,000 to $15,000 \mathrm{ppm}$. Municipal water supplies are usually less than $500 \mathrm{ppm}$. Good tasting drinking water contains about $300 \mathrm{ppm}$ dissolved solids; water for irrigation should be less than $200 \mathrm{ppm}$; and supercritical pressure, steam generators opanate with less than $0.1 \mathrm{ppm}(3.1)$. Note. 1 ppm equals 0.0022 grams per pound.

The complex topics of electrolytic solutions and electrolytic conductance measurements are well discussed in standard electrochemistry books $(3.2,3.3)$. The interested reader is referred to such texts for detailed discussion of the topics of this chapter. In order to describe salt tracer experiments, an abbreviated discussion of electrolytic solutions and the measurement of elctrolytic conductance is presented below.

\subsection{Electrolytic Conductance Mechanisms}

The ability of a salt solution to conduct electricity is explained by two phenomenon (1) ionic velocity or mobility and (2) ionic dissociation. The strong dependence of solution resistance on the concentration of dissolved solids results because at higher concentrations interionic interactions increase and ionic dissociation decreases. At "infinite dilution," where only a minute trace of solute is present, ionic dissociation of the solute is 
complete and the ions move through the solution unhindered by interactions with other charge carriers. As solution strength is increased, the presence of other ions in the solution reduces the fraction of the solute aissociated and therefore available to transport charge; the other ions also slow the velocity of ionic movement due to electrical interactions between oppositely charged ions. The complex nature of electrical conduction in electrolytic solutions obviously depends on the specific electrolyte and solvent involved. The presence of other solutes within a solution can alter the electrolytic conductance behavior of the solute of interest. Most importantly, however, the electrical conductance of solutions is strongly dependent on temperature. The conductance of aqueous solutions is strongly temperature dependent and changes about $1 \%$ per degree Fahrenheit (3.3). Accurate solution temperature control is a must for reliable conductance measurements.

\subsection{Electrolytic Solutions as Tracers}

With the conductance behavior of electrolytic solutions briefly explained, the discussion shall now turn to the utilization of salt solution tracers for mixing experiments. It is necessary only to remember that the salt solution is introduced into the experimental array at some distance upstream of the detectors. Items 
relating to conductance measurements which have a fundamental: influence on this experimental method includes (1) molecular diffusion of salts due to concentration gradients, (2) general behavior of solution resistance versus concentration and (3) the concentration of the tracer compared to the concentration equivalent of the main flow.

The low mass diffusivity of salt solution tracers introduces a fundamental difficulty in coolant mixing experiments with internal detectors. A stream of salt solution injected into a flow field will be dispersed in part by large scale turbulent eddies thus generating inhomogeneities of solution concentration (turbulent fluctuations), particularly in regions near the injector, but electrical conductance measuring devices, conductivity cell.s, require a homogeneous solution in order to provide reliable measurements. An inhomogeneous solution within a conductance cell will indicate a different resistance than would be indicated by a homogeneous solution involving the same quantity of electrolyte (salt). Specifically, the measured resistance is difficult to interpret because of the nonlinear relationship between conductance and solution concentration. The concentration of solute in parts of the solution being measured changes the overall resistance more than the dilution of solute in other 
parts of the solution offsets it. This three dimensional, solution inhomogeneity problem is a complex question that is difficult to assess. However, if the conductance is monitored in all subchannels within the flow channel, the instrumentation should detect the same. total amount of salt going past an axial plane located downstream of the injector as is known to be injected. This monitoring criterion is refered to as the salt "Mass Balance" and is an effective measure for assessing the inherent accuracy of the conductivity instrumentation. Because stripping, the failure to meet the mass balance criterion, is characterized in part by specific flow conditions within the experiment, a mass balance should be an integral check of any salt tracer experiment:

The electrical resistance versus solution concent-: ration; $R$ vs. $C$, curve in Figure 3.1 shows that salt injection instrumentation methods can be expected to have good resolving power (the ability to monitor weak signals) because the resistance of the solution is strongly dependent on solution strength at low concentrations. The nonlinear behavior of $R$ vs. $C$ gives flexibility to the experimenter with regard to the results sought. The nonlinear character also influences the accuracy of the technique when low salt concentrations must be detected; the salt injection technique is very capable of monitoring weak signals common to a coolant 
mixing experiment. This is a marked advantage over the linear temperature versus enthalpy relationship characteristic of hot water tracers.

\subsection{Conductance Measurement Networks}

The measurement of the electrical conductance of an electrolytic solution consists of using the solution to complete an electrical circuit. The circuit itself is a combination of electrical equipment to measure an unknown electrical resistance. Several methods of measuring and recording the unknown resistance can be used. The primary requirements of the method used are that the resistance be reliably and rapidly measured. A preliminary consideration in selecting measuring equipment is the option of using either direct current DC or alternating current AC circuitry. AC measurements are preferred over DC for reasons discussed below. The use of an $A C$ conductance measuring circuit instead of a DC circuit significantly influences the accuracy of conductance measurements. A tabulation of the characteristics of each technique is given in Table 3.1. Briefly, the major reason for using the $A C$ circuit is the ability of this method to overcome polarization errors inherent to the DC technique (discussed later); the major disadvantage of the AC circuit is the introduction of inherent reactance effects within the 
Table 3.1

Characteristics of $\mathrm{AC}$ and DC Conductance Measuring Circuits*

\section{Alternating Current}

Polarization can be greatly reduced and eliminated for practical purposes

More accurate measurements with standard equipment

No stray DC influence on measurements

Amplification simple and inexpensive

Reactance effects complicate measurements
Direct Current

No reactance effects that are inherent to $A C$

Simple Electrical Network

Thermoelectric and contact potentials may interfere with measurements

High sensitivity equipment is more expensive and less common

*References $(3.2,3.3,3.4)$ 
circuitry. Accurate AC equipment is readily available; also stray DC currents, contact potentials and thermoelectric effects, do not interfere with $A C$ measurements. Details concerning electrical conductance measuring equipment and methods used for this work are given in Appendix 2.

\subsection{The Conductivity Cell}

The apparatus that uses the electrolytic solution to complete the electrical measuring circuit is the conductivity cell. The solution acts as an electrical

conductor between the cell ${ }^{\circ} \mathrm{s}$ two exposed electrodes when they are submerged into the solution. With this cell, the conductance of the solution may be determined and used as a measure of the concentration of dissolved salt in the solution. The resistance measured between the electrodes or within the cell is determined by the cell's design as well as by the solution.

The electrical network equivalent of a conductance cell (3.5) is shown in Figure 3.2(A). The solution acts as a resistance $R$ between the two electrodes; it is this component of the electrical network shown that is of interest. The capacitance $C$ is the result of the dielectric action of the solution between the electrodes and of the capacitive effects in the lead wires connecting the cell to the measurement equipment. 
(A)

CONDUCTIVITY CELL WITH BRIGHT PLATINUM ELECTRODES

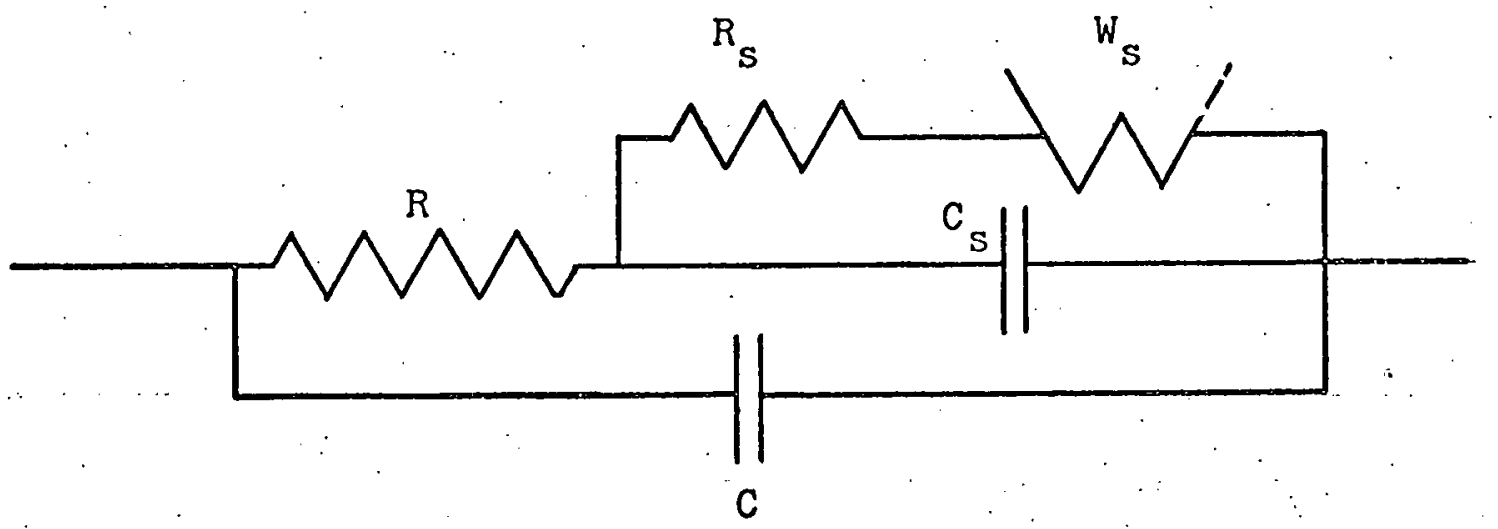

(B)

CONDUCTIVITY CELL WITH PLATINIZED PLAT INUM ELECTRODES

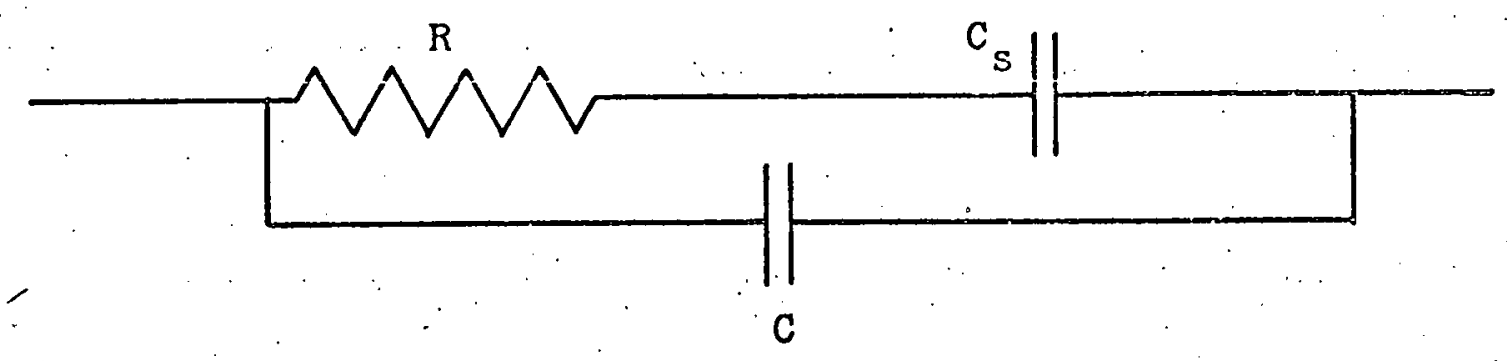

FIGURE 3.2 - ELECTRICAL NETWORK EQUIVALENT OF A CONDUCTIVITY CELL USING AC MEASURING TECHNIQUES (From 3.5) 


$$
R_{S}, W_{S} \text { and } C_{S} \text { are effects at the electrode }
$$

surfaces. These surface effects are consequences of the change of the electrical conduction mechanism from that of a solid wire to that of an electrolyicic solution. Because ionic velocities are slow, a double layer of ions is generated at the electrode surfaces in the process of AC charge transport; the layer acts as a capacitance $C_{s}$ in series with the solution resistance. Electrolysis at the electrode surfaces is represented in the network equivalent by $R_{S}$ and $w_{S}$ these surface phenomenon are in parallel with $C_{S} \cdot R_{S}$ is a representation of the resistance to charge flow generated by the electrolysis process, and $W_{S}$ is a "Warburg Impedance" which may be considered a resistance in series with a capacitor. For further details the reader is refered to Robinson and Stokes (3.5). The electrolysis process occuring at the surfaces of the electrodes, refered to as polarization, interferes significantly with $A C$ conductance measurements. "Kohlrausch (2.6) discovered that errors due to polarization in the measurement of conductance can be minimized by covering the electrodes by a deposit of finely divided black platinum." (3.7) Jones and Bollinger ( 3.7 ) have studied platinization in more detail. Platinizing the electrodes of a conductance cell proceeds by cleaning the cell surfaces in a 
solution of isopropyl achohol, ethyl ether and hydrochloric acid (see Equipment List, Appendix 4). Platinum black is next electroplated on the electrodes from a platinizing solution made of $3 \%$ platinum chloride dissolved in a $0.025 \%$ lead acetate solution. With the cell electrodes platinized, the conductance measurements become considerably simpler as evidenced by the network electrical equivalent of the platinized conductivity cell shown in Figure 3.2(B). The electrolysis effects represented by $R_{S}$ and $w_{S}$ are for all practical purposes, eliminated from the network equivalent by platinization. The effectiveness of platinization can be readily evaluated by making conductance measurements at several frequencies, say 60, 100 and 10,000 Hertz. Polarization effects are frequency dependent and decrease with increasing frequency. Audio range frequencies (less than 15,000 Hertz) only are of interest here because other reactive elements in the measurement circuit become overbearing at higher frequencies. The deviation of measured resistance of a given solution with changes in frequency (in the audio frequency. range) should be at most a few per cent if the cell has been platinized properly. The cell user is cautioned that, in order to prevent gas entrainment onto the platinized surfaces, a conductivity cell should be 
stored in a salt solution when not in use (say $0.1 \mathrm{~N}$ $\mathrm{NaCl}$ ). Only when storage is for more than a month should the platinized surfaces be allowed to dry in air. As was mentioned previously, the resistance measured across the leads of a conductivity cell immersed in a solutinn is determined by the snlution's concentration and by the design of the conductivity cell itself. The ratio of electrode separation distance $I_{e}$ to exposed electrode area $A_{e}$ is the cell constant and is a function of cell design only:

$$
\mathrm{K}_{\mathrm{c}}=I_{\mathrm{e}} / \mathrm{A}_{\mathrm{e}}\left(\mathrm{cm}^{-1}\right)
$$

This standard definition is really oversimplified; it assumes that the exposed area of each electrode is parallel and that the exposed electrode surface is constant along its length. The cell constant is the geometric characteristic which relates measured resistance $R_{m}$ to the specific resistance $r_{S}$ (or to the specific conductance $\mathrm{k}_{\mathrm{s}}$ ) of the solution:

$$
\begin{array}{ll}
r_{s}=R_{m} / K_{c} & (0 h m-c m) \\
k_{s}=K_{c} / R_{m} & (m h o / c m)
\end{array}
$$

A conductivity cell constant may be either calculated with this simple geometry method or calibrated with a solution of known conductance. Calibration, the more reliable technique, may be accomplished by either the reference solution method or the reference cell method (3.8). In the reference solution calibration technique, 
a solution of known conductance is used to determine $\mathrm{K}_{\mathrm{C}}$ with the measured resistance known. Table 3.2 gives the specific conductance of several standard solutions of potassium chloride dissolved in distilled water and exposed to air; the strong temperature dependence and range of cell constants should be noted. Tra cell constant range is required so that the measured resistance will be within a high accuracy range on the wheatstone bridge as discussed in Appendix 2 . With the reference cell method, the cell to be calibrated and a reference cell of known cell constant, e.g., a commercial cell, are submerged in a common solution. The reference cell is used to measure the solution specific resistance, and the calibration procedure becomes identical to the reference solution method.

It is easily established that the unknown cell constant $K_{\mathrm{cu}}$ is related to the unknown measured resistance $R_{m u}$, the reference cell constant $K_{c r}$ and the reference measured resistance $R_{m r}$ by i

$$
\mathrm{K}_{\mathrm{cu}}=\mathrm{K}_{\mathrm{cr}} \mathrm{R}_{\mathrm{mu}} / \mathrm{R}_{\mathrm{mr}} \text {. }
$$

\subsection{Accurate Conductance Measurements}

The accurate measurement of the specific conductance or specific resistance of an electrolytic solution requires the following major conditions (3.5):

(1) accurate electrical measurements, 
Table 3.2

Standard Reference Solutions*

Normality Definition Temp. $\left({ }^{\circ} \mathrm{C}\right) \quad \begin{gathered}\text { Specific } \\ \text { Conductance }\end{gathered}$ Constant (m1cromhos) Range

\begin{tabular}{|c|c|c|c|c|}
\hline \multirow[t]{3}{*}{$1.0 \mathrm{~N}$} & $71.1352 \mathrm{~g}$ & 0 & 65,176 & \multirow[t]{3}{*}{$50-10$} \\
\hline & $\begin{array}{r}\text { SCl } \\
\text { Solution }\end{array}$ & 18 & 97,838 & \\
\hline & . $\quad$ : & 25 & 111,342 & \\
\hline \multirow[t]{3}{*}{$0.1 \mathrm{~N}$} & $7.41913 \mathrm{~g}$ & 0 & $7,137.9$ & \multirow[t]{3}{*}{1.0} \\
\hline & $\begin{array}{l}\text { Solution } \\
\text { Solution }\end{array}$ & 18 & $11,166.7$ & \\
\hline & & 25 & $12,856: 0$ & \\
\hline \multirow[t]{3}{*}{0.01} & $\begin{array}{r}0.74526 \mathrm{~g} \\
\mathrm{KCi} / 1000 \mathrm{~g}\end{array}$ & 0 & 773.64 & \multirow[t]{3}{*}{$\begin{array}{r}0.05- \\
0.5\end{array}$} \\
\hline & Solution & 18 & $1,220.52$ & \\
\hline & & 25 & $1,408.77$ & \\
\hline
\end{tabular}

From (3.8) 
(2) avoidance of polarization errors,

(3) accurate control of solution temperature and,

(4) in the case of standard techniques, a solution of homogeneous concentration.

For this work, sodium chloride $\mathrm{NaCl}$ dissolved in city water (1.0 - 3.0 grams - NaCl / Ibm - City water) was used as the salt solution tracer. City water with a specific conductance ranging from $2500-4000 \mathrm{ohm}-\mathrm{cm}$ was used for the main flow fluid. AC measurements with heavily platinized, platinum electrode, conductivity cells were used to provide accurate measurements of solution conductance. Temperature control was achieved by making all measurements under isothermal, room temperature conditions.

It cannot be overemphasized that electrolytic conductance measurements are complicated in nature and susceptible to error in numerous ways. Although the operational procedures are straightforward and simple, the measurer should always be on the iookout for indications that something is wrong. Unfortunately, rëliable conductance measurements are subject to a myriad of errors which are often subtle in nature. Erroneous signals do, however, offer signals to a judicious investigator. 


\section{Chapter 4}

EXPERIMENT DESIGN AND CONSTRUCTION

\subsection{Experiment nesign_Criterja}

The experimental investigation of interchannel

coolant mixing is the main objective of this work. The design and construction of the Mixing Instrumentation Test Facility MITF shall be discussed in this chapter.

The experimental MIIF was designed and constructed based on the following criteria:

(1) axially detailed, experimental coolant mixing resurts,

(2) a salt solution tracer,

(3) internal detection instruments,

(4) a partial bundle section geometry (rhombus), and

(5) a plexiglas flow channel.

Prior to June 1972, the project was handicapped by Iimited financial support which retarded the initial activities of the experimental program. After June 1972, external support of the project was received from the USAEC, and the experimantal facility was completely redesigned and reconstructed by the author.

4.2 Experimental Objectives

The objectives of the experimental efforts regarding interchannel coolant mixing follow: 
(1) to evaluate the compatability of internal instrumentation for salt solution tracer experiments and

(2) to assimilaie interchannel coolant mixing data with continuous axial resolution.

4.3 The History of MIMF, the Mixing Instumentation Test Facility

MITF has had a long history of difficulties during construction and operation. The problems have been in three general areas: the experimental rod array, the test section channel or flow housing; and the detection instrumentation. Since 1971, four rod arrays and two test section channels have been constructed. Prior to Fall 1972, the problems of the experimental facility were further compounded by limitations in the hyoraulic facilities.

The first experimental mixing test facility was constructed in the MIT Heat Transfer Laboratory and connected to an existing hydraulic loop. A schematic of the hydraulic loop and a cross section of the experimental test section are shown in Figures 4.1 and 4.2, respectively. Experimental test section No. 1 was originally constructed and described by J. Turi (4.1). Basically this test section was a $5 \times 6$ parallelogram array of $1 / 4$ inch diameter tubes with single 


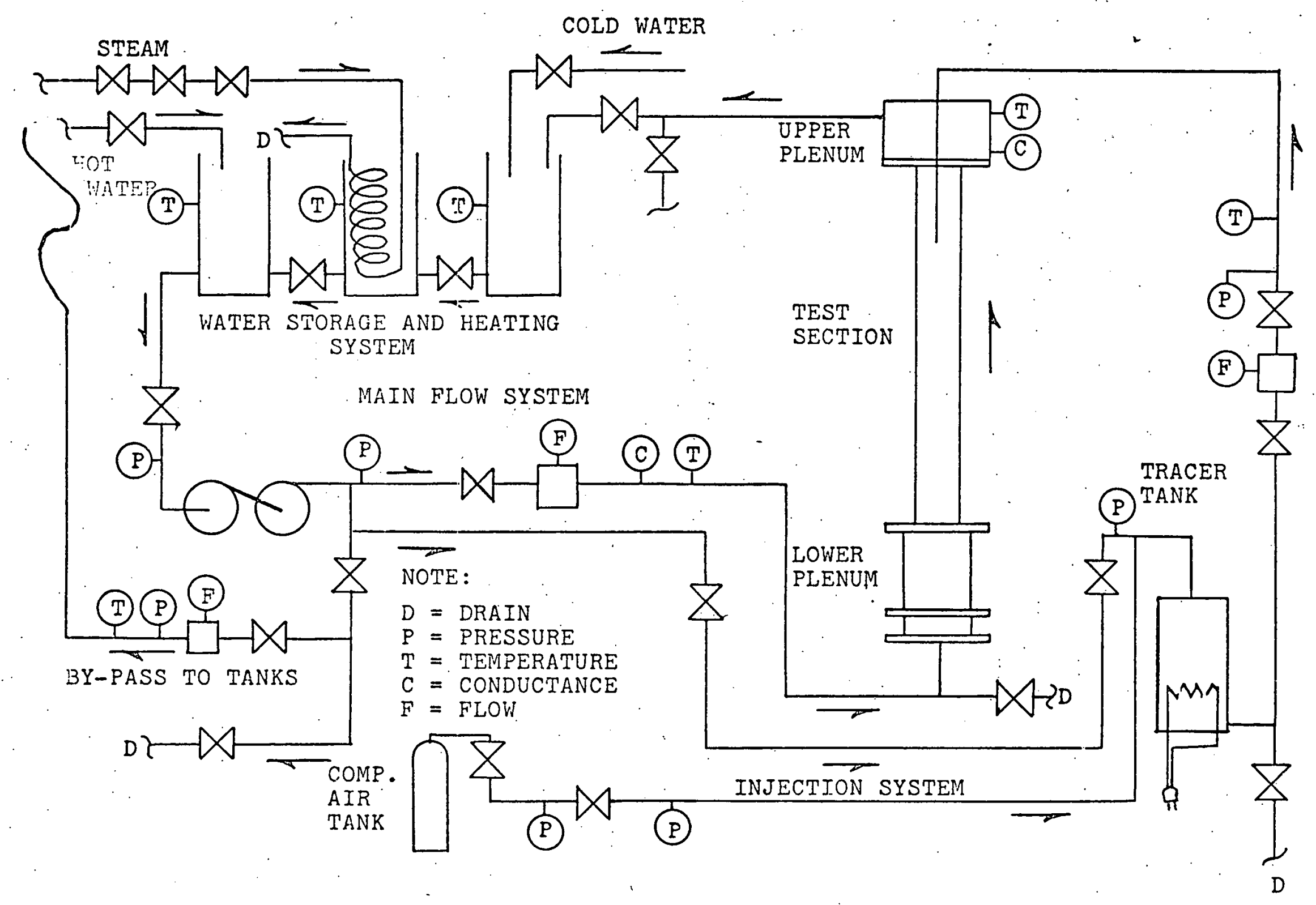

FIGURE 4.1 - SCHEMATIC OF HYDRAULIC LOOP NO. 1 USED FOR MIXING EXPERIMENTS 
FIGURE 4.2 - CROSS SECTION OF EXPERIMENTAL TEST SECTION NO. 12

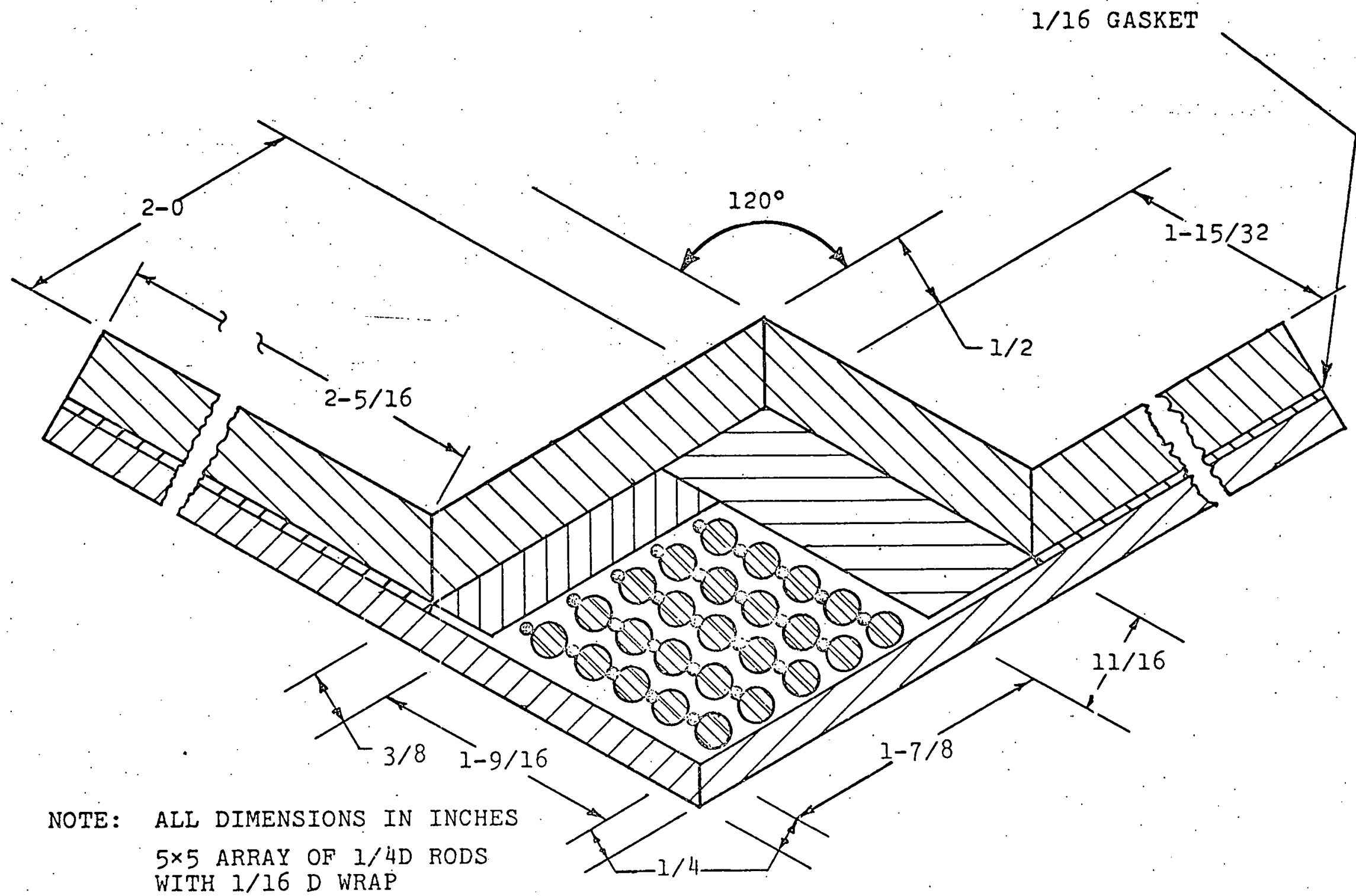


wire-wrap spacers maintaining an equilateral, triangular lattice on a 5/16 inch rod-to-rod pitch. The rod array was 72 inches long and had a 12 inch wirewrap lead (axial pitch). The experimental test section was designed to be representative of the corner of a 217-pin LMFBR fuel assembly, cf. Figure 1.2. It was hoped that interchannel coolant mixing results characteristic of interior, peripheral and corner subchannels could be obtained with this facility. Also, near-wall interior and deep interior (four rows of subchannels from any wall) were to be monitored so as to evaluate the influence of flow by-pass on mixing at the rod array edge. The experimental test section was constructed so as to accommodate up to a $6 \times 8$ array. By changing the number of rods in the array and using shims to fill the unoccupied flow areas, the effect of non-typical $60^{\circ}$ corners could be assessed. The changes of bundle geometry of both the experimental, rhombus rod arrays and the regular, hexagonal rod arrays are tabulated in Table 4.1. The by-pass flow for a given rod diameter and rod-to-rod pitch is characterized by the inverse of the ratio of the number of interior subchannels to the number of peripheral subchannels (see also Table 6.2). It will be noted that the rhombus offers little, if any, flow advantage over the regular hexagonal geometries.

However, the construction of the flow channel is 
Table 4.1

Geometrical Characteristics of Hexagonal and

Parallelogram, Triangular Lattice Rod Bundles of Interest

$\perp$

Array Number Rods! Number Number Numbar Interior

Geometry of Rods Side Corner Interior Perip. Peripheral

Subch. Subch. Subch.

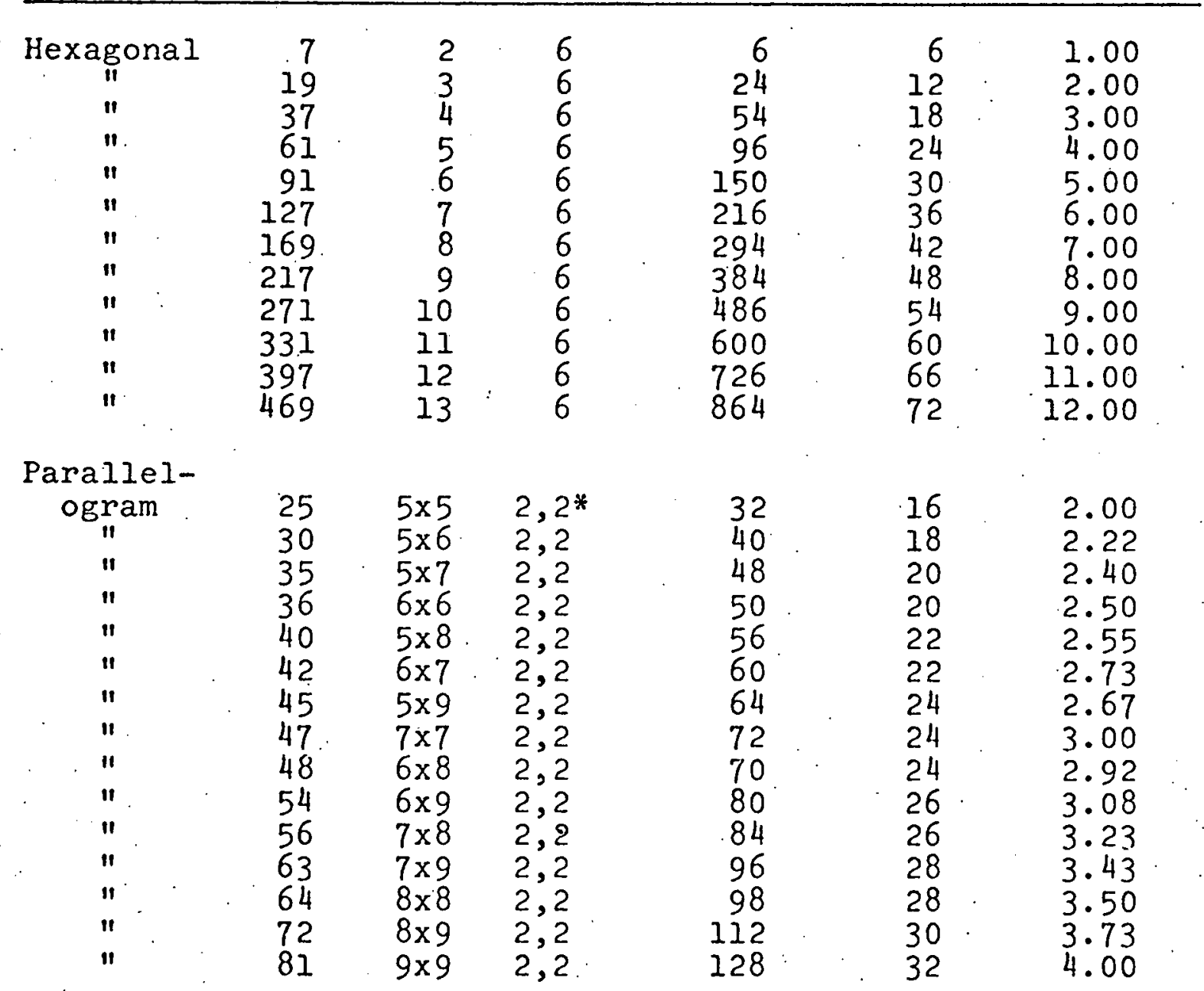

*Number of $120^{\circ}$ Corner Subchannels, Number of $60^{\circ}$ Corner Subchannels 
simplified in the case of the rhombus. The test section flow channel was made in two sections, one with $3-120^{\circ}$ elbow, one with $1-120^{\circ}$ elbow, see Figure 4.2. These two pieces were hela together with bolts every 2 inches. The hydraulic loop consisted of three main systems: (1) the main flow system, (2) the injection system and (3) the water storage and heating system. Three tanks, each made of two-55 galion drums welded together, provided for 330 gallons of water storage. The tanks could be Filled with either hot or cold water. One of the three tanks contained a steam fed, copper coil for heating and regulating the water temperature. The bypass loop on the main flow system was a valuable aid in regulating the temperature of the stored water and in deaerating the water during heating. The main flow system had a two-stage centrifugal pump, flow regulating and flow monitoring equipment. The main flow entered the lower plexiglas plenum (with flow straightener). flowed up through the test section, entexea the plexiglas upper plenum and discharged by gravity either to the storage tanks or to a floor drain.

The tracer injection system was basically a commercial hot water tank pressurized by a compressed air cylinder. The tank was equipped with an electric heating element which could be used to maintain the temperature of the tracer solution. (This heating 
element was completely destroyed by the strong salt solutions.) The tracer was monitored, regulated and then injected into the main flow. The hydraulic systems discussed above were a complete redesign of the original arrangement by Turi.

The original rod array built by Turi used a single stationary needle injector and multilevel conductance cells mounted over 6 inch intervals in the upper 36 inches of the array. Four interior subchannels were instrumented, the injection subchannel and the three contiguous subchannels. The cell electrodes were glued to holes drilled through the sides of the plexiglas (Iucite) tubes making-up the array; they consisted of bright platinum discs soldered to copper lead wires. The electrode lead wires were fed through the tube and connected via a switching network to a simple AC Wheatstone bridge. The electrodes were not platinized and protruded markedly into the subchannels: the conductance measurements were, consequently, uisacceptably frequency dependent.

The tracer was carried by a tube from the tracer tank to the injecticn tube. The injection tube was closed at the lower end so that the tracer solution was forced through the stationary needle mounted at about $20^{\circ}$ from the tube axial centerline and pointed in the direction of the flow. During inftial operation, the 
plexiglas tube broke at a location which had been reakened in mounting the electrodes. The tube could not support the injection system pressure at the required tracer flows. This Iailure necessitated disassembly of the original No. 1 test section.

After disasseminy, the design of the injoction ana detection systems was modified considerably by the author so as to improve the capabilities of the experimental facility. The injection tube was changed to provide for an axially moving injector; the conductance cells were located at one axial location and more subchannels were monitored. The moving injector needle was constructed using two concentric aluminium tubes. The outer $1 / 4$ inch outside diameter $O D$, thin-wall tube was slotted (1/16 inch vide) from 31 inches to 1 inch from the upper end of the tube. $\Lambda 3 / 16$ inch $O D$ tube (plugged on the lower end) was inserted inside the $1 / 4$ inch tube. A $1 / 16$ inch OD needle vas inserted (at approximately $20^{\circ}$ from the direction of fiow) into the inner tuibe through the slot in the outer tube. The needle was ground dow to be flush with the outside of the outer tube. The tube was next wrapped in the usual manner with the injector needle passing under the wire-wrap.

Disassembly of No. 1 test section revealed that the flow channel was both designed and manufactured in a manner which resulted in a poorly defined filow area. 
With the second version of No. 1 rod array completed, it was found during assembly that the plexiglas tubes were structurajly too weak and brittle for service in the test section. At this point, construction was initiated on the third version of No. 1 rod array using solid plexiglass rods instead of the tubes used previously. To simplify electrode construction and to increase the structrual strength of the instrumented area of the rod. a 30 AWG (American Wire Gauge) copper wire was used to form the electrodes instead of the platinum disk. Figure 4.3 shows qualitatively how these electrodes were mounted on the plexiglas rods. First, a 1-3/8 inch deep hole is drilled down the centerline of the rod from the top. Then electrode mounting holes are drilled each $60^{\circ}$ (at the proper orientation with respect to the rod support holes) so that an electrode would be in each subchannel around the rod. These mounting holes are drilled at $1-1 / 4$ and $1-1 / 2$ inches from the top of the rod. The holes should be backfilled with glue to hold the electrode wires in place. The wire should be held in place at the lower support hole with glue also.

A major consideration in designing and mounting the electrodes was the platinization of the electrode surfaces. Because the platinizing solution costs about $\$ 10$ per ounce, the elctrodes must be arranged so that the cost of platinization is not prohibitive (electrodes should not be platinized before ascembly as handling destrous the weakly bonded platinized surfaces). 

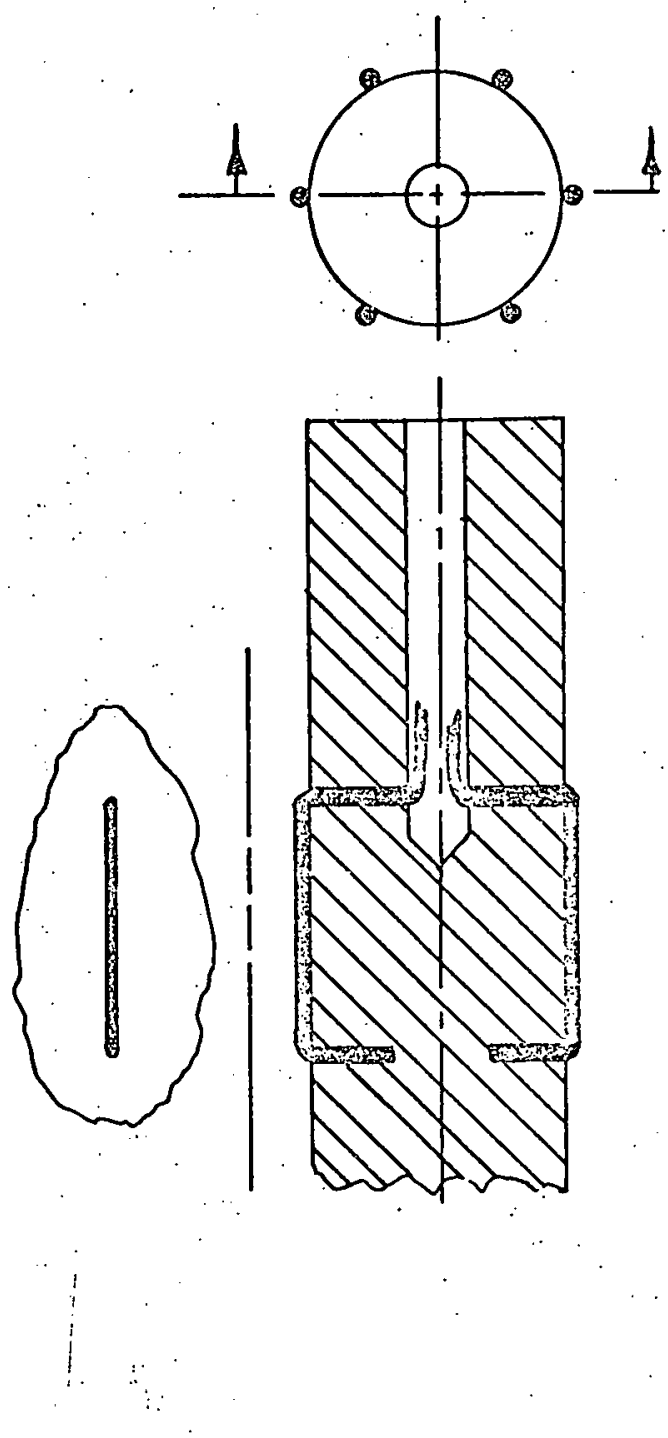

FIGURE 4.3 - ROD-MOUNTED ELECTRODE DESIGN 
To keep the volume of platinizing solution reasonable, the electrodes should be near the end of the rods. The multiple axial level, electrode mounting scheme would be impractical because of the electrode platinization expense:

4.4 The First Experiment

With the third version of test array No. 1, a series of experiments on interchannel coolant mixing were run. The first and only reasonable experiment in the series was made on 16 April, 1972 , the results of this run are given in Figure 4.4 and are presented only for the sake of illustration. The following parameters were used for this experiment:

Main Flow $=72 \mathrm{Ibm}$ water $/ \mathrm{min}$, Water Temp $=140 \mathrm{~F}$ (Cambridge, Mass., City Water)

Tracer Concentration $=0.5$ gram NaCl$/ \mathrm{lbm}$ water, Injection Rate $=1.21 \mathrm{bm} / \mathrm{min}$

Subchannel Reynolds Number $=4500$ (Approx.). Subchannel Flow Rate $=0.951 \mathrm{bm} / \mathrm{min}$. The tracer solution was injected into subchannel No, 1 (the subchannel arrangement is shown in the inset in Figure 4.4): measurements were taken each $1 / 2$ inch over the first 10 inches, and every 2 inches from 10 to 16 inches. The 0.0 inch position is with the needle about $1 / 2$ inch below the instrumentation plane. The wire-wrap was in the right hand direction so that any swirl flow 


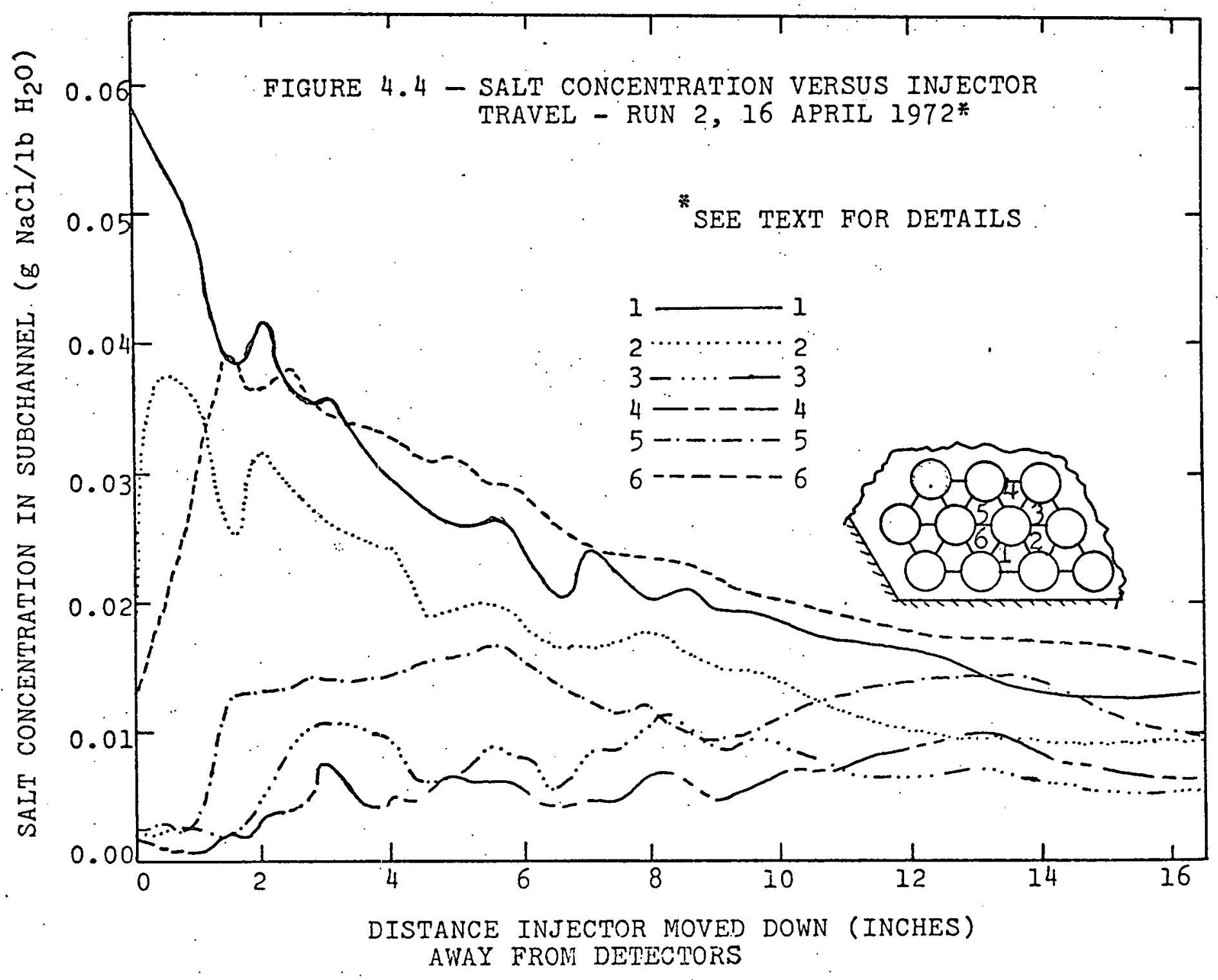


would be directed in the counterclockwise CCW direction (looking down from the top of the test array). The uncertainties in the geometry of the rod array and the flow channel necessitates the dismissal of any confidence in the fine axial structure of the data. The general exponential-like decay of the tracer concentration in the injection subchannel and dispersion to neighboring subchannels was expected. Unfortunately, this data is highly uncertain and of little quantitative value.

Subsequent runs in the first experiment series (with the third version of test array No. 1) revealed unexpected results after the data reduction. Even though injection was into subchannel 1, all of the tracer appeared in subchannel 2, and the trend was consistent for all but the first run of the series (․․2). Post disassembly examination revealed that bubbles of air left in the backfill adhesive had caused internal pressurization and subsequent hallooning of the plexiglas rods in the region just above the electrodes. The experiments were all run at elevated temperatures (140F) so as to increase the Reynolds number of the experiments. A two stage, high head-low flow centrifugal punp was being used in low head service; the resulting low flow rates required that the main flow be heated in order to establish turbulent flow. The viscosity of water reduces 
by a factor of two between room temperature and $140 \mathrm{~F}$. So, for a fixed flow rate, the Reynolds number was doubled by heating the water.

Because the plexiglas looses strength vexy rapidly above $100 \mathrm{~F}$ and because the backfill adhesive dried at room temperature, ine slight pressurization of the bubbles upon heating to $140 \mathrm{~F}$ caused an irregular ballooning of the instrumented array rods. These flow blockages were responsible for the unexpected mixing data; however, these blockages were totally unexpected, and no record of their location or size was made.

Also it should be noted that the wrap spacer on the aluninium injector tube had become loose due to adhesive failure in the hot water. The wrap was inplace but loose.

The array rods suffexing from ballooning were replaced with new rods that were manufactured ascertaining there were no air bubbles in the backfill adhesive. The injector rod was rewrapped. The test section was reassembled with version four of test array No. 1, prepared for operation and stored for three months. Data taken on 8 0ctober, 1972, was of an unexpected nature. Examination of the test array showed the rods to be distorted and out of position. The plexiglas rods had crept in storage and in general 
were too flexible to use for the array: also, as previously noted, the flow channel was of very poor quality. Since the experimental work was now externally sponsored, funds were available to accurateiy rebuild the flow channel and to rebuild the rod array from metal rods. The design and construction of test section No. 2 (test array No, 2 and flow channel No. 2) is discussed next.

\subsection{Facility Redesign and Reconstruction}

With the MITF returmed to the drawing boards after considerable operating experience, the design of the test section, particularly the instrumentation, was improved markedly. The No. 2 rod array was made entirely of 304 stainless steel. (SS). The test section flow channel No. 2 was made of one inch thick plexiglas sheet and accurately machined. Stronger and lighter. upper and lower plenums were made from aluminium, and the experiment was moved from tine EPL (Engineering Projects Laboratory) - Heat Transfer Laboratory to the EPI Experimental Engineering Iaboratory No. 2 (EPI-EEL-@) where a flow test loop of broader capability could be constructed. Most importantly, a probe-type, electrode mount was used instead of the rod mounting scheme described earlier. This modification of instrumentation design considerably expands the capabilities and flexibilities of the facility as will be discussed later. 
EPI-EEL-2 provided a larger volume of stored water since a 55,000 gallon subfloor canal was available. Here a large pumping facility (designed by A.S. Hanson) had already been built to provide flow for planned 61pin, hexagonal bundle tests. The facilities of EEL-2 permitted experiments over a larger Reynolds number range at room temperature; thus, heating, deareation, draining and storage did not limit the operation of the experimental facility. Numerous direct and indirect difficulties originating from limitations in the hydraulic facilities used with test section No. 1 were therefore not present in the experiments on test section No. 2. Figure 4.5 gives a schematic of the mixing investigation pump facility in EPL-EEL-2; each of the two 20 horsepower pumps is rated at 300 gallons per minute GPM at a 180 ft-water head ( 78 psig). The pumps can be run individually, in series or in parallel.

\subsection{Test Section Redesign}

The test section flow channel and its plenums were rebuilt to accurate dimensions. Flow channel No. 2 was constructed from one inch plexiglas sheet. The channel was bolted together every 2 inches over its 72 inch length and later cemented to seal the assembly (see Figure 4.6). The upper and lower plenums were made of 18 inch long, 6.75 inch $O D$, aluminium tubes with $3 / 8$ inch 


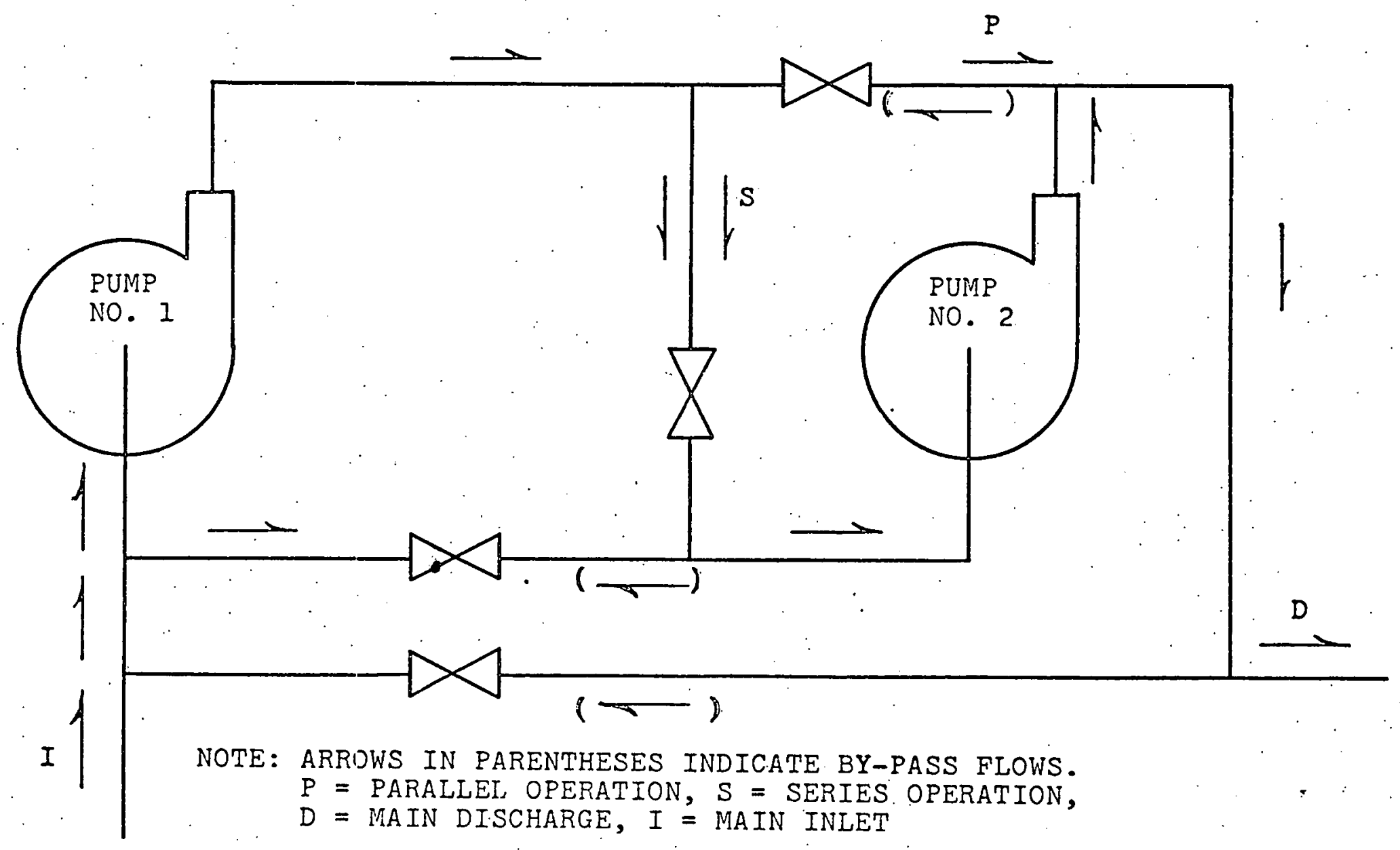

FIGURE 4.5 - SCHEMATIC OF MIT MIXING PROJECT PUIMP FACILITY 


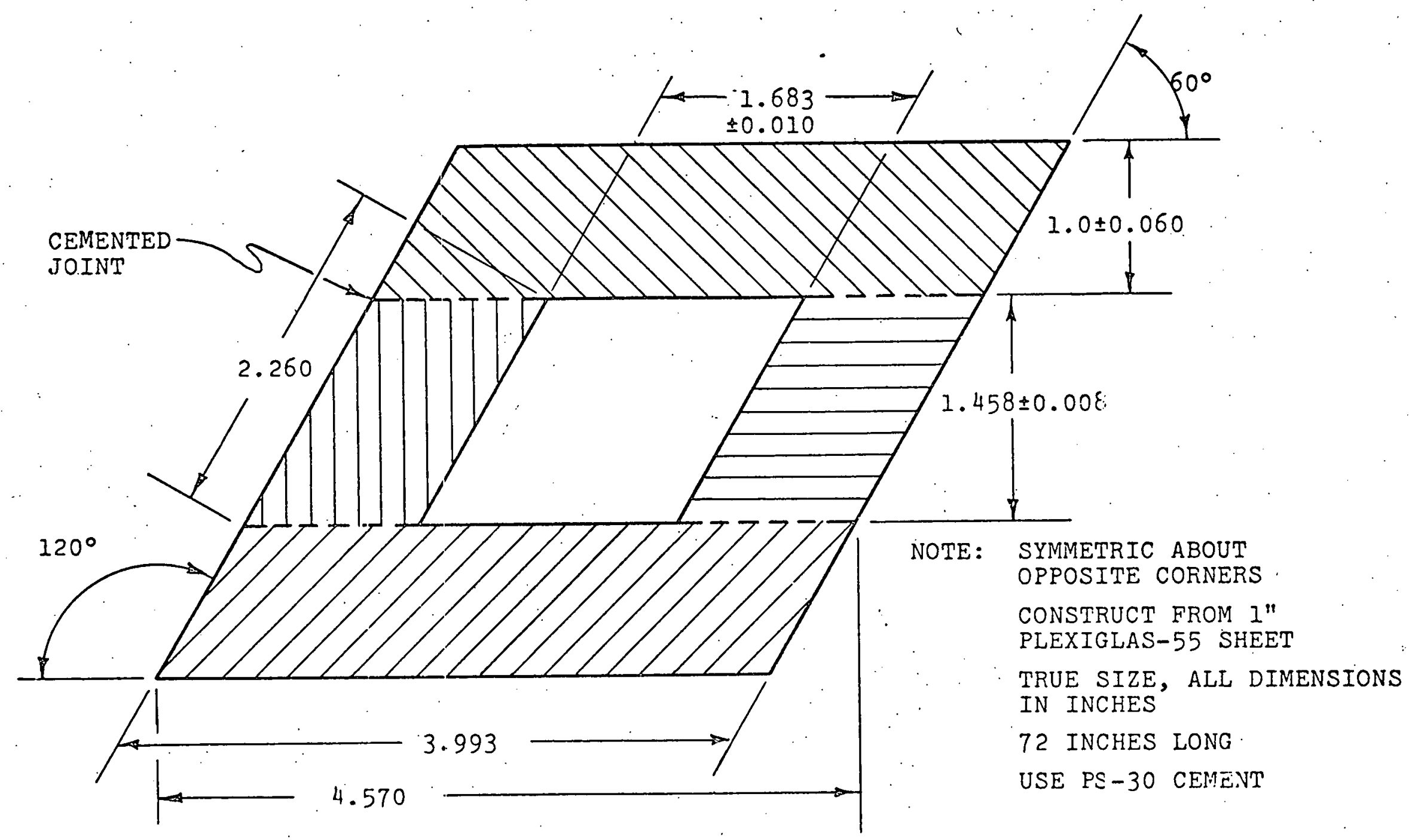

FIGURE 4.6 - CROSS SECTION VIEW OF THE TEST SECTION FLOW CHANNEL NO. 2 
thick aluminium plates welded or bolted to the plenum ends. The upper plenum was open on the top to permit access to the top of the test array the top plenum was drained by gravity to the canal from which the water was drawn (at a point about $30 \mathrm{ft}$. from the pump inlet). The lower plenum received the flow from the pumps and was internally equipped with a flow straightener to give a uniform inlet flow to the test section channel.

The rod array was rebuilt with type 304 stainless steel SS rods and wire-wrap. The rods were cut to length and faced-off on each end. On the lower end, two $1 / 8$ inch diameter rod support holes were drilled transversely through the rod centerline at 1 and at 1-1/2 inches; at 2 inches a wire-wrap support hole, $1 / 16$ inch in diameter was drilled parallel to the rod support holes through the rod center line. This wrap support hole establishes the relative angular orientation of the wrap with respect to the rod in the assembled array. At the upper end of the rod an upper rod support hole of $1 / 8$ inch diameter was drilled dowm the rod centerline to a depth of $1 / 4$ inch. Figure 4.7 shows the end details of the test array rods. The 304 SS wire-wrap was soldered into the wrap support and bent $90^{\circ}$ to lie flat against the rod. The lower end of the injector rod was similar to the other array rods; 


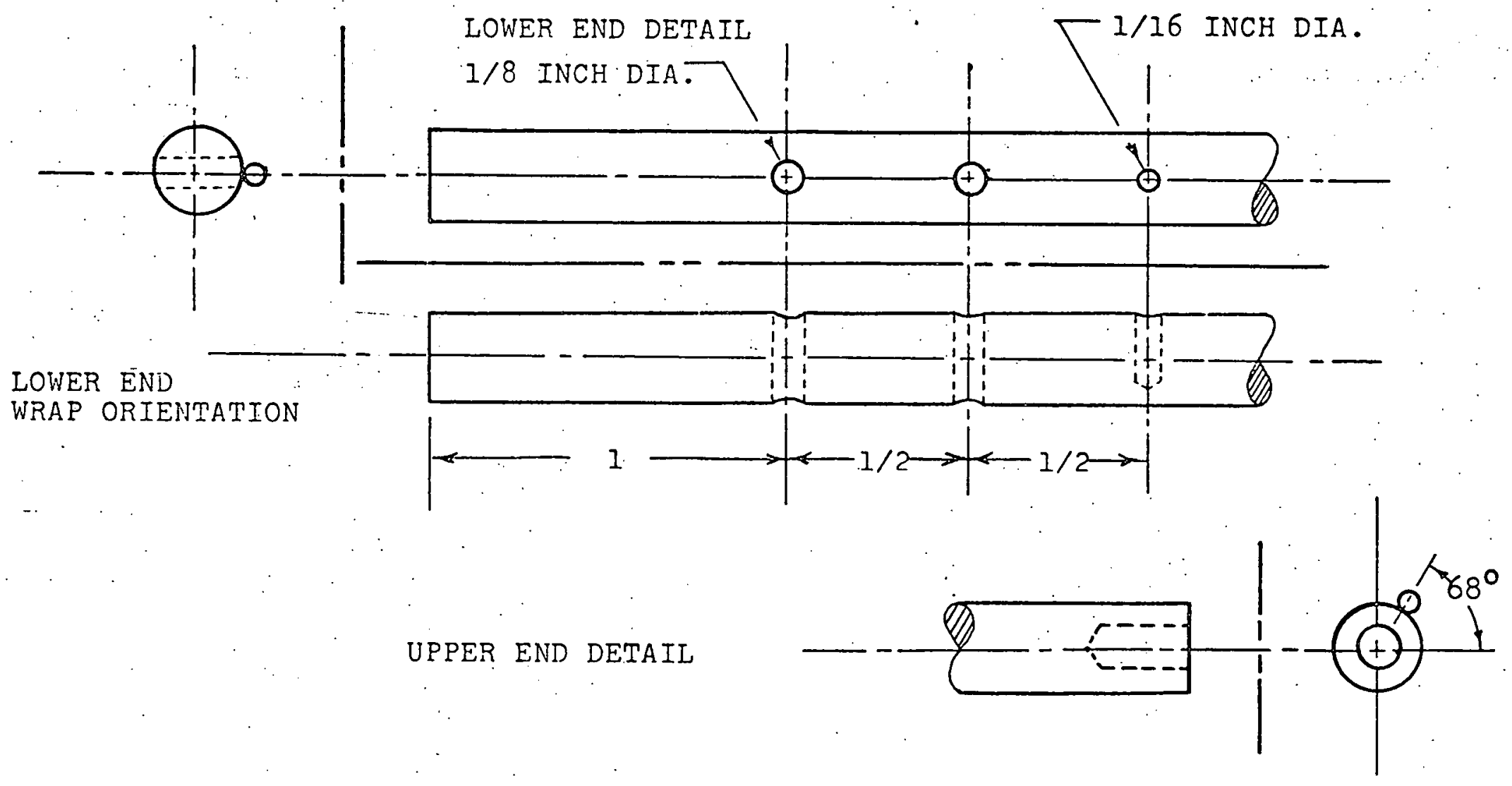

I/8 INCH DIA.

NOTE: SCALE $2 X$ TRUE SIZE

RODS ARE $1 / 4$ INCH O.D. 304 STAINLESS STEEL

WITH 12 INCH LEAD (RIGHT-HANDED) WIRE WRAP

SPACERS $1 / 16$ INCH O.D.

FIGÚRE 4.7 - ARRAY ROD END DETAILS 

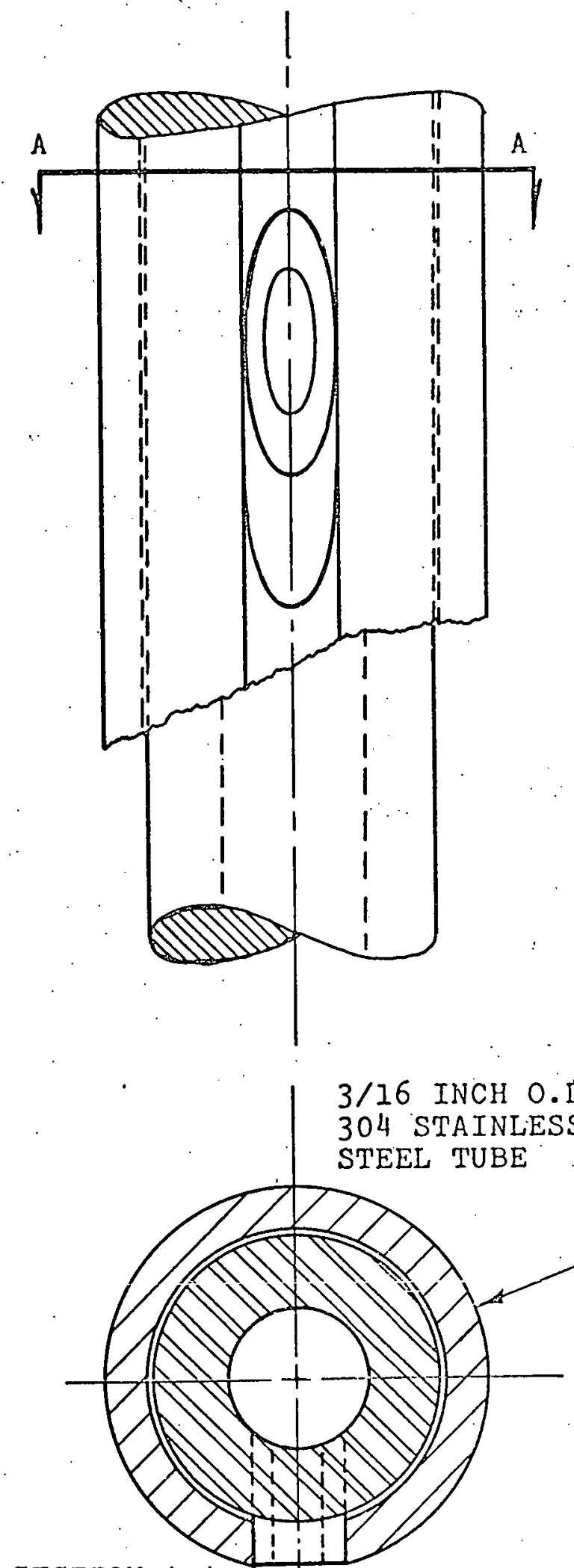

SECTION $A-A$

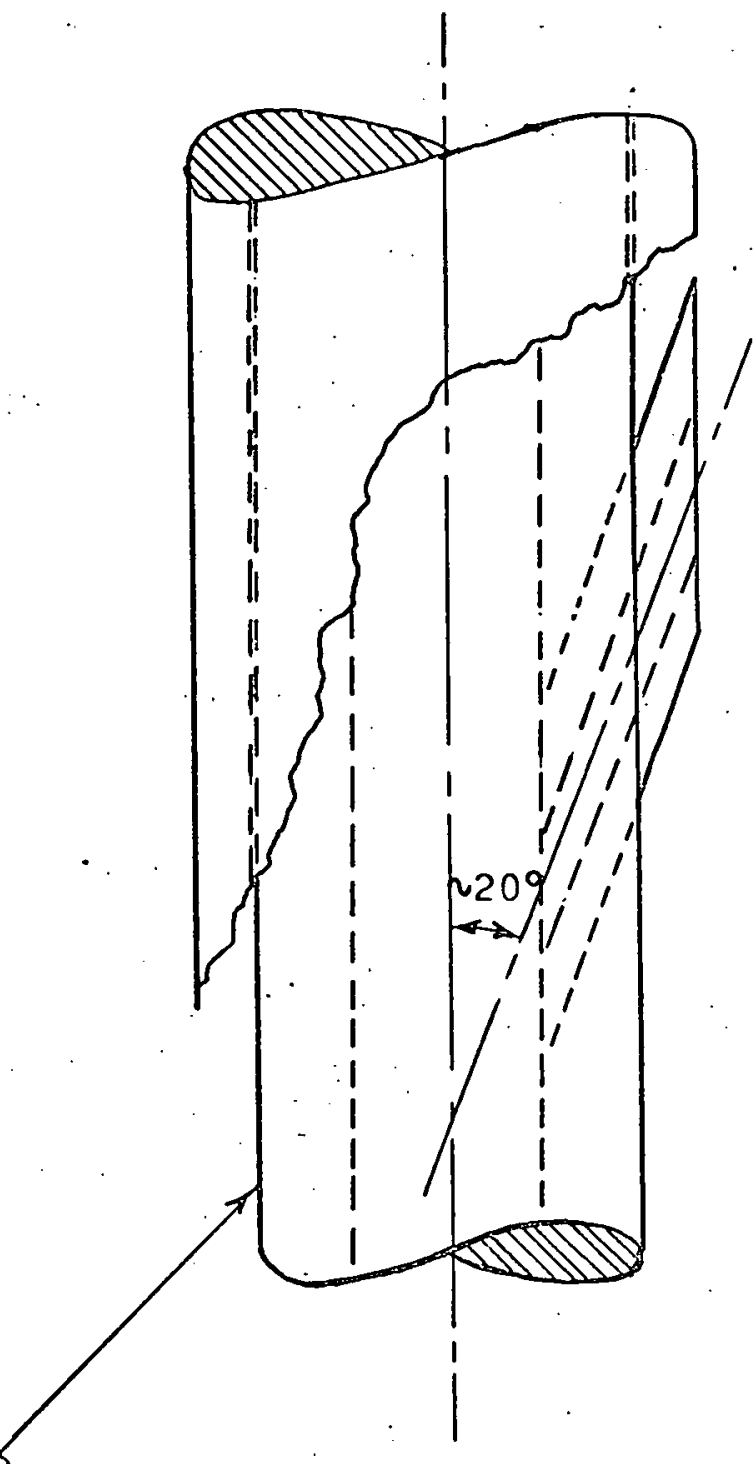

INJECTION TUBE 0.050 INCH OD. $\mathrm{X}$ 0.035 INCH ID. 
finally, the injector rod was wrapped in the usual manner.

The 25 test rods were assembled into a $5 \times 5$ rhombus array; on the lower end, the rods were supported and angularly oriented by mounting each rod on two $1 / 8$ inch diameter support rods which passed through the two rod support holes. The support rods were held in place by $1 / 8$ inch 304 . SS plates mounted at the bottom of the channel and recessed into the walls. The assembled array was slid into the flow channel and held in place by bolting the lower plenum cover to the bottom of the flow channel. Next, the array rods were held in position at the top by an upper rod support plate which has $1 / 8$ inch diameter rods extending 2 inches between the plate and the top of the array rods immediately below. The upper support rod extends $1 / 4$ inch into the upper array rod support hole. Thus, the 25 array rods are heia in position with respect to each other at the channel exit by the upper support rods extending down from the upper rod support plate. Figure 4.9 shows the upper assembly rod support plate, and Figure 4.10 shows a schematic of the upper rod support and instrumentation probe support'.

\subsection{Instrumentation Redesign}

of all modifications, perhaps the nost sinnificant 


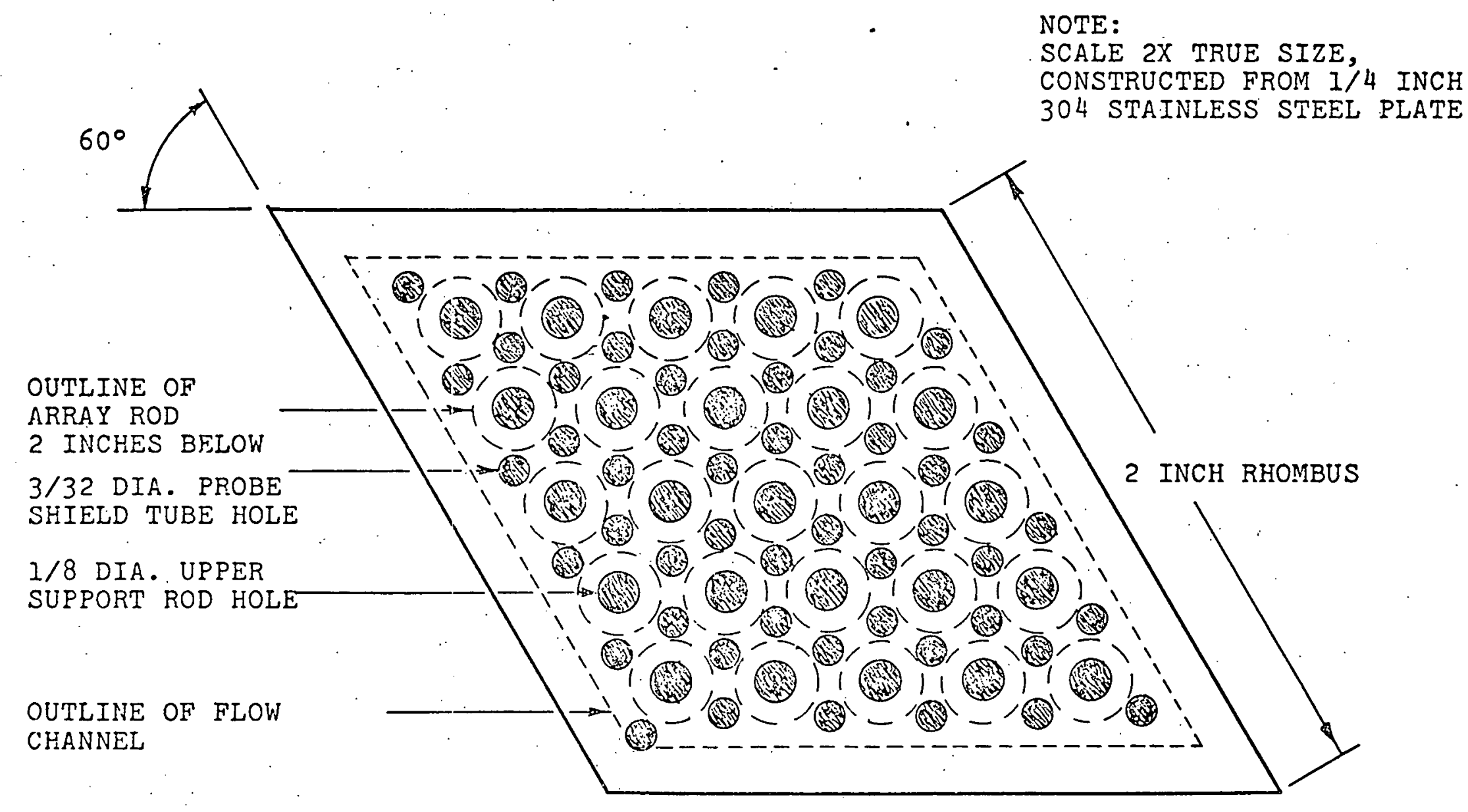

FIGURE 4.9 - UPPER ROD SUPPORT PLATE DRAWING 


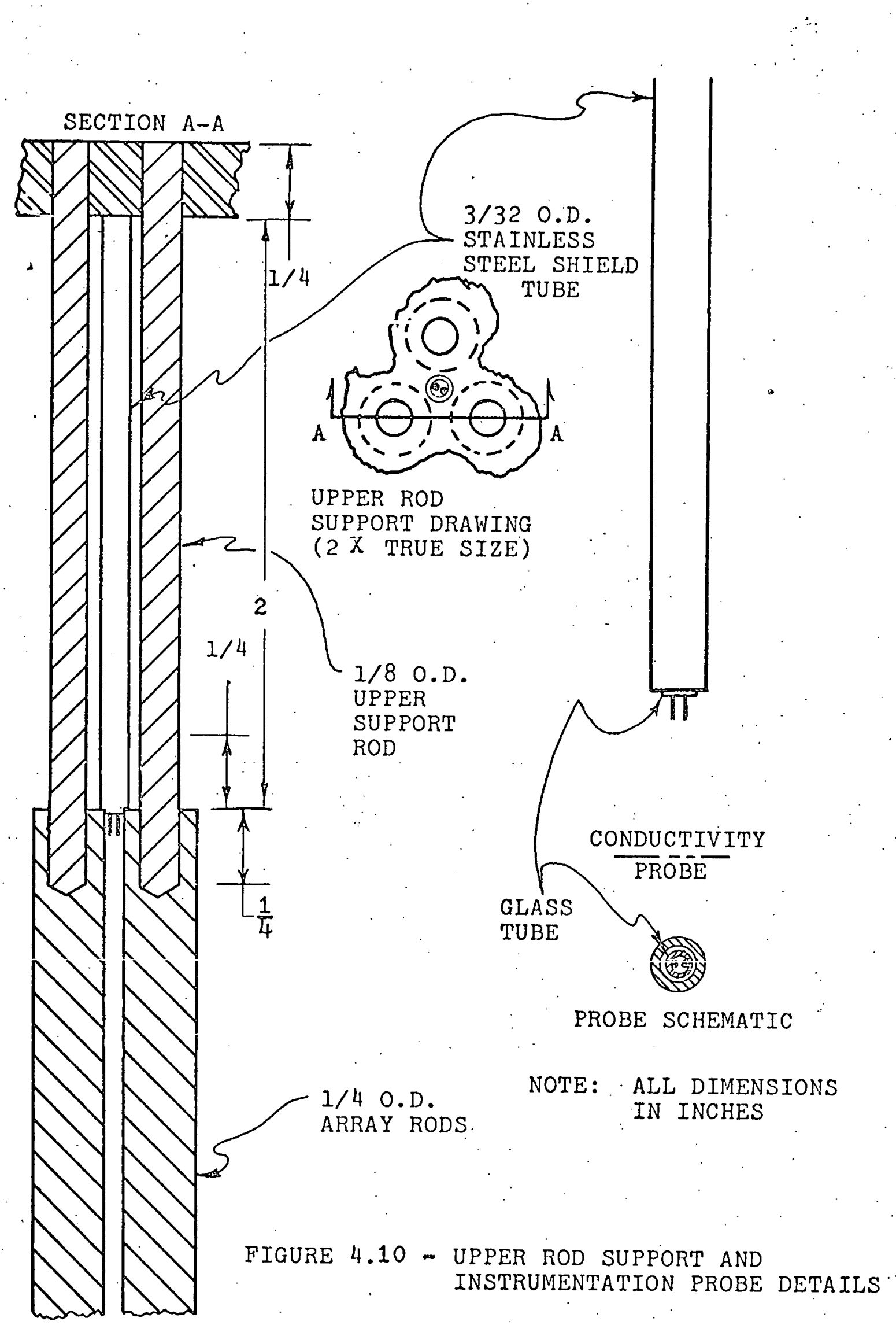


was the change in detection instrumentation design. Instead of mounting the detection instrumentation on the rods, it was supported from the upper array rod support plate as shown in Figures 4.9 and 4.10. The detector probes entered the rod array through $3 / 32$ inch OD instrumentation sirield tubes. This scheme enables the experimenter to exercise any one of several detection systems for the data acquisition process, i.e.. internal conductivity cells, internal thermocouples or external conductivity cells. (if the probe is replaced by a tube for sample withdrawal). Of course, either a salt solution or hot water tracer can be injected through the injection device, and the entire instrumentation system can be changed without disassembly of the test section. Figure 4.10 gives a schematic of the conductivity probes.

4.8 The EPL-EEL-2 Mixing Instrumentation Test Facility The redesigned test section described in sections 4.4 - 4.6 was connected to the mixing project pump facility. The main flow rate to the test section was measured using two rotameters connected in parallel as showm schematically in Figure 4.11. The plenums, as noted, were rebuilt from aluminium; the lower plenum had a flow-straightener made of one inch diameter tubes, and the upper plenum was gravity drained. A pressurized 


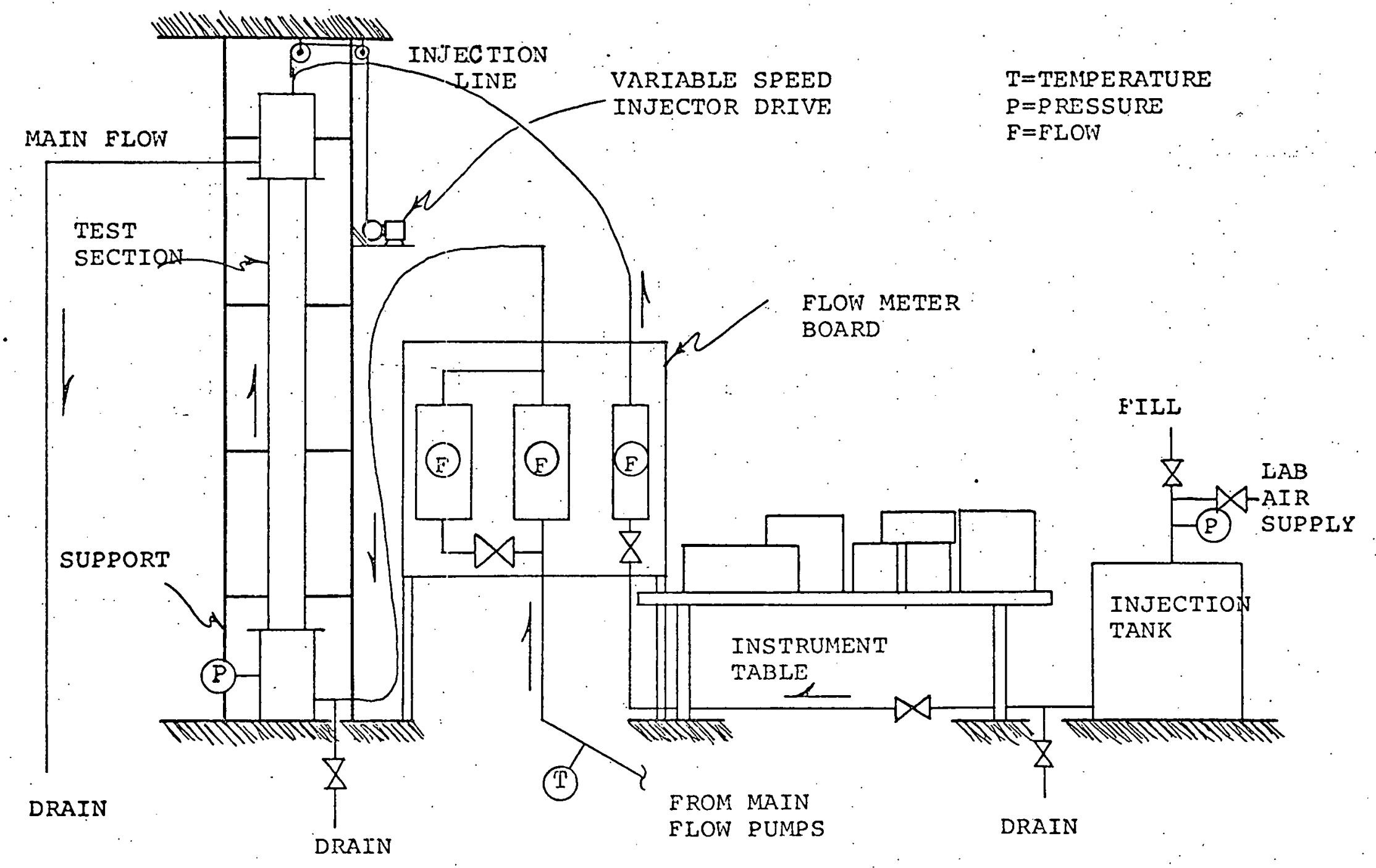

Figure 4.II - SCHEMATIC DIPAGRAM OF THE EPL-EEL2 MIXING INSTRUMENTÁTIOÑ TEST FACILITY 
Injection tank delivered the tracer solution to the Injector rod via a rotameter. A variable speed drive was connected to the moving inner injector tube so that it could be moved automatically. Note that the hydraulic systems were considerably simplified in the EEL-2 facility.

4.9 Design Modifications of the Injector Rod Operational difficulties with the tracer injection rod were encountered due to assembly techniques and design and due to infector drive over-pull. The modifications required to overcome these difficulties are discussed below.

The injector rod design illustrated in Figure 4.8 and discussed in section 4.5 was modified early in the experimental program at EEL-2. The hypodermic tube $(0.050$ inch OD $x 0.033$ inch ID - 304 SS) was not suitable for maintaining the angular position of the internal injection tube within the slotted outer tube. Because the injector tube (needle) was also to serve as the upper and lower stop pin for the inner tube, this injector rod falled shortly after being placed in service. 
After disassembly, an angular rod positioning hole was drilled two inches below the needle device. The needle was replaced and soldered in-place before inserting the inner tube into the slotted outer tube. The needle was next ground flush with the surface of the inside tube. Then the inner rod was inserted into the slotted outer tube and oriented angularly so that a 1/16 inch diameter stainless steel rod could be inserted into the inner rod angular positioning hole. The angular positioning pin was carefully soldered in-place such that no solder spilled over into the annular gap between the two concentric tubes making up the injector rod. Once in-place, the angular positioning pin served to locate the injector needle in the center of the slot in the outer tube and to stop the motion of the inner tube with respect to the outer tube when the angular positioning pin reached either the bottom or the top of the slot in the outer tube. The $1 / 16$ inch diameter pin. inserted into the inner injection tube for rod positioning proved to be unsatisfactory, but all work reported here was done using this design.

For future work it is recommended that a method of providing for angular position of the inner rod be developed using a flat spring mounted into a slot in the inner tube wall. A piece of 0.012 inch thick SS sheet metal, 
$1 / 16$ inch wide and $1 / 4$ inch long formed into a circular arc could be tack-welded to one end of the slot. The arc would be formed so that the center of the spring would protrude about 0.030 inch higher than the inner tube: thus, the strip would act as an angular positioning device. Importantly, such an inner tube could be readily Installed into or removed from the outer tube of the injector rod, i.e., the spring would be compressed into the slot on the inner tube while traveling under the unslotted portion at the end of the outer tube.

With this scheme, it would not be necessary to perform the relatively difficult soldering operations discussed previously.

The inner, moving tube of the injection rod was made of 0.028 inch wall, 3/16 inch OD SS tubing which bends easily. Once bent, this tubing can be straightened only approximately. Moving an "unstraight" inner tube through the outer tube causes the slot in the outer tube to spread open. It is strongly recommended for future work that the moving injection tube be carefully guarded and handled to prevent bending of this inner tube. (Note, spreading of the slot introduces an injector needle, angle orientation error and thus influences the experimental results.) 
4.10 Design and Modification of the Conductivity Cell Probe

The original design of the probe-type conductivity cell is show schematically in Figure 4.10. vriginally. two platinum electrodes about 1 inch long and 30 AWG (0.010 inch) were seldered to 30 AWG copper :ire. These wires were fed through the inside of a 0.068 inch diametex glass capillary tube ( 3.94 inch long). Also, a piece of nylon string was fed through with the wires and positioned between the wires inside the tube. The tube was then heated with a match causing the nylon to foam. When the tube cooled, the wires were securely held in place. The upper and lower ends of the glass tube were sealed using plastic cement. The probe was inserted into a $3 / 32$ inch OD SS tube ( 0.007 inch wall) to protect the. glass tube.

Operational difficulties with these probes were caused by glass breakage, probe positioning and water in-leahase. These probilems were eliminated by the various design modifications discussed below.

It is very important that there be no electrical connection between the electrodes or their lead wires anywhere other than at the electrodes themselves. To eliminate difficulties with lead wire current leakages (due to the presence of water inside the probe), all electrode wires were painted with electrical motor 
insulating paint (General Electric Co. GIYPTAL) which was baked (cured) for two hours at 240F. This insulation covered the entire length of the platinum wire and the soldered platinum-copper joint (the copper wire was manufactured with a baked-on enamel insulation). This insulating process prior to assembly of the glass probe reduced water leakage problems.

The paint was scraped-off the $1 / 2$ inch long platinum wire protruding from the glass tube. Then the glass probe was inserted into a 4 inch long, $3 / 32$ inch OD SS shield tube (originally a 2-1/2 inch long shield tube was used with disasterous glass breakage results). The 'probe end of the glass tube was positioned $1 / 16$ inch below the end of the shield tube, and each end of this shielded probe was sealed. with a plentiful application of epory (plastic cement did not work). The epoxy was. cured at $140 \mathrm{~F}$ for two hours, and the electrode end of the probe was trimmed to the size of the shield tube. The epoxy end seals protected the probe from leakage in the event of jnternal glass breakage.

The electrodes of the probe were cut to a length which gave an optimum instrument reading, i.e., cell constant. For the work at hand $3 / 32$ inch (nominal) Iong electrodes gave a balance bridge resistance of about 10,000 Ohms. This was the optimum balance point for the instruments used, andit gave sensitive measurements over 
the required response range without the use of several instrument scales. Once cut to length, small adjustments to the cell constant were made by bending the electrodes. Note in Appendix 2 that the cell design determines the i measured balance resistance and unbalanced bridge voltage. Given a rugged probe with the required conductivity cell design, the final operational difficulty to be overcome was probe positioning at the array outlet. It was hoped that the probe could be inserted $1 / 4$ inch into the test array from the exit; however, mechanical interference between the probe and the wire-wrap prevented this. The wire-wrap was cut back $1 / 4$ inch from the top of all. rods to allow insertion of the probes into the subchannel. other probe positioning problems were caused by the proximity of rod array materials. A good rule for avoiding material proximity, electrode interference is to keep all electrode surfaces separated from all other materials by a minimum of $1 / 16$ inch of solution. One final note on probe design concerns the length of the platinum electrodes. Because platinum wire is very expensive and because numerous probes are necessary to complete a mixing experiment, it is desirable to keep the length of the platinum electrode wire short. Also it is recommended that the copper lead wires to the cell be heavier than 24 AWG. 


\section{Chapter 5: \\ EXPERIMENTAI RESULTS}

\subsection{A Summary of the Experimental Results}

This chapter presents results of the instrumentation development experiments, the interchannc? coolant mixing experiments and the flow visualization experiments done with the 25-rod rhombus array. For instrumentation development, experiments were performed to determine the influence of the following items on experimental results:

(1) injection flow rate (injection velocity),

(2) salt ( $\mathrm{NaCl}$ ) solution tracer concentration.

(3) salt type ( $\mathrm{NaCl}$ and $\mathrm{NaNO}_{3}$ ).

(4) injector design (needle and transverse hole),

(5) Reynolds number, and

(6) Injector mechanjcal behavior.

Interchannel coolant mixing experiments have been done for the following cases:

(1) interior subchannel injection, turbulent flow,

(2) interior subchannel injection, laminar flow,

(3) peripheral subchannel injection, turbulent flow.

(4) peripheral subchannel injection, l2minar flow. Flow visualization experiments were done for turbulếnt and laminar flow with injection into a peripheral subchannel. Table 5.1 summarizes the experiments done to determine the infiuence of experimentai onerating para- 


\section{Table 5:1}

Experiments to Determine the Influence of Experimental

Operating Parameters on Results

\begin{tabular}{|c|c|c|c|c|c|c|c|}
\hline $\begin{array}{l}\text { RUN } \\
\text { IDENT. } \\
\text { NUHBER }\end{array}$ & $\begin{array}{l}\text { TRACER } \\
\text { CONCENT. } \\
\left(\frac{\text { grain NaCl }}{\text { lom water }}\right)\end{array}$ & $\begin{array}{l}\text { INJECT. } \\
\text { FLON } \\
\left(\frac{1 \mathrm{bm}}{\mathrm{min}}\right)\end{array}$ & $\begin{array}{l}\text { MAIN } \\
\text { FLON } \\
\left(\frac{I \mathrm{bm}}{\mathrm{min}}\right)\end{array}$ & $\begin{array}{l}\text { WATER } \\
\text { TEMP. } \\
(F)\end{array}$ & $\begin{array}{l}\text { DATE } \\
(1973)\end{array}$ & $\begin{array}{l}\text { NUNBBER } \\
\text { SUBCH. } \\
\text { MONI'T. } \\
\text { NO.AXIAL } \\
\text { POINTS }\end{array}$ & $\begin{array}{l}\text { INJECT. } \\
\text { SUBCH. } \\
\text { TYPE } \\
\text { (INJ. } \\
\text { TYPE)* }\end{array}$ \\
\hline $0 / 2-A$ & 2.0 & 0.35 & 450 & 66 & 17 June & $4 / 228$ & $I(N)$ \\
\hline $0 / 2-B$ & 2.0 & 0.66 & 450 & 66 & 17 June & $4 / \$$ & $I(N)$ \\
\hline $0 / 2-c$ & 2.0 & 0.17 & 450 & 66 & 17 June & $4 / \$$ & $I(N)$ \\
\hline $0 / 2-D$ & 2.0 & 0.51 & 450 & 66 & 17 June & $4 / \$$ & $I(N)$ \\
\hline $0 / 2-E$ & 2.0 & 0.17 & 225 & 66 & 17 June & $4 / \$$ & $I(N)$ \\
\hline $0 / 2-F$ & 2.0 & 0.35 & 225 & 66 & 17 June & $4 / \$$ & $I(N)$ \\
\hline $0 / 1-1$ & 1.0 & 0.35 & 450 & 66 & 19 June & $4 / 226$ & $I(N)$ \\
\hline $0 / 1-B$ & 1.0 & 0.66 & 450 & 66 & 19. June & $4 / 228$ & $I(N)$ \\
\hline $0 / 1-c$ & 1.0 & 0.17 & 450 & 66 & 19 June & $1 / 228$ & $I(N)$ \\
\hline $0 / 1-I$ & 1.0 & 0.17 & 225 & 66 & 19 June & $1 / 224$ & $I(N)$ \\
\hline $0 / 3-A$ & 3.0 & 0.35 & 450 & 66 & 19 June & $4 / 238$ & $I(N)$ \\
\hline $0 / 3-B$ & 3.0 & 0.66 & 450 & 66 & 19 June & $4 / 234$ & $I(N)$ \\
\hline $0 / 3-G$ & 3.0 & 0.22 & 450 & 66 & 19 June & $4 / 242$ & $I(N)$ \\
\hline
\end{tabular}


Table 5.1. (Concluded)

\begin{tabular}{|c|c|c|c|c|c|c|c|}
\hline $0 / 3-\mathrm{H}$ & 3.0 & 0.11 & 450 & .66 & 19 June & $4 / 236$ & $I(N)$ \\
\hline $0 / 2.9-A$ & 2.9@ & 0.35 & $350^{\frac{\#}{7 n}}$ & 67 & 25 June & $4 / 266$ & $I(N)$ \\
\hline $3 / 2-A$ & 2.0 & 0.35 & 450 & 73 & $20 \mathrm{July}$ & $4 / 144$ & $I(N)$ \\
\hline $3 / 2-E$ & 2.0 & 0.16 & 180 & 73 & $20 \mathrm{July}$ & $4 / 144$ & $I(N)$ \\
\hline $4 / 2-A$ & 2.0 & 0.35 & $430^{\circ}$ & 73 & 25 JuIy & $4 / 138$ & $I(T)$ \\
\hline $4 / 2-B$ & 2.0 & 0.66 & 450 & 73 & $25 \mathrm{July}$ & $4 / 142$ & $I(T)$ \\
\hline $4 / 2-0$ & 2.0 & 0.16 & 450 & 73 & 25 JuIy & $4 / 144$ & $I(T)$ \\
\hline $4 / 2-E$ & 2.0 & 0.16 & 225 & 73 & $25 \mathrm{Juzy}$ & $4 / 142$ & $I(T)$ \\
\hline $1 / 2-D$ & 2.0 & 0.35 & 450 & 67 & 25 June & $5 / 250 \%$ & $I(N)$ \\
\hline $1 / 2-E$ & 2.0 & 0.35 & 450 & 67 & 25 June & $7 / 284$ & $I(N)$ \\
\hline $1 / 2-F$ & 2.0 & 0.35 & 450 & 73 & $12 \mathrm{JUIY}$ & $7 / 240 \%$ & $I(N)$ \\
\hline
\end{tabular}

\footnotetext{
* I = Interior Subch.,$F=$ Peripheral Subch, $N=$ Needle Inj. $T=$ Transverse Inj. + Run Series/Salt Tracer Concentration (grams/Ibm) - Flow Conditions

\$ Data not Reduced due to Nagnetic Recorder Failure, Original Data in (5.1) \# Approximate Flow Given, Test Section Drain Valve Accidentally Left Open.

@ Salt Typed Changed - Sodium Nitrate, $\mathrm{NaNO}_{3}$ instead of $\mathrm{NaCl}$

\% Data Reduction Difficulties, Refer to ( 5.1 )
} 
meters on coolant mixing results. Table 5.2 surnmarizes the experiments aone to examine the interchannel coolant mixing behavior of wire-wrap spaced rod arrays. The flow conditions in each subchannel type during the various experiments are given in Table 5.3.

A total test section pressure loss (plenimin-to-plenum) versus flow curve is given in Figure 5.1. The subchannel identification code used for all experiments (except RUN No. 1B - IT, done in 1972) is given in Figure 5.2.

\subsection{Data Collection and Processing}

The method used to assimilate the experimental data was the same for all experiments done in 1973. For these experiments, a single detector (with about $3 / 32$ inch long electrodes) was located at the rod array outlet with the electrodes just inside the subchannel of interest: then the injector was pulled toward the bundle outlet at a constant speed (typically $1 \mathrm{ft} / \mathrm{min}$ ) by a servomotor. For a given experiment, the detector would be moved from one subchannel to another and the injector re-inserted and withdrawn as many times as necessary (keeping the flow conditions constant):

An array proximity, electrode interference effect was known to be occurring in some subchannels into which the conductivity cell detector was inserted, that is, the metal of the experimental array was interfering with the 
Table 5.2

Interchanne]. Coolant Mixing Experiments with a Wire-Wrap

Spaced Rod Array

\begin{tabular}{|c|c|c|c|c|c|c|}
\hline $\begin{array}{l}\text { RUN } \\
\text { IDENT. } \\
\text { NO. }{ }^{+}\end{array}$ & $\begin{array}{l}\text { TRACER } \\
\text { CONCENT. } \\
\left(\begin{array}{l}\text { Eram } \\
\text { I } \mathrm{Nm} \cdot \mathrm{Cl}\end{array}\right)\end{array}$ & $\begin{array}{l}\text { INIJECT. } \\
\text { FIOW } \\
\left(\frac{\mathrm{J} \cdot \mathrm{bm}}{\mathrm{min}}\right)\end{array}$ & $\begin{array}{l}\text { MIAIN } \\
\text { FLOW } \\
\left(\frac{I \text { bm }}{\text { min }}\right)\end{array}$ & $\begin{array}{l}\text { WA TER } \\
\text { TEMP. } \\
(\mathrm{F})\end{array}$ & $\begin{array}{c}\text { DATE } \\
\begin{array}{c}(1973) \\
.\end{array} \\
\end{array}$ & $\begin{array}{l}\text { NUMBER } \\
\text { SUBCH } \\
\text { MONIT./ } \\
\text { NO AXIAL } \\
\text { POINTS }\end{array}$ \\
\hline $1-I T$ & 2.0 & $0.35=$ & 450 & 72 & $17 \mathrm{July}$ & $29 / 133$ \\
\hline $1 \mathrm{~A}-\mathrm{IT}$ & 2.0 & 0.68 & 455 & 62 & 27 May & $13 / 116$ \\
\hline $1 B-I T^{*}$ & 1.0 & 1.2 & 72 & 140 & $\begin{array}{l}17 \text { May, } \\
1972\end{array}$ & $11 / 27$ \\
\hline $2-I L$ & 2.0 & 0.044 & 50 & $82^{\#}$ & $19 \mathrm{JuIy}$ & $25 / 128$ \\
\hline $5-\mathrm{PT}$ & 2.0 & 0.39 & 450 & 74 & 27 July & $19 / 134$ \\
\hline $6-P L$ & 2.0 & 0.053 & $38^{\$}$ & $80^{\#}$ & $28 \mathrm{JuIy}$ & $19 / 138$ \\
\hline
\end{tabular}

\footnotetext{
+ Run ID No.: $I=$ Interior Subch., $\mathrm{P}=$ Peripheral Subch. $\mathrm{T}=$ Turbulent, $I=I$ aminar

\& Based on the Equal Average Velocity Criterion, EAVC

\$ Drain Valve Open, Approximate Flow Given

\# About $10 \mathrm{~F}$ Temperature Rise due to Low Pump Flow

* Experiment done in Heat Transfer Lab' with Test Section No. 1, Poor Flow Geometry

@ Fever Subchannels shown in Results if No Salt Tracer was Observed
} 
Table 5.3

Subchannel Reynoldis Numbers and Flow Velocities for the Experiments

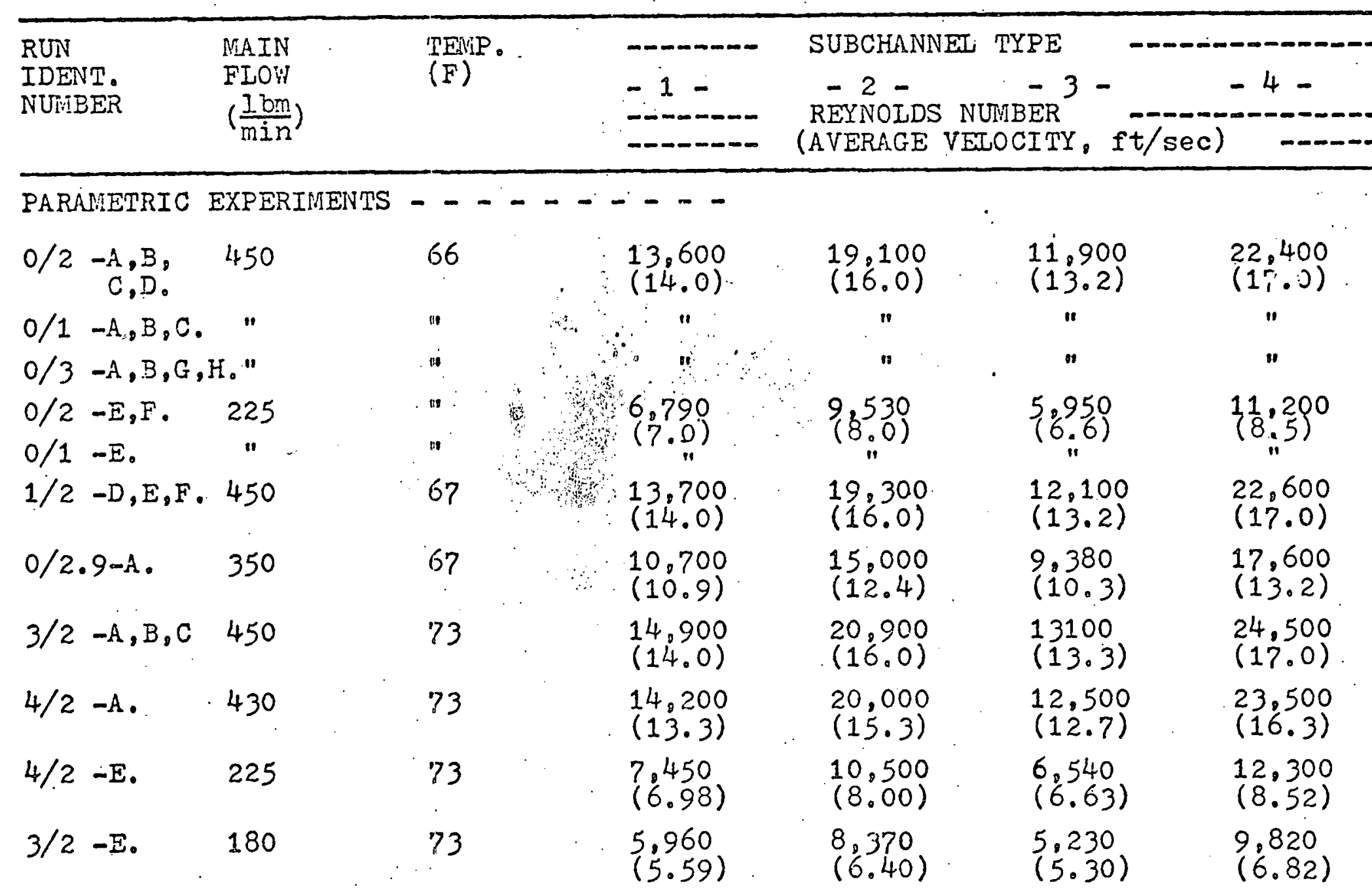


Table 5.3 (Concluded)

\begin{tabular}{|c|c|c|c|c|c|c|}
\hline $1-I T$ & 450 & 72 & $\begin{array}{l}13.900 \\
(14.0)\end{array}$ & $\begin{array}{l}19.500 \\
(16.0)\end{array}$ & $\begin{array}{l}12,200 \\
(13.3)\end{array}$ & $\begin{array}{l}22,900 \\
(17.0)\end{array}$ \\
\hline $1 \mathrm{~A}-I \mathrm{~T}$ & 455 & 62 & $\begin{array}{l}13.100 \\
(14.0)\end{array}$ & $\begin{array}{l}18,300 \\
(16.1)\end{array}$ & $\begin{array}{l}11,500 \\
(13.3)\end{array}$ & $\begin{array}{l}21,500 \\
(17.2)\end{array}$ \\
\hline $1 B-I T$ & 72 & 140 & $\begin{array}{l}4,850 \\
(2.27)\end{array}$ & $\begin{array}{l}6,800 \\
(2.59)\end{array}$ & $\begin{array}{l}4.250 \\
(2.15)\end{array}$ & $\begin{array}{l}8.000 \\
(2.77)\end{array}$ \\
\hline $2-I I$ & 50 & 82 & $\begin{array}{l}1,580 \\
(1.31)\end{array}$ & $\begin{array}{l}2.900 \\
(1.96)\end{array}$ & $\begin{array}{l}1.250 \\
(1.12)\end{array}$ & $\begin{array}{l}3.870 \\
(2.38)\end{array}$ \\
\hline $5-\mathrm{PT}$ & 450 & 74 & $\begin{array}{l}15.100 \\
(14.0)\end{array}$ & $\begin{array}{l}21,200 \\
(16.0)\end{array}$ & $\begin{array}{l}13.300 \\
(13.3)\end{array}$ & $\begin{array}{l}24,900 \\
(17.0)\end{array}$ \\
\hline $6-P I$ & 38 & 80 & $\begin{array}{l}1.173 \\
(0.99)\end{array}$ & $\begin{array}{l}2,160 \\
(1.49)\end{array}$ & $\begin{array}{l}930 \\
(0.85)\end{array}$ & $\begin{array}{l}2.880 \\
(1.81)\end{array}$ \\
\hline
\end{tabular}

* Numbers have been rourded, See Tables 5.1 and 5.2 for further details concerning the experiments. 


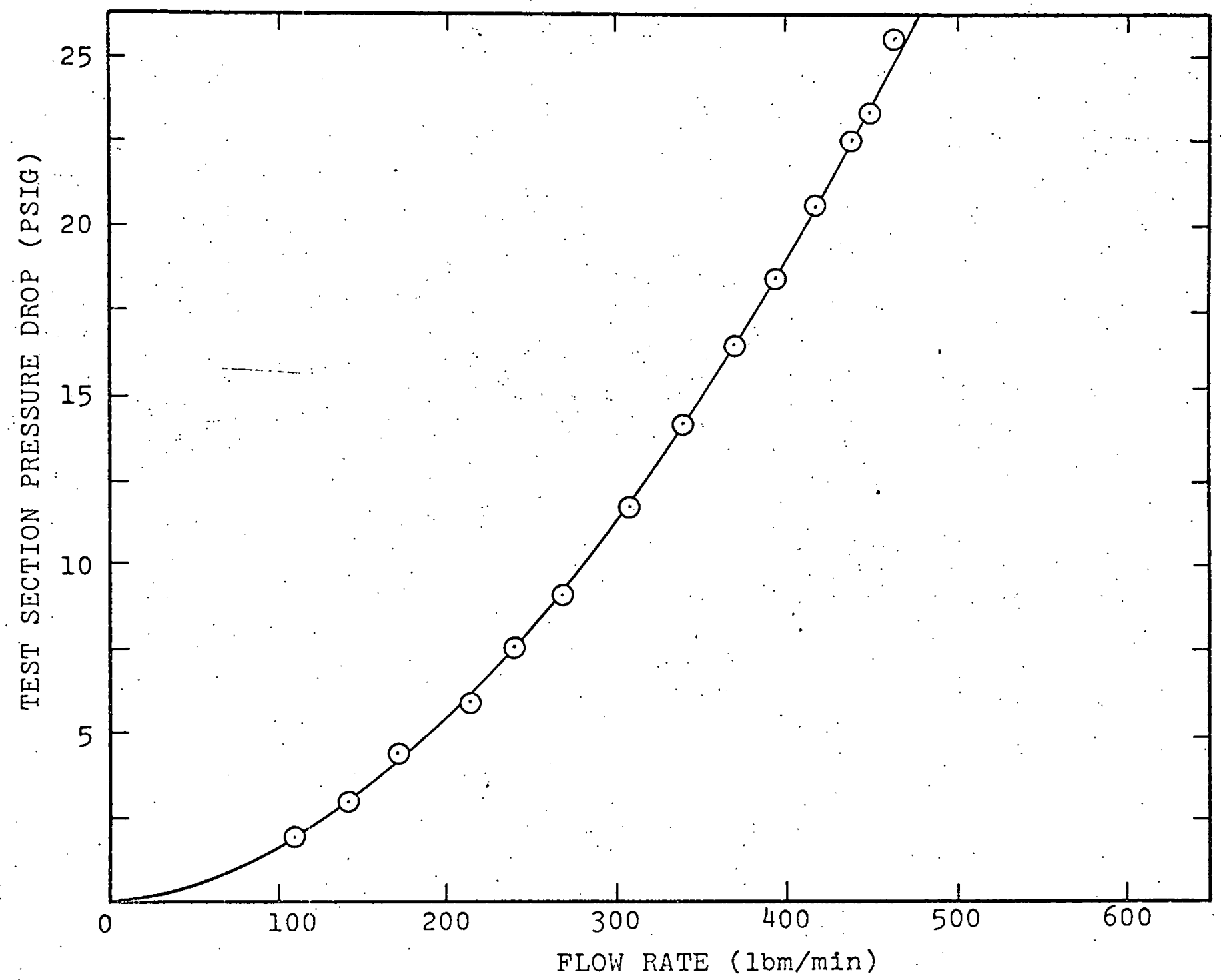

FIGURE 5.1 - PRESSURE DROP VERSUS FLOW RATE $\triangle P$ VS. $Q$ FOR THE TEST SECTION 


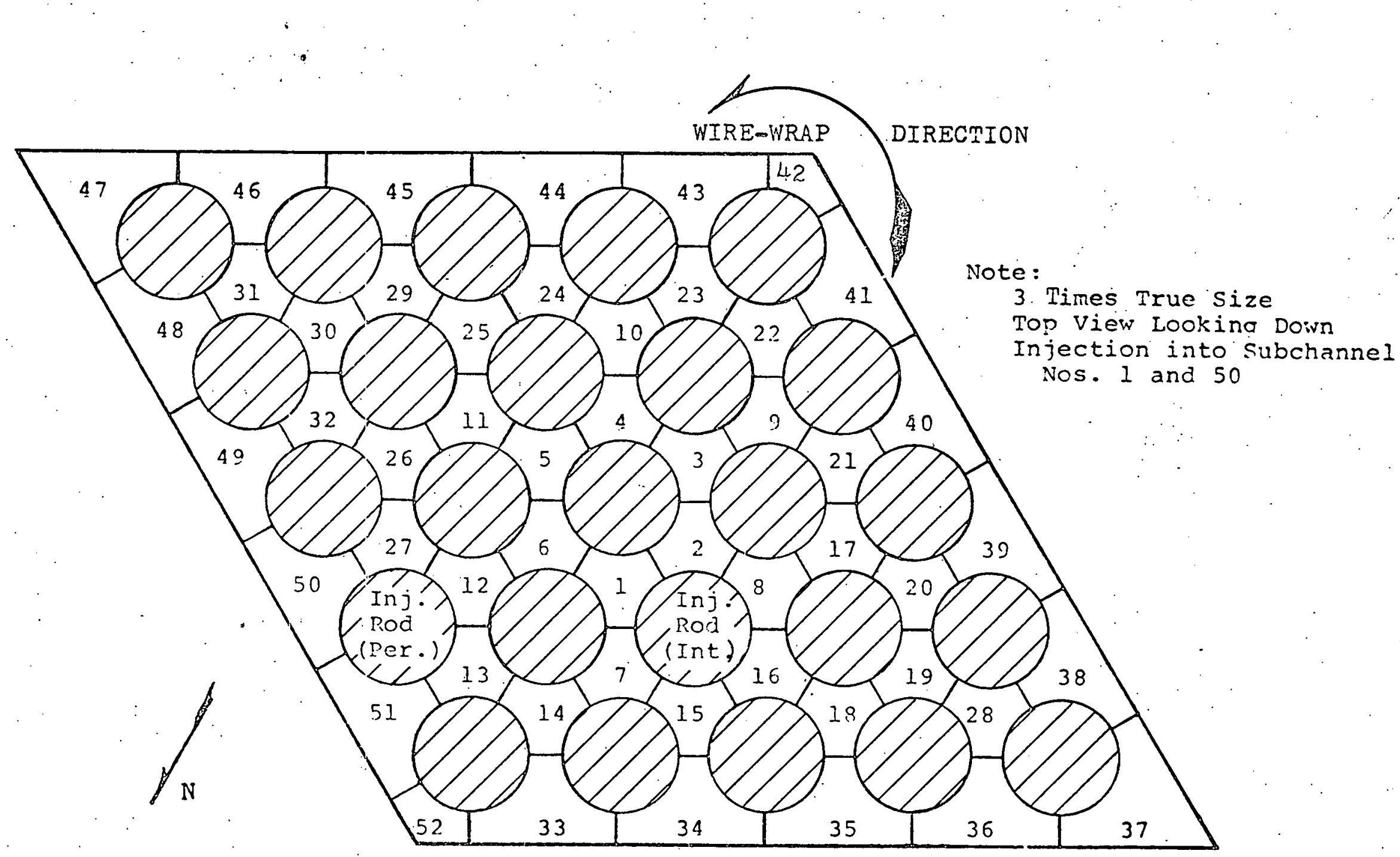

Figure 5.2-SUBCHANNEL ARRANGEMENT OF THE EXPERIMENTAL TEST SECTION SHOWING SUBCHANNEL IDENTIF ICATION NUHBERS AND INUECTOR ROD LOCATIONS 
operation of the electrical conductance probe. The effect was usually small (when it occurred) and vas observed as a shift in the balanced bridge resistance of the main flow (with no tracer insertion). Because the - interference was dependent on the exact positioning of the detector probe within a given subchannel. it was not possible to directly compensate for the interference by generating a calibration curve for each subchannel (This would be possible if a detector were permanently positioned in each subchannel to be nonitored).

To accommodate the array proximity electrode interference effects occurring with the data collection technique used, the wheatstone bridge was balanced for each subchannel with the probe in position for example, suppose the balanced bridge resistance with no array interference was $9500 \mathrm{chms}$; with array interference, the balanced bridge resistance would range from $9500 \mathrm{ohms}$ to about 8900 Ohms.

It was shoum that the efrect of changing the bridge resistance (in the range of interest) did not significantly influence the calibration curve. Also, other experiments showed the array proximity, electrode interference effect was approximately independent of salt solution concentration.

It is believed that the significance of the accommodation procedure may be illustrated by attempting to superimpose the 3100 ohm curre in Figure 5.3 onto the 3600 


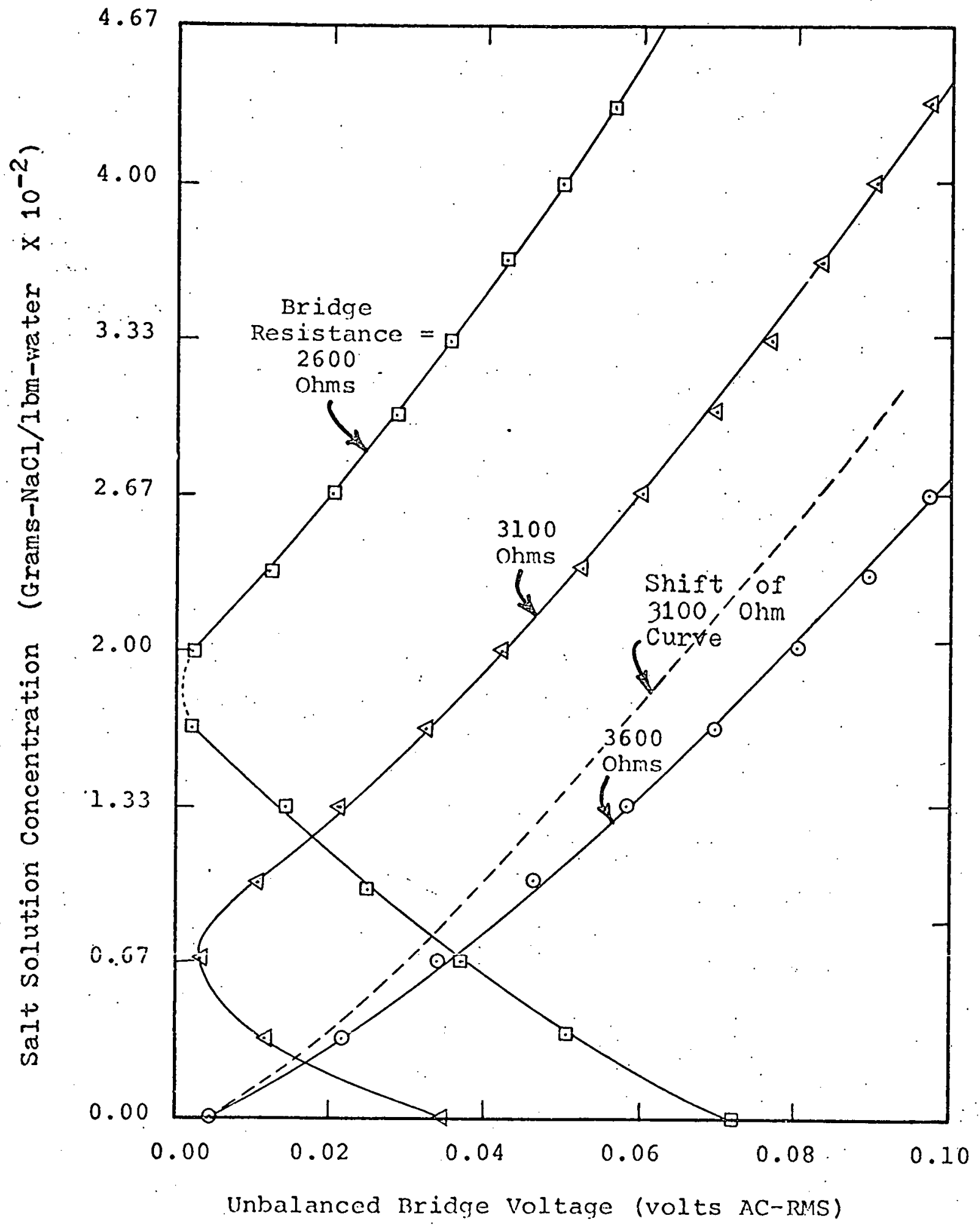

Figure 5.3 - THE INFLUENCE OF THE WHEATSTONE BRIDGE RESISTANCE SETTING ON UNBALANCED BRIDGE VOLTAGE MEASURED SHOWING THE VARTATION WITH SOJIUTION CONCEN!YPATTON 
Ohm curve by moving the $3100 \mathrm{Ohm}$ curve downward (see the dashed line); this oorresponds to a back ground balanced bridge resistance change of $14 \%$. (Note if the upper part of the $3100 \mathrm{Ohm}$ and the $2600 \mathrm{Ohm}$ curves were shifted to the right, instead of downward, all three curves would coincide).

Because the data reduction was primarily on the left side of the graph and because the actual interference background changes typically ranged from $0 \%$ to $6 \%$, this was not felt to be a major error.

The data was recorded using the unbalanced Wheatstone bridge method (discussed in Appendix 2). The original data was simultaneously recorded onto graph paper using a $X-Y$ plotter and onto a magnetic tape using a FM recorder. The magnetic tape provicied an analog (continuous) reproduction of the data which was played into an analog computer that filtered and digitized (converted the analog signal to a digital signal) the playback of the magnetic tape signal, see Appendix 7 . ine digitized signal was received and averaged by a digital computer which produced a paper-tape record of the data. The paper-tape was used to generate a punched card record of the data. The punched cards were edited and assembled for processing using the VIIMIX code (Appendix 3). Considerable editing efforts of the data were required in order to ascertain tha data used faithfully 
reproduced the original data (plotted with the $X-Y$ plotter during the experiment); this was because of various mechanical difficulties in the data generating and handling processes. Editing effort was further required to axially synchronize the data taken independently for each subchannel. As discussed in Appendix 7. it is felt that the error in axial synchronization or coincidence of the data is less than $\pm 1 / 3$ of an inch (the magnitude of this error is set by injector. system design, in part).

MITMIX converted the data from an unbalanced bridge voltage into salt concentrations using a curve fit of calibration data. The calibration data was obtained by mixing known solutions of tracer and measuring the unbalanced bridge voltage using the same equipment and detector used for data acquisition. Two instrument scales were required for this work (a high scale for near the injector and a low scale for detection far from the injector); typical calibration data from each scale is showm in Figures 5.3.1 and 5.3.2; the lines drawn through the data were generated using the curve fitted through the calibration by MIMIX.

The recorded data was converted from an unbalanced bridge voltage to a salt concentration by first subtracting the balanced bridge voltage (the background voltage was 5 to 10 millivolts $A C-R M S$ due to $A C$ reactance effects) 


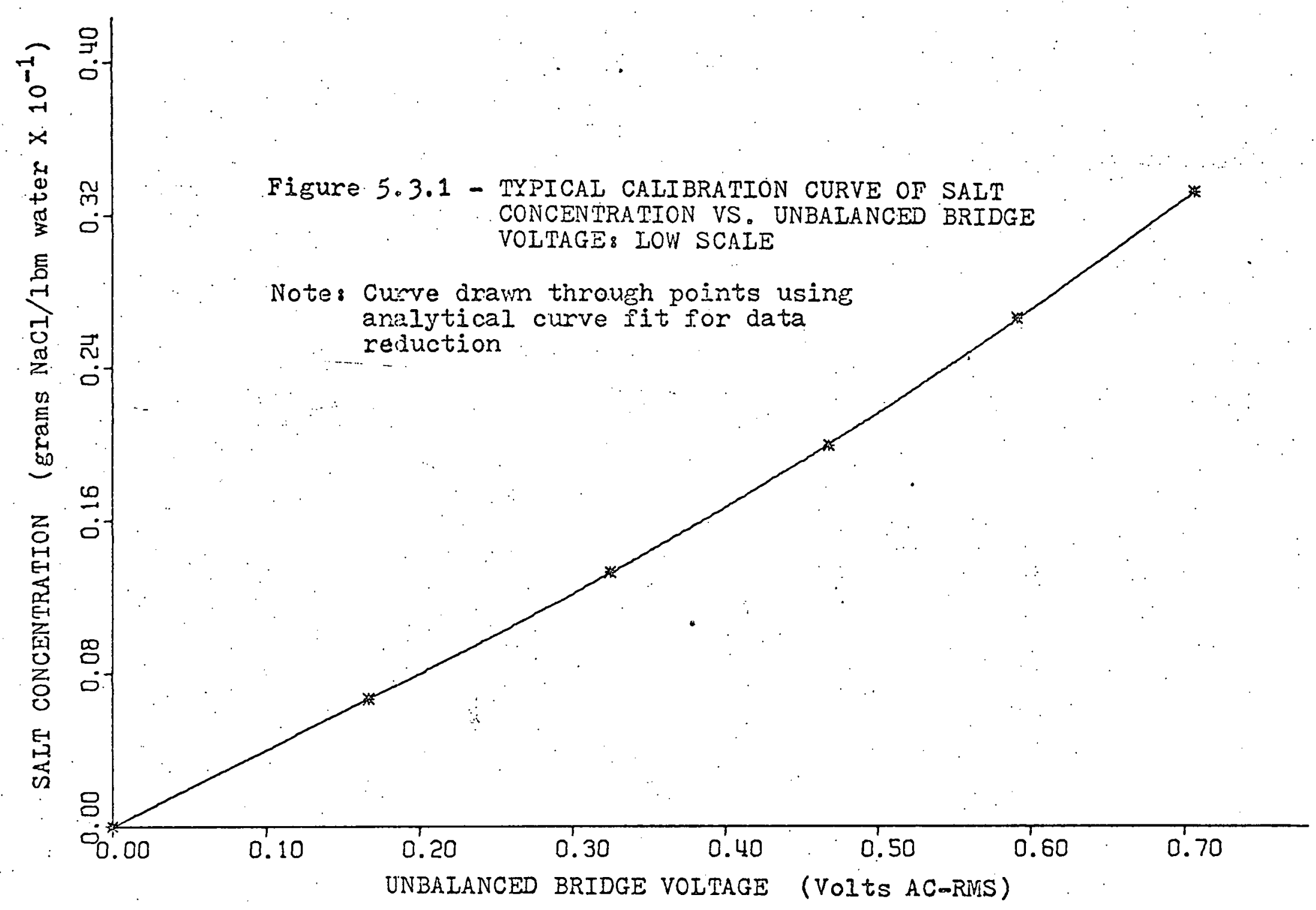




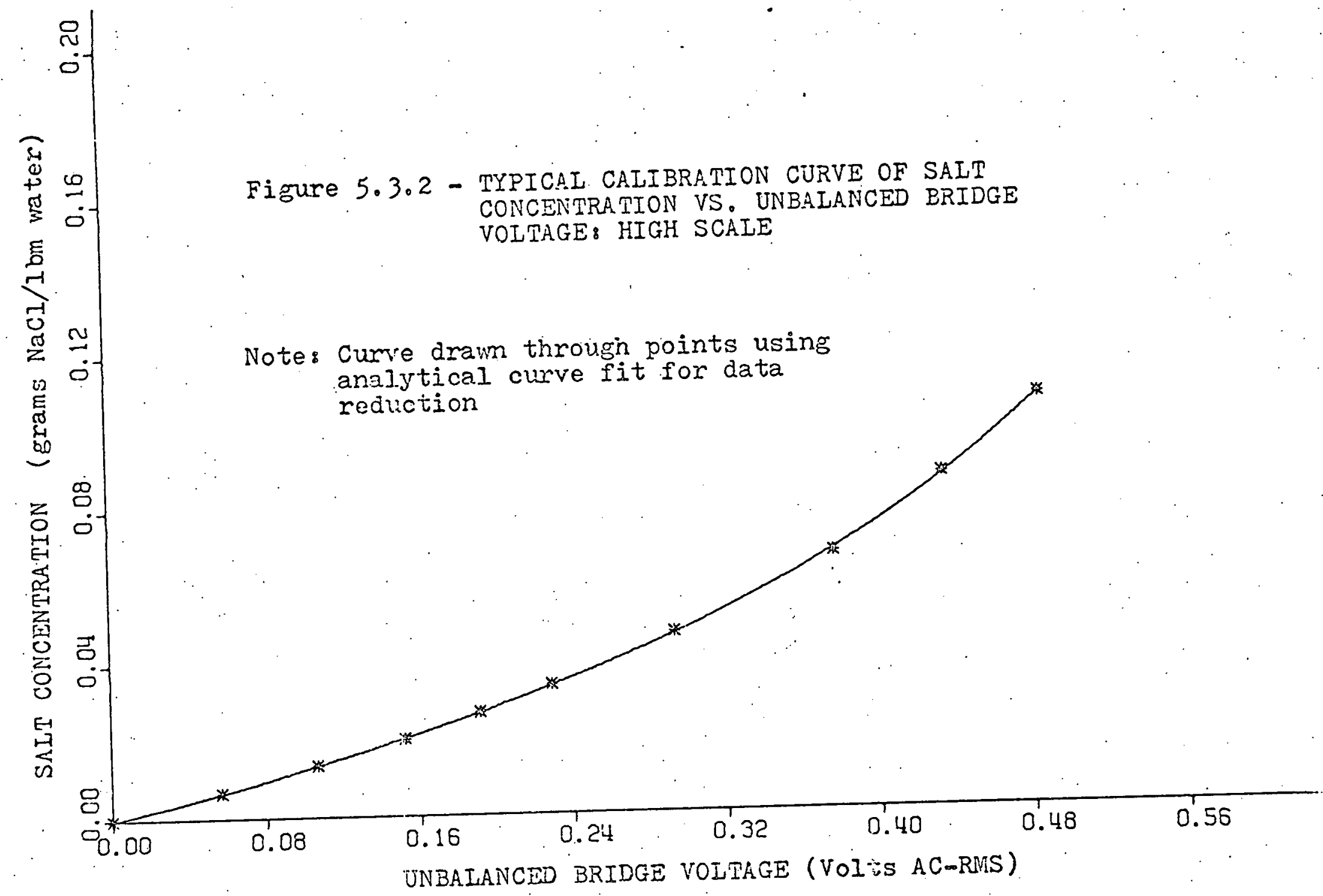


from the unbalanced signal voltage. This voltage difference was converted to salt concentrations via calibration data (based on the voltage difference and the solution concentration of the calibration data) taken with no array interference during the measurements.

MITMIX reduced ine data, calculated the experimental mass balance and generated plots of the results. The code also generated normalized and integrated plots of the data: these plots have not been presented here but may be reviewed in Faton ( 5.1 ).

The data from RUN NO. 1A-IT and $1 B-I T$ was reduced manually instead of by automatic data processing equip ment. The data for all subchannels in RUN 1B - IT (see Figure 4.4) was taken (using a detector in each subchannel) with the injector stationary at each axial location. As noted previously, all other data was taken with a moving injector while monitoring a single subchannel. at a time.

5.3 The Influence of Expeximental operating Farameters on Coolant nixing Resu].ts

In order to control the length of this section, the results of the parametric studies for determining the influence of operating parameters on expeximental results shall be presented without a lengthy presentation of figures; the original data and the reduced data used to arrive at 
the conclusions in this section may be reviewed in Eaton (5.1) or in Appendix 9.

For this work, the standard for the injection flow rate was set by the equal average velocity criterion EAVC, i.e., the average velocity of the injection flow was equal to the average velocity of the subchannel into which. the tracer was injected. Injection rates for EAVC are given in Table 5.4 for water at 60F; these values were used for all 1973 experiments.

Injection Flow Rate (Velocity): There was no unexpected influence of injection flow rate on experimental results: the general nature (that is, the overall shape and the magnitude of the normalized concentrations observed) of the tracer concentration versus injector travel curve was unchanged with changes in injection flow rate (velocity). Obviously, the amount of salt detected would change according to the change of injection rate (salt insertion rate).

A small influence of insertion rate was noted when the injection device was passing under the wire-wrap (over the slot in the injector tube). The tracer injection flow influence on mixing results decreased as the distance between the injector and the detector increased and was hardly noticable with the injector more than one lead (12 in.) from the detector. The perturbations were not noticable beyond the subchannels contiguous to the 


\section{Table 5.4}

Equal Average Velocity Criterion for. Injection Operations *

Flow Regime

-Turbulent--.---Laminar

Interior Subchannel.

Flow Fraction, $w_{i} / w_{b}$

0.00077

0.00065

Main Flow, $w_{b}, 1 \mathrm{bm} / \mathrm{min}$

450.

50.

Injection Flow, $w_{i}, 1 \mathrm{bm} / \mathrm{min}, 0.35$

0.033

$\mathrm{cc} / \mathrm{min} \quad 158$

14.8

Peripheral Subchannel

$\begin{array}{lll}\text { Flow Fraction, } w_{i} / w_{b} & 0.00089 & 0.00098 \\ \text { Main Flow, } w_{b}, 1 \mathrm{bm} / \mathrm{min} & 450 . & 50 . \\ \text { Injection Flow, } w_{i}, I \mathrm{bm} / \mathrm{min}, 0.40 & 0.049 \\ & \mathrm{cc} / \mathrm{min} 181 & 22.2\end{array}$

Based on water at $60 \mathrm{~F}$; All subchannels assumed to be in the Same Flow Regime: Reynolds Number Exponent in the Friction Factor Correlation equal -0.20 for Turbulent Flow and -1.00 for Laminar Flow. 
injection subchannel. As the injection flow varies from the EAVC, the perturbations decrease slightly as the flow decreases; however, as the flow increases, the perturbations become more pronounced; then as the injection: flow increases further, say greater than $3 \mathrm{X}$ EAVC, the effect again reduces because the local flow is highly disrupted by the turbulent jet mixing near the injector. Adding further flow disturbances does not have so great an effect in an already disturbed flow field. The results regarding the influence of tracer flow rate were verified with injection flows varing between one-third and twice the flow given by the EAVC (in intormal experiments, this result was confirmed with injection flows over four times the EAVC flow).

Salt Solution Iracer Concentration: The effect of varjing the salt solution concentration (using $\mathrm{NaCl}$ ) holding the injection flow rate constant was observed to be similar to the effect of varying injection flow rate while holding the tracer concentration constant. The general nature of the data was similar in all cases; the only differences being due to the change in the amount of tracer observed. The perturbations due to changes in the tracer insertion velocity were not observed.

Salt Type: Experiment No. 0/2.9-A was done using sodium nitrate $\mathrm{NaNO}_{3}$ instead of $\mathrm{NaCl}$. Although mechanical difficulties with the injector were encountered during 
this experiment; it was established that there was no significant differences between salt types and that the normalized results were the same. This results because the mass diffusivity was very low for both salts, particularly if compared to the momentum diffusivity of the flow.

It is necessary to compensate the injection solution concentration for differences in molecular weight when changing the salt tracer type, i.e., $\mathrm{M}-\mathrm{NaCl}=58.4$ and $\mathrm{M}-\mathrm{NaNO}_{3}=85$. The $\mathrm{NaNO}_{3}$ tracer experiment was run with a solution concentration of 2.94 grams/1bm which was analagous to a $2.0 \mathrm{gram} / \mathrm{lbm}$ solution of $\mathrm{NaCl}$.

Injector Design: In order to compare the infiuence of injector design on coolant mixing results, a series of parametric experiments were done using a transverse hole injector design, i.e., RUN Nos. $4 / 2$ - A, B, C \& E. From comparison with RUN Nos, $3 / 2$ - A \& E, done using a needle. injector and similar injection flows, the influence of injector design on mixing results was seen to be substantial, particularly in the region near the point, about $1 / 3$ lead lengths below the end of injector travel, where the injector passes under the wire-wrap (closest to the detector). Note, RUNS $4 / 2-A, B, C, \& E$ must be compared with RUNS $3 / 2$ - A \& E because of evolution of the mechanical behavior of the injector tube since prior parametric experiments. 
Because the transverse hole injector introduced an unnatural transverse momentum into the injection subchannel, it was decided to use a needle-type injector mounted as close as practical $\left(15^{\circ}-20^{\circ}\right)$ to the axial direction. This injector design was expected to give experimental results with the leasi injection subchannel flow perturbation, and therefore give results most compatable with typical assurptions of existing fuel assembly thermalhydraulic analysis codes.

Reynolds livuber: Momentum. (eddy) diffusivity and therefore mass transfer within the experimental array is dependent on Reynolds number. Also, the flow regime, i.e., whether laminar or turbulent, is determined by the Reynolds number of the flow.

In all of the mixing experiments reported here, there vas a noticable effect of large-scale eddy diffusivity on the results. This effect was noted as flutter in the recording pin on the $X-Y$ plotter (which directly recorded the conductance cell signal). Because of electronic flutter in the magnetic tape recorder, this flow flutter can not be shown in detail in the results of this report (because filtering and averaging the electronic ilutter also filters and averages the flow flutter). Flow fluttering influences can be seen in some of the reduced data; nevertheless.

This flow induced tracer concentration fluttering 
was most significant with the injector within one lead length (12 in.) of the detector, and in general it decreased with increases in injector-detector separation. The magnitude of this flutter was also dependent on subchannel location (with respect to the injection subchannel) and decreaseu with increases in dislance from the injection subchannel.

The tracer concentration fluttering was strongly dependendent on Reynolds number. For turbulent flows with $\operatorname{Re}>10,000$, little flutter was observed. The flutter effects were more and more apparent as the Reynolds number decreased toward flow transition ( $R e \cong 2300$ ) and a notable increase could be determined between low turbulent flow and laminar flow.

To keep the discussion of flutter in perspective. note that the magnitude of flutter was seldom more than $\pm 10 \%$ of the measured value and could be distinquished at very low values of fluctuation, say $\pm 0.05 \%$ of measured value. The frequencj of the tracer concentration variations was typically 0.5 - 3.0 cycles/second; the resulting plot of a fluttering signal (using 1 inch of graph for each 2 inches of injector travel and a graphing speed of 6 inches/minute) was not a blurred line but distinctly showed the wave-like nature of the flutter. Apparently the cause of the flow fluttering was a lowflow instability in the injection system which may have 
been influenced by vortex shedding from the wire-wrap spacers.

Injector Mechanical Eehavior: of all the experimental parameters influencing the mixing results, the mechanical behavior of the injection device had the far greater effect.

The primary operational difficulty in performing the mixing experiments discussed in this chapter was failure of the injector device. In the handling, use and repair of the injector, the intended mechanical design was modified (evolved) by wear, minor bends, slot spreading, etc. - all which resulted chiefly in an angle positioning error of the injector rod with respect to the slotted injector rod: the error was always less than $\pm 4^{\circ}$, but increased with time and varied with axial. position.

The mixing results were very dependent on this angular positioning error in the injection direction (see Figure A.19.1). This was particularly a sensitive problem because the injector had to be inserted and withdrawn to repeat the injection process as the detector was moved sequentially to each subchannel monitored in a given experiment.

It was found that the difficulties with the injector angular orientation could be overcome, for all practical purposes by initially positioning the injector at the 
same angular position before each withdrawal. The withdrawal process was identical for each subchannel and the results could be repeated. Therefore, similar injection conditions could be obtained for all subchannels monitored in an experiment. Nevertheless, for future work, this behavior problem can he eliminated by changes in injector design and careful handling as discussed in Chapter 4.

\subsection{Interchannel Coolant Mixing Experiments}

As noted in section 5.1 , coolant mixing experiments were done for turbulent and laminar flow with injection - into an interior and a peripheral subchannel, see Tables 5.2 and 5.3. Detection was accomplished with an electrolytic (salt solution) conductance probe positioned inside the rod array but within $1 / 4$ inch of the bundle exit. For each experiment, a scan of the exit concentration of all subchannels with the injector fully inserted showed which and how many subchannels needed to be monitored to ascertain that all tracer dispersion could be observed.

It will be noted that the detailed nature of the results of the coolant mixing experiments are doninated by the complex, wire-wrapped rod array geometry. These results for the coolant mixing experiments, presented next, include a mass balance versus injector travel curve for the experiment and a tracer concentration versus injector travel curve for each subchannel moni- 
tored. The subchannel tracer concentration curves are presented in groups of four (because of limitations in computer plotiing); the tracer concentration of the injection subchannel is given on all curves so as to maintain a perspective between all subchannels.

Note that the injector traveled over more than two lead lengths in the experiments. For any computations with this data, the axial reference mark (consistent for all experiments), should be taken at the point where the tracer concentration falls to zero. in the injection subchannel (in the vicinity of $y / 1=2.0-2.2$ ); this drop occurs at $1 / 2$ inch from the top of the array, i.e., at the end of the injector tube slot. The detector was positioned about 5/32 inch downstream of the slot end.

In order to deternine the location of a wire-wrap at any axial position $X$ refer to Figures 4.7 and 4.8 . Briefly, the wraps start 70 inches from the top of the rods and have a lead length of 12 inches. The injector slot is $150^{\circ}$ clockwise from the wrap support (start) hole. The wire-wrap is over the slot in the injector tube at 0.381 ( $41 / 2$ inches) and 1.381 (16 1/2 inches) below the top of the slot. Attempts to visualize flow in a wire-wrap spaced, rod array geometry will come only with inherent (but not insurnountable) difficulty. Interior Subchannel Injection, Turbulent Flow: Figures 5.4 .1 through 5.4 .9 give the results of the 


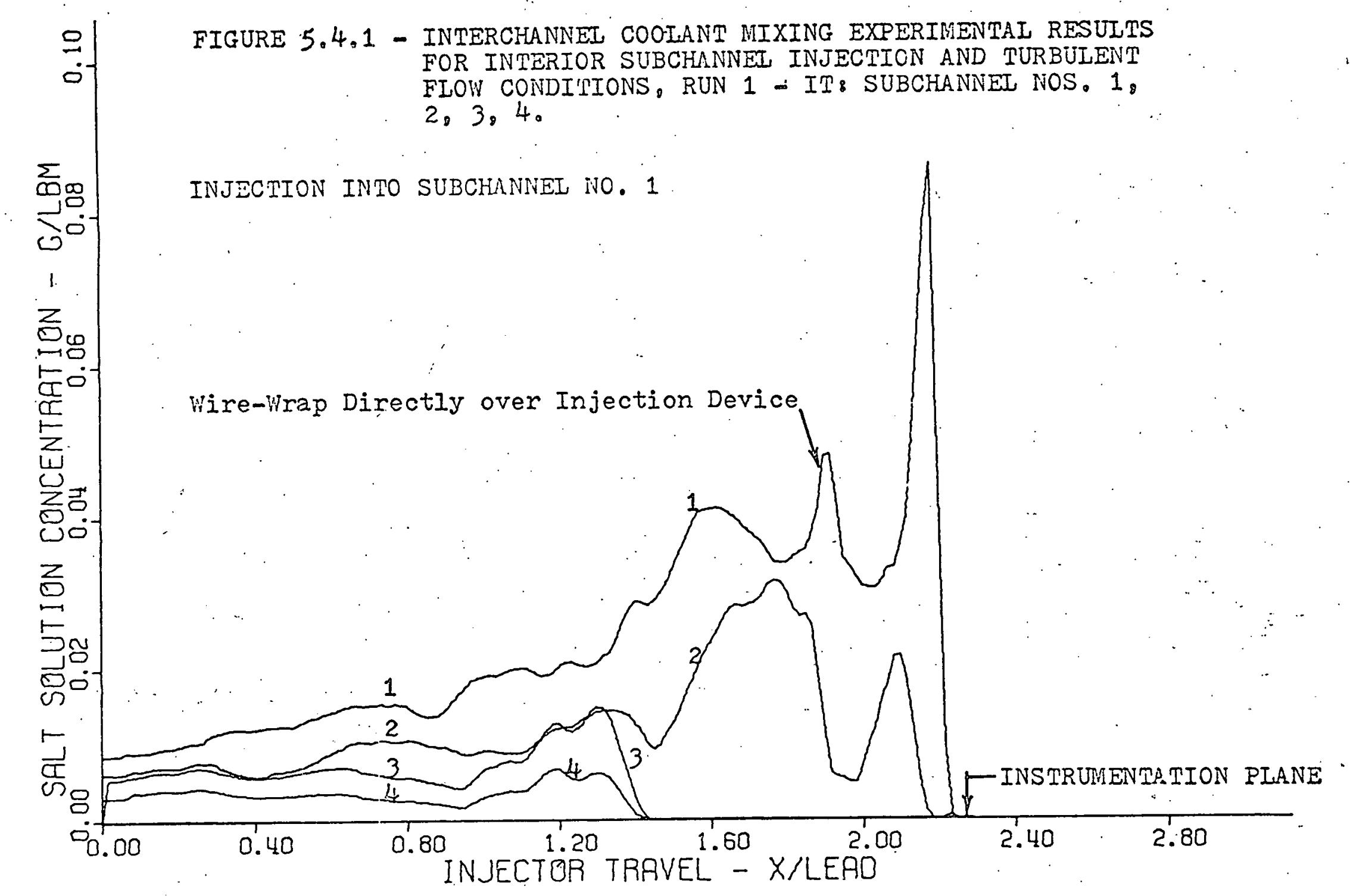




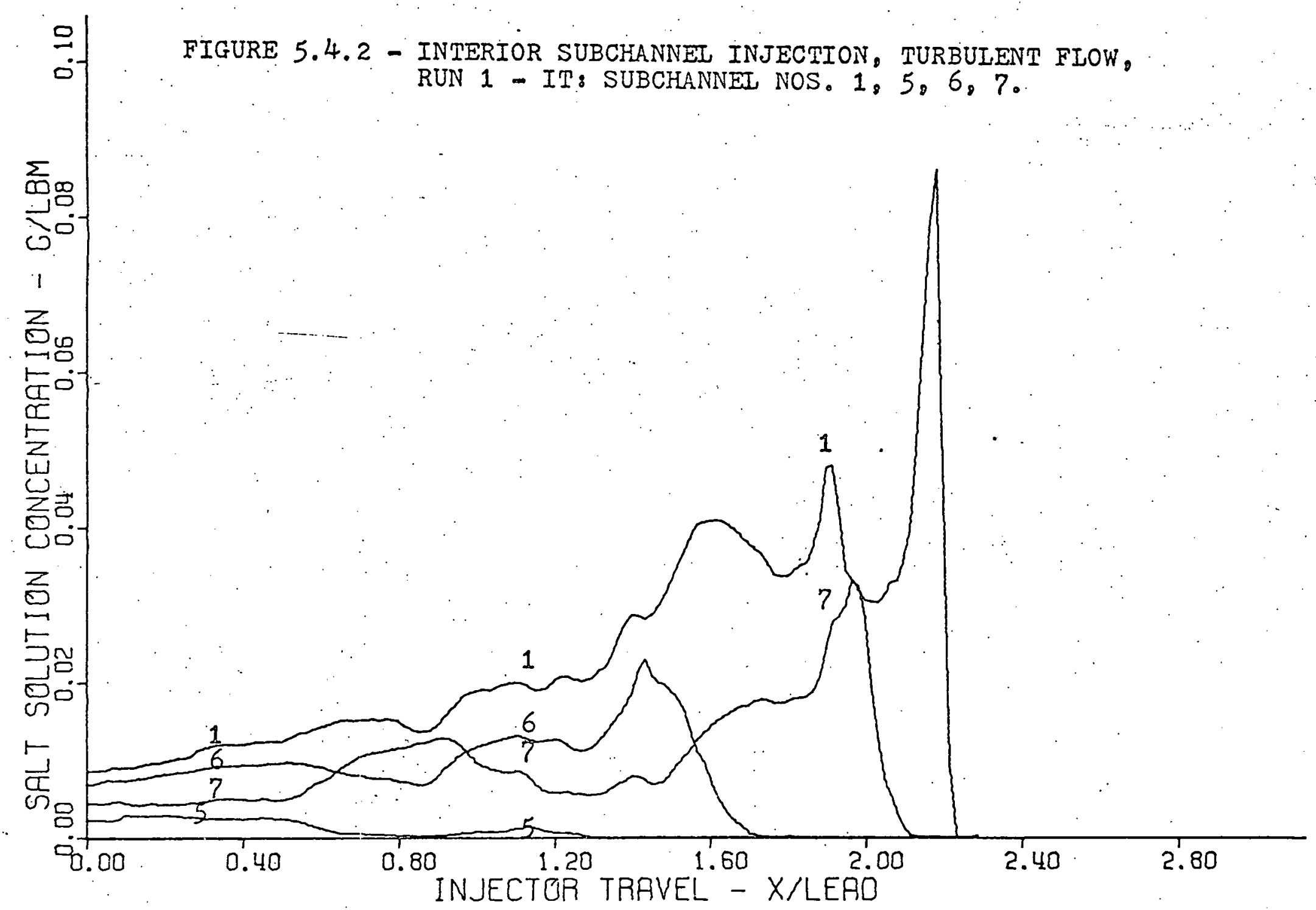




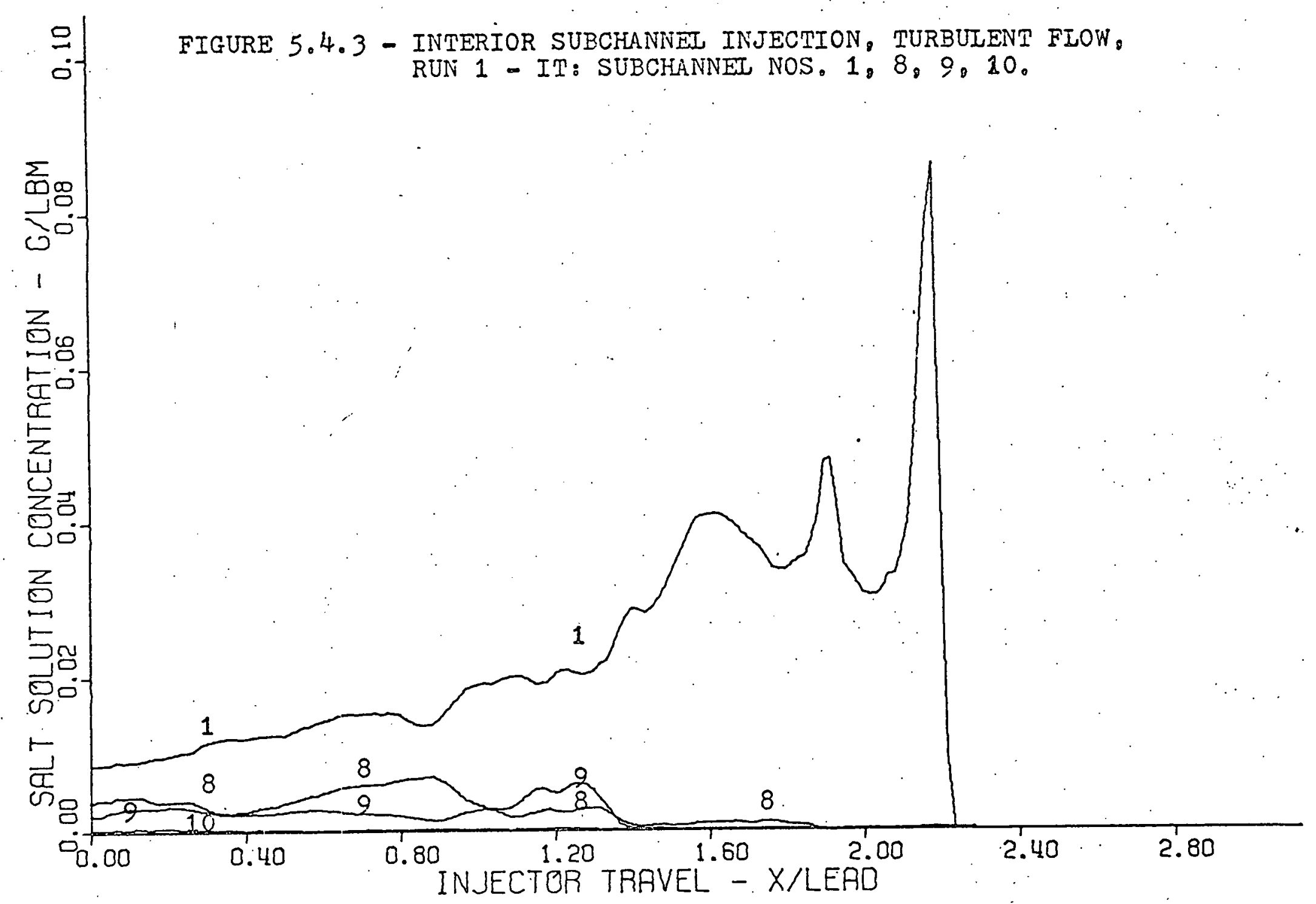




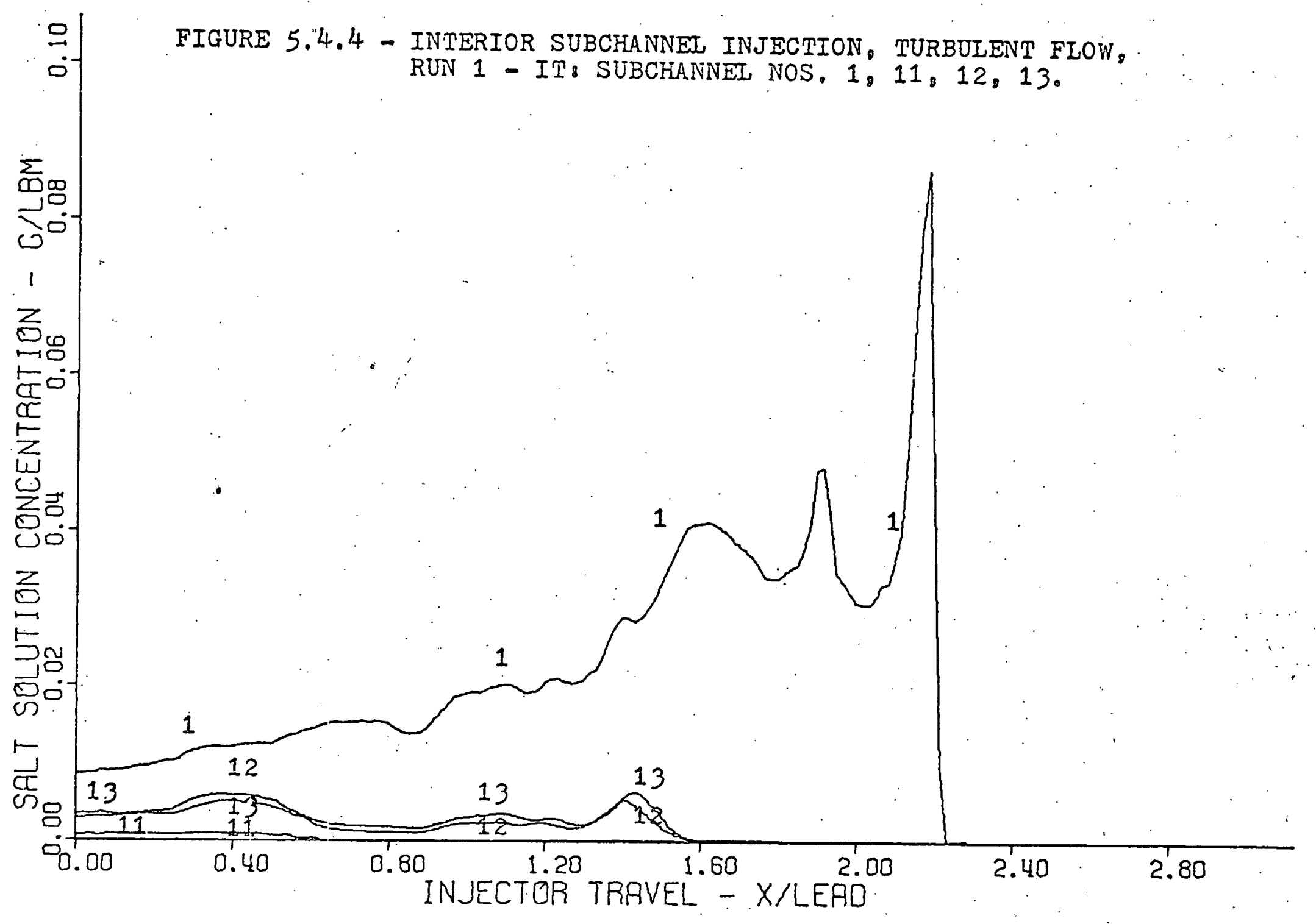




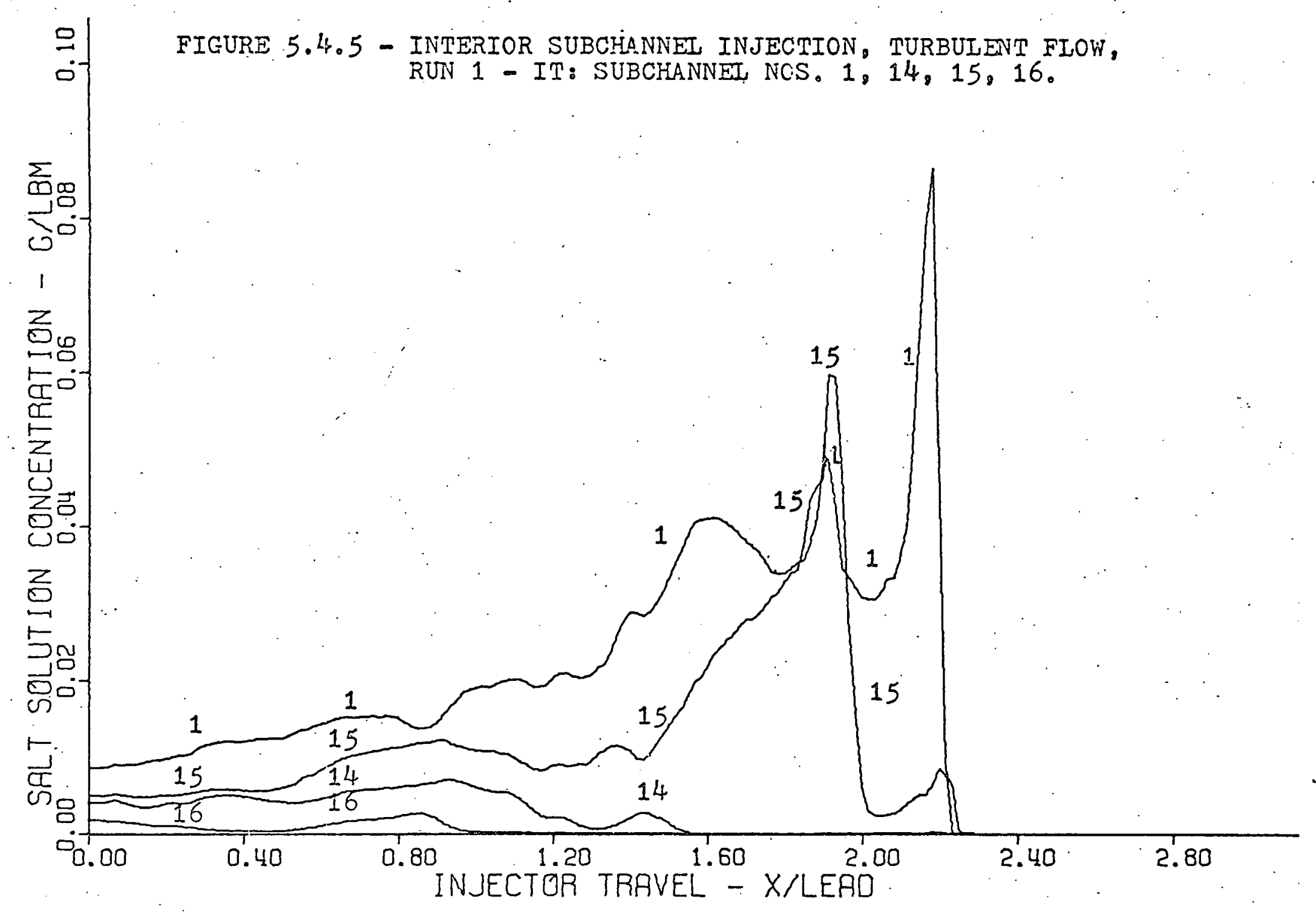




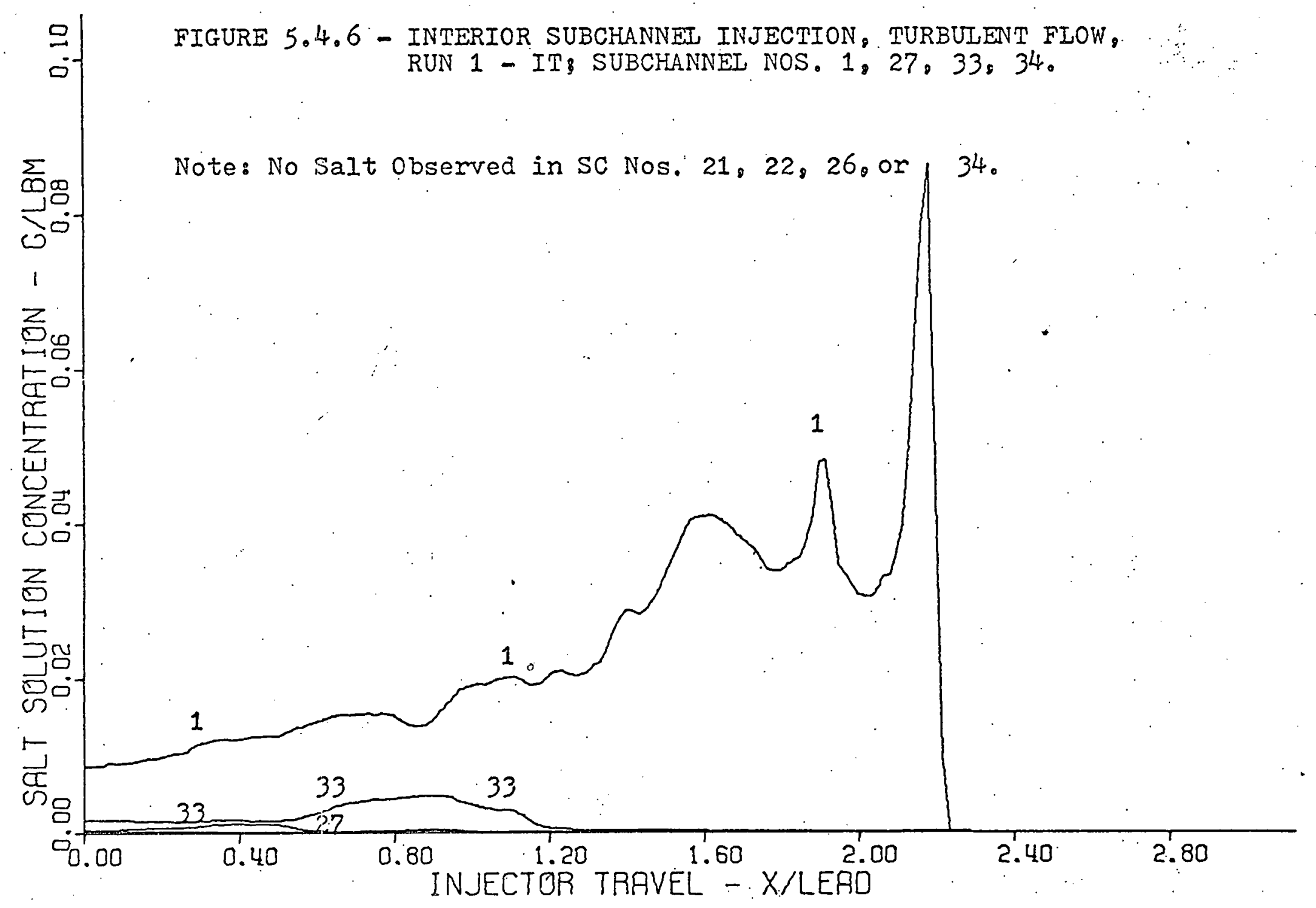




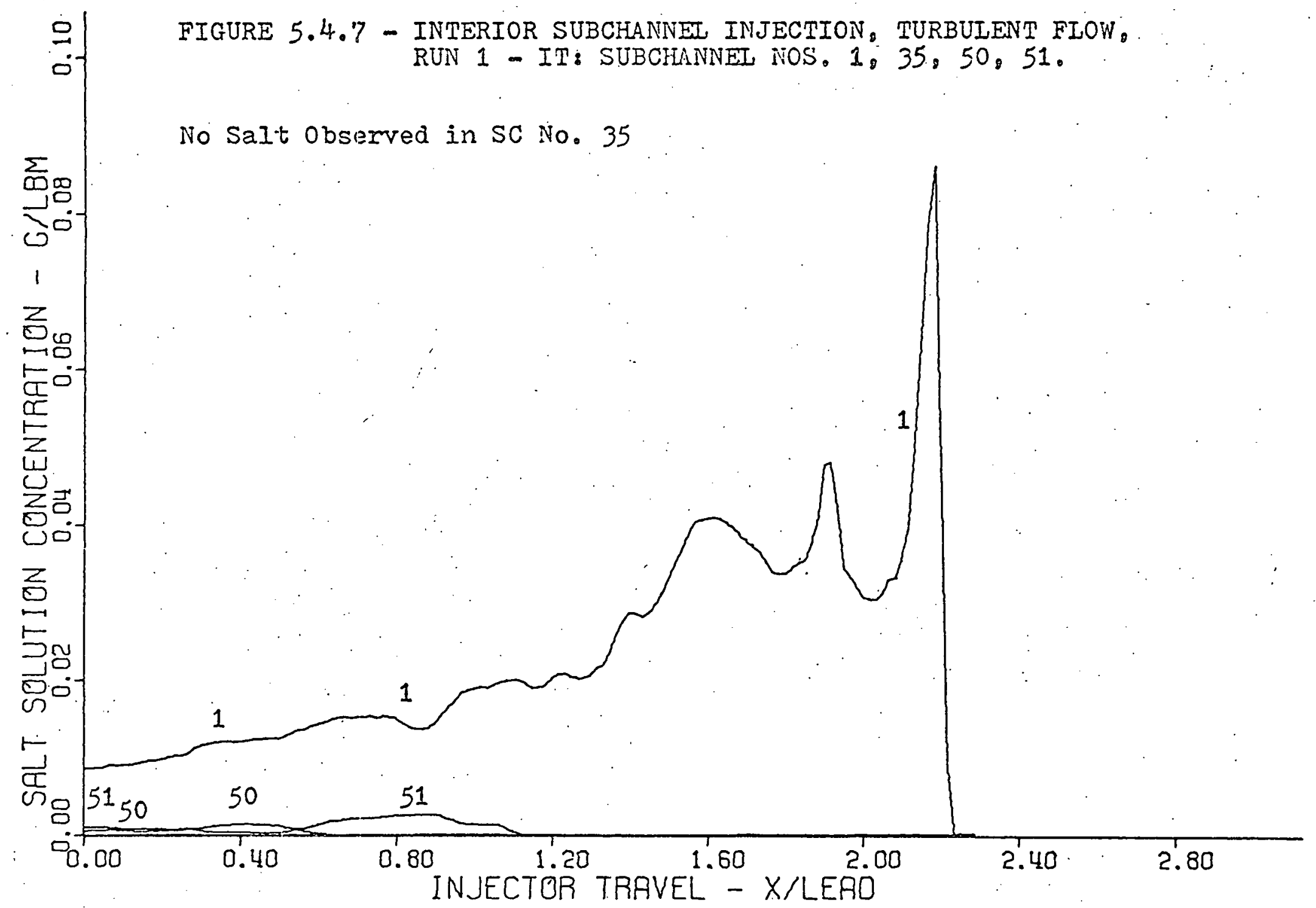




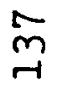

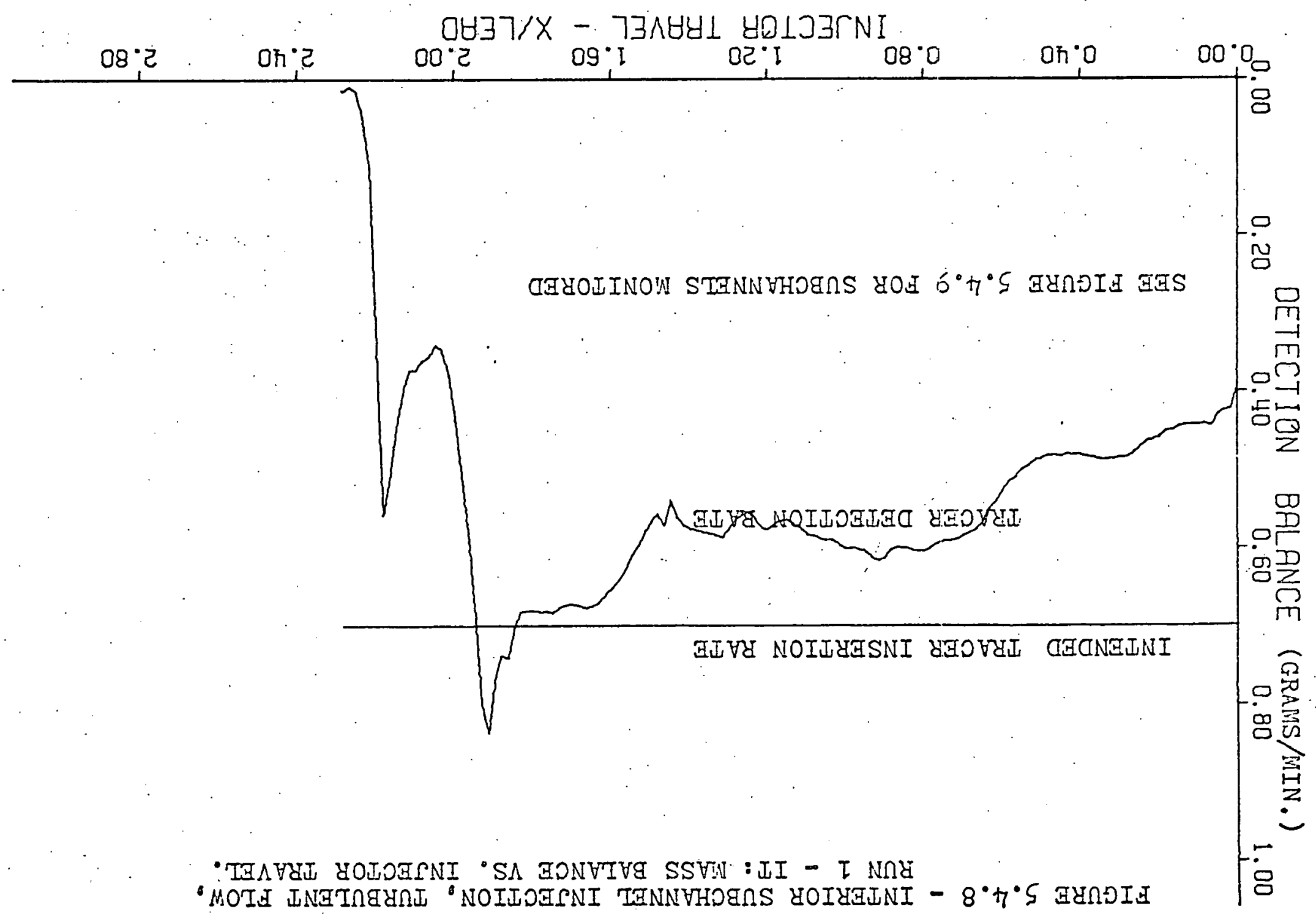




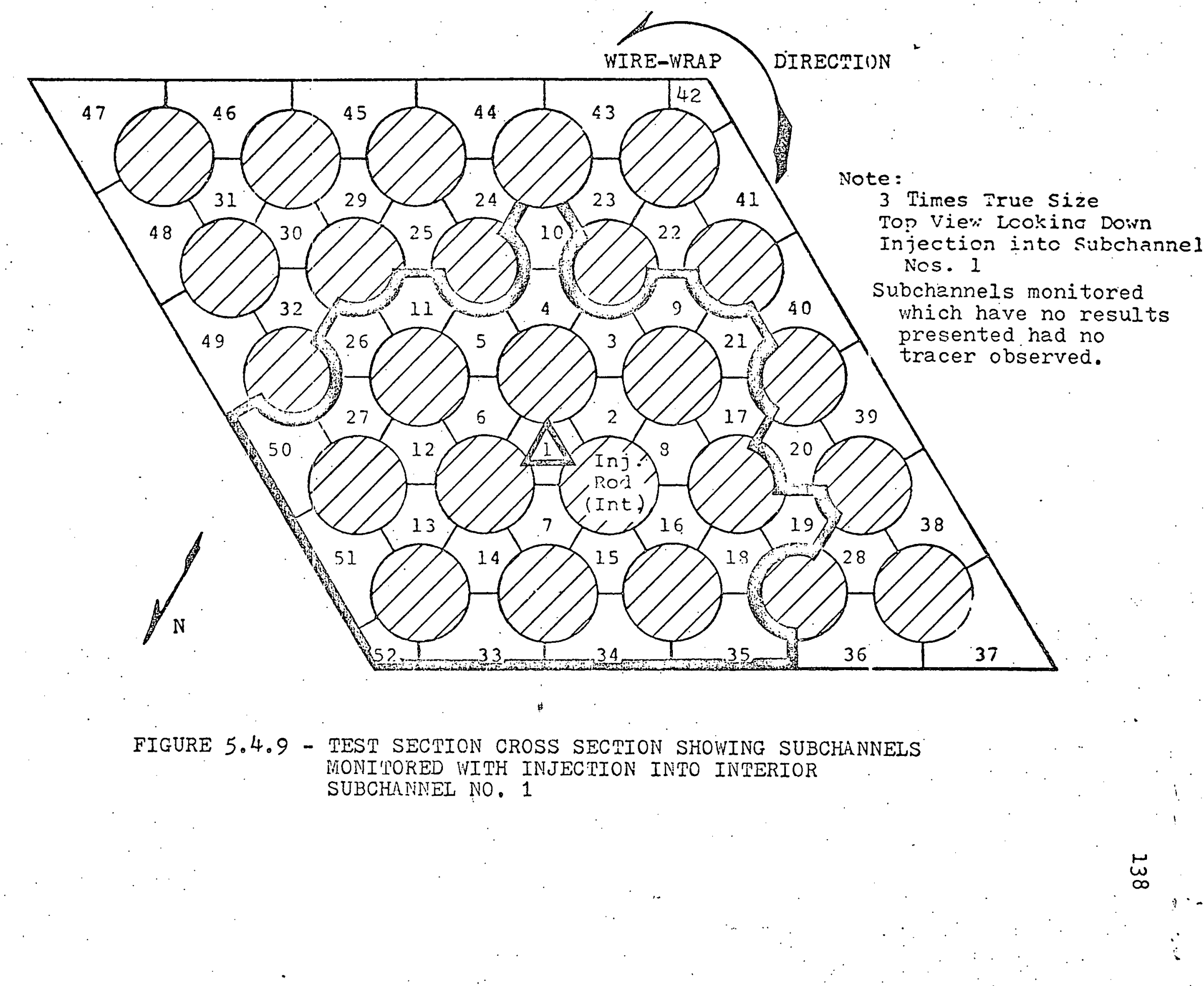


coolant mixing experiment done vith salt solution tracer injection into subchannel No. 1 (interior type) and with turbulent flow conditions, RUN No. 1 - IT. It was felt that subchannel No. 1 represented a typical

- interior type subchannel; i.e., it was independent of rod array perimeter esfects. The interion injection subchannel was separated from peripheral subchannels by two or more interior type subchannels.

The general nature of the curves show that the wirewrap spacers play an important role in interchannel coolant mixing via flow sweeping - especially when the injector is within one lead length of the detector. More than one lead length away from the detector, natural turbulent interchange becomes the more dominant of the coolant mixing processes.

It may be noted that the salt concentration is not symmetrically dispersed around the injection subchannel, cf. subchannels No. 3 and No. 5 or No. 2 and No. 6 . It is interesting that the salt concentration reduces in progressing from subchannel No. 2 to No. 3 to No. 4 to No. 5, indicating a slight flow swirl around the central array rod. The large presence of salt in subchannel No. 15 results because the injection stream was being diverted by a wire-wrap passing from subchannel No. 1 to No. 15 via No. 7 - apparently streaming through No. 7 attached (underneath) to the wire-wrap.

The baiance curve indicates that quite a lot of 
the salt was not monitored in the first $3 / 4$ lead length of injector travel and that stripping was occuring in the final $1 / 4$ lead of travel. The mass balances of these experiments will be discussed in section 5.5 .

RUN No. $1 \mathrm{~A}$ - IT was made priox to the parametric studies and vas done using $2 \mathrm{X}$ EAVC injection. The results for this run were similar to those for RUN 1 - IT; perturbations were noted due to the higher injection velocity (the salt insertion rate was twice as much $c_{i}=2.0$ grams $/(\mathrm{bm})$. However, the main differences were due to the mechanical behavior of the injector rod: the rod was new for RUN 1A - IT. The results of this run are given in sppendix 9. The mass balance curve was of the same general nature as the one for RUN 1 - IT; however, more mass loss in the first 18 inches of injector.

travel occurred because fewer subchannels were monitored in this run.

The results of RUN 1B - IT were obtained in 1972 with $4 \mathrm{X}$ EAVC injection and have been show in Figure 4.4 and discussed in earlier sections. It should be re-emphasized that the axial detail of the data was $1 / 2$ inch or more, that the data was reduced manually, and that the reometry was poor.

Interior Subchannel Injection, Laminar Flow: The interchannel coolant mixing results given in Figures 5.5.1 through 5.5.10 are for interior subchannel (No. 1) 


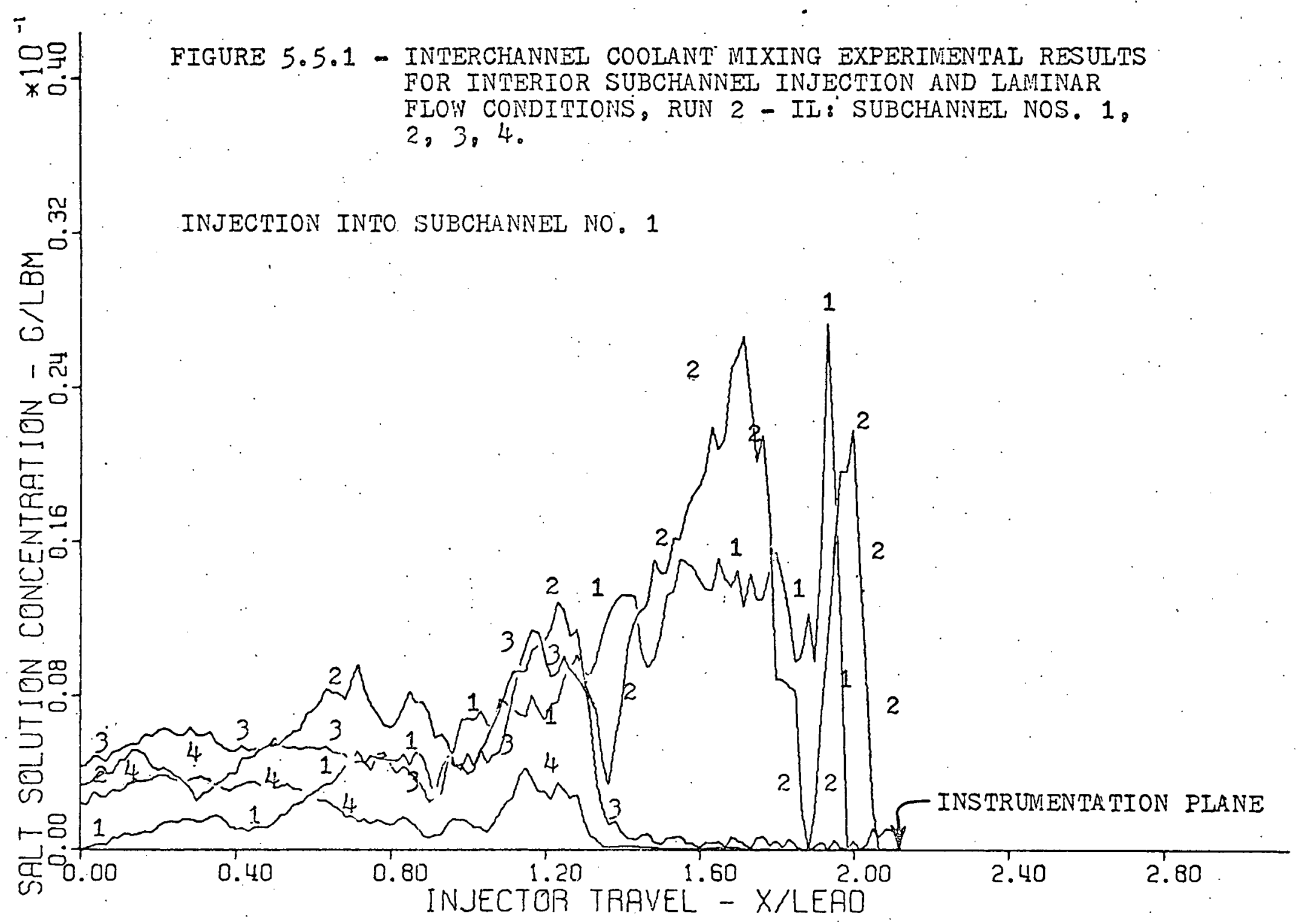




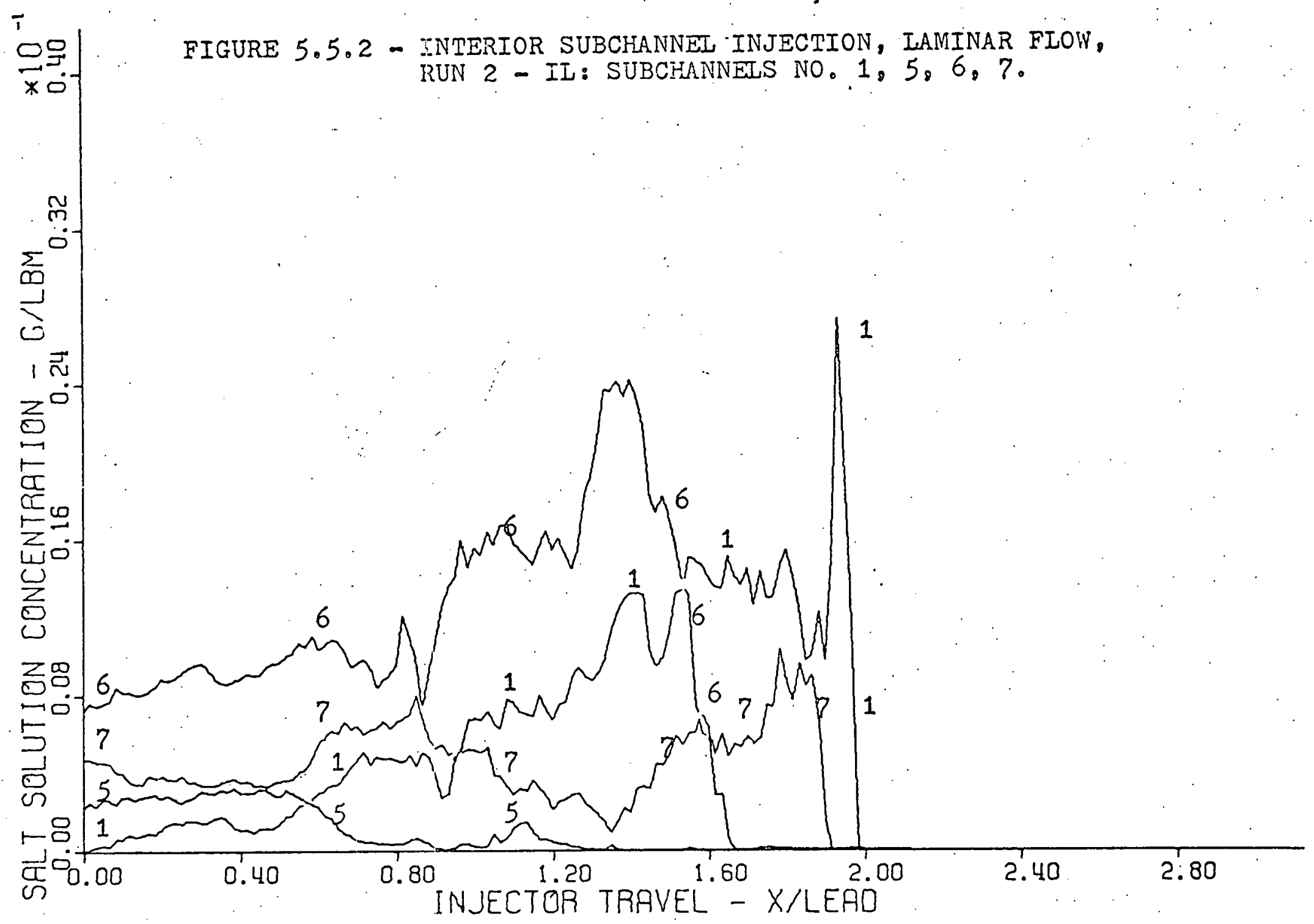




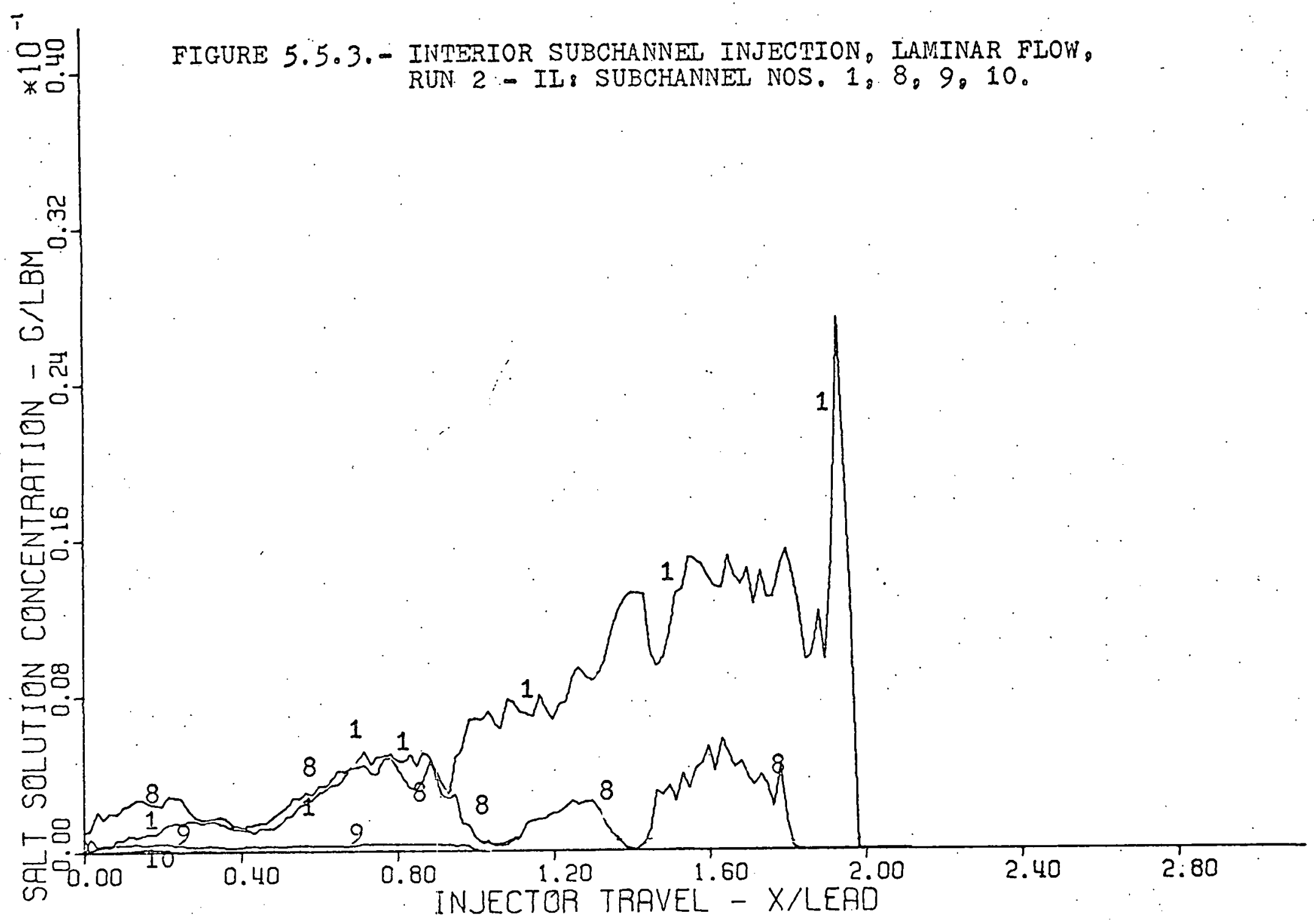




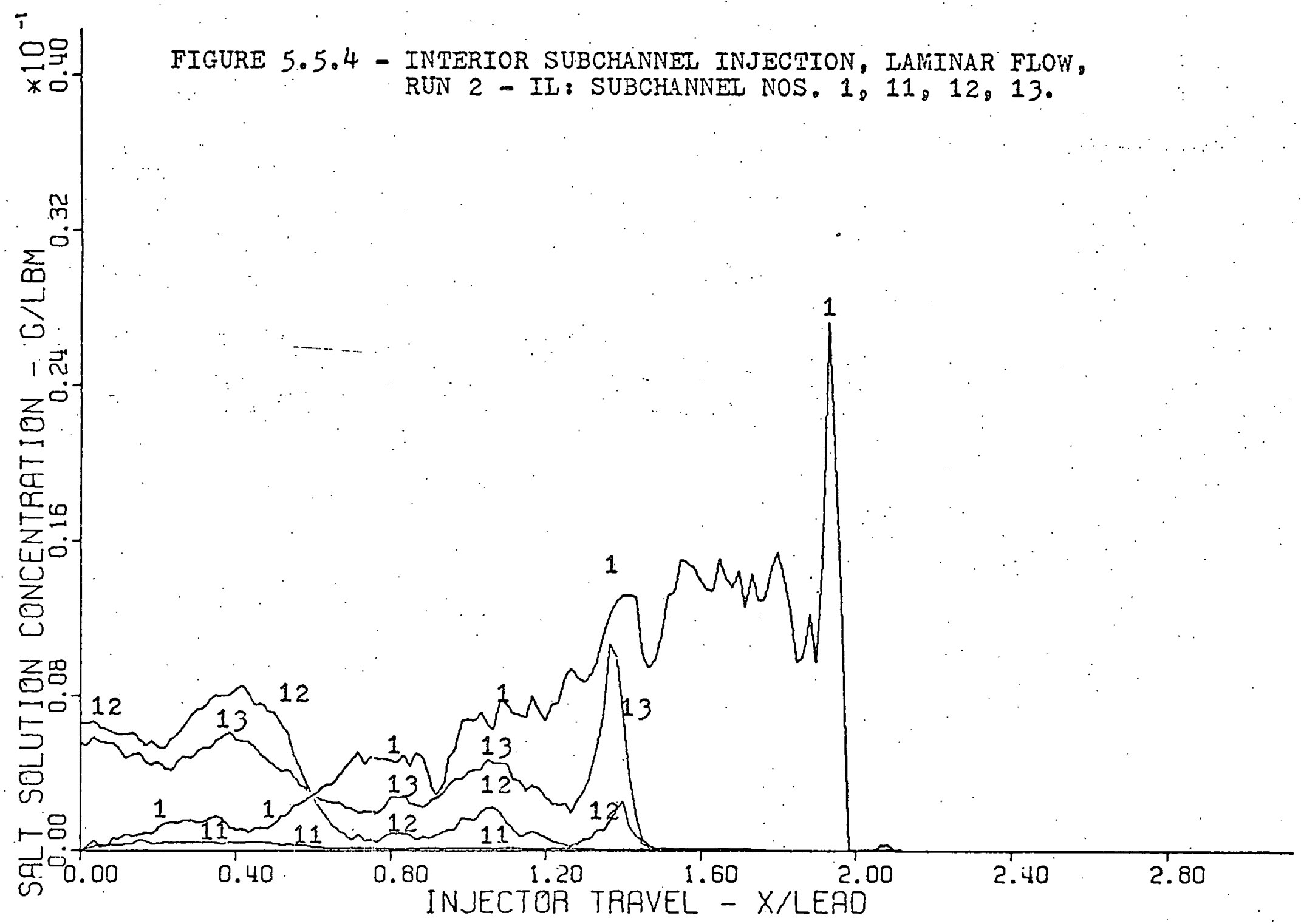




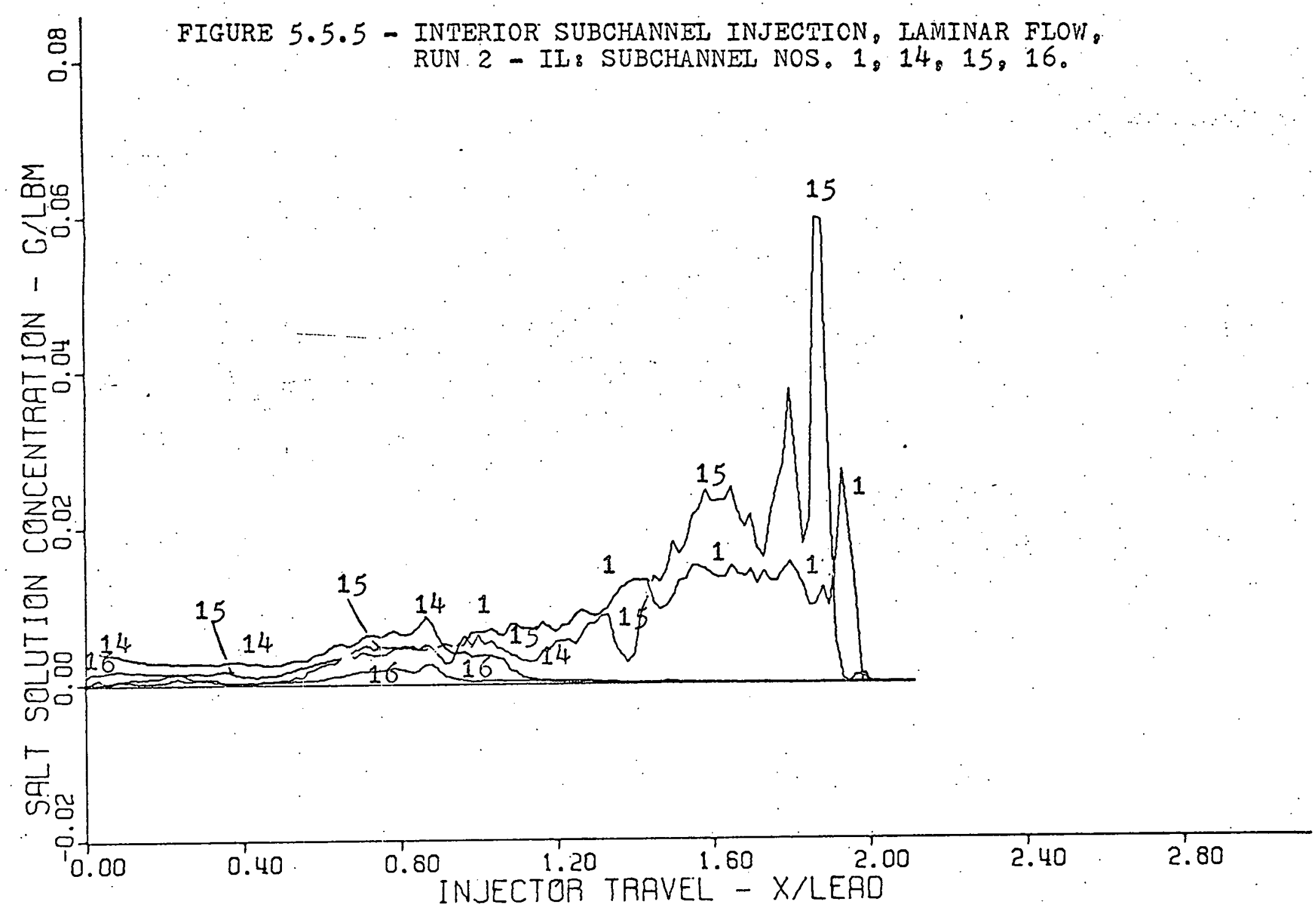




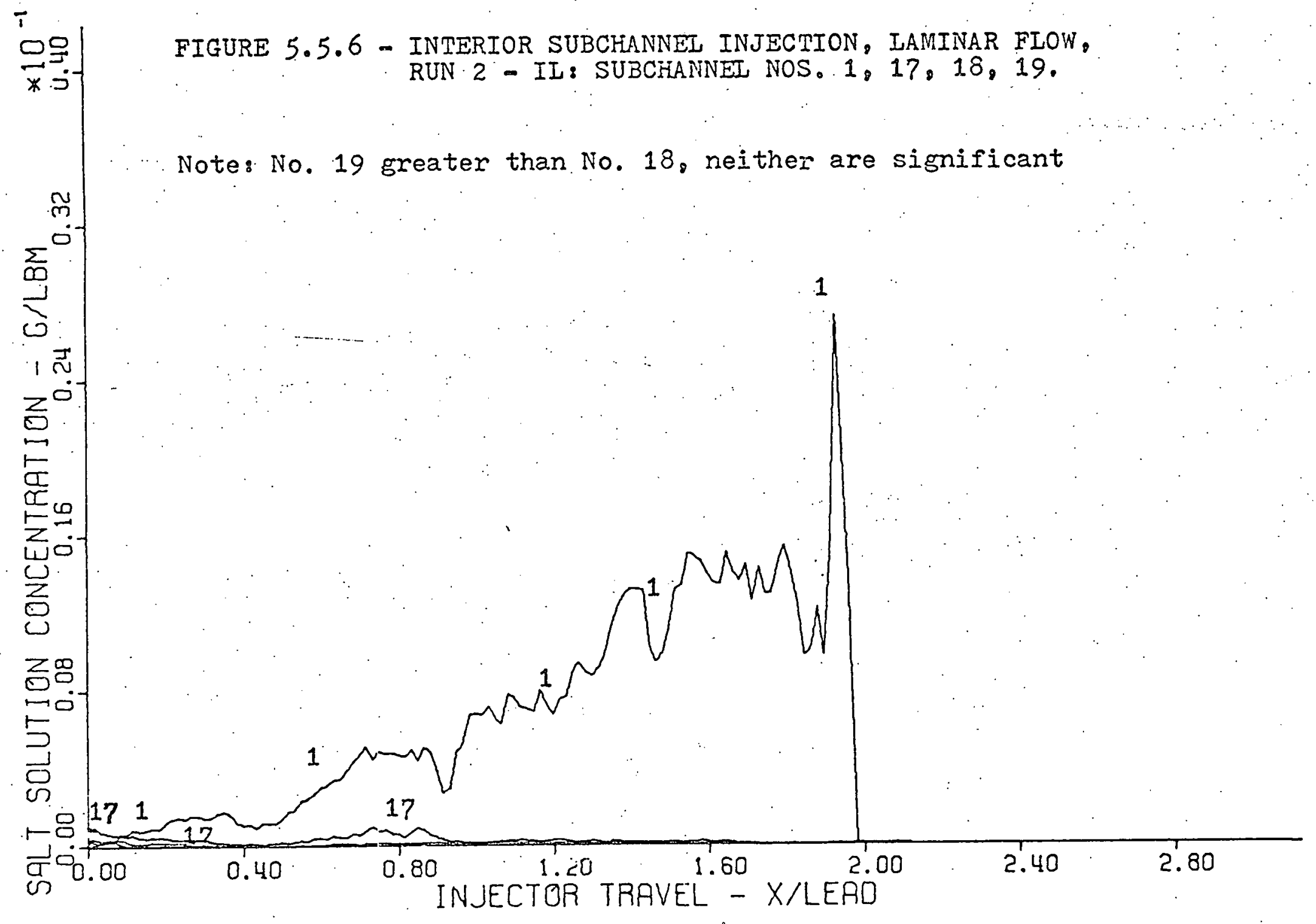




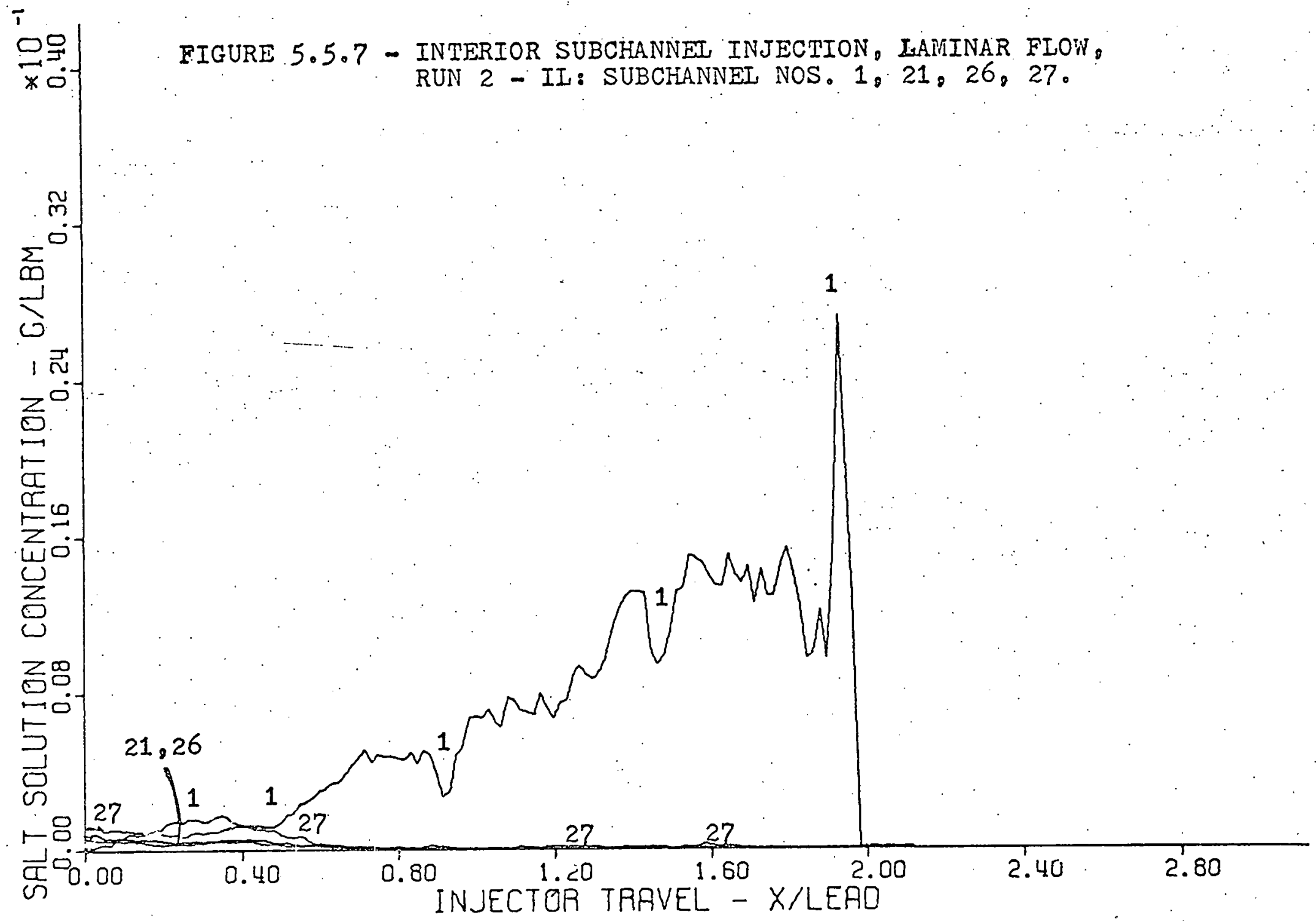




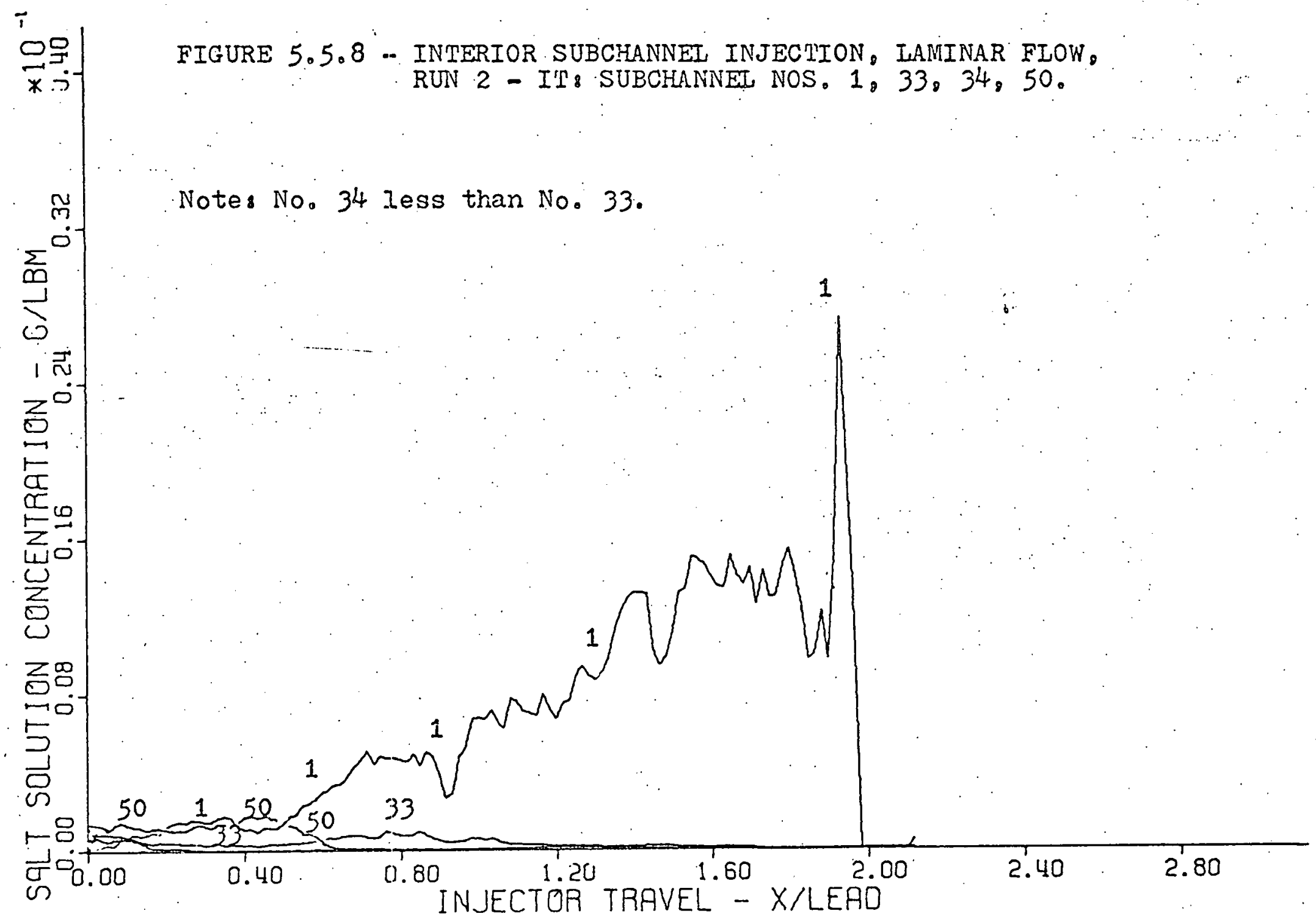




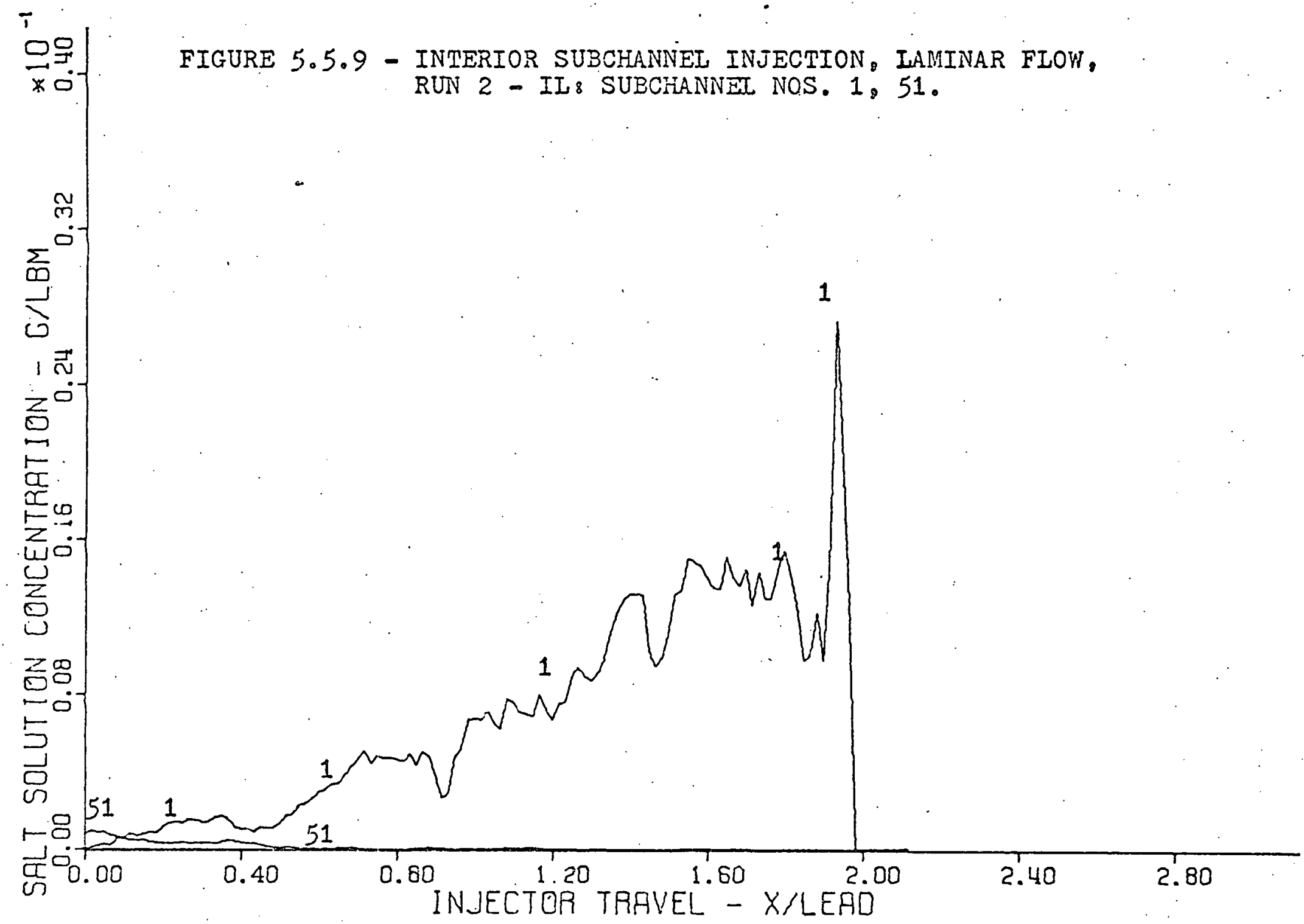




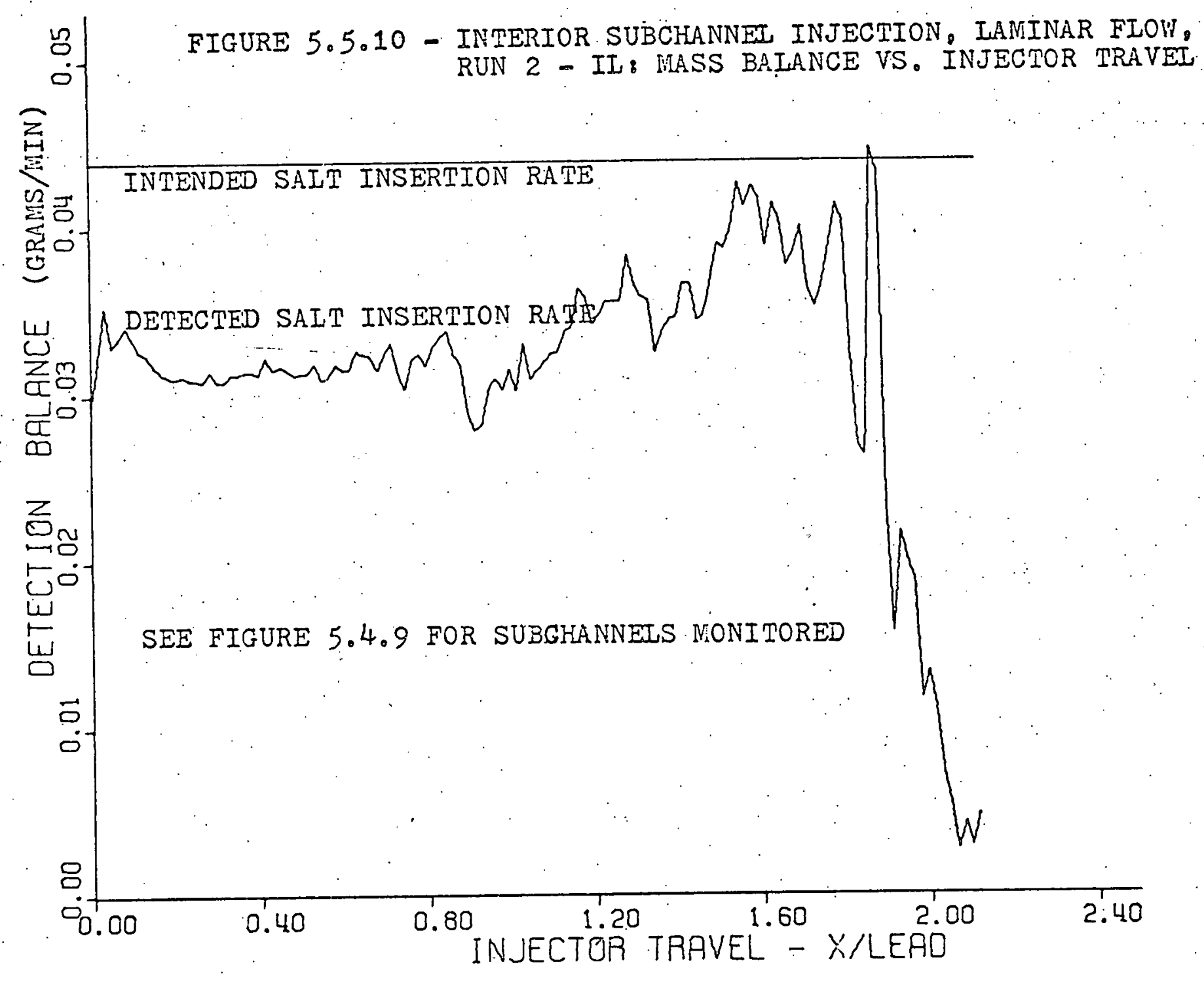


injection with laminar flow concitions, RUN No. 2 - II. Subsequent to the experiment, it was found that the peripheral subchannels were operating above the critical Reynolds number. For all work reported for RUir 2 - II, laminar flow conditions have been assumed throughout. Because most of the subchannels of interest i:se of the interior type and in laminar flow, this peripheral turbulence was probably not a significant error.

The generally jerky nature of the results was due to the flow flutter effects (low Reynolds number) discussed earlier. The tracer concentration versus injector travel behavior may be seen to be similar in shape for the various subchannels; however, note that all of the effects due to wire-wrap induced flow sweeping (characterized by the more abrupt changes in the curves, i.e., the hills and valleys) are more pronounced with respect to the injection subchannel concentration, e.g., subchannels No. 2 , No. 3, No. 6 and No. 15. However, in subchannel No. 7 , there is little difference between the magnitude of the laninar and turoulent flow results.

The mass balance curve (detection balance)for this run shows stripping effects in the last $1 / 4$ lead of travel. Less mass loss occurred in the first $1 / 2$ lead of injector travel in the laminar rlow case than in the turbulent flow case. Further, because of mechanical interference which prevented making concentration 
measurements in some of the subchanneds (No. 19, and 52), a small amount of salt is known to be missing. Peripheral subchannel Injection, Turbulent Flow: Figures 5.6.1 through 5.6.6 show the results of salt solution tracer injection into peripheral subchannel No. 50. with turbulent Ilow conditions; RUN No. 5 - FT. The results are again dominated by wire-wrap spacer effects, but with peripheral injection, the effects of wire-wrap flow sweeping dominates the tracer dispersion over the entire length of injector travel ( $21 / 2$ lead lead lengths). The data clearly shows a large swirl flow around the rod bundle periphery in the clockwise (wire-wrap rotational) direction, cf. subchannels No. 49 (note the absence of tracer), 50,51, 52, 33, $34,35,36$, and 37 . It is also interesting to note that the turbuelnt interchange coolant mixing between the peripheral subchannels and the interior subchannels is relatively insignificant; perhaps because the swirl flow remains near the walls of the channel and away from the rod gaps. Further discussion of swirl flow at the bundle periphery will be given in section 5.6 on flow visualization.

The turbulent flow mass balance for peripheral subchannel injection was very similar to that for interior subchannel injection. Significant stripping occured in the last $1 / 4$ lead of the injector travel 


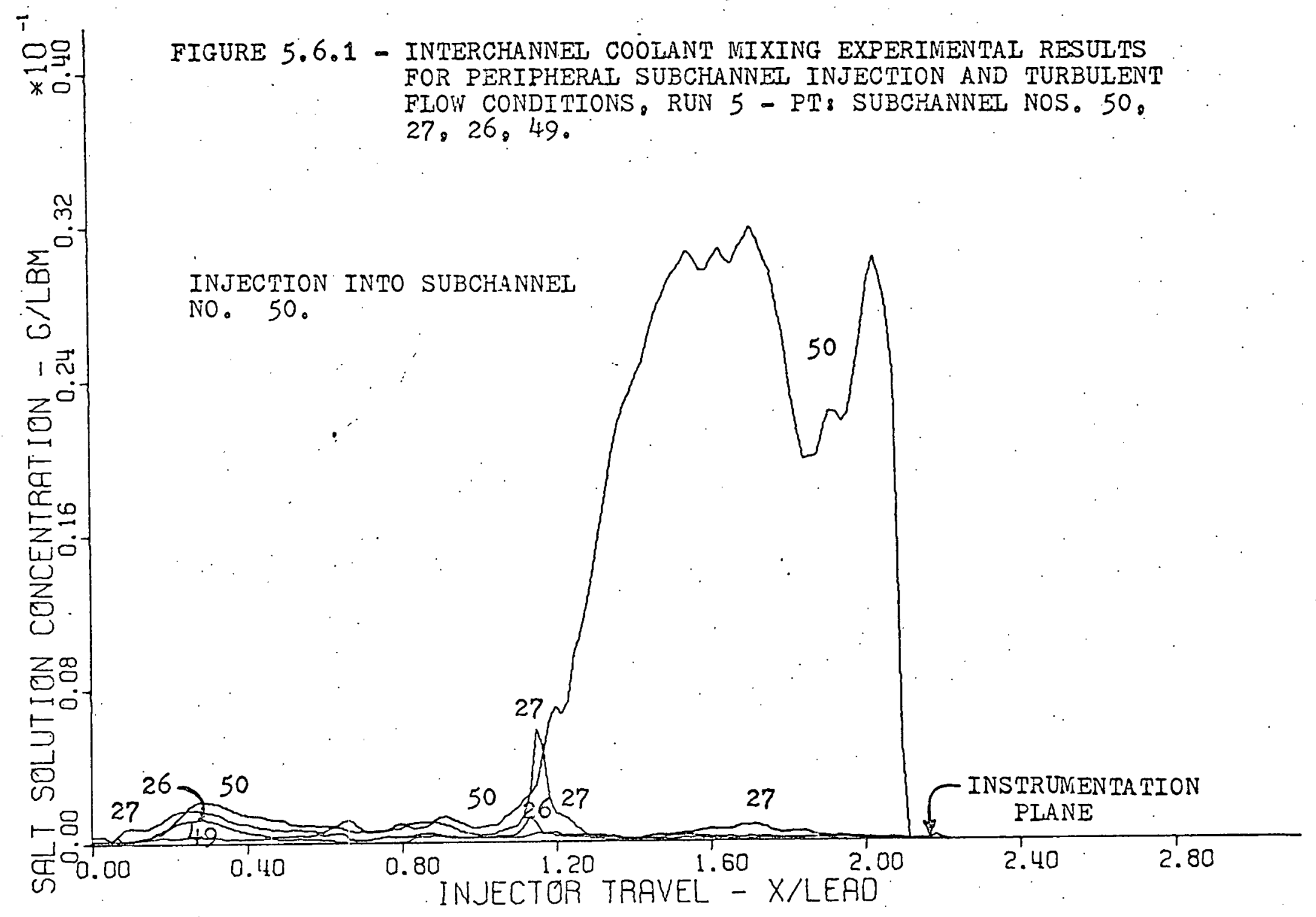




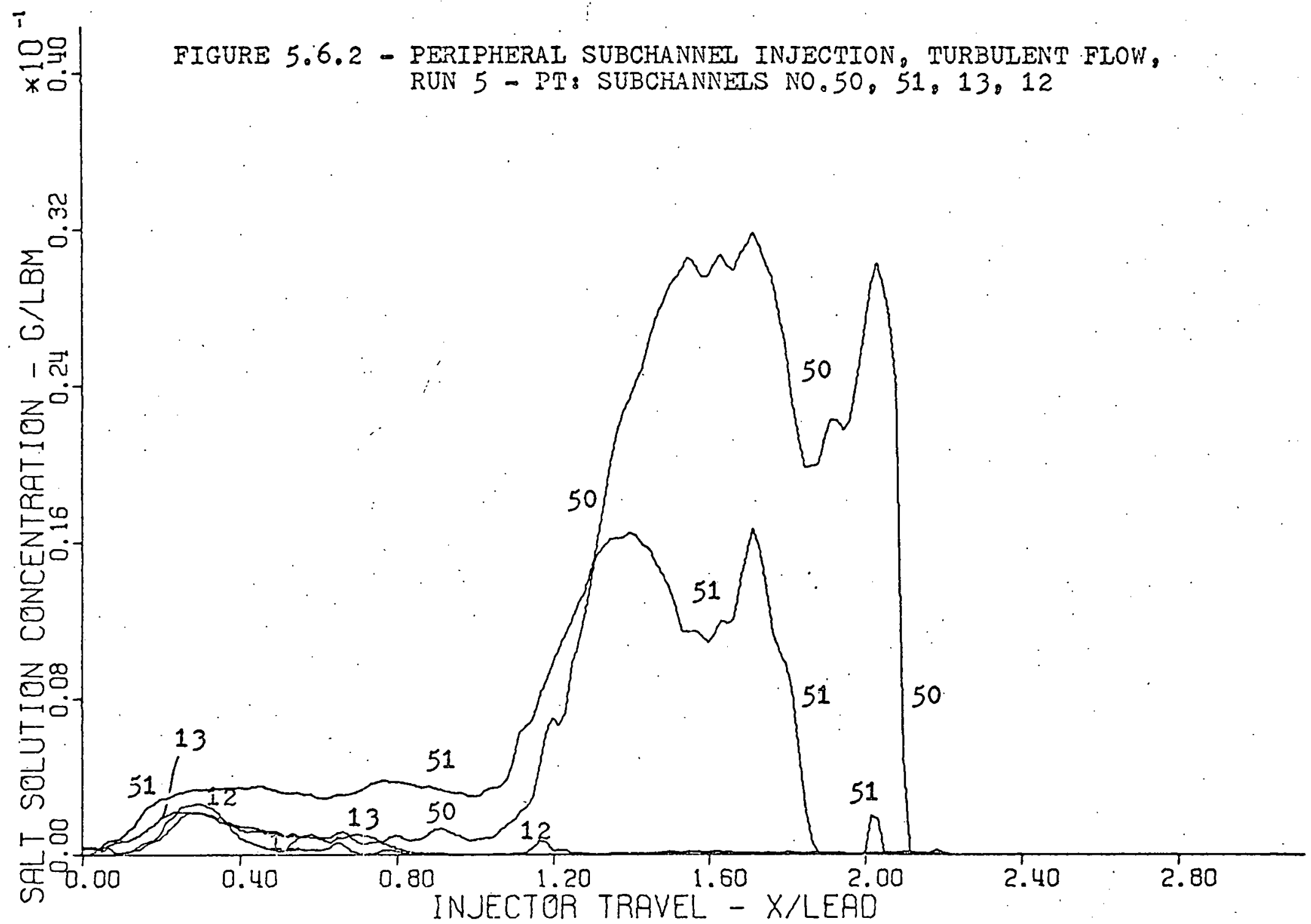




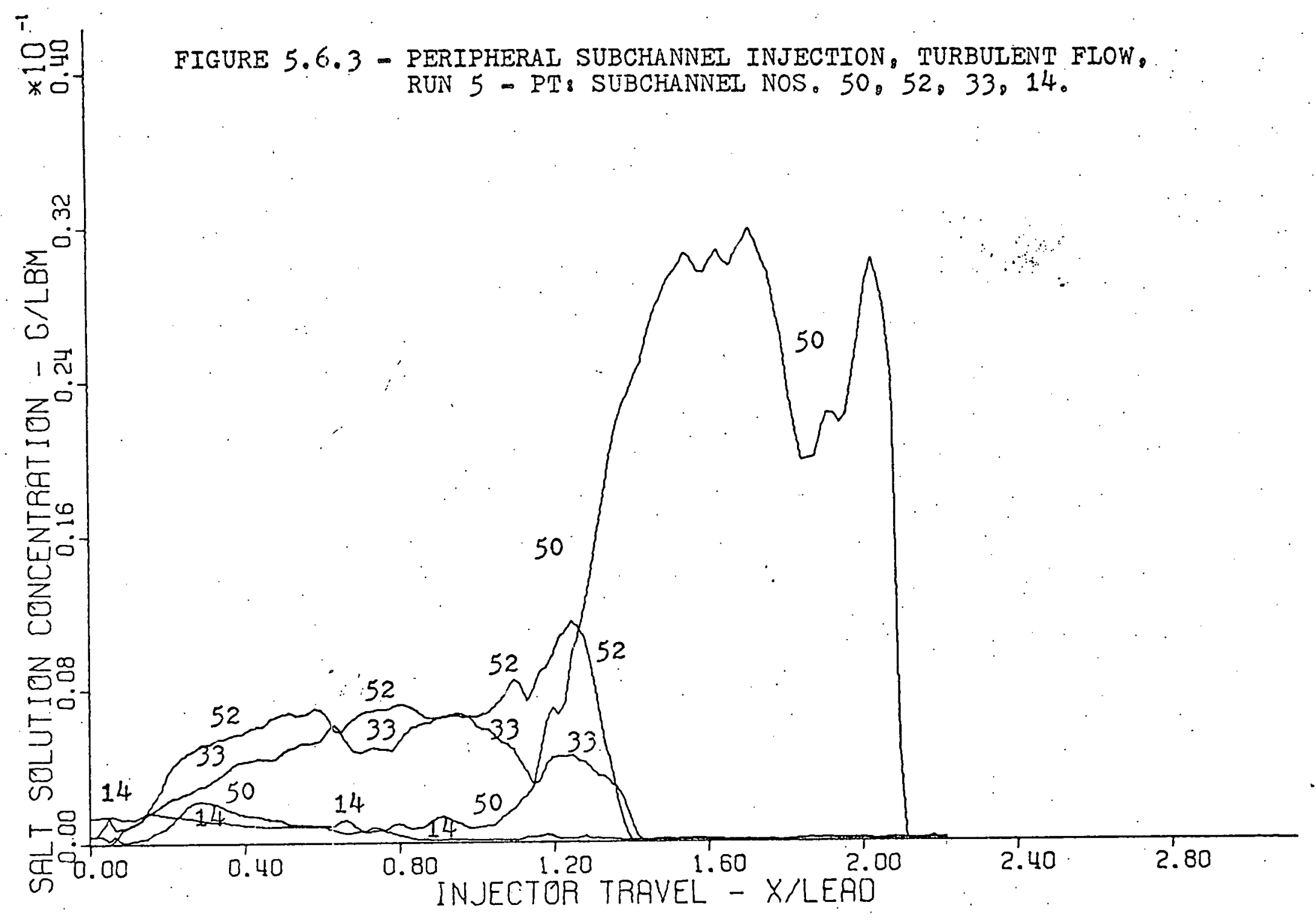




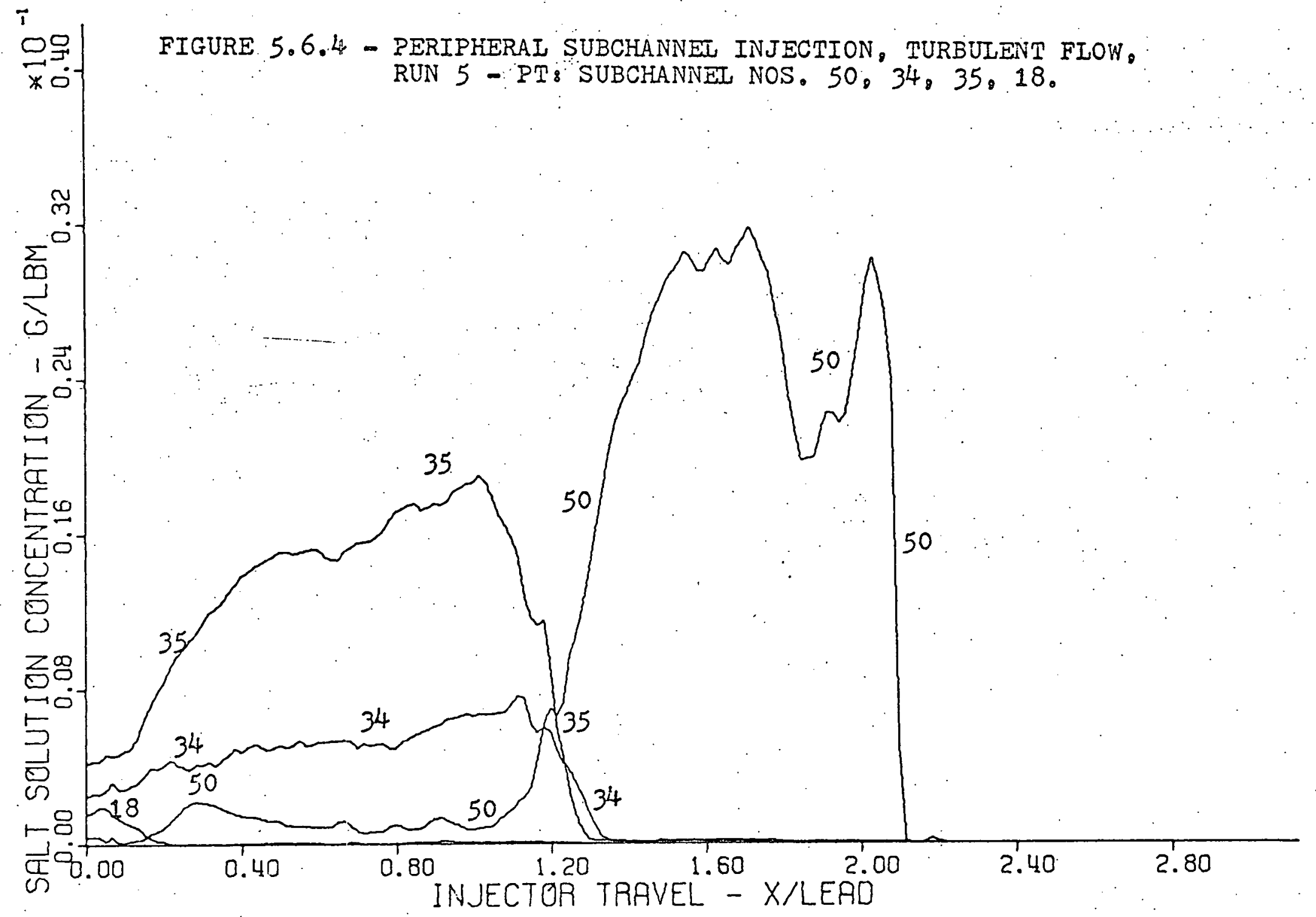




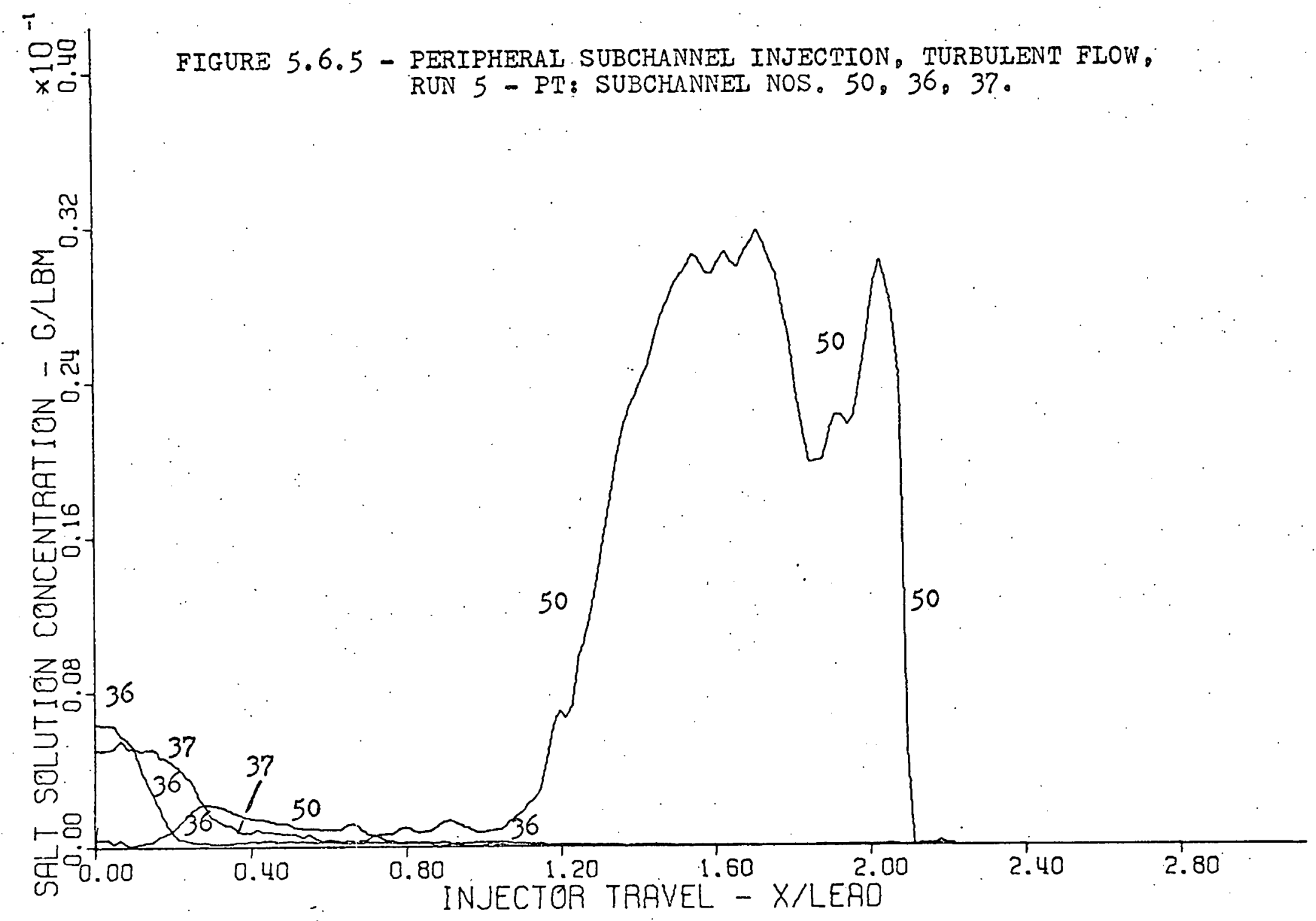




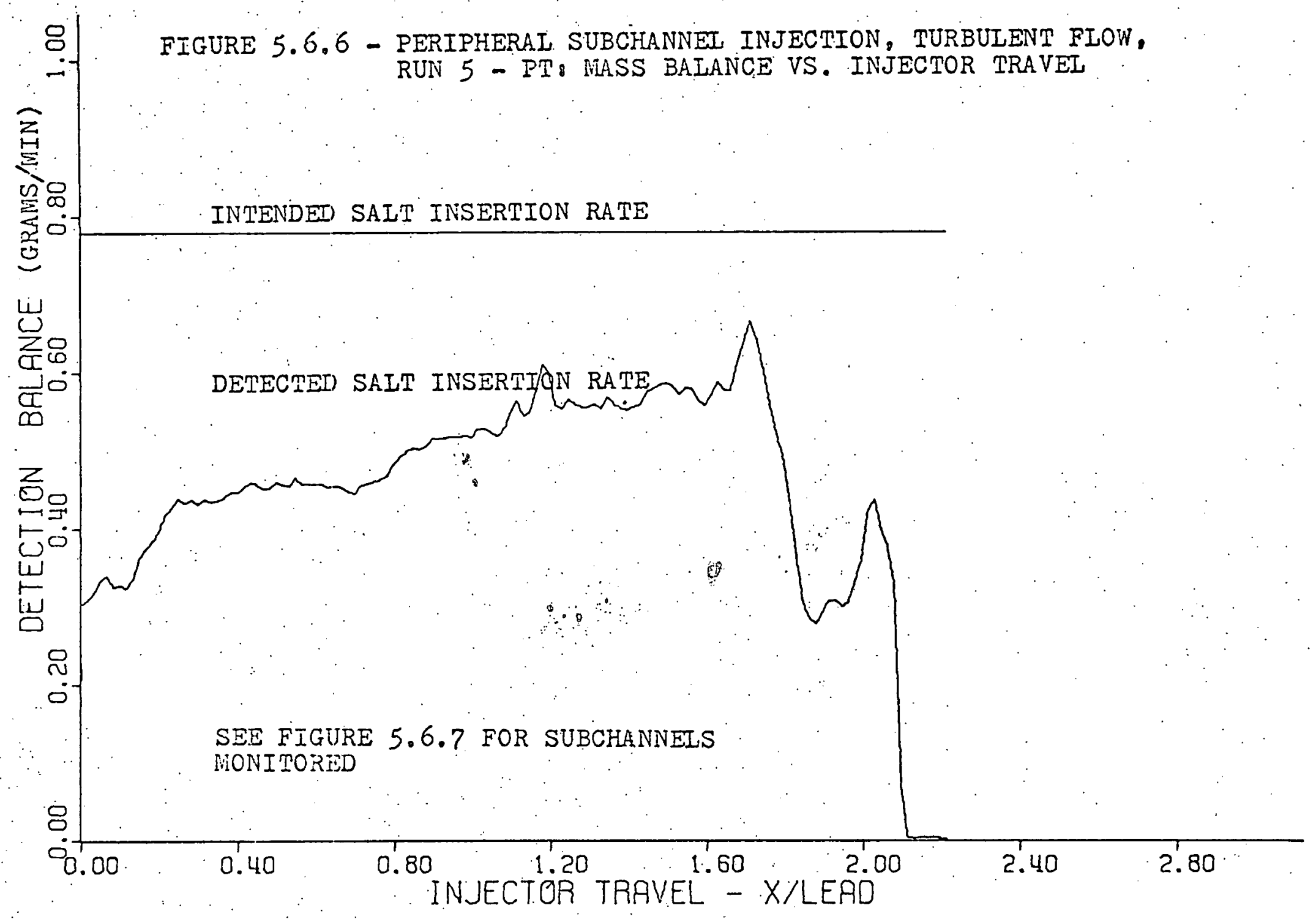




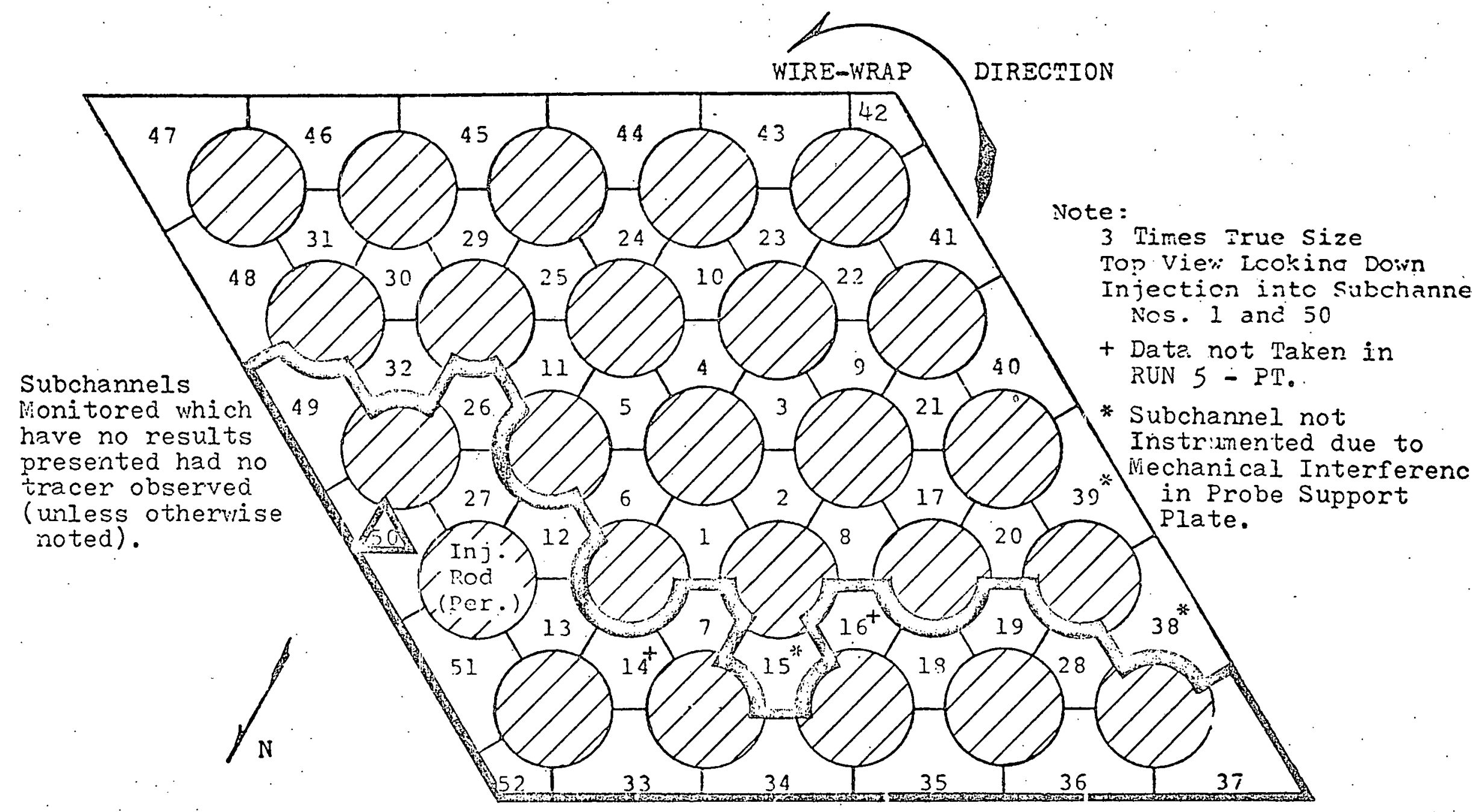

FIGURE 5.6.7 - TEST SECTION CROSS SECTION SHOWING SUBCHANNELS MONITORED WITH INJECTION INTO PERIFHERAI SUBCHLNNEL NO. 50. 
is knowm to be due to lack of data for subchannels No. 38 and 39.

Peripheral Subchannel. Injection, Laminar Flow: Figures 5.7 .1 through 5.7 .7 show the laminar filow results of interchannel coolant mixing with injection into a peripheral subchanneI (No. 50), RUN No. 6 - II (Note that the subchannel plotting order is different in RUN 6 - PI and RUN 5-PT). During this run a test section drain valve was accidently left open so that the exact main flow was unknown, but the peripheral subchannels were difinitely in laminar flow. It was estimated that about $75 \%$ of the metered flow went to the test section. (using crude calculations and post-experiment observatjons). Again for laminar flow, the roughness of the curves is the result of fluttering in the original data. Comparing laminar and turbulent flow, coolant mixing results for peripheral subchannel injection gives results similar to the comparison with interior subchannel injection. That is, the generai trends are similar for both cases; the effects of wire-wirap sweeping are more pronounced and the extremes in behavior are more noticable. This is due to the loss of natural turbulence and due to changes in the drag coefficient of the wire-wraps. The increased tracer concentration fluttering for the laminar flow cases may be due in part to vortex shedding from the wire-wraps and/or due to a low-flow instability in the injection system. 


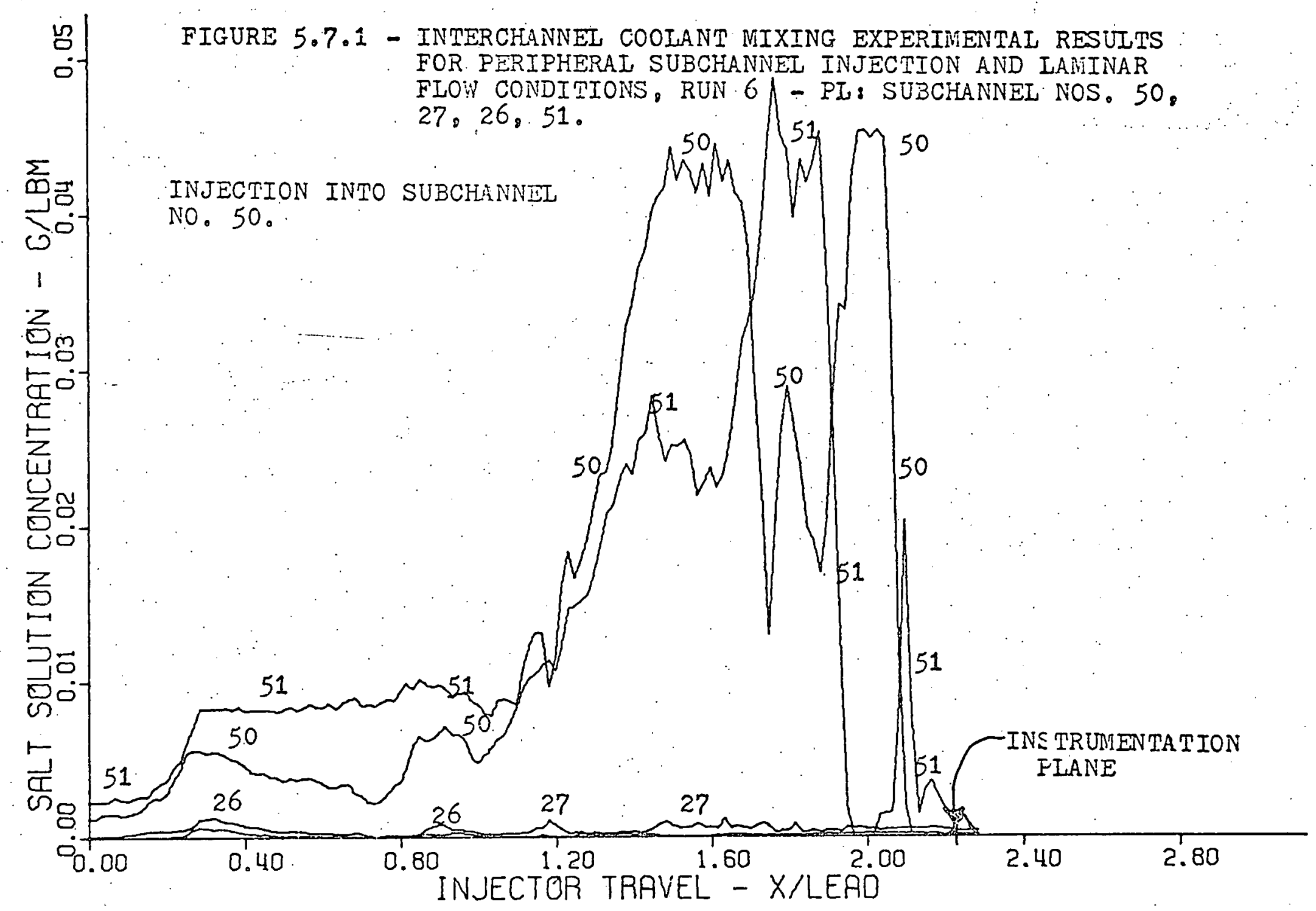




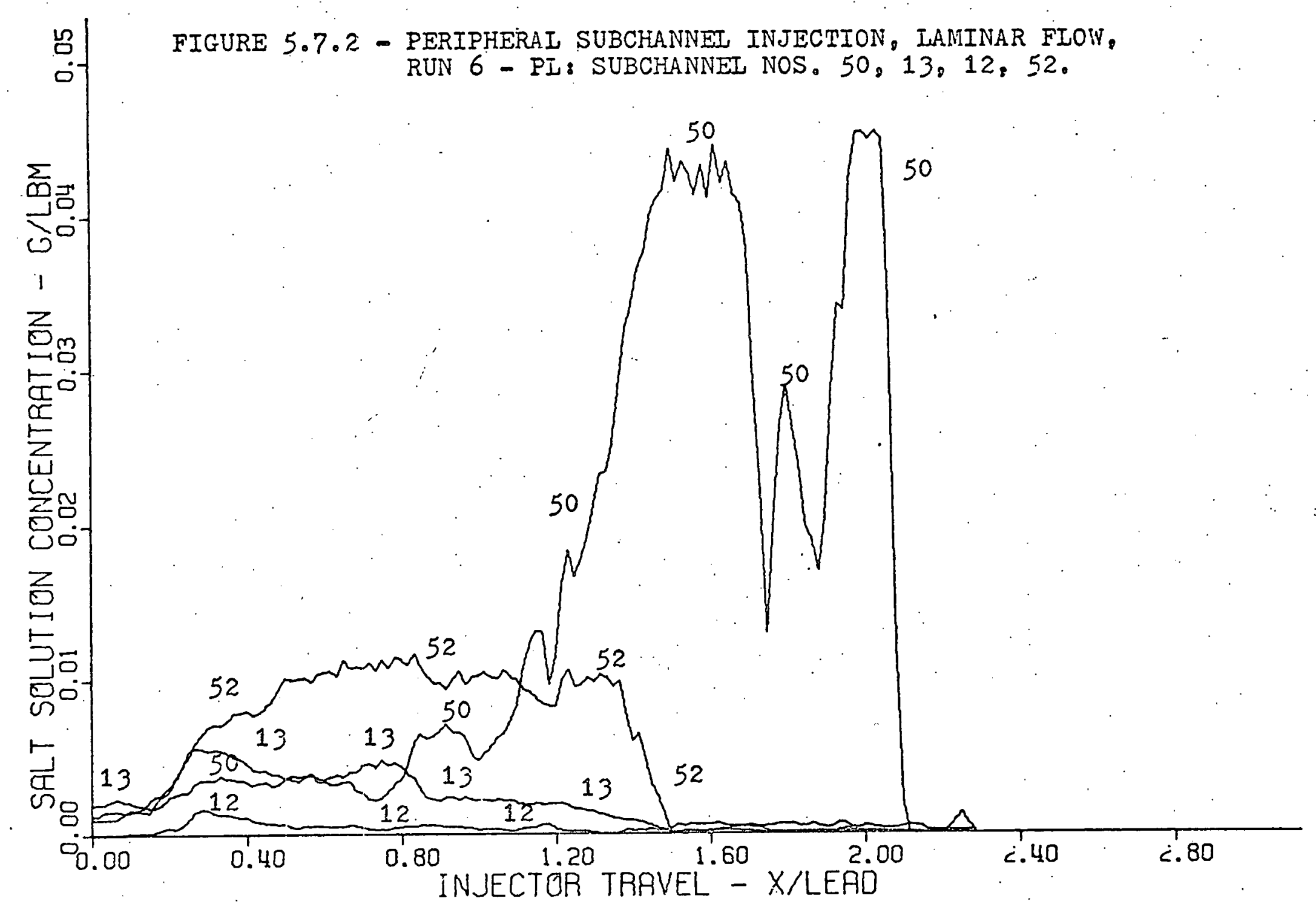




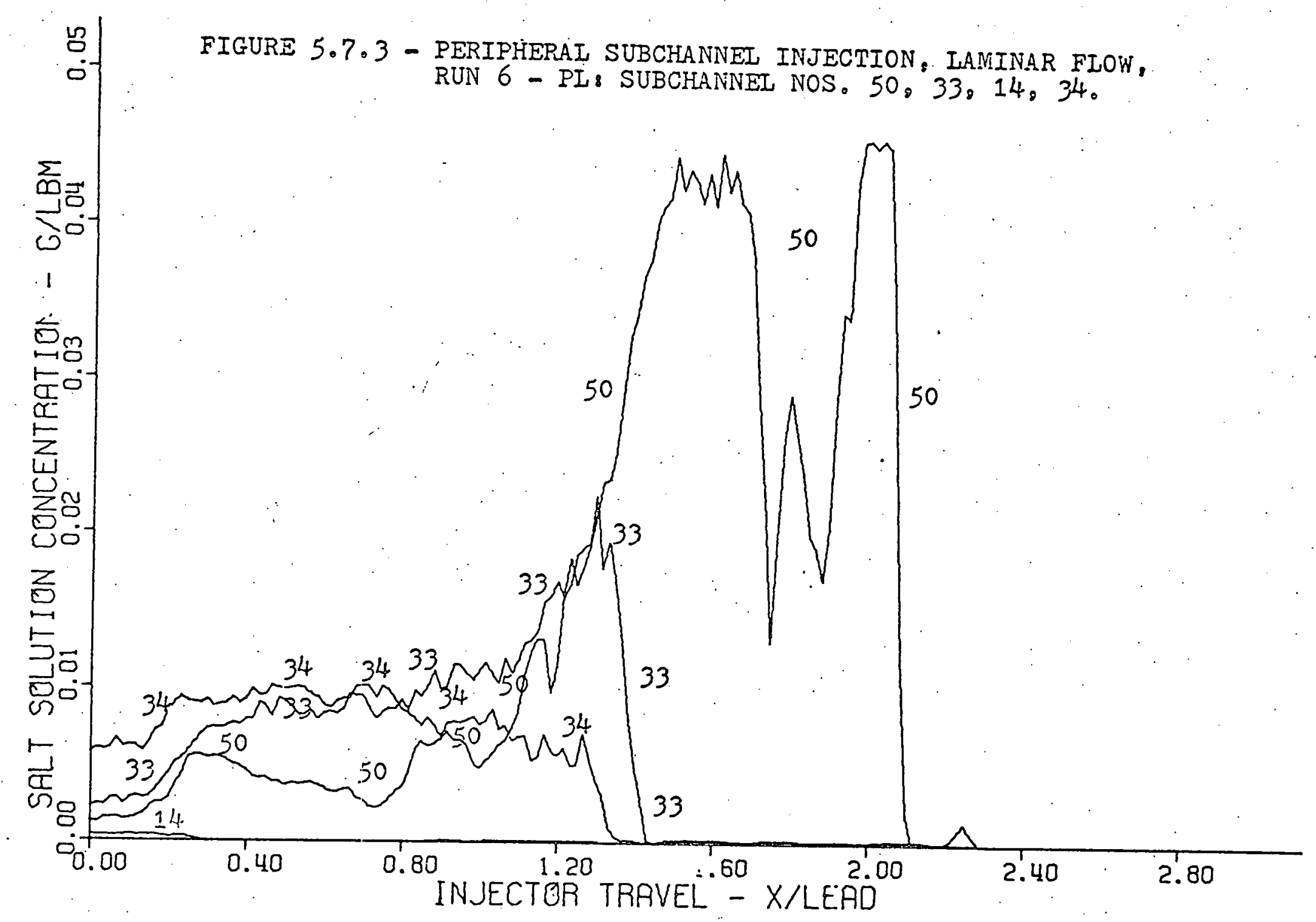




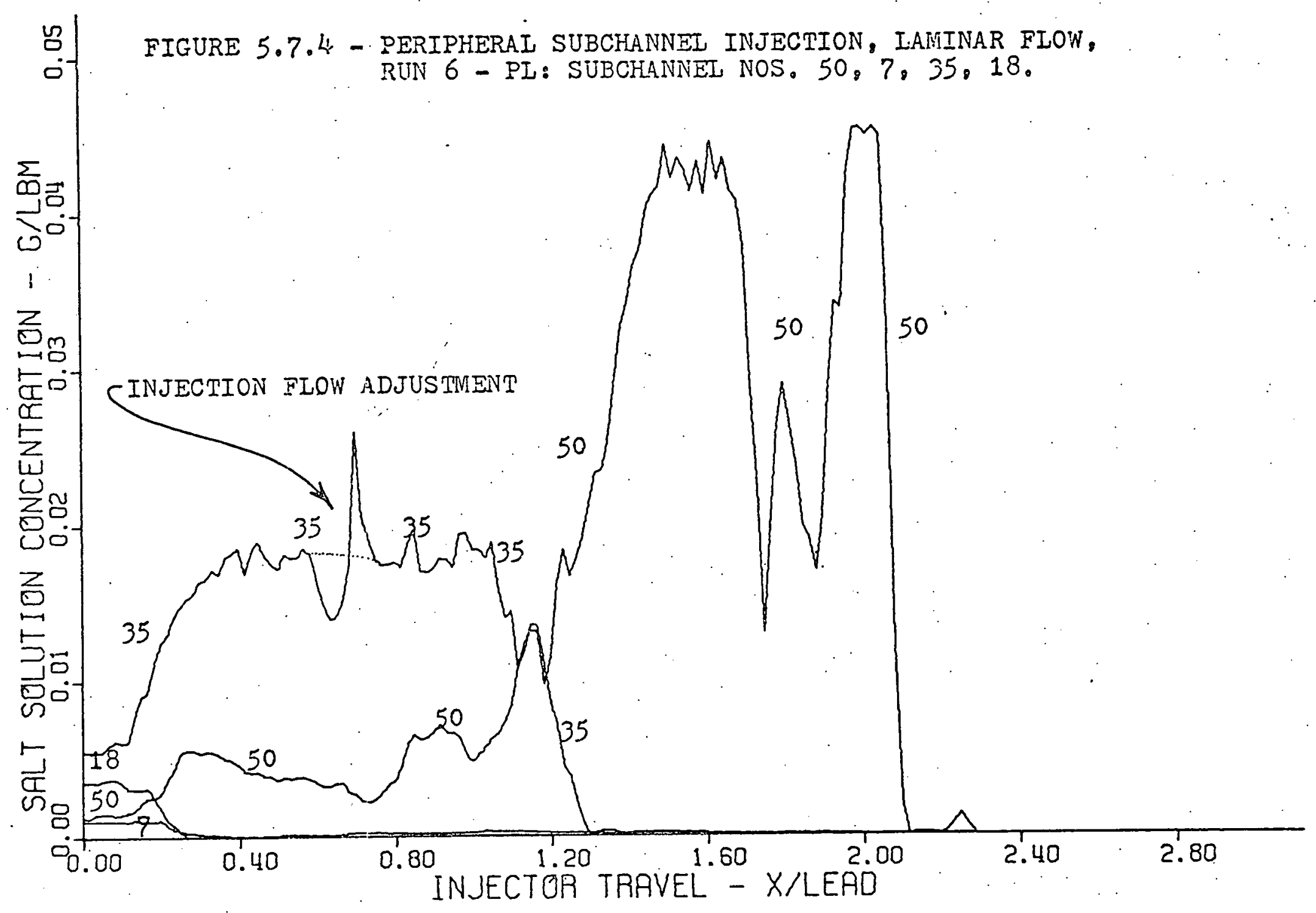




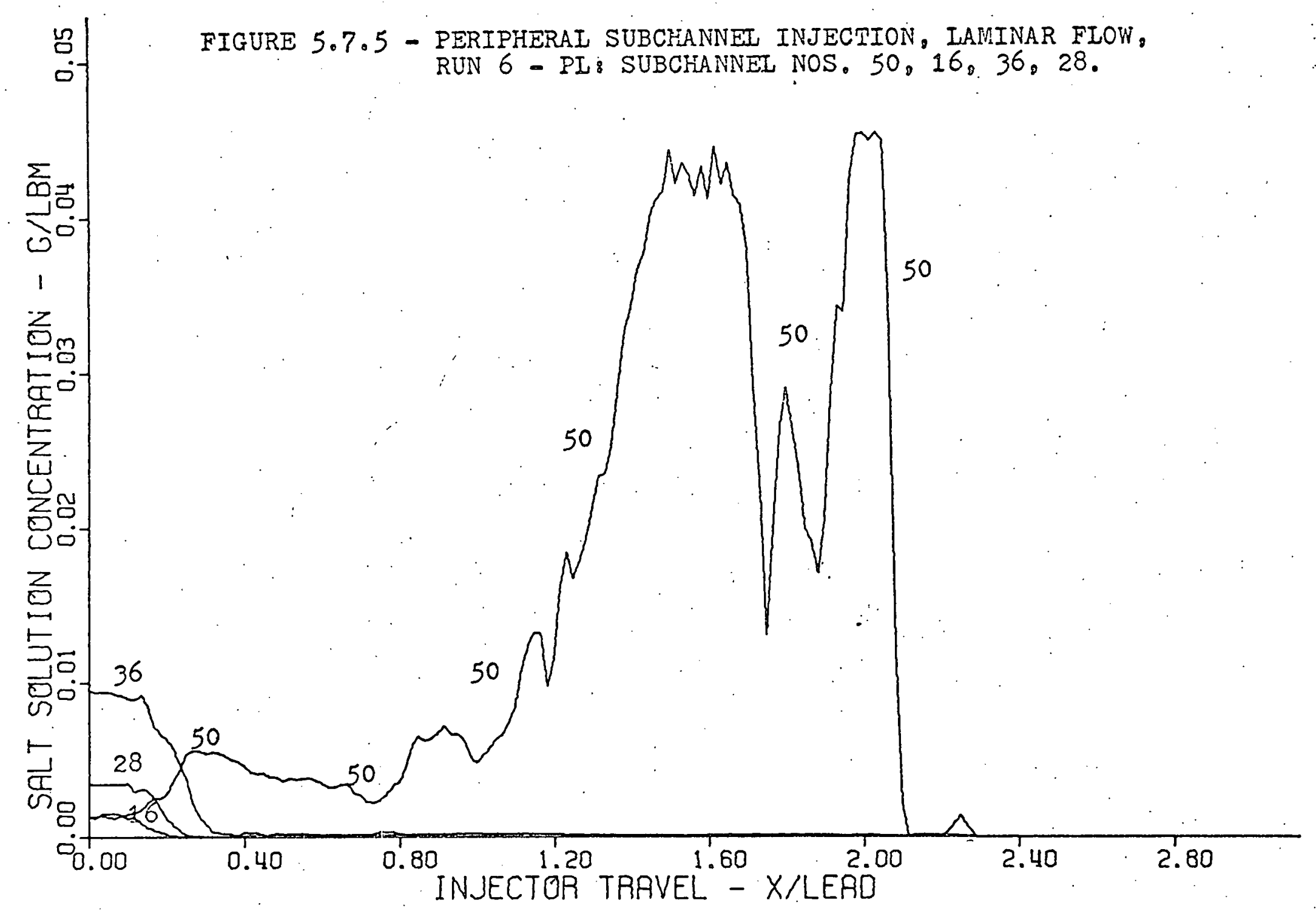




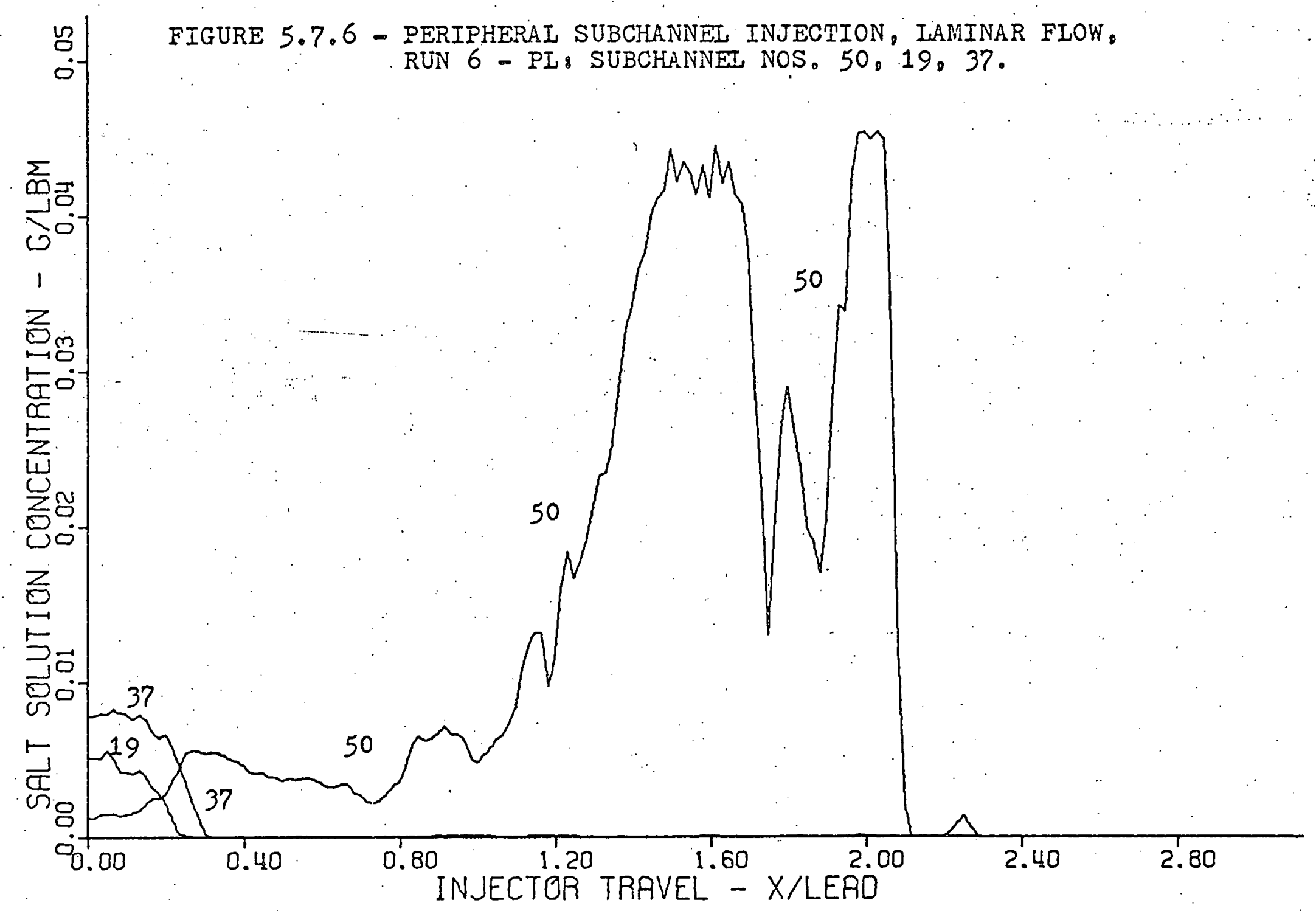




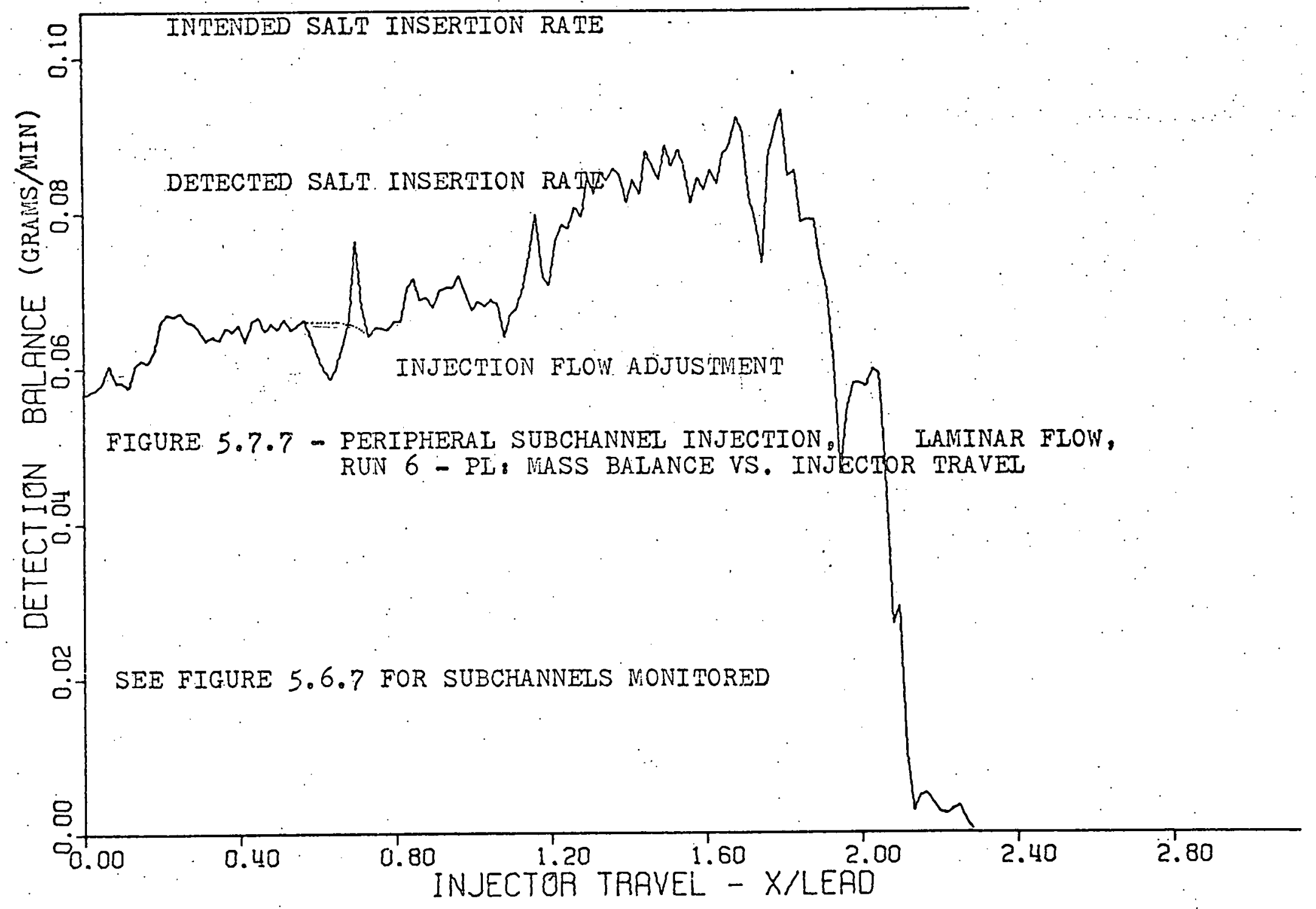


The behavior of the mass balance curve was similar to the previous laminar flow case, $i_{0} e_{0}$, less stripping effects in the bundle exit region and less loss of mass in the first lead of injector travel than was the case for turbulent flow results in the same subchannels.

\subsection{Comments on the Lass Balarice Results}

Stripping, the failure to meet a mass balance due to the presence of large inhomogeneities of tracer concentration in the flow field, is not surprizing during injector travel within the $1 / 2$ a lead length of the detector; this stripping is an irherent limitation of the axially moving injection technique when using internal detectors. However, failure to meet the mass balance criterion with the injector well separated (over one lead length) from the detector was surprising, and it was not due to stripping effects.

It is felt that this "loss of salt tracer" or loss of mass effect in the first lead of injector travel is due to one of the following reasons;

(1) calibration curve errors due to array rod proximity, electorde interference,

(2) inadequate flow regulation,

(3) a leak in the injection system downstrearn of the injection flow meter, and/or

(4) electronic interference in the data storage system. 
The calibration curves used for the data reduction were generated with the detector probe (only one vas used) in a large plastic barrel (for mixing solutions of known concentration). It is possible that array proximity, electrode interference (due to the presence of rodarray metal near the probel, not present with the jathering of calibration data, is responsible for the loss of mass problems in the experimental mass balance results.

. An experiment done on 24 June 1973, at the suggestion of D.D. Lanning, revealed that the effect of array interference was independent of salt concentration (and flow), but that it always gave the appearance of more salt than was actually present. Further, the interference was different from subchannel to subchannel and was dependent upon positioning, e.g., angular orientation of the electrodes, of the probes inside each subchannel. The effects did not appear significant because they were typically a $0 \%$ to $3 \%$ change in the balanced bridge voltage of the main flow water with no tracer; occasionaliy the change was more than $3 \%$. but was never more than $10 \%$.

Initially, a detector for each subchannel was planned and calibration in-position was intended. The initially large inventory of glass probes quickly dwindled to a few redesigned (reinforced) probes. Since positioning errors could not be overcome with the data collection technique required (repositioning the probe many times 
for each experiment), the interference effect was accommodated by balancing the wheatstone bridge with the probe in-position. Conversion of unbalanced bridge voltage data to salt solution concentrations was done using the same calibration curves for all data. The unbalanced bridge vcItage versus salt concentration calibration curves were nearly linear in the range of interest for the experiments, so this was a small error for each subchannel. However, the accumulation of all the error of this data reduction process is present in the balance curves. Further, as the injector-detector separation is increased, any such errors might become larger because more subchannels are involved.

It is important to note that the intended injection lines on the balance curves are the way things were supposed to be - not the way they were. Because an inadequate flow regulating valve was being used, flow control of the injection system was difficult. Every effort was mado to keep the injection flow within $+10 \%$ of the intended value. Nevertheless, the differences between actual injected flow and intended injection flow are not reflected in the straight line shown in the balance curves; the differences are definitely in the actual mass balance curve, as well as, in the individual subchannel results.

The plastic tube connecting the injection flow meter 
to the injector rod was press fitted onto the top of the moving steel tube of the injector rod. It is possible that an undetected leak was occurring at this connection. Further, the leak would have been greatest and most noticable with the injector fully inserted because of the increased injection system pressure required to inject into the bundle upstream of the exit. But when the injector was fully inserted, the connection was submerged in the discharge flow of the outlet plenum (and remained wet after withdrawal) so that a small leak would not have been noticed. The amount of tracer solution missing is something less than $0.101 \mathrm{bm} /$ minute - a very smal $\mathrm{I}$ (drip-like) flow. If a leak was occurring, it would explain why less mass was lost in the laminar flow mass balances than in the turbulent flow cases (due to the lower test section pressure loss).

As was noted earlier, the calibration data was taken with the same electronic equipment as was the mixing data. But the $X-Y$ plotter was not used when recording calibration data. It was noted that the plotier did interfere slightly with the signal when both the plotter and the magnetic recorder (see Figure $\hat{A} 2.4$ ) were connected to the AC voltmeter amplifier. This electronic interierence was observed as a small reduction in the voltage measured by the plotter when connecting the magnetic tape recorder to the circuit. The nature of this electronic complication 
would also explain the loss of mass phenomenon as it was observed.

Unfortunately, the significance of the above seemingly insignificant difficulties could not be assessed during experimental operations due to the long and complicated data handling and prucessing methods requireu ior this work (due to lack of the appropriate equipment).

It is the author's opinion that if accurate flow regulation and in-position calibration of stationary conductance probes:is used for future work, the mass balance "loss of mass" phenomenon will be greatly reduced or eliminated. The calibration data should be recorded in a manner identical to the inixing data, and needlessto-say, the injection system should be leak-tight.

\subsection{Flow Visualization Experiments}

A solution of methyl violet indicator was injected into the peripheral injection subchannel in order to do flow visualization studies. Farlier flow visualization efforts in interior subchannels had been unsuccessful using inking pen fluids and potassium permanganate (a strong oxidant of dark purple color). However, injection of methyl violet tracer into the peripheral subchannel (\# 50) provided valuable information about the fluid mixing behavior in the wire-wrap spaced rod array. Using the dye tracer, an approximate value of the 
average angle of the tracer dispersion path (in the peripheral subchannels) with respect to the rods was measured to be $5.5^{\circ} \pm 1.0^{\circ}$ (at an average bundle Reynolds number of 17.500) while the ancle of the wire-wrap is $4.7^{\circ}$, i.e.. a 12 inch lead on a $1 / 4$ inch OD rod. The observed peripheral, swirl flow angle was somewhat greater than the wire-wrap. angle which is perhaps not expected because the maximurn expected flow deflection would occur with the tracer path synchronized with the wire-wrap at $4.7^{\circ}$.

Recently, Lorenz, et al. (5.2) have done flow visualization experiments on the ANL 91-pin bundle and have observed a similar bulk swirl generated by wire-wrap spacers at the periphery of the bundle. Lorenz has measured a peripheral tracer dispersion angle with an average value of $3.15^{\circ}$; the maximum angle observed was $5.85^{\circ}$ (wire-wrap angie $=4.5^{\circ}$ ). The average angle represents the swirl velocity while the maximum angle represents superimposed diffusion of the tracer.

E.U. Khan (5.3) has mentioned that one theory concerning the peripheral swirl flow velocity observed (particularly concerning the observation of iracer at angles greater than the wire-wrap angle) notes that the observed transverse velocity of a swirl flow should appear higher than the wrap angle because between peripheral subchannels the rod and wall act as a nozzle which increases the average, peripheral swirl flow velocity (in the proximity of the rodto-wall gap). 
As was confirmed by experimental salt tracer measurements, in both turbulent and laminar flow, the tracer migrated a considerable transverse distance. Over the range of Reynolds numbers tested, tracer (both dye and salt) was present at the bundle outlet in subchannels No. 36, 37 and 38 with injection into No. 50 two lead lengths ( 24 inches) downstream. Using the salt tracer data; a flow deflection of about four rod-to-rod pitches (from subchannel No. 50 to 35 ) was observed with the injector 13 inches from the detector; this data gives a flow angle of $4.9^{\circ} \pm 1.4^{\circ}$.

Varing the injection rate in turbulent flow visualization experiments had little influence on the gross tracer distribution in the rod bundle. The primary visual eifect of injection velocity changes were in the region near the injection device. For increased tracer insertion velocity, these changes were characterized by more turbulent jet mixing and more jet ricocheting (particularly with injection near a wire-wrap). Away from the injector, the primary influence of injection rate. variation was a small change in the darkness, not the position, of the dispersing tracer (the concentration was the same for al. w work - dark).

For laminar flow $(\operatorname{Re} \simeq 1500)$, the flow was observed to be "fluffy," possibly due to vortex (large eddy) shed ding from the wire-wrap. A rule of thumb equation 
for vortex shedding frequency is

$$
f=0.2 \mathrm{v} / \mathrm{d}_{\mathrm{w}}
$$

Eq. 5.1

where $f$ is the vortex shedding frequency $\left(\sec ^{-1}\right), V$ is the fluid velocity ( $f t / \mathrm{sec}$ ) and $d_{w}$ is the diameter of the flow obstruction ( $f t_{0}$ ). The 0.2 coefficient is empirical and varies from 0.2 to over 0.8 , but for this approximate treatment 0.2 will suffice. The frequency of wire-wrap vortex shedding may be calculated to be about $60 \mathrm{sec}^{-1}$; such a frequency would explain the fluffy nature of the flow, but is too high to explain the fluttering in the original data. (Vortex shedding may have been an exciting mechanism in the low-flow instabilities, nevertheless).

The tracer dispersion pattern in laminar flow was characterized by a more dominant "turbulent jet" type of dispersion superimposed on a swirl flow similar to that in turbulent flow. With increases in injection velocity, the dispersing jet would spread into a wider dispersion angle. Flow perturbations near the injector also increased with injection velocity.

Detailed data of the flow visualization experiments were not taken; however, an abbreviated photographic record of this work is given in Appendix 8 . 


\section{Chapter 6}

RECOMMENDATIONS FOR FUTURE WORK

Using the moving injector instrumentation technique a variety of illuminating experiments could be conducted in order to provide a better understanding of rod bundle thermal-hydraulics. A list of such experiments is given in Table 6.1 and discussed below. The influence of rod array geometrical parameters, i.e., rod diameter, rodto-rod pitch and wire-wrap lead and the influence of the total number of array rods on interchannel coolant mixing are important in the thermal-hydraulic and thermalmechanical design of LMFBR fuel and blanket assemblies and in the interpretation of mixing results from various experimental rod bundles.

\subsection{Influence of Rod Bundle Ceometrical Parameters on Coolant Mixing}

This work has provided preliminary mixing results for a wire-wrap spaced rod bundle in a rhombus shaped flow channel. In order to give a more realistic experimental flow field, future work should be done with hexagonal rod bundles.

The influence of both the wire-wrap axial pitch (lead) $I$ and the pitch-to-diameter ratio $P / D$ on inter- 
Table 6.1

Recommendations for Future Experimental

Work in Interchannel Coolant Mixing

Section

6.1 Influence of Rod Array Wire-Wrap Lead and Pitch-toDiameter Ratio

6.1 Influence of Rod Diameter (Bundle Scale)

6.2 Influence of Hexagonal Rod Array Size, i.e., Number of Rods or Bundle Size

6.3 Mixing Behavior in Different Subchannel Types: Interior, Peripheral and Corner

6.3 Influence of Channel Valls and Corners on Rod Array Mixing

6.4 Flow Blockage and Distorted Rod (or Wall) studies; the Effect of Bundle Looseness

6.4. Coolant Mixing in Bare Bundles and the Influence of Spacer Grids on Mixing Benavior

6.4 Transient Experiments

6.4 Outlet Velocity Profile Measurements: Experimental Mass Balance Calculations

6.5 Data Reduction with Moving Injection and Stationary Detection

6.6 Comparison of Results with salt Solution and Hot water Tracers

6.7 Integral Experiments: A Comparison of Heated Rods and $I x i a l l y$ Integrated, Injected Tracer Results 
channel coolant mixing is of interest. Varing the wirewrap lead length varies the mixing rate and pressure losses so that an optimization is necessary. The $P / D$ parameter influence is also of interest because it changes from one reactor type to the next and because blanket assemblies have a lower $P / D$ than fuel assemblies. The influence of the rod diameter $D$ (bundle scale or overall size) on coolant mixing behavior is of interest. Bundle scale or rod diameter varies with fuel assembly designs, and blanket assemblies have a larger rod diameter than fuel assemblies.

Understanding coolant mixing parameters over the range of rod bundle geometrical parameters, i.e., wirewrap lead, fuel rod pitch-to-diameter ratio (equilateral. triangular lattice) and fuel rod diameter shall be important in future fast breeder reactors in which the fuel assembly design reflects changes in fuel cycle economics and reactor development. In addition, these influences axe an important part of assessing existing experimental data taken on bundles with varying rod array geometrical parameters.

6.2 Influence of The Number of Array Rods Blanket assemblies typically have 61,91 or 127 rods, a smaller number of rods than fuel assemblies (typically 217 rods). Further, it is a common practice 
to conduct experiments with rod bundles that have less rods than is characteristic of reactors. An important part of interchannel coolant mixing studies wi?l involve examining the influence of the number of rods used for a hexagonal shaped test section on observed mixing behavior. It has been suggested by Markòczy [0.1] that the effect of the number of rods might decrease monotodically as the number of rods increases. Figure 6.1 (also refer to Table 4.2) shows the ratio of the number of exteriorto-interior type subchannels versus the number of rods for hexagonal rod bundles; this illustrates that the channel valls or flow duct should be expected to have an influence on the average or overall rod bundle mixing rate which varies with the number of rods in the array. This effect would be most noticeable around the outermost rod rows of the array. The $217^{\circ}$ pin bundle characteristic of LMFBR cores has a peripheral-to-interior subchannel ratio of 0.125 while the $19,37,61$ and 91 pin arrays most commonly used for experiments have respective ratios of $0.500,0.333,0.250$ and 0.200 ; this ratio varies from 0.250 to 0.167 for typical blanket assemblies.

\subsection{Influence of Subchannel Location}

Anamolies in coolant flow areas do not influence the flow field further than about two rod rows from the perturbation [6.1]. Fuel assembly channel walls are a marked deviation in flow geometry, but away from the walls, 


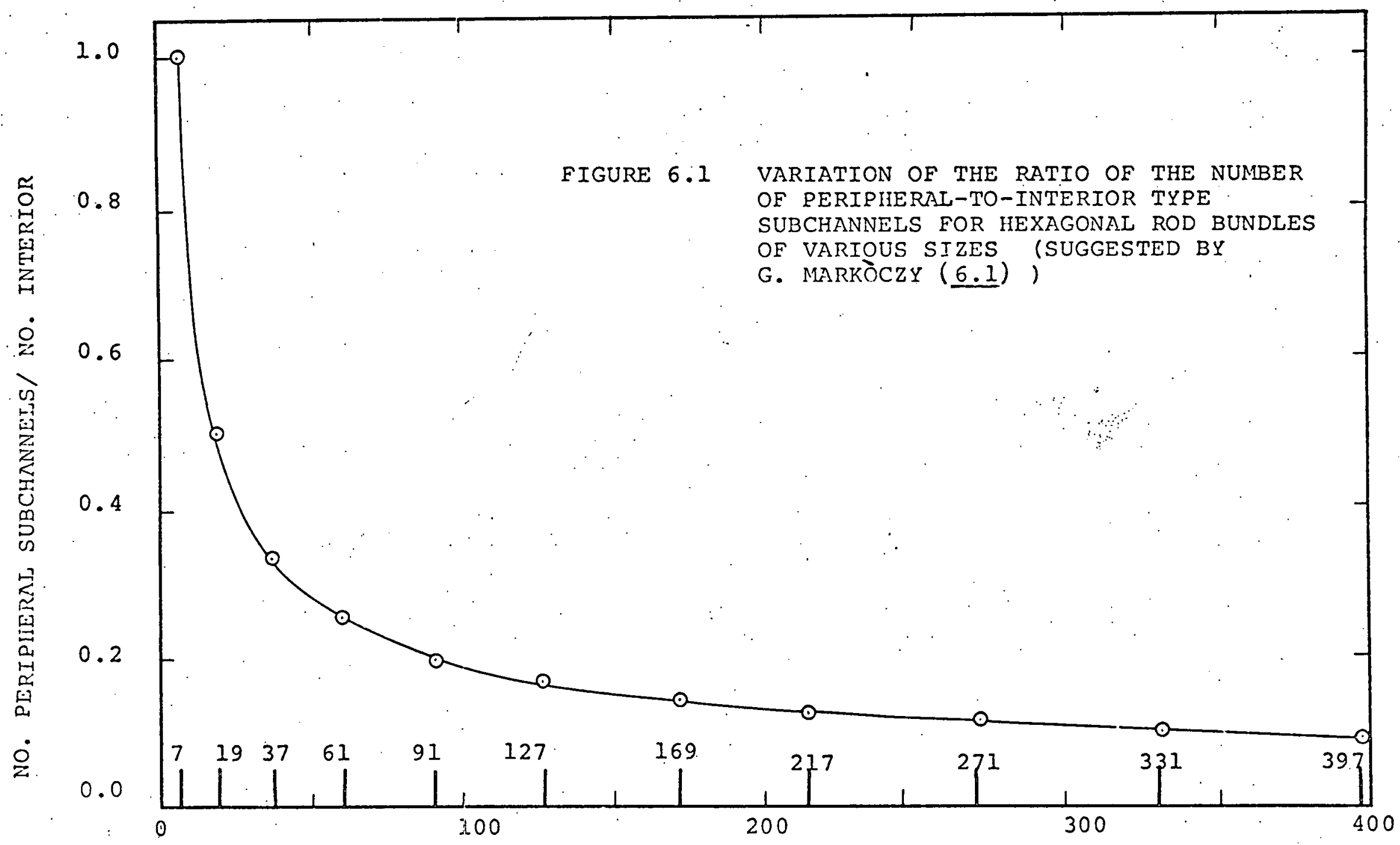

NUMBER OF FUEL RODS IN HEXAGONAL BUNDLE 
the rod array tends to behave similarly to an infinite rod array. Obviously, interchannel coolant mixing in interior subchannels is influenced by the wall if the subchannel is near the wall. The coolant mixing in both interior and peripheral subchannels is influenced by the proximity of a corner subchannel the salt tracer tech-. nique could be used (with injection into all subchannels of interest)] in order to establish the influence of these geometrical irregularity proximities. It wolid be necessary to examine mixing behavior in several interior subchannels of differing proximity to peripheral subchannels to determine the influence of a wall on rod bundle mixing behavior. Examining mixing behavior in several interior and several peripheral subchannels of different proximities to a corner subchannel could establish the influence of hexagonal duct corners on rod array coolant mixing.

\subsection{Miscellaneous Rod Bundle Mixing Experiments}

Using the instrumentation methods herein developed, a series of experiments could be done illuminating fluid mechanical phenomenon in the vicinity of flow blockages, bowed rods, distorted rods and distorted channel walls. The methods could also be used to investigate single phase mixing in bare rod arrays and to examine the influence of spacer grids on coolant mixing. Coolant mixing 
behavior during flow transients might also be examined.

It is recommended that, in future work, velocity profiles at the cod array outlet be measured using a pitot tube to experimentally check the flow split

$\therefore$ analysis used in the MITMIX code balance calculations, see Appendix 3. In addition to measuring outlat velocity, it may be possible to measure any swirl flow component as well.

6.5 The Role of Diffusivity in Computer Code Data Analysis The purpose of the work herein reported is to aid in the thermal-hydraulic design of IMFBR fuel assemblies. Further observations regarding diffusivities might be useful, particularly if the computer codes for thermalhydraulic analysis of LMFBR's were to be required to perform a comparative analysis of data generated in various mixing experiments which used either sodium flow or water flow. Extensive experimental results exist for tracer insertion using salt solution injection, heated water injection and heated rods with water flow and for tracer insertion using heated rods with sodium flow. In order to utilize this data, an analytical procedure having a highly flexible energy mixing capabilities is required.

The molecular (mass) diffusivity of a salt tracer and the thermal diffusivity of the main flow (with heat tracers) plays an important role in the dispersion of 
either the salt solution or the heat in a rod array. Table 6.2 gives the interrelationship of the various diffusivities of interest. The cases of interest in code analysis include:

(1) LWFBR Fuel Assemblies, continuous heat addition, $\operatorname{Pr} \cong 0.005$.

(2) Experimental Rod Arrays with Sodium Flow, tracer insertion via heated rods - continuous heat addition, $\mathrm{Pr} \cong 0.005$.

(3) Experimental Rod Arrays with Water Flow, tracer insertion via heated water injection at a point or heated rods, continuous heat addition, $\operatorname{Pr} \cong 5.0$, and

(4) Experimental Rod Arrays with Water Flow, tracer insertion via salt solution injection at a point, $S c \cong 500$.

In the cases above, the fluid mixing is sinilar and is governed by the flow conditions; however, in progressing from (1) to (4), the level of energy mixing, i.e., thermal diffusivity or mass diffusivity, changes by several orders of magnitude with respect to the momentum diffusivity. The energy mixing is governed by both the flow media and the tracer type. 
Table 6.2

Diffusivity Ratios in Experimental Kod Arrays and LMFBR Fuel Assemblies ${ }^{+}$

Flow Media

(Single Phase)

Geometry

WA TER

SODIUN:

$\therefore$

$\operatorname{Pr}^{*}$

$1 / \mathrm{Le}^{*}$

$\mathrm{Sc}^{*}$

Insertion Technique

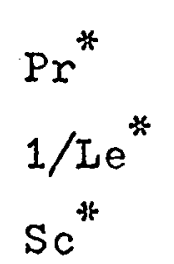

EXPERINENISAL

EXPERIVENTAL

OR

LMFBR FUEL

$\triangle$ SSEVIBLY

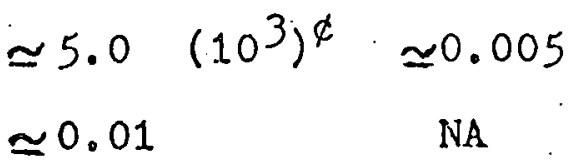

(1)$$
\simeq 500.0 \quad\left(10^{5}\right) \quad \mathrm{NA}
$$

CONTINUOUS

Heat

POINTW

Heat

Salt Solution
CONTINUOUS Heat

+ See also section 2.5

$\varnothing$ The relative significance of momentum diffusivity in transport of heat or mass, normalized to LIFBR fuel assembly conditions

(axial integration of point insertion data may give results characteristic of continuous insertion over the range of injector travel

* $P_{r}=\frac{\text { Momentum Diffusivity (Flow liedia) }}{\text { Thermal Difísivity (Feat Tracer) }}$

$$
1 / \text { Le }=\frac{\text { Thermal Diffusivity (Heat Tracer) }}{\text { Mass Diffusivity (Salt Tracer) }}
$$

$\mathrm{Sc}=\frac{\text { Momentum Diffusivity (Flow Nedja) }}{\text { Mass Diffusivity (Salt Tracer) }}$ 


\subsection{Data Analysis}

A class of interchannel coolant mixing computer codes for rod bundles are written to "follow the fluid" so that these codes, such as the COBRA series, are suited for data reduction of experiments with moving detection and stationary injertion. This is an importent distinction because with stationary injection, the tracer insertion is constant with respect to the wire-wrap anguzar orientation; however, with moving injection, the angular orientation of the wrap and the injector coincide only once each lead length.

Data analysis or comparison with results of the class of predictive codes above with data from moving tracer injection presents a geometrical dilemma. The straightforward method is quite bulky and would require running: a separate data reduction run for each injector-detector axial separation distance of interest (within one lead length). An alternative method of data analysis, which requires further consideration, would attempt to predict the integrated results. This method would be similar to a single heated rod experiment (with heat or mass addition into one subchannel), and is discussed in more detail in section 6.7 .

One other difficulty with salt insertion is the high injection-to-background concentration ratio. Conveniently, the COBRA code would use heat transport in data reduction 
calculations to model mass transport. Using the heat . transfer analogy for mass transfer calculations is quite acceptable; however, the codes, in order to perform the analogous calculations with high injection/background concentrations, would require insertion temperatures of the order $800-1000 \bar{F}$, perhaps more. This high insertion temperature would result in two problems with existing codes. First, high pressures would be forced to prevent change of phase; also in the high pressure and temperature range the specific heat of water deviates markediy from unity. A false water enthalpy table would be required. Second, adding this much heat would lead to a significant change in bundle average and local thermalphysical properties so that a false fluid property table would be necessary, also. Another possibility would be: to modify the code to accommodate mass transfer. The problems of data analysis using available computer codes are not major obstacles; however, some effort will be required to adapt a code, e.g., COBRA, to analyze salt tracer experiment data.

The COBRA II and III $(\underline{6.2}, \underline{6.3}, \underline{6.4}, \underline{6.5}, \underline{6.6})$ codes have been modified by the author ( 6.7 ) during work not related to this project, so that the high tracer injectionto-background difficulties would present little or no difficulty during data analysis of salt tracer experiments. This activity consisted basically of modification of the 
COBRA codes to do compressible (or incompressjble), single-phase coolant calculations. The coolant properties in these modified codes are calculated, and the coolant transport properties are determined using correlations.

\subsection{Integral Experiments}

An interesting possiblility arises in comparing axially traversing salt injection experiments with heated rod experiments. If one integrated the tracer detected (as the injector was axially traversed) at a stationary

- probe using a moving injector, would this be analogous to the signal received at a detector (at the same location with an equal, uniform tracer insertion into the same subchannel over the entire injector travel length, e.g., a heated rod? Further consideration of this question might lead to an extension of the capabilities of rod bundle, mixing experiments.

\subsection{Flow Visualization}

Injecting dye type tracers, such as methyl violet (suggested by 1 . Kirchner, MIT), can provide a visual record of mixing phenomenon occurring in the bundle. Flow visualization experiments literally illuminate salt tracer type experiments because the molecular diffusivity of dye tracers is quite low compared to the mornentum 
diffusivity, i.e., dye tracers have high Schmiat numbers as do salt tracers. Because flow visualization offers such a rapid and luicid view of the mixing phenomenon, it is recommended that such experiments be included as part of peripheral subchannel investigations (where transparent channels are used). A primary difficulty with flow visualization is quantifying the results with sufficient accuracy to provide meaningful information. The method of presenting the results of flow visualization experiments used by Lorenz, et al. (5.2) overcomes this difficulty, in part, by outlining the boundaries of the tracer dispersion.

\subsection{Recommendations for Future Experiment Design and} operation

This section presents recommendations regarding the design and operation of coolant mixing experiments based on experiences with the MITF described in Chapter 4. The discussion is oriented towards salt tracer, coolant mixing experimentos.

From the results presented, one finds that in order to observe the complete behavior of coolant mixing in wire-wrap spaced rod arrays, detailed data is required in the axial direction ( 5 points/inch or more). This data is most conveniently obtained using a moving injection device holding the detectors at a fixed position.

The injector should be designed to inject the 
tracer solution stream in a radial direction toward the centroid of the injection subchannel and in an axial direction about $15^{\circ}$ to $20^{\circ}$ from the injection rod centerline. A hypodermic tube, soldered in-place and ground flush with the moving inner rod, is recommended for the injection device geometry. The salt tracer insertion rate should be based on an injection velocity equal to the average velocity of the injection subchannel (the EAVC - Equal Average Velocity Criterion) and on a mass insertion rate which gives instrument responses of the appropriate range, i.e., 0\% to $50 \%$ of the applied bridge voltage; mass insertions of 0.5 to 1.0 grams/ minute are typical of the latter requirement. The injection system must be designed to supply an accurately measured and constant flow to the injector rod; with moving injection, variation of the back-pressure in the experimental rod array must be considered.

The recommendations for the nechanical design of the injection rod have been discussed in section 4.9. The primary requirement of injector design, construction, and handling is the avoidance of error in the angular posito ioning of the needle injector; to accomplish this, the inner tuive must be kept perfectly straight, the sliding: angular positioning device must be wear resistant, the inner rod must rnove freely, and the injection rod must be accurately constructed. 
The detection system should have a conductivity cell detector positioned near the bundle outlet in each subchannel of interest. The probes should be positioned such that a minimun electrode interference occurs due to the proximity of the rod array. The electrodes should be made of platinum inetal and be platinized prior to being placed in-service. A cell constant of about 3.0 should give Wheatstone bridge balance points which will give accurate unbalanced theatstone bridge voltage measurements, i.e., approximately 10,000 0hms. The electordes, typically $3 / 32$ inch long, should be positioned just inside the subchannel near the rod array outlet. Most importantly, a calibration curve should be taken for each probe only after it has been positioned in the rod array. If repositioning is required or if the water temperature changes more than $5 \mathrm{~F}$, a new calibration curve should be generated for each probe. Care must be taken to prevent electric current leakages between the Iead wires connecting the probe electrodes to the instruments; this is expecially troublesome in the submerged part of the connection. Also, the probes must be as far as possible from any materials of the rod. arrays; a $1 / 16$ to $1 / 32$ inch clearance should give minimal electrode interference. The cells cannot function if in contact with any extraneous materials. See section 4.10 for other details on the conductivity probe design. 
The experimenter is urged to become familiar with Appendix 5, Appendix 2 and Chapter 3 before attempting conductance measurements. 


\section{Chapter 7}

\section{CONCLUSIONS}

Understanding interchannel coolant and energy mixing behavior in wire-wrap spaced geometries is an important requirement in the thermal-hydraulic and thermal-mechanical design of fuel assemblies for $L M F B R^{\circ} s$. This report discusses the design of tracer injection experiments, particularly instrumentation, to examine the coolant mixing behavior of wire-wrapped rod arrays. Also reported are a series of experiments run to determine the influence of various experimental operating parameters on coolant mixing results. Results of coolant mixing experiments with turbulent and laminar flow are presented for a 25-pin, rhombus shaped, wire-wrap spaced rod bundle with geometrical parameters typical of a INFBR, i.e., a rod diameter $=0.25$ inch, a rod pitchto-diameter ratio -1.25 and a wire-wrap lead $=12.0$ inches.

\subsection{Instrumentation Design}

The primary concerns in the design of the tracer injection, coolant mixing experiments are injection system design, detection system design and tracer selection. The primary concerns of injection system design are location, mobility and insertion duct geometry. The primary concerns of detection system. 
design are instrument type, set by the tracer type, and instrument location with respect to the rod array. Tracer selection was discussed in detail in the report with salt solutions and heat tracers considered the 1 prefered types.

For this work, $\geqslant$ concentric tube, injecton rod design; movable over the upper thirty inches ( $2 \frac{1}{2}$ lead

. lengths) of the rod bundle, was used with a hypodermic needle injector mounted about $20^{\circ}$ from the tube centerline. Results using a needle injector were compared with a transverse hole injector and found to have less main flow perturbations. Electrolytic conductance cells were used as detection instrurnents and were mounted on externally supported probes and positioned near the rod array outlet, inside the upper one-quarter inch of the rod array. A salt ( $\mathrm{NaCl}$ ) solution was used for this work and was considered better than heat as a tracer because it offered a higher tracer concentration-tobackround concontation ratio, because the non-linear nature of electrolytic conductance versus solution strength is better suited for coolant mixing experiments, and because low mass diffusivity is prefered for coolant mixing experiments.

7.2 The Influence of Onerating Parameters on Experimental Results

Experiments to determine the influence of various 
operating parameters on coolant inixing results showed that the results were independent of salt insertion rate, i.e., either injection solution concentration or injection velocity. With injection velocity changes more main flow perturbations were noted due to the injection flow, however. A comparative experiment using sodiun nitrate gave results similar to those for $\mathrm{NaCl}$ indicating no influence of salt type. The major influence of Reynolds number was a decrease in detection noise with increases in main flow. The most significant effect on experimental results was due to the mechanical behavior of the moving injection device. Careful design, handling and use of the injector rod vould eliminate all such mechanical difficulites.

\subsection{Interchannel Coolant Mixing Results - Interior Subchannel. Injection}

The average injection velocity used for the work was equal to the average velocity of the subchannel into which injection occurred. A tracer insertion rate of about 1.0 grams/ninute lead to detection in the optimum response range of the AC neasuring equipment. A tracer solution strength of 2.0 grams-NaCl/libm-water gave optimum detection conditions with injection flow set by the equal average velocity criterion.

Using the salt solution tracer technique, laminar 
and turbulent flow, coolant mixing experiments were done with injection into an interior and a peripheral subchannel. The axially-detailed mixing results were taken over thirty inches of injector travel. From the inierior subchannel injection data, it may be concluded that flow sweeping has a dominating effect on the trocer dispersion with the injector within about one foot of the detector. st greater injector-detector separations, the influence of natural turbulent interchange becomes increasingly significant in deternining the dipersion of the tracer. Furthermore, the axial behavior of interchannel coolant mixing can not be properly assessed using experimental data with axial separation greater than one inch (or less).

The tracer dispersion pattern was unaltered by the change from turbulent to laminar flow; however, the magnitude of the amount of tracer mixed or dispersed with respect to the amount present in the injection subchannel was markedly increased. This increase was apparently due to the absence of eddy diffusivity (natural turbulence) and due to an increase in the wirewrap drag coefficient (the sweep flow driving force). The turbulent noise detected considerably increased in changing from turbulent to laminar flow; apparently due to vortex shedding from the wire-wrap spacers and, 
again, due to the absence of natural turbulent interchange. A low-flow, injection system instability may have been the cause, also.

\subsection{Interchannel Coolant Mjuing Results - Peripheral} Injection

The differences between laminar and turbulent flow with peripheral subchannel injection were similar to those noted for interior subchannel injection; however, with pexipheral subchannel injection, the tracer dispersion was dominated by flow sweep over the entire thirty inches of injector travel. A swirl flow around the bundle periphery was clearly present and vas determined to be at an average angle of $4.9^{\circ} \pm 1.4^{\circ}$ from the bundle axis using salt tracer data. Also, the swirl flow did not mix with the flow in adjacent interior subchannels but remained near the flow channel walls.

\subsection{Instrumentation Perfoxmance}

The criterion for assessing the performance of the injection and detection system design used was that the mass of salt tracer detected should equal the amount of salt injected. Mlass balance calculations indicated stripping, the failure to meet mass balance criteria due to inhomoreneous solution concentrations, occurred somewhat in the six inches of injector travel closest to the detector; this was an inherent design limitation. An unexpected and significant "loss of mass" occurred in the region 
with eighteen to thirty inches of injector-detector separation. This error is due to either the use of inadequate calibration curves, poor flow regulation or (and) a possible leak in the injection system. Nevertheless, changes in design and procedure have been discussed which would reduce or eliminate this error.

. $\quad 7.6$ Flow Visualization Results

Flow visualization experiments done with peripheral subchannel injection qualitatively verified results of operating parameter influences discussed earlier. The average swirl flow angle was visually determined to be $5.5^{\circ} \pm 1.0^{\circ}$ from the bundle axis. 


\section{REFERENCES}

1.1 Rogers, J.T. and N.E. Todreas, "Coolant Interchannel Mixing in Reactor Fuel, Rod Bundles, SinglePhase Coviants," Heat Transfer in Rod Pundles (N.Y., ASinE, 1968), pp. $1-56$.

1.2 Brodkey, R.S. "Fluid Motion and Mixing," Chapter 2. Mixing Theory and Practice, Volume 1, Ed. by V.iv. UhI and J.B. Gray (N.I.. Academic fress, 1966), pp. 7 - 110 .

1,3 Todreas, N.E. and J.A. Turi, "Interchannel Mixing in Wire-Wrapped Iiquid Metal Fast Breeder Fuel Assemblies," Nuclear Technology, V13, N1, January 1972, pp. $36-52$.

1.4 Markdczy。G. "Core Heat Transfer and Fluid Flow in the GCFR," Paper presented at the 17 th ANS Annual Meeting, Boston, June 1971.

21 Personal Communications with $T_{0}$ Ginsberg, Argonne National Laboratory, August 1971.

2.2 Iorenz, J.J. and T. Ginsberg, "Results and AnaIysis of 7-pin Wire Wrap Mixing Tests" ANS

Transactions, V15, N2. (Washington, ANS, November 1972). pp. 867-868.

2.3 Iorenz, J.J., "survey of Current Thermal Hydraulic Studies Applicable to I:nFBR Fuel Assembly Design," USAEC Report, ANI-CT-73-05, March 1973.

24 Lorenz, J.J., "Liquid Wietal Heat Transfer in Pin Bundle," USAEC Report, ANI-RDP-14, February 1973, pp. $3.2-3.3$.

2.5 van Erp, J.B. and T.C. Chawla, "Experimental Evaluation of Subchannel Coolant Crossflow in IMFBR Subassemblies with Wire-Wrap Spacers," ANS Transactions. $\mathrm{V} 15$, N2 (Washington, ANS, November 1972), pp. $856-85 \%$.

2.6 van Erp, J.B., "Out-of-Pile Studies, Fuel Element Failure Propigation," Reactor Development Progress Report, USAEC Report, ANL-RDD-9, September 1972, pp. $9.14-9.15$. 
2.7 Graves, A.W., "Pre-Test Predictions of the ANL 91Pin Hot Vater Injection Mixing Experiment," TI-707240-016. Atomics International, March 1973.

2.8 Marian, V.R. and D.P. Hines, "Transfer of Coolant Between Adjacent Subchannels in Wire-Wrap Spacer and Grid Spacer Bundles," ANS Transactions, V14, N2 (Boston, ANS, June 1971) pp. 807-808.

2.9 Collingham, R.E., W.I. Thorne and J.D. McCormack, "217-Pin Wire-"'rapped Bundle Coolant Mixing Test." USAEC Report, HEDL-TME-71-146, 1971.

2.10 Personal Communications with A.S. Hanson, MIT, Cambridge, Mlass., April 1973.

2.11. Skok, J., "Mixing of the Fluid Due to Helicoidal Wires of Fuel Pins in a Triangular Array." DRP/ SETITR/CAD, $r$. 605, May 1970.

2.12 Baumann, W. . H. Hoffman and K. Rust, "Selection of Spacers for the Fuel Assemblies of FBR," Karlsruhe ANS Meeting, 1970.

2.13 Okamato, Y., M. Hishida and N. Alsino, "Hydraulic Performance of Rod Bundles of Fast Reactor Fuels Pressure Drop, Vibration and Mixing Coefficient," IAEA/SM-130/5. Monaco, friarch 1970.

2.14 Okamato, Y. N. Akino, E. Emori and M. Tarida, "Hydraulic Tests of FBR Fuel Sub-Assemblies (JEFR), Part 2 Final Report," PNC-SJ-250-71-37, JAPFNR-24, Japan Atomic Energy Research Institute, September 1971.

2.15 Davidson, C.R., "AI FBR Single Channel Developmental Test Results," TR-097-210-001, Atomics International, 1972.

2.16 Bolz, R.E. and G.I. Muve, editors, Handbook of Tables for Apnlied Engineering Science (cleveland. Chemical Rubber Co., 1970), pp. 452-453.

2.171967 ASNE Steam rables (New York, ASHE, 1967).

2.18 Iand, N.S., "A Compilation of Nondimensional Numbers," NASA-SP-274 (Washineton; NASA 1972).

3.1 Bender, R.J. " "Why Water Desalting Will Expand," Power, V113, N8, August 1969. pp. 171-178. 
3.2 Glasstone, S. Introduction to Electrochemistry (New York, van Nostrand; 1942).

3.3 Harned, H.S. and B.B. Owen, The Physical Chemistry of Electrolvtic Solutions (N.Y., Reinhold, 1968).

3.4 Malmstadt, H.V., C.G. Enke and E.C. Toren, Electronics for Scientists (N.Y., Benjamin, 1963), pp. 273283.

3.5. Robinson, R.A. and R.H. Stokes, "The lieasurement of Conductivities and Transport Numbers," Chapter 5. Electrolytic Solutions (Iondon, Butterworths, 1959), pp. $87-102$.

3.6 Kohlrausch, F., Wied. Anno, v60, 1897, p. 315.

3.7 Jones, G. and D.M. Bollinger, "The measurement of the Conductance of Electrolytes, VII. On Platinization," Journal of the American Chemical Society, $\mathrm{V} 57, \mathrm{~N} 2,1935, \mathrm{pp}, 280-284$.

3.8 "4959 Conductivity Bxidge Directions:" Manual 177335 - Issue 1。 Leeds and Northrup Company.

4.1 Turi, J.A., "An Investigation of Interchannel Mixing in Wire Mrapped Iiquid Hetal Fast Breeder Reactor Fuel Assembilies," W.S. Thesis, Nuclear Engineering Department, NiI'T, Cambridge, Sept. 1970.

4.2 Eaton, T.E., "Spring 1972, Mixing Experiment Data File," Not Communicated.

5.1 Eaton, T.E. "Summer 1973, Mixing Experiment Data File," Not Communicated.

5.2 Lorenz, J.J. D.R. Pedersen and R.D. Pierce, "Pexipheral-Flow Visualization Studies in a 91 Element Bunale," USAEC Report, ANI/KAS 73-17, June 1973.

5.3 Khan, E.U., Personal Communication, August 1973.

6.1 Markòczy, G.. Personal Communication, June 1973.

6.2 Rowe, D.S, and C.W. Angle, "Crossflow Mixing Between Parallel Flov Channels During Boiling," USAEC Report, BNYL-371, "Part Is COBRA - Computer Program for Coolant Boiling in Rod Arrays, "March 
6.2 1967. "Part II, Heasurements of Flow and Enthalpy cont. in Two Parallel Channels," Decernber 1967, "Part III Effect of Spacers on lixing Between Two Channels," January 1969.

6.3 Rowe, D.5. "CCBRA II - A Digital Computer Program for Themal Hydraulic Sub-Channel Analysis of Rod Bundle Nuclear Fuel Elements," USAEC Report, BNWL-1229, February 1970.

6.4 Wheeler, C.I., G.C. Main and D.C. Kolesan, "COBRA II-A: A Program for Thermal Hydraulic Analysis of Very Large Bundles of Fuel Pins," USAEC Report, BNWI-1422, August 1970.

6.5 Rowe, D.S., "COBRA III - A Digital Conputér Program for Steady State and Transient Thermal-Hydraulic Analysis of Rod Bundle Nuclear Fuel Elements, USAEC Report, BNIL-B-82.

6.6 Rove, D.S. "COBRA-III C: A Digita.I Computer Program for Steady State and Transient Thermal-Fydraulic Analysis of Rod Eundle Nuclear Fuel Elements," USAEC Report, BNUL-1695, Harch 1973.

6.7 Project Staff:" "Gas-Cooled Fast Breeder Reactor, Quarterly Progress Report for the Period August 1; 1972 through October 31, 1972," USAEC Report. GuIf-GA-A12421.

A1.1 Sangster, W.A. "Calculation of Rod Bundle Pressure Ioss," ASPE Paper 68-W/ht-35 (N.Y., ASPE,1968)

A7.1 Tobey, G., J. Graeme, and I. Huelsman, operational Amplifiers - Design and Application (N.Y., MifGrawHill, 1971)。 
NOMENCIA TURE

A - Conductance Cell Electrode Area, $\mathrm{cm}^{2}$.

$A_{i}$ - Flow Ares of Sibchannel Type is $i^{2}$.

C - Salt Solution Concentration

$C_{D}$ - Mass Diffusion Coefficient, $\mathrm{ft} \mathrm{t}^{2} / \mathrm{hr}$.

$c_{i}$ - Salt Solution Injection Concentration, grams-NaCl/

$c_{p}$ - Specific Heat at Constant Pressure; BTU/1bm.

$\mathrm{C}_{\mathrm{S}}$ - Conductivity Cell Electrode Surface Capacitance.

$\mathrm{C}_{\mathrm{v}}$ - Variable Wheatstone Bridge Capacitance.

D. - Fuel Rod Diameter, in.

De $_{i}$ - Equivalont Hydraulic Diameter of Flow Area Type i.

$\mathrm{d}_{\mathrm{w}}$ - Wire-Wrap Diameter, in.

$f \quad$ - Friction Factor.

$f \quad-$ Vortex Shediding Frequency $\sec ^{-1}$.

G - Inalog Circuit Gain

i - Subchannel Identification Subscript: $1=$ Interior, $2=$ Peripheral, $3=120^{\circ}$ Corner, $4=60^{\circ}$ Correr.

ID - Tube Inside Diameter, in.

k - Thermal Conductivity, BiU/hr-ft-F.

$K_{c}$ - Conductivity Cell Constant, Ohm-cm.

$\mathrm{K}_{\mathrm{cr}}$ - Reference Conductivity Cell Constant, Ohm-cm.

$\mathrm{K}_{\mathrm{u}}$ - Unknown Conductivity Cell Constant, Ohm-cm.

$\mathrm{k}_{\mathrm{s}}$ - Salt Solution Specific Conauctance, mho-cm.

$i_{\mathrm{e}}$ - Conductance Cell Electrode Length, cm.

Le - Lewis Number. 
MODE- Time Constant on Analog Computer, sec.

OD - Outside Tube or Rod Diameter, in.

P. - Rod-to-Rod Pitch, in.

P - Potentiometer Voltage, Volts (Apperidix ?)

$\mathrm{Pe}_{\mathrm{h}}$ - Peclet Number, Heat Transfer.

$\mathrm{Pe}_{\mathrm{m}}$ - Peclet Number, Mass Transfer.

Pr - PrandtI Number.

Q - Total Bundle Flow Rate, $1 \mathrm{bm} / \mathrm{min}$ or GPM.

R - Electrical Resistance, Ohms.

$\mathrm{R}_{\mathrm{b}}$ - Fixed Wheatstone Bridge Resistance, Ohms.

Re- - Reynolds Number.

$R_{m}$ - Measured Electrical Resistance, Ohms。

$R_{m r}$ - Resistance Measured with Reference Cell, Ohms.

$R_{m u}$ - Resistance Measured with Cell having Unknown

$R_{S}$ - Conductivity Cell Electrode Surface Resistance.

$R_{u}$ - Unknown Resistance, Ohms.

$r_{s}$ - Salt Solution Specifj.c Resistance, Ohms-cm.

$R_{v}$ - Variable Wheatstone Bridge Resistance, Ohms.

s - Laplace Transform Variable.

Sc - Schmidt Number.

T. - Temperature, $\mathrm{F}$ or $\mathrm{C}$.

V - Fluid Velocity, ft/sec.

$\mathrm{V}_{\mathrm{a}}$ - Applied Wheatstone Bridge Voltage, Volts AC-RMIS.

$\mathrm{V}_{\mathrm{m}}$ - Measured Wheatstone Bridge Voltage, Volts AC-RMS.

$w_{b}$ - Total Bundle (Main) Flow Rate, lbm/ min.

$w_{i}$ - Injection Flow Rate, Ibm/min or cc/min. 
$w_{i}$ - Flow in Subchannel Type $i, 1 \mathrm{bm} / \mathrm{min}$ (Appendix 1).

$W_{S}$ - Electrode Surface, Warburg Impedance Effect.

X - Axial Injeztor Mravel, inches.

$x_{i}$ - Flow Split Fraction to Subchannel of Type $\mathfrak{i}$ (Fraction of Wain Flow), Ibm/min.

$x$ - Analog Computcr Input Signal

y - Analog Computer Output Signal

$\Delta P$ - Pressure Loss, psig.

p - Fluid Density, $1 \mathrm{bm} / \mathrm{ft}^{3}$.

- $\eta_{i}$ - Number of Subchannels of Type $i$.

$\mu \quad-F I u i d$ viscosity, $1 \mathrm{bm} / \mathrm{hr}-\mathrm{ft}$.

$\tau$ - Time Constant, sec.

$\omega$. Frequency, $\sec ^{-1}$. 
Append1x 1

HYDRAULIC ANALYSIS OF THE EXPERIMENTAL FACILITY

This appendix presents the results of flow calculations for the 25-pin rhombus array of $1 / 4$ inch rods used for experiments reported in the text. This rod array was assembled into a triangular lattice configuration with a rod pitch-to-diameter ratio of 1.25 such that the cross section geometry was a parallelogram with 5 rods on each side, see Figure Al.1. The unit flow areas, or subchannels, have been indicated in the figure. Subchannel type 1 refers to an interior flow passage, type 2 to a wall or peripheral subchannel, type 3 to a $120^{\circ}$ corner subchannel, and type 4 to a $60^{\circ}$ corner subchannel. The analysis reported here is significant because it is used to determine the appropriate injection flow rate for the salt solution tracer, also the results are used to establish the flow regime, 1.e., laminar, transition or turbulent, within the experimental array.

Using the method described by Sangster (A1.1), the fraction of the total flow passing through each subchannel is calculated assuming that the flow is fully turbulent and that there are no transverse pressure gradients. The turbulent friction factor is calculated 


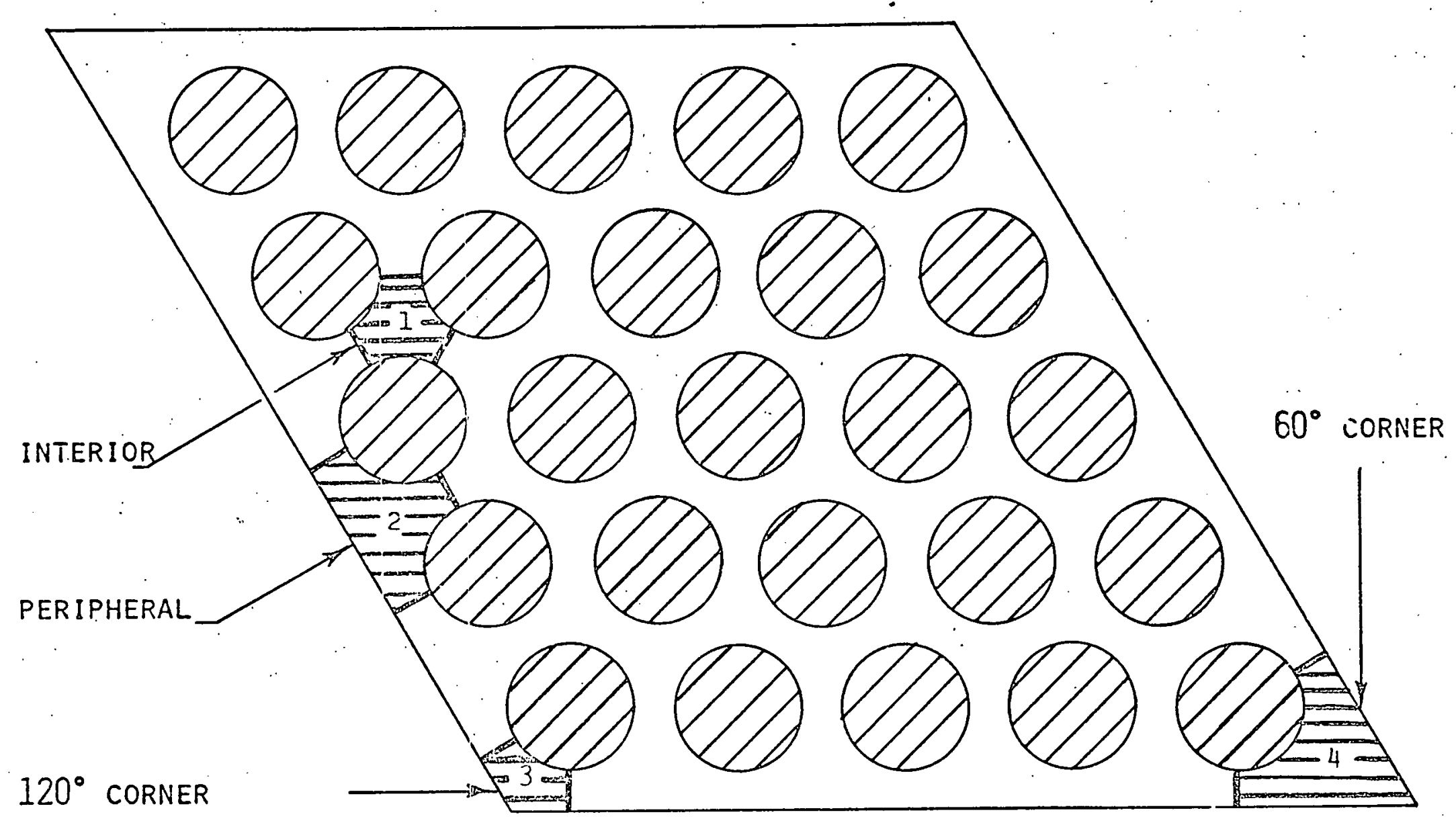

FIGURE AI.1 - CROSS SECTION OF EXPERIMENTAL ROD BUNDLE SHOWING THE VARIOUS SUBCHANNEL TYPES 
using the Blasius smooth tube correlation:

$$
f=0.316 /\left(R e^{0.25}\right)
$$

For this work, the only significance of Eq. Al.l is the exponential dependence of the Reynolds Number. The calculations procede by determining the fraction $w_{1}$ of the total rod bundle flow $w_{b}$ passing through a subchannel type 1:

$$
\mathrm{w}_{1}=\mathrm{x}_{1} \mathrm{w}_{\mathrm{b}}
$$

$x_{1}$ is the flow split factor and is determined by the geometry of the rod array and by the Reynolds number dependence of the friction factor:

$$
\begin{aligned}
x=1 / & {\left[\eta_{1}+\eta_{2}\left(\frac{A_{2}}{A_{1}}\right)\left(\frac{D_{e_{2}}}{D_{e_{1}}}\right)^{0.715}+n_{3}\left(\frac{A_{3}}{A_{1}}\right)\left(\begin{array}{l}
D_{e_{3}} \\
D_{e_{1}}
\end{array}\right)^{0.715}\right.} \\
& \left.+\eta_{4}\left(\frac{A_{4}}{A_{1}}\right)\left(\frac{D_{e_{4}}}{D_{e_{1}}}\right)^{0.715}\right]
\end{aligned}
$$

The flow in other subchannel types $w_{i}$ is related to $w_{j}$ by

$$
\frac{w_{1}}{w_{1}}=\left(\frac{A_{i}}{A_{1}}\right)\left(\frac{D_{e_{i}}}{\overline{D_{e_{1}}}}\right)^{0.715}
$$


The results of the rod bunde geometry calculations and of the flow split analysis are given in Table Al.l. The effect of the wire-wrap spacers on the geometry has been averaged into the calculations. Table Al.l gives the fraction of the total flow in the rod bundle $x$ passing through a typical subchaninel of the type indicated; also, the local velocity and Reynolds number for these coolant passages are given as a function of the main flow $w_{b}$. The variation with main flow Reynolds number and flow velocity in the various flow areas. is shown in Figure Al.2 and Al.3, respectively. 
TABLE AI. 1

Hydraulic Calculations for the Experimental Facility*

\begin{tabular}{|c|c|c|c|c|c|}
\hline Item/Area & $\begin{array}{l}\text { Bundle } \\
\text { Average }\end{array}$ & Type 1 & Type & Type 3 & Type 4 \\
\hline Area & 1.149 & 0.0162 & 0.0325 & 0.0116 & 0.0435 \\
\hline Perimeter & 31.28 & 0.491 & 0.803 & 0.380 & 0.977 \\
\hline$d_{e}$ & 0.1470 & 0.132 & 0.162 & 0.122 & 0.178 \\
\hline$n$ & . & 32 & 16 & 2 & 2 \\
\hline$\cdot$ & 1.0 & 0.0130 & 0.0301 & 0.00878 & 0.0431 \\
\hline $\mathrm{v} / \mathrm{w}_{\mathrm{b}}$ & 0.0337 & 0.0310 & 0.0358 & 0.0293 & 0.0384 \\
\hline $\mathrm{Re} / \mathrm{W}_{\mathrm{b}}$ & 32.3 & 26.7 & 37.9 & 23.4 & 44.6 \\
\hline$W_{b}-C R I T$ & 70.1 & 86.1 & 60.7 & 98.3 & 51.6 \\
\hline
\end{tabular}

* 25 rod Thombus array, rod diameter $=0.250 "$ wrap diameter $=0.063^{\prime \prime}$

Area $\Leftrightarrow$ in 2

perimeter $(=)$ in

Hydraulic diameter $(=)$ in

$\mathrm{W}_{\mathrm{b}}\left(\Rightarrow 1 \mathrm{bm} / \mathrm{hr} \quad \mathrm{W}_{\mathrm{b}}-\mathrm{CRIT}_{\mathrm{R}}(\Rightarrow) 1 \mathrm{bm} / \mathrm{hr}\right.$, flow at which Re $=2300$ $\mathrm{V}(=)$ ft/sec
Average effect of wire-wrap included in geometric calculations Specific flow conditions for water at $60^{\circ} \mathrm{F}$ and Turbulent Flow 




FIGURE Al.2 - REYNOLDS NUMBER VS. FLOW RATE FOR VARIOUS FLOW AREAS IN THE EXPERIMENTAL TEST SECTION 


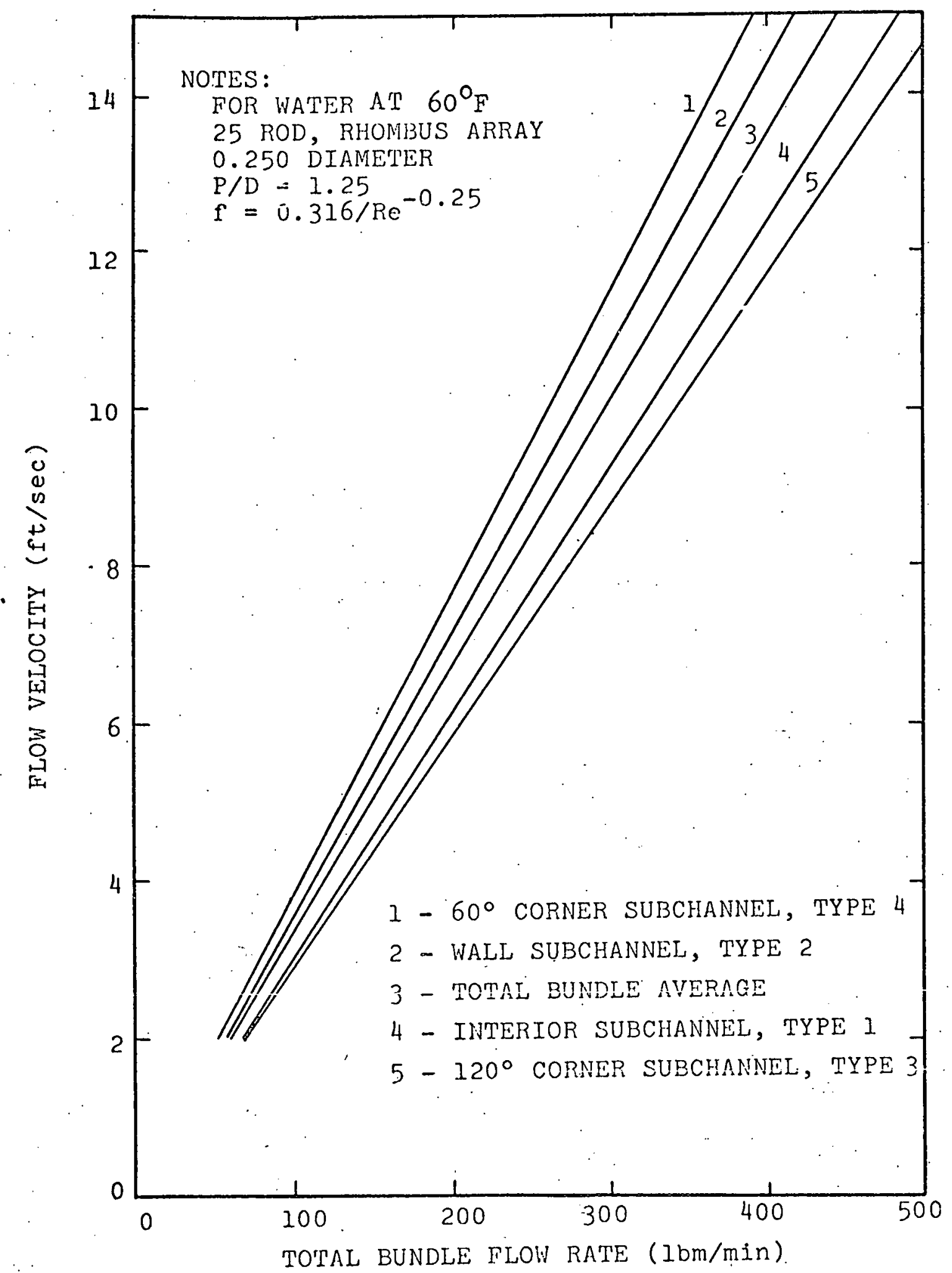

FIGURE AI.3 -FIOW VELOCITY VS. TOTAL FLOW RATE FOR VARIOUS FLOW AREAS IN THE EXPERIMENTAL TEST SECTION 


\section{Appendix 2}

CONDUCTANCE MEASUREMENT METHODS AND EQUIPMENTT

The conductivity cell was discussed in detail in Chapter 3. It should be remembered that the cell is used to measure the specific electrical resistivity of a solution so as to determine the concentration of solute within the solution. This chapter shall discuss the methods and equipment used in the project for measuring the specific conductance of solutions. Briefly, two methods are discussed - (I) the balanced wheatstone bridge method and (2) the unbalanced Wheatstone bridge method. The use of a fast data acquisition (magnetic tape recording) system is an invaluable tool for expediting the experiments; fast data acquisition requires the use of an unbalanced Wheatstone bridge.

The common method for measuring solution specific conductance is the balanced weatstone bridge. Figure A2:I shows a schematic diagram of wheatstone bridge conductance measurement equipment. A variable frequency, variable voltage osclilator (power supply) was used to apply a voltage to bridge points 1 and 3 . The unknown resistance $R_{u}$ of the conductivity cell is connected across leg 1-2; when the variable resistance $R_{V}$ 


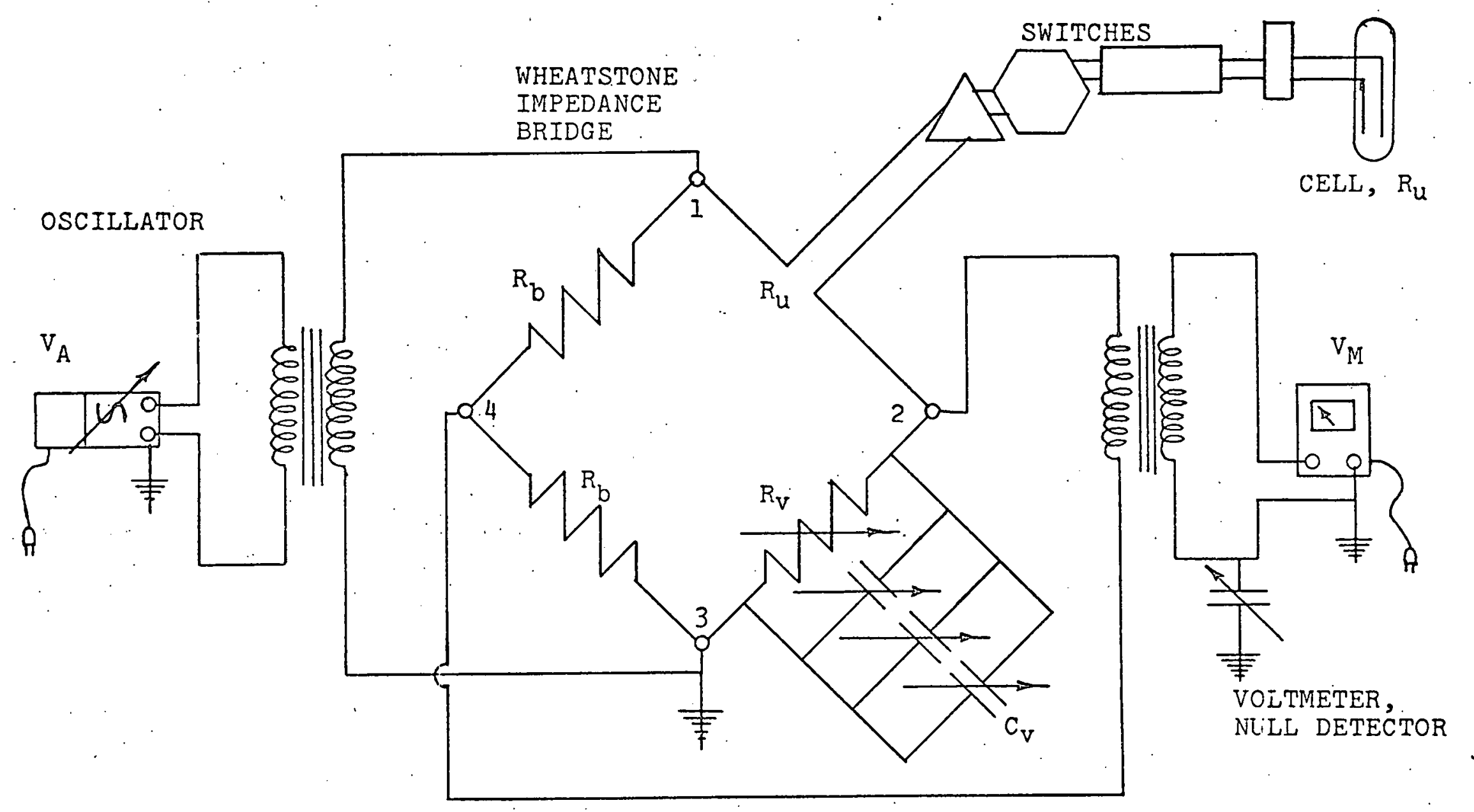

FIGURE A2.I - SCHEMATIC OF WHEATSTONE BRIDGE CONDUCTANCE MEASUREMENT EQUIPMENT 
in bridge leg $2-3$ is adjusted to equal $R_{u}$, the voltage between points 2 and 4 of the bridge goes to zero. With the voltage nulled, the bridge is referred to as balanced. Bridge legs $1-4$ and $3-4$ are constant resistances $R_{b}$ built into the bridge. The null detector is a standard alternating current (root-mean squared) AC-RMS voltmeter. Both the oscillator and the voltmeter are connected to the Wheatstone bridge via bridge isolation transformers so as to eliminate stray DC currents from the bridge circuit. The capacitors in parallel with the variable resistance in bridge leg 2-3 are included in the circuit to balance the reactive (inductive and capacitive) effects in the conductivity cell circuit. These capacitances were seldom required, and their major value was in accentuating the null point during the iterative bridge balancing procedure. This use of these capacttors did not alter the resistance measured; however, the necessity of using large capacitance In parallel with the variable bridge resistor is an indication of cell problems, e.g., loss of polarization or cell electrical interference. The capacitor on the voltmeter null detector reduces needle flutter due to turbulent noise (from inhomogeneous solutions) within the detector. Normally it is recommended that this capacitor not be used because turbulent noise is meaningful 
information about the experiment. The oscillator should be operated normally at 1000 Hertz and with a specified output voltage. For this work the oscillator output voltage was 1.5 Volts AC-Rris which gave a bridge voliage variation of $0.0-0.4$ Volts AC-RriS. As mentioned in Chapter 3, resistance measurements of the same solution at three frequencies, say 100 (200 gives a sharper null), 1000, and 10,000 Hertz gives a measure of polarization errors. The unbalanced wheatstone bridge technique reeps the variable resistance $R_{\mathrm{V}}$ constant and correlates the electrolytic solution concentration directly to the measured voltage on the null detector. Figure A2.2 shows a typical calibration curve of unbalanced bridge voltage (AC-RMS) versus salt concentration. As would be expected, the unbalanced voltage is sensitive to small salt concentrations and insensitive to changes at higher concentrations. This is an ideal behavior for mixing experiments; however, the unbalanced voltage should be kept kelow about 0.3 volts AC-Rris to avoid large errors in the deduced concentrations due to the nonlinearity in the calibration curve, cf. Figure A2.2. This error growth restriction may be accomplished by regulating the mass insertion rate of the tracer salt. Figure A2.3 shows'a plot of unbalanced Wheatstone bridge voltage versus balanced bridge resistance, 
where the resistance used for the unbalanced voltage measurement was that of the channel water (solverit). The relationship between unbalanced bridge voltage and balanced bridge resistance (directly proportional to solution specific resistance) is nearly linear which might have been predicted. Given the general behavior of the unbalanced Wheatstone bridge, as indicated by Figures A2.2 and A2.3, this method is well suited to salt solution concentration measurements. The unbalanced bridge voltage responds similarly to the balanced Wheatstone bridge resistance. The unbalanced Wheatstone bridge is well suited for fast data acquisition. For this work, the data was actually taken in a continuous manner. The voltmeter signal was amplified and output to a $x-y$ plotter, see Figure A2.4. This continuous analog signal may be recorded, say on a high quality, magnetic FM (frequency modulated) tape recorder and then converted into punched computer cards for use with the MITMIX code (Appendix 3 ).

Some form of continuous data recording is vital to the experiments. Preferably the data should ultimately appear as punched computer cards. As mentioned above, the data. may be recorded on a tape recorder; it also could be recorded on a paper tape punch or feed directly into a small computer. Any of these methods may be used to generate discontinuous 


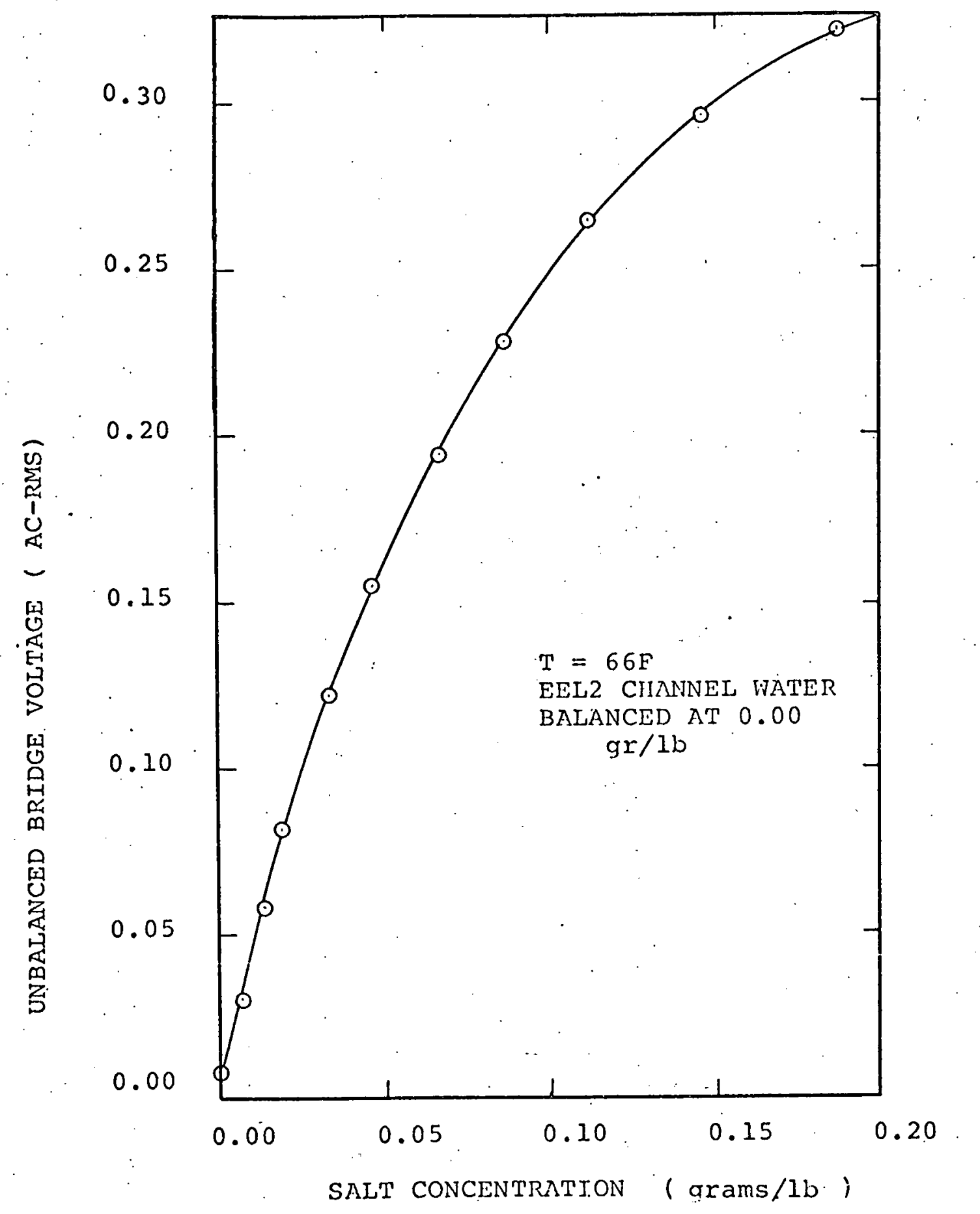

FIGURE A2.2 - MEASURED VOLTAGE VERSUS SOLUTION CONCENTRATION USING UNBALANCED WHEATSTONE BRIDGE METHODS 


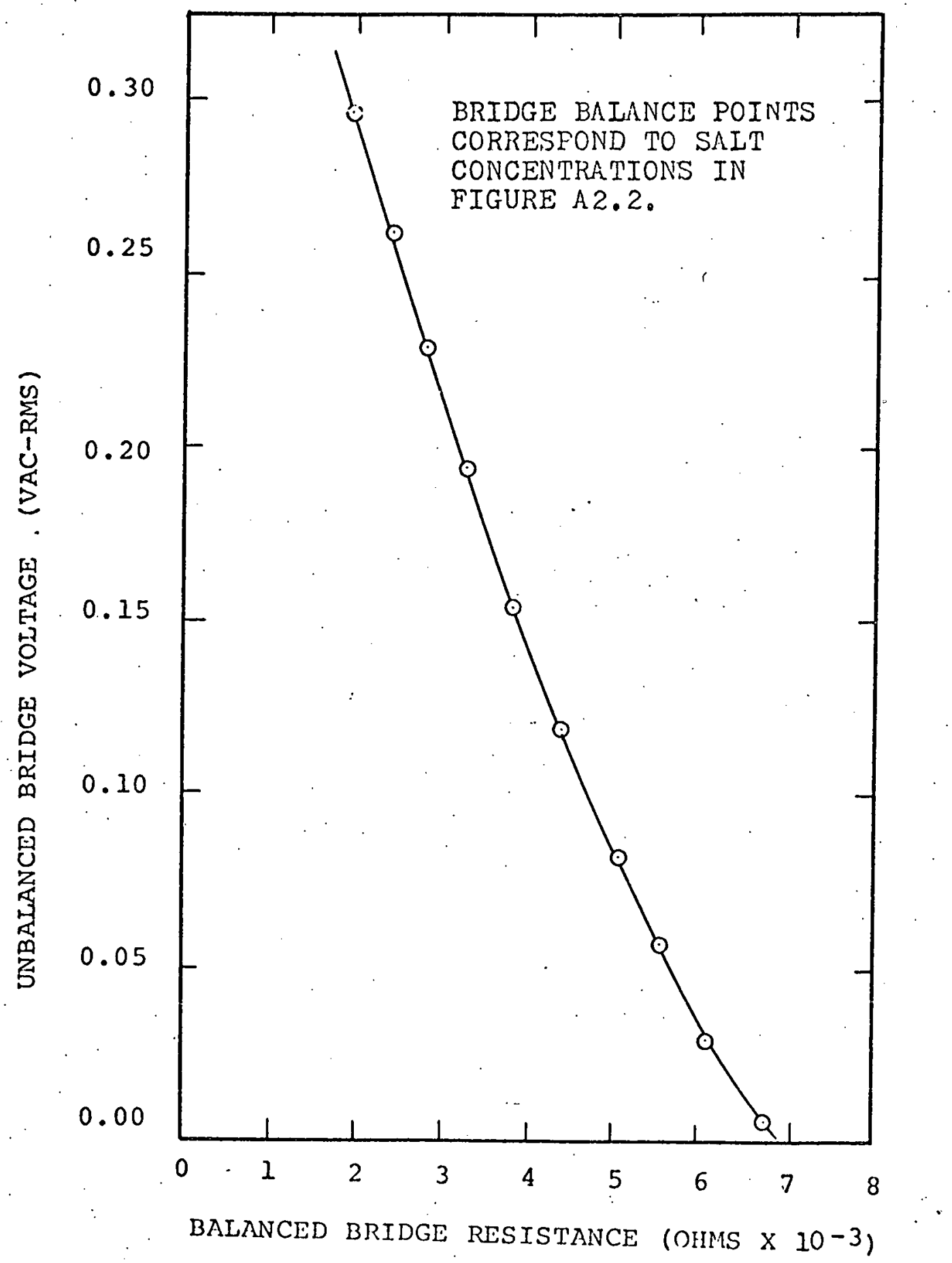
FIGURE A2.3 -MEASURED UNBALANCED BRIDGE VOLTAGE VERSUS
BALANCED BRIDGE RESISTANCE 


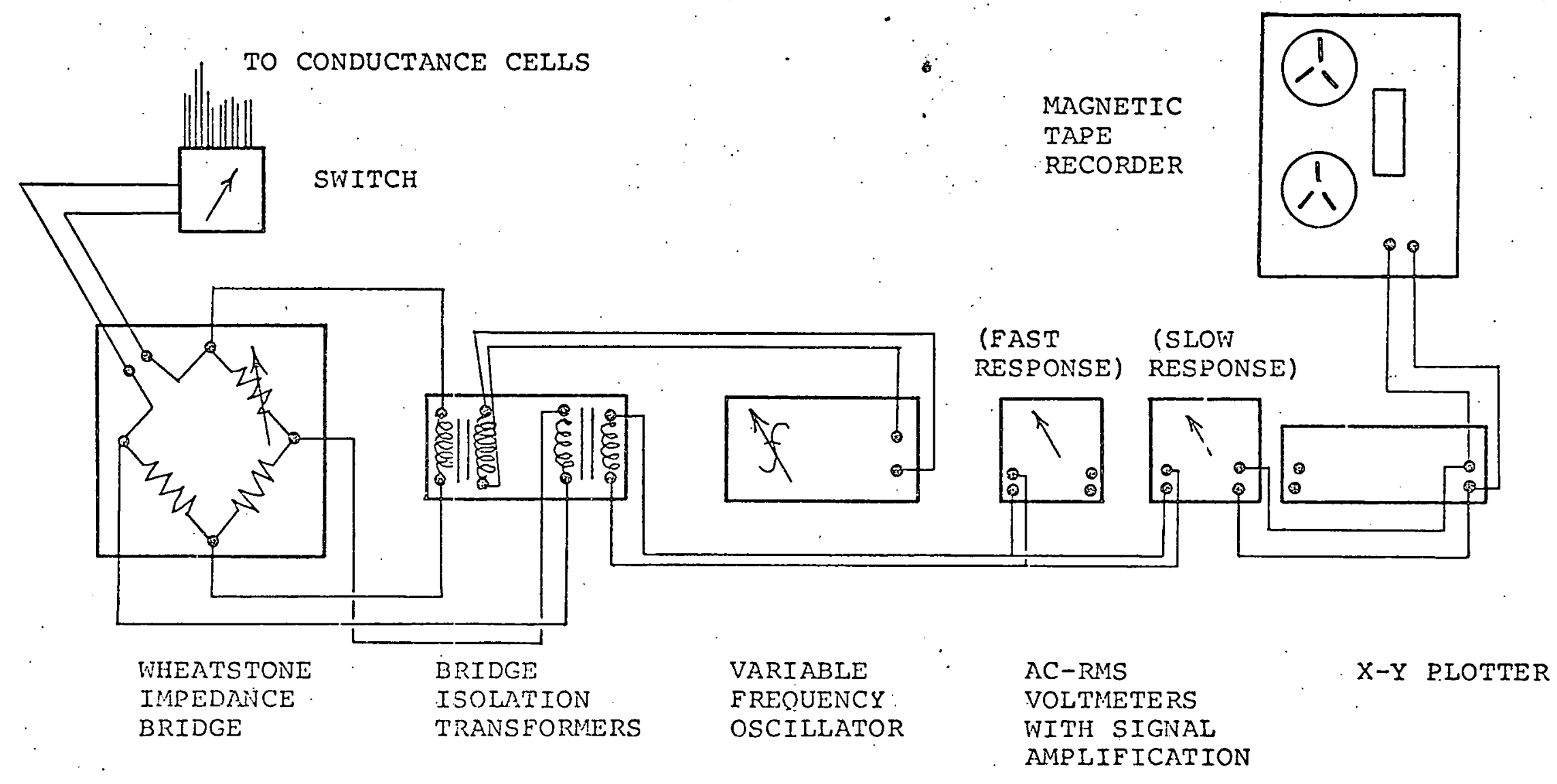

FIGURE A2.4 - SCHEMATIC OF THE CONDUGTANCE MEASUREMENT EQUIPMENT 
(digtal) punched card data from the analog (continuous) signal detected. Using this method, the plotted continuous signal is not transformed into salt concentration but remains in the form of a detected voltage. A function generator might be employed to generate the calibration curve so that the plotted continuous signal would reflect the mass detected instead of the voltage. The punched card output for use with MITMIX is still necessary in order to provide a calculated mass balance, to prepare plots of the results, and to transform the detected voltage to detected mass using a more accurate calibration curve than is available with a function generation. 
Append1 3

MITMIX - A DATA REDUCTION PROGRAM FOR THE

MIT MIXING PROJECT EXPERIMENTS

In order to expediate the reduction of data from interchannel coolant mixing experiments done at MIT, a - simple computer program called MITMIX has been written as part of this work and is avallable from the MIT Nuclear Engineering Department Computer Code Library. The code has been written in two similar versions - one for use with the MIT Information Processing Center IBM 370/165 digital computer and one for use with the MIT Laboratóny of Nuclear Science IBM $360 / 65$ digital computer. The primary functions of MITMIX are

(1) to prepare a curve fit of the calibration data for salt tracer experiments,

(2) to translate the measured resistances or voltages into salt solution concentrations using the calibration curve,

(3) to perform a hydraulic flow split calculation for use in the mass or heat balance computations,

(4) to calculate mass or heat balances from the flow split analysis and experimental data supplied,

(5) and to prepare plots of the experimental data and the balance calculation results. 
The experimental data for the varlous subchannels monitored are input as a function of injection displacement. A flow split analysis simllar to thát reported in Appendix 1 is calculated using the method of Sangster (AI.I); MITMIX has the internal capability to calculate subchannel geometrical parameters for an equilateral triangular lattice, rod bundle. The flow split calculations are used to establish the rate at which tracer, either BTU/min for the case of heated water injection or grams/min for the case of salt tracer injection, has been detected. Obviously, the rate at which tracer flows past the instrumentation should equal the rate at which tracer is injected into the main flow field.

For the salt tracer:

$$
\begin{aligned}
w_{1}\left(C_{i}-C_{B}\right) & =\sum_{j=1}^{n} \cdot w_{j}\left(C_{j}-C_{B}\right), \\
\text { (Injected tracer) } & =\text { (detected tracer) }
\end{aligned}
$$

where $C_{i}$ is the injected salt solution concentration; $C_{B}$ is the background equivalent salt concentraction; $w_{i}$ is the tracer injection flow rate; $w_{j}$ and $C_{j}$ are the caiculated flow rate (from the flow split analysis and measured main flow rate) and the salt concentraction (from the transformed experimental data) of subchannel $f$, respectively. Similarly for heated water injection:

$$
w_{i} c_{p}\left(T_{1}-T_{B}\right)=\sum_{j=1}^{n} w_{j} c_{p}\left(T_{j}-T_{B}\right)
$$


where $\mathrm{T}_{\mathrm{B}}$ is the background or main flow temperature; $c_{p}$ is the speciflc heat of water; $T_{j}$ is the temperature measured In subchannel $\mathrm{j}$. The balance calculations done in MITMIX are simply the difference between the detected tracer flow rate and injected tracer flow rate.

The flow split analysis is an important part of the balance calculations. It should be noted that the MITMIX - flow split calculations are simple in nature; detailed considerations of the flow field have been neglected. Only average subchannel velocities are calculated, and no allowance is made for tracer injection. Changes of fluid thermalphysical properties have been neglected also. The influence of these flow details on the final results is small compared with other errors in the experiments.

The specific heat of water is nearly constant over the temperature range of interest $(50 \mathrm{~F}-180 \mathrm{~F})$ so that temperature is a direct measure of enthalpy (the actual tracer being monitored) for heat balance calculations. But, the non-linear nature of the specific resistance versus solution strength curve for salt tracers necessitates a translation of specific resistance or unbalanced bridge voltage data to salt solution concentration using a curve fitting procedure. MITMIX establishes a data reduction curve using calibration data generated by mixing homogeneous solutions of the tracer (which have known concentrations) and measuring the specific resistance (or an 
unbalanced bridge voltage - see Appendix 2). An analytical curve is fit through the calibration data using the method of least squares. This calibration curve is then used to translate the data taken during the experiments into solution concentrations. The solution concentrations are used for mass balance calculations and for presentation of the results of tracer dispersion due to interchannel coolant mixing mechanisms. An important assumption in the mass balance computation is that the measured salt concentration is uniform over the subchannel of interest. No allowance has been made for nonuniform salt concentrations; however, the results of the mass balance calculations will be an indication of any difficulties due to inhomogeneous salt solutions. It may be convenient or desirable to present the data in normalized form. For a heated water tracer, the normalized, measured temperature in subchannel $j_{0}{ }^{{ }}{ }_{N j}$ may be determined by:

$$
\mathrm{T}_{N j}=\left(\mathrm{T}_{j}-\mathrm{T}_{B}\right) /\left(\left(w_{i} / w_{1}\right) \times \mathrm{T}_{1}-\mathrm{T}_{B}\right)
$$

And for a salt tracer, the normalized, measured salt concentration in subchaninel. $j: C_{i v j}$ is similarly given bys

$$
C_{N j}=\left(C_{j}-C_{B}\right) /\left(\left(w_{1} / w_{1}\right) \times C_{i}-C_{B}\right)
$$

In the normalization equations, $A 3.3$ and $A 3.4$, the injection temperature or salt concentration has been multiplied by $w_{i} / w_{1}$, the ratio of the injection flow rate to the 
Injection subchannel flow rate; without this multiplier the "normallzed" results would not range between 0.0 and 1.0 because the injection flow is less than the injection subchannel flow. 
Appendix 6

\section{A DISCUSSION OF EXPERIMENTAL ERRORS}

No experiment is complete until the various causes of error and their influence on the experimental data has been considered. For the work reported hora, errors were introduced into the results by experimental operations, by data handling and reduction, and by calculational approximations. Although there are numerous error sources, a few sources were responsible for most of the error. The items listed in Table $\$ 6.1$ which contribute most to error in the experimental results have been indicated with an asterisk (*).

Measurement in accuracy of instruments introduced a small experimental error. The flow meters used for this work were accurate to $\pm 1 \%$, and the thermometer was accurate to $\pm 1^{\circ} \mathrm{F}$. The main flow had variations of $\pm 2 \%$. The injection flow variations were as much as $\pm 10 \%$ due to difficulties with the flow regulating system for a given experiment, the injection flow was relatively consistent (either high or low). The other sources of instrument error were in the data acquisition system. The applied bridge voltage introduced an experimental error if its value differed between experimental data collection and calibration curve data collection. The 
Table A6.1

Sources of Error in the Experimental Results

Experimental Operation Errors - - - -

(1) Injection flow meter - error in flow measurement

(2) Main flow meters - error in flov measurement

(3) Main flow thermometer - error in temperature measurement

(4) Injection system flow variations

(5) Main flow system variations

(6) Oscillator output voltage - variation of bridge applied voltage.

(calibration curventate

error)

(7) Loss of platinization on detector electrode surfaces

(8) Injector drive speed variations (this is a synchronization error - an error between the actual location of the injector and the location recorded during data collection).

(9) Data recording system electronic interference (flutter and commercial noise - see Appendix 7)

(10) Array geometry errors - (angular location of wire-wrap, assembly tolerance, etc.)

(11) Array proximity, electrode interference,

(12) Injector angular location error (due to wear)

(13) Injector tube, slot spreading error (also an injector angular positioning error)

(14) Injector tude siot (IIow area increase in the injection subchannel)

(15) Backround salt concentration shift

(16) Amplifier time constant

(17) CaIibration curve inadequacy

(18) Probe Positioning

Data Conversion and Handling Errors - - - -

(1) Axial resolution, data points/inch injector travel.

(2) Filtering and averaging 


\section{Table A6.1 (Concluded)}

(3) Data synchronization (digitization frequency) (4) Data assembly and editing Calculational Error - - - -

(1) Simplified flow split analysis

(2) Calibration curve data fit 
applied bridge voltage was kept within $\pm 5 \%$, and its influence would have been consistent for a given set of data. The measured unbalanced bridge voltage signal was amplified by a voltmeter and recorded onto a magnetic tape recorder. Although a small consistent voltage measurement error was introduced by the voltmeter amplifier, the main experimental error from signal amplification was due to the time response. The amplifier had a slight dampening influence on the Wheatstone bridge output signal. The data acquisition error due to electronic equipment was considered quite small because the calibration data, and the experimental data were recorded and processed using the same electronic equipment.

Errors were introduced into the experimental results by mechanical tolerances in the rod array. The rod-torod pitch was accurate to within $\pm 2 \%$, and the flow channel dimensions were accurate to $\pm 2 \%$. The wire-vmap angular orientation was accurate to $\pm 5^{\circ}$. In the injection subchannel, the slot in the injector rod introduced a subchannel flow area increase of about 10\%. Because the moving injector tube was slightly bent in handling, it caused the outer slotted tube to spread; this caused a needle angular positioning error of up to $\pm 4^{\circ}$; the experiments were done, however, so that the angular needle location error would be consistent. Error in the experimental results was introduced by 
converting the data from a recorded analog signal to a digital output for use with digital computers. In order to keep the volume of data within reasonable limits, the recorded signal was filtered (electronically averaged) and numerically averaged. Each point plotted in the results was the average of $100-200$ points and a point was plotted for each second of actual experiment operation. One point per second corresponds to an axial data frequency (axial resolution) of 0.2 or 0.1 inch of injector travel.

The major sources of error were inadequate injection flow regulation, array proximity electrode interference, injector angular positioning, and axial data misalignment (due to the data collection technique). Further details on these more significant errors is given in Chapters 4 and 5. Briefly. most of the error in th data of this report may be eliminated in future experiments of this type by using the herein recommended injector rod design changes and by using numerous, stationary, conductance probes with immediate data digitizing equipment. 


\section{Append1x 7 \\ ANALOG-TO-DIGITAL CONVERSION}

The FM recording of the unbalanced Wheatstone bridge voltage was played back into an analog computer where the signal was filtered and digitized, 1.e., converted from a continuous analog signal to a discontinuous digital signal (for use with digital computers). This digitized signal was read by a digital computer; the digital computer was programmed to take a multiple point (nominally 200-400 points) average for each point recorded. The averaged points were stored on a magnetic disc. Because of software limitations at the MIT Joint Computer Facility (JCF the Mechanical and Civil Engineering Departments share the facility), another digital computer was used to read the averaged data from the magnetic disc and then to produce a punched paper tape as well as a listing of the data. The paper tape was taken to the MIT Information Processing Center where punched computer cards were made from the punched paper tape. These punched cards were edited and used for the data input to MITMIX, a data reduction code discussed in Appendix 3.

The FM recording of the unbalanced Wheatstone bridge voltage (recorded as $0.0-1.7$ VDC) when played back into an oscilliscope for signal analysis was found to have a 
commercial frequency ( 60 Hertz) noise and a small component of 5 Hertz (nominal) tape recorder flutter; the alternating current $A C$ componeris were superimposed on the recorded direct current DC signal. To obtain the desired part of the playback signal (the DC component) the analog computer was programmed to act as a "low pass filter", i.e., a filter which prevents the passage of signals above a given maximum (this statement is oversimplifiea, for a more detalled treatment see Tobey et al. $(\underline{A 7.1}))$.

Figure A7.I shows the circult diagram used to filter the recorder playback signal. The input signal $x$ is related to the output signal $\mathrm{y}$ :

$$
y=x \frac{\left(R_{1} P_{1}\right) /\left(R_{2} P_{2}\right)}{1+\frac{(M O D E)}{\left(R_{2} P_{2}\right)} s}
$$

where $s$ is introduced by Laplace transformation of the integration. This may be more conveniently written as

$$
y=x \frac{G}{I+\tau s}
$$

where the gain of the circult $G$ is given by

$$
G=\frac{R_{1} P_{1}}{R_{2} P_{2}}
$$

and the response time constant $\tau$ is

$$
\tau=\frac{\text { MODE }}{R_{2} P_{2}}=\frac{1}{\omega} \quad \frac{\text { seconds }}{\text { radian }}
$$




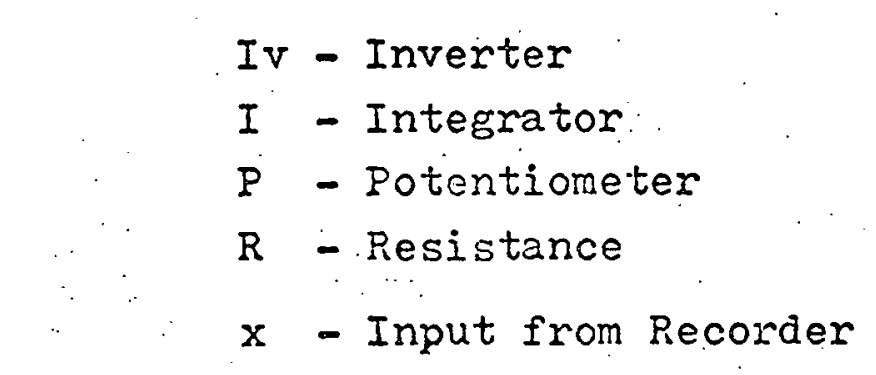

$$
\begin{aligned}
& G=\frac{R_{1} P_{1}}{R_{2} P_{2}}=\text { Gain } \\
& \tau=\frac{\text { MODE }}{R_{2} P_{2}}=\text { Time Constant (sec/radian) } \\
& y=\text { output to Analog-to-Digital Converter }
\end{aligned}
$$

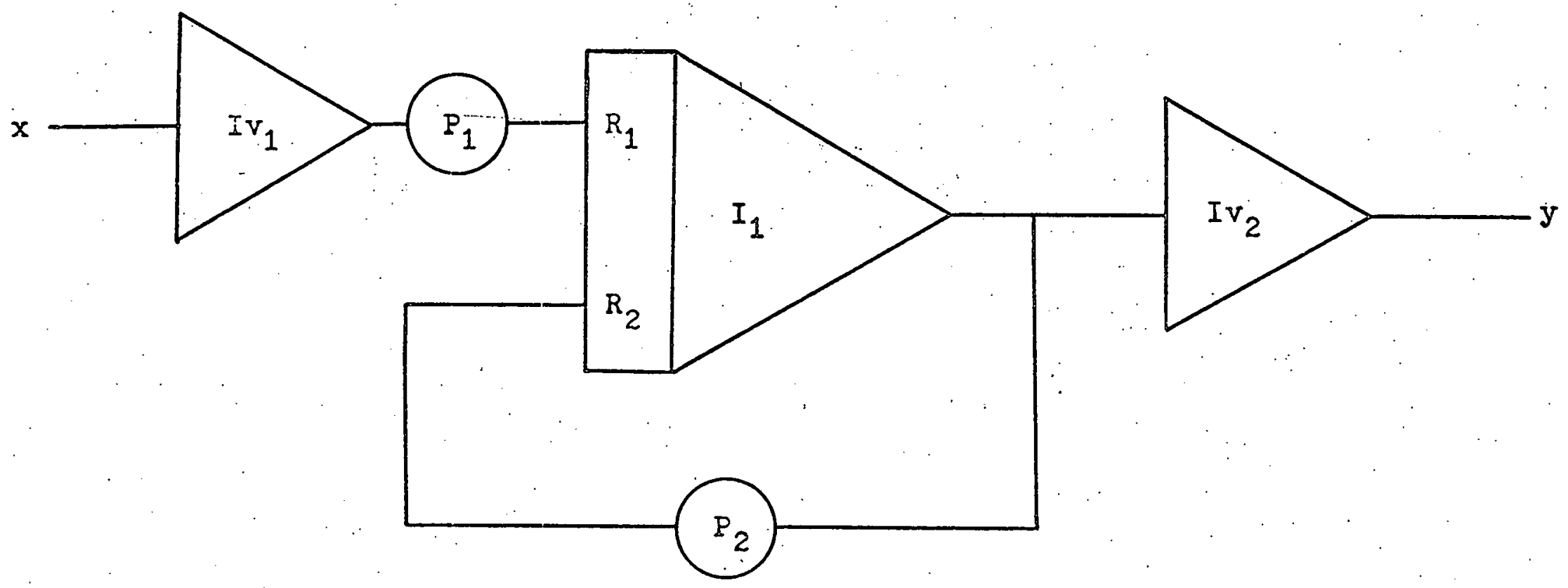

A7.1 - IOW-PASS FILTER CIRCUIT DIAGRAM 
The frequency beyond which signals are attenuated $\omega$ is

$$
\omega=\frac{1}{2 \pi \tau} \text { Hertz }
$$

For this work $w$ sholild be about 40 Hertz and the gain should be adjusted to give a maximum signal of \pm 10 volts input to the $A D C$. After $A D C$, the signal is normalized (10 volts maximum).

Making $\tau$ too large, say $\omega=5$ Hertz, causes difficulties with data reduction because the filter circuit has a time response which is too slow to follow the variations of the recorded data. 


\section{Appendix 9}

GRAPHICAL RFSULTS OF MHE PARAMETRIC EXPERIMENTS

This appendix presents the graphical resilts of the experiments used to extablish the influence of operating parameters on the results. The experiments have been listed in Table 5.1; refer to Tables 5.2 and 5.3 for further details regarding the experiments. The results of experiments $0 / 2-B, 0 / 2-C, 0 / 2-D, 0 / 2-E$ and $0 / 2-F$ are not given here because the magnetic recorder was malfunctioning during the experiments; the original data was recorded with the $X-Y$ recorder and may be reviewed in Eaton ( 5.1 ).

The reader is cautioned that the mechanical behavior of the injection rod varied between the different dates of the experiments because of handling, repair and wear. Comparison of experimental results should only be made for data taken on the same day. The large losses of mass in the mass balance curves is due chiefly to the low number of subchannels monitored and to error in the tracer insertion rate. Array proximity, electrode interference effects were also present but are not responsible for the large absence of detected tracer.

For the parametric experiments, only the injection subchannel and the three contiguous subchannels were monitored, subchannel Nos, 1, 2, 6 and 7 , respectively. It was felt that any influence of experimental operating 
parameters could be determined by monitoring only the injection region of the rod array.

For all results in Appendix 9, injection was into interior subchannel No. 1 , the various experimental data comparisons used to establish the influence of operating parameters on the experimental, interchannel coolant mixing results have been listed in Table A9.1. 
Table A9.1

Comparative Data*

\begin{tabular}{|c|c|c|}
\hline VARIABLE & $\begin{array}{l}\text { COMPARAIIVE } \\
\text { DATA } \\
\text { (RUN NOS) }\end{array}$ & $\begin{array}{l}\text { DATA } \\
\text { PRESENTA } \\
\text { (FIGURE }\end{array}$ \\
\hline \multicolumn{3}{|l|}{ Salt Type } \\
\hline $\begin{array}{l}\mathrm{NaCl} \\
\mathrm{NaNO}_{3}\end{array}$ & $\begin{array}{l}1 / 2-D \\
0 / 2.9-A\end{array}$ & $\begin{array}{l}\text { A9.17.1 } \\
\text { A9.10.1 }\end{array}$ \\
\hline \multicolumn{3}{|c|}{$\begin{array}{l}\text { Tracer Insertion Rate } \\
\text { Salt Solution Concentration }\end{array}$} \\
\hline $\begin{array}{l}2.0 \text { grams } / 1 \mathrm{bm}(\mathrm{NaCl}) \\
1.0 \text { grams } / 1 \mathrm{bm} \\
3.0 \text { grams } / 1 \mathrm{bm}\end{array}$ & $\begin{array}{l}0 / 2-A \\
0 / 1=A \\
0 / 3-A\end{array}$ & $\begin{array}{l}\text { A9.1.1 } \\
\text { A9.2.1 } \\
\text { A9.6.1 }\end{array}$ \\
\hline $\begin{array}{l}2.0 \text { grams } / 1 \mathrm{bm} \\
1.0 \text { grams } / 1 \mathrm{bm} \\
3.0 \text { grams } / 1 \mathrm{bm}\end{array}$ & $\begin{array}{l}0 / 2-B \\
0 / 1=B \\
0 / 3=B\end{array}$ & $\begin{array}{l}\text { Ref. } 5.1 \\
\text { A9.3.1 } \\
\text { A9.7.1 }\end{array}$ \\
\hline $\begin{array}{l}2.0 \mathrm{grams} / 1 \mathrm{bm} \\
1.0 \mathrm{grams} / 1 \mathrm{bm}\end{array}$ & $\begin{array}{l}0 / 2-c \\
0 / 1-c\end{array}$ & $\begin{array}{l}\operatorname{Ref}_{1} 5.1 \\
\mathrm{~A} 9.4 .1\end{array}$ \\
\hline $\begin{array}{l}2.0 \text { grams } / 1 \mathrm{bm} \\
1.0 \text { grams } / 1 \mathrm{bm}\end{array}$ & $\begin{array}{l}0 / 2-E \\
0 / 1-E\end{array}$ & $\begin{array}{l}\text { Ref. } 5.1 \\
\text { A9.5.1 }\end{array}$ \\
\hline
\end{tabular}

Tracer Solution Injection Velocity

\begin{tabular}{|c|c|c|}
\hline $\begin{array}{l}\text { EAVC\& } \\
\text { EAVC X } 2 \\
\text { EAVC X } 1 / 2 \\
\text { EAVC X } 1-1 / 2\end{array}$ & $\begin{array}{l}0 / 2-A \\
0 / 2=B \\
0 / 2-C \\
0 / 2-D\end{array}$ & $\begin{array}{l}\text { A9.1.1 } \\
\operatorname{Ref} 5.1 \\
\operatorname{Ref} 5.1 \\
\operatorname{Ref} 5.1\end{array}$ \\
\hline $\begin{array}{l}\text { EAVC } \\
\text { EAVC X } 2\end{array}$ & $\begin{array}{l}0 / 2-E \\
0 / 2-F\end{array}$ & $\begin{array}{l}\operatorname{Ref} 5.1 \\
\operatorname{Ref} 5.1\end{array}$ \\
\hline $\begin{array}{l}\text { EAVC } \\
\text { EAVC X } 2 \\
\text { EAVC X } 1 / 2\end{array}$ & $\begin{array}{l}0 / 1-A \\
0 / 1=B \\
0 / 1-C\end{array}$ & $\begin{array}{l}\text { A9.2.1 } \\
\text { A9.3.1 } \\
\text { A9.4.1 }\end{array}$ \\
\hline
\end{tabular}


Table 19.1 (Continued)

\begin{tabular}{|c|c|c|}
\hline 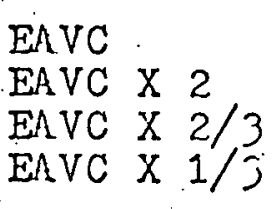 & $\begin{array}{l}0 / 3-1 \\
0 / 3-B \\
0 / 3-G \\
0 / 3-H\end{array}$ & $\begin{array}{l}\text { A9.6.1 } \\
\text { A9.7.1 } \\
\text { A9.8.1 } \\
\text { A9.9.1 }\end{array}$ \\
\hline $\begin{array}{l}\text { EAVC } \\
\text { EAVC X } \\
\text { EAVC X } \\
1 / 2\end{array}$ & $\begin{array}{l}4 / 2=A \\
4 / 2=B \\
4 / 2=C\end{array}$ & $\begin{array}{l}\text { A.9.13.1 } \\
\text { A.9.14.1 } \\
\text { A9.15.1 }\end{array}$ \\
\hline $\begin{array}{l}\text { EAVC } \\
\text { EAVC X } 2\end{array}$ & $\begin{array}{l}1-I T \\
1 A-I T\end{array}$ & $\begin{array}{l}5.4 .1=7 \\
A .9 .20 .1-4\end{array}$ \\
\hline
\end{tabular}

Injector Geometry

Needle (Tube)

Transverse Hole

$3 / 2-A$
$4 / 2-A$

A9.11.1

A 9.13 .1

Needle

Transverse Hole

$3 / 2-E$
$4 / 2-E$

A 9.12 .1

A9.16.1

Reynolds Number

Flow Variation ${ }^{+}$

(Turbulent Flov only)

\begin{tabular}{|c|c|c|}
\hline $\begin{array}{l}4501 \mathrm{bm} / \mathrm{min} \\
225 \mathrm{Ibm} / \mathrm{min} \\
(\mathrm{EAVC})\end{array}$ & $\begin{array}{l}0 / 2-A \\
0 / 2-E\end{array}$ & $\begin{array}{l}\text { A9.1.1 } \\
\text { Ref. } 5.1\end{array}$ \\
\hline $\begin{array}{l}450 \mathrm{lbm} / \mathrm{min} \\
225 \mathrm{lbm} / \mathrm{min} \\
(\mathrm{EAVC} \mathrm{X} \mathrm{2)}\end{array}$ & $\begin{array}{l}0 / 2-B \\
0 / 2-F\end{array}$ & $\begin{array}{l}\text { Ref. } 5.1 \\
\text { Ref. } 5.1\end{array}$ \\
\hline $\begin{array}{l}450 \mathrm{ibm} / \mathrm{min} \\
225 \mathrm{Ibm} / \mathrm{min} \\
(\mathrm{EAVC})\end{array}$ & $\begin{array}{l}0 / 1-\Lambda \\
0 / 1-E\end{array}$ & $\begin{array}{l}\text { A9.2.1 } \\
\text { A9.5.1 }\end{array}$ \\
\hline $\begin{array}{l}450 \mathrm{Ibm} / \mathrm{min} \\
180 \mathrm{Ibm} / \mathrm{min} \\
(\text { EAVC) }\end{array}$ & $\begin{array}{l}3 / 2-A \\
3 / 2-E\end{array}$ & $\begin{array}{l}\text { A9.11.1 } \\
\text { A9.12.1 }\end{array}$ \\
\hline $\begin{array}{l}501 \mathrm{bm} / \mathrm{min} \\
25 \mathrm{Ibm} / \mathrm{min} \\
\text { G(VC) }\end{array}$ & $\begin{array}{l}4 / 2-A \\
4 / 2-E\end{array}$ & $\begin{array}{l}\text { A } 9.13 .1 \\
\text { A9.16.1 }\end{array}$ \\
\hline
\end{tabular}


Table A9.1 (Concluded)

Flow Regime

Turbulent
Iaminar

Turbulent

Iaminar

$$
\begin{aligned}
& 1-I T \\
& 2-I I \\
& 5-P T \\
& 6-P L
\end{aligned}
$$$$
5.4 .1-7
$$$$
5.5 .1-9
$$$$
5.6 .1-6
$$$$
5.7 .1-6
$$

Injector Mechanical Behavior *

17 July
New, 27 inay .
25 June
10 July
17 June

$5.4 .1-7$ A.9.20.1-4

Ref. 5.1

Ref. 5.1

A9.1.1

Data Reduction Technique

Machine Manual
$1-I T$.

$1 A-I T$
$5.4 .1-7$

A $9.20 .1=4$

Data Collection Technique

lioving Injector

Stationary Injector
$1-I T$

$1 B-I T$

Data Frequency (As reduced)

10 points/inch
5 points $/$ inch

$$
0 / 2-A
$$

A9.1.1

19.11 .1

NOTES :

* Due to changes in injector mechanical benavior. similar data will not be the same if taken on different dates.

+ See Table 5.3 for details of the flow conditions.

\& EAVC - Equal Average Velocity (Injection) Criterion. 


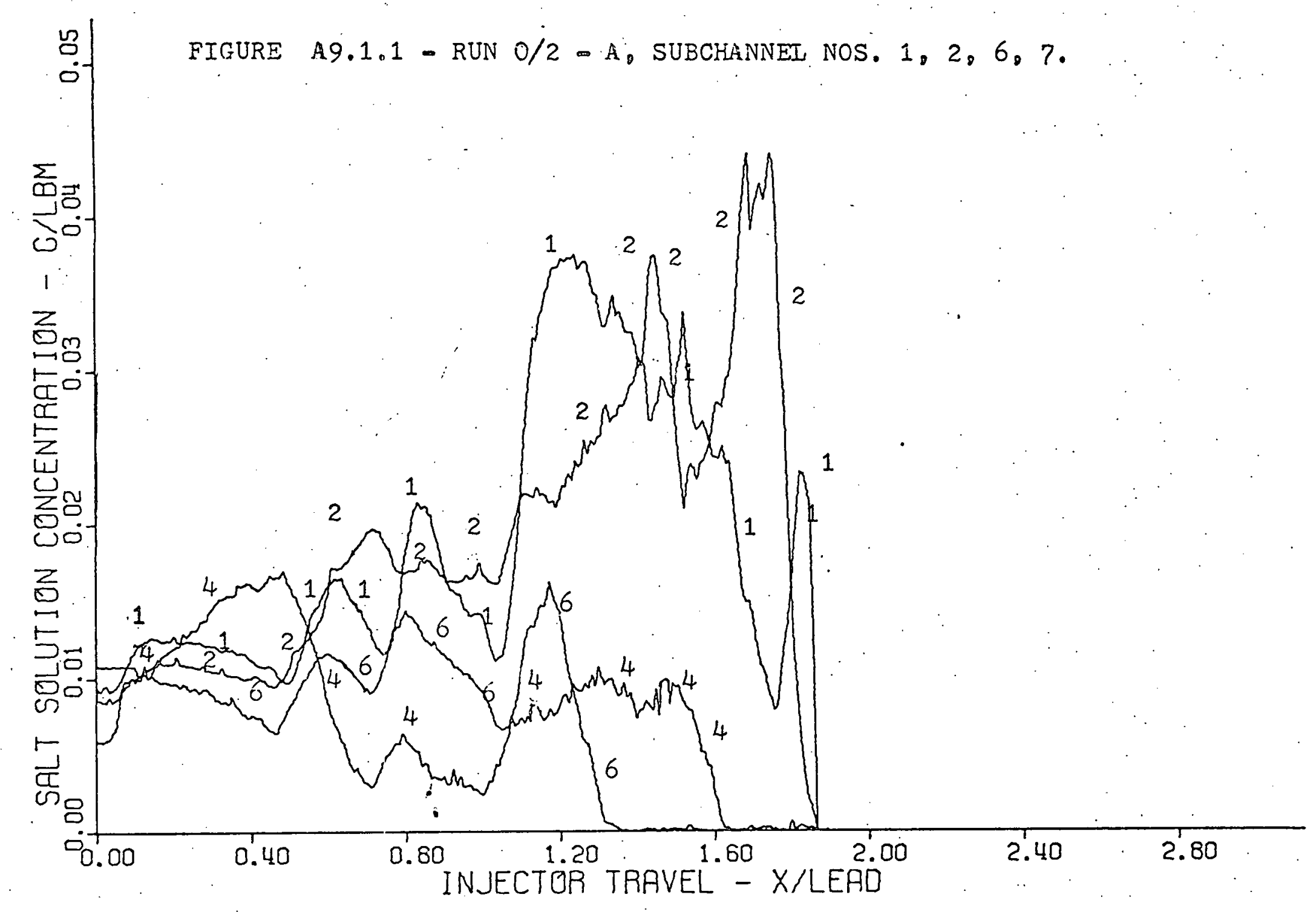




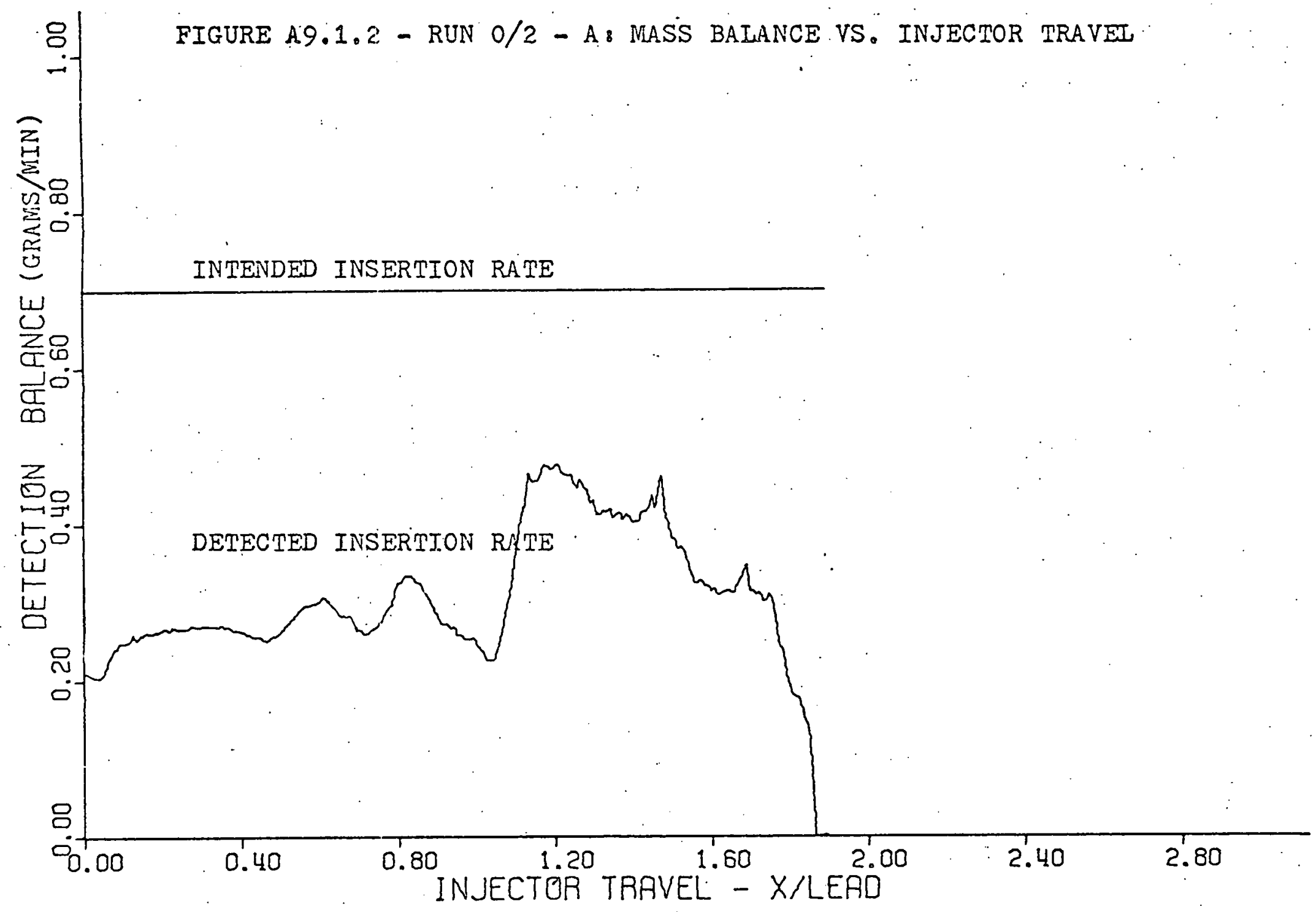




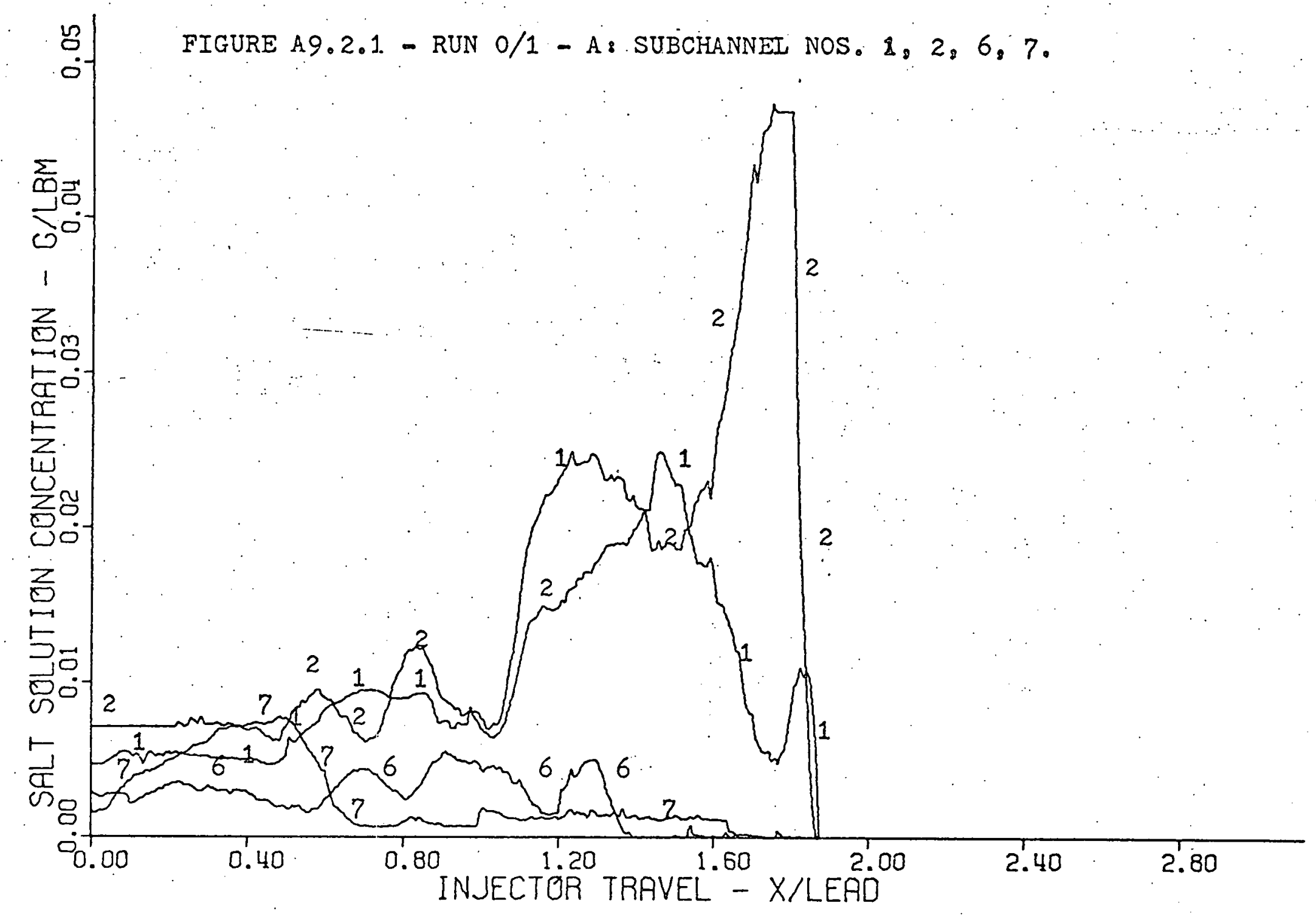




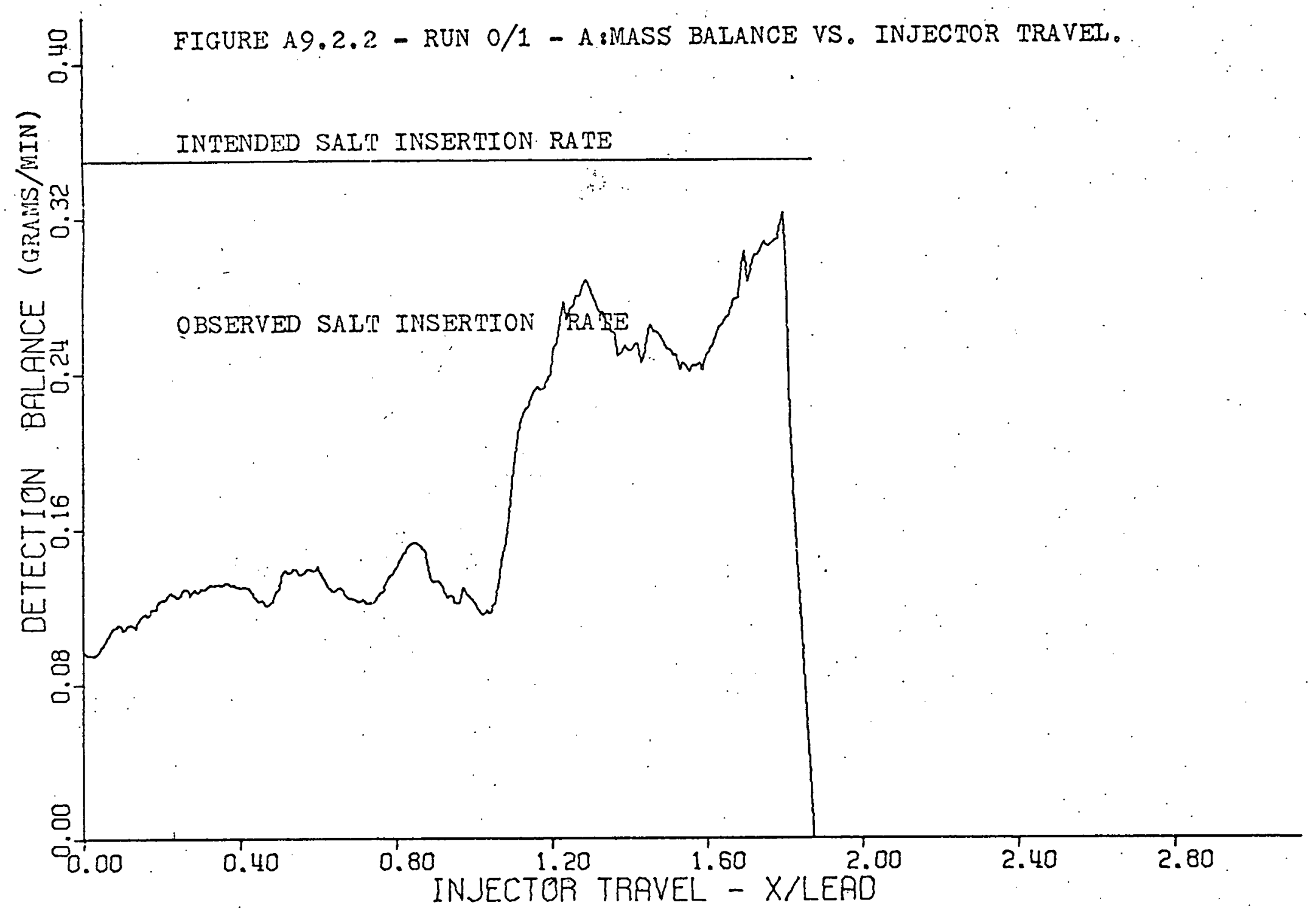




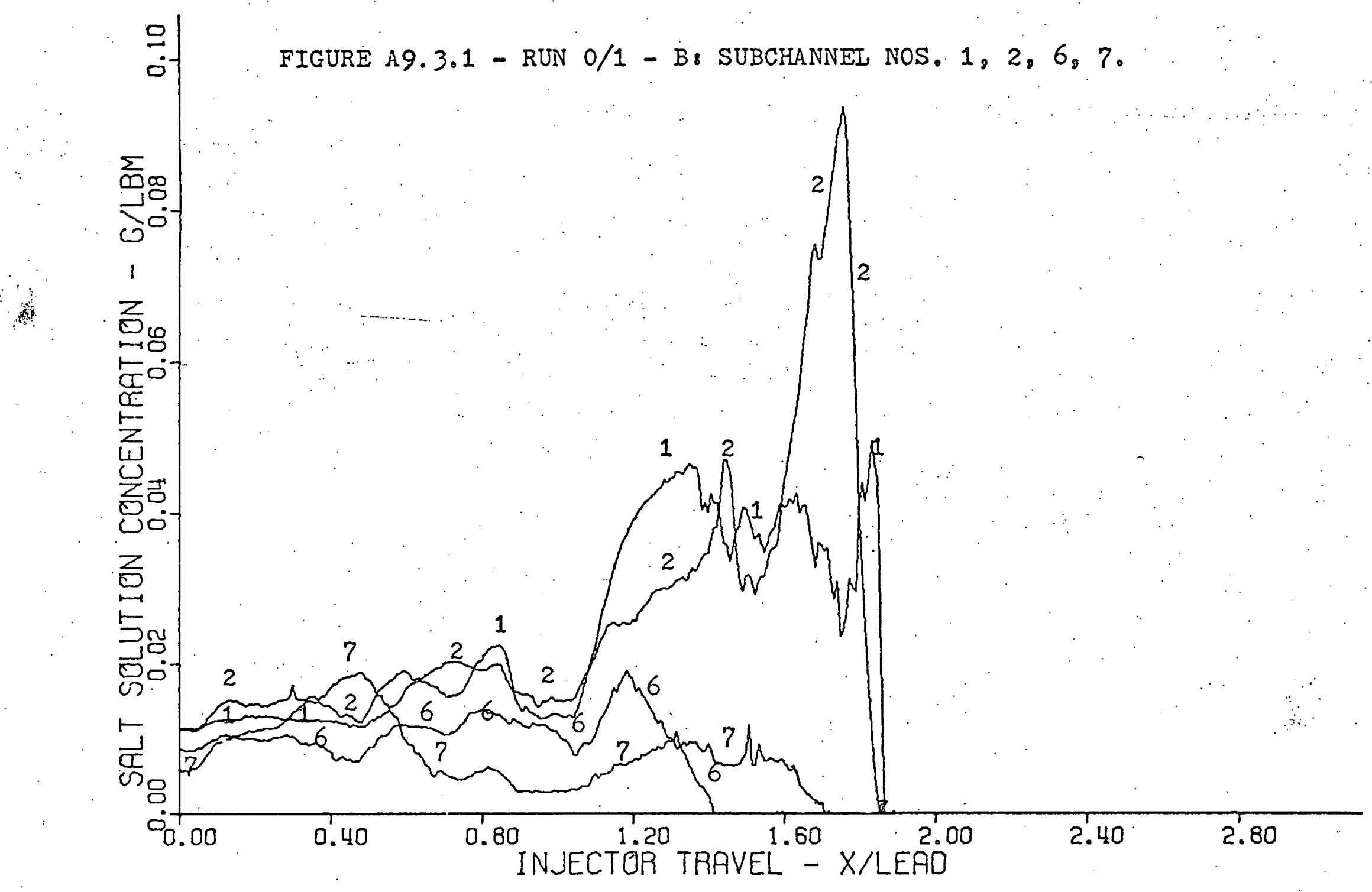




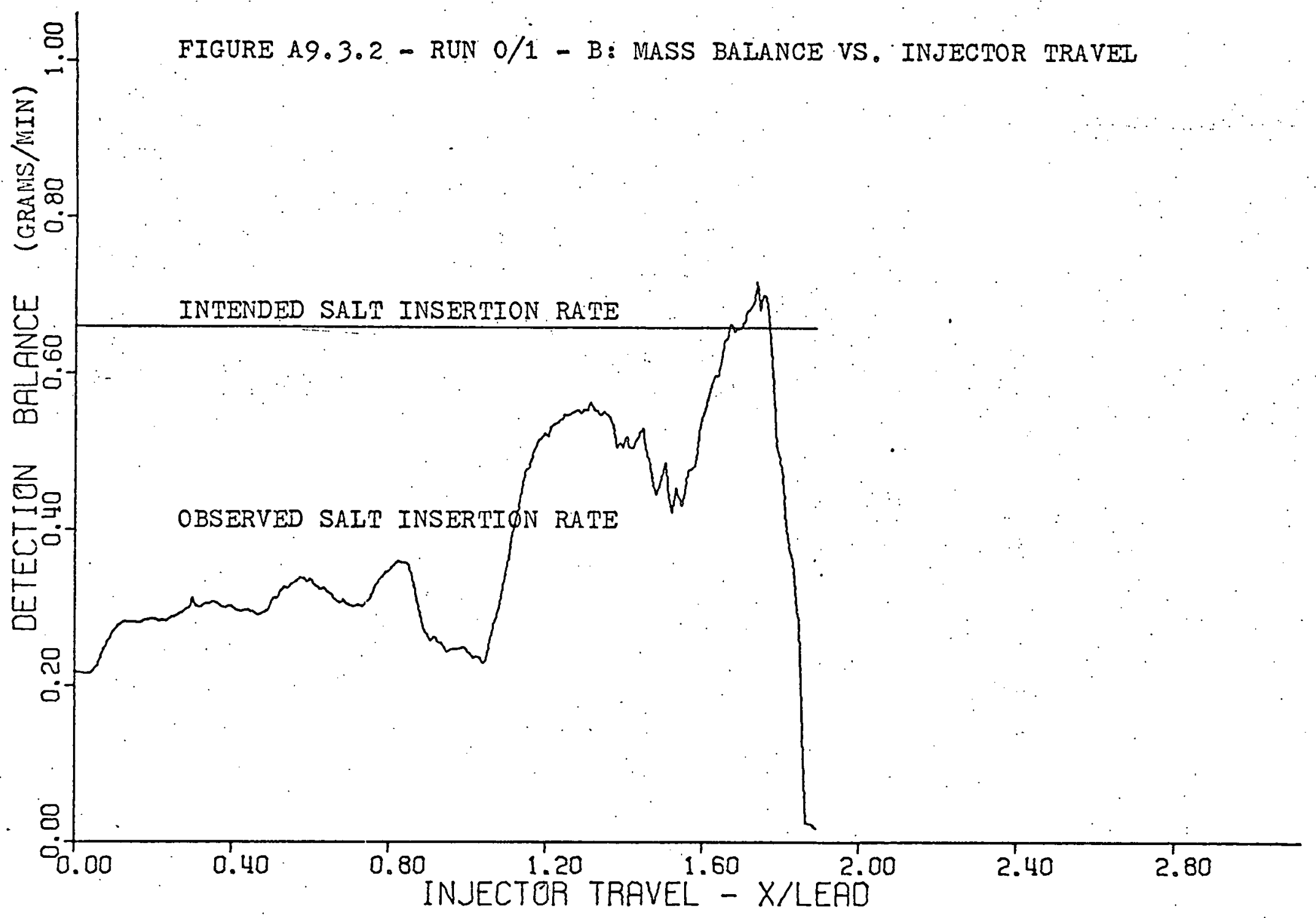




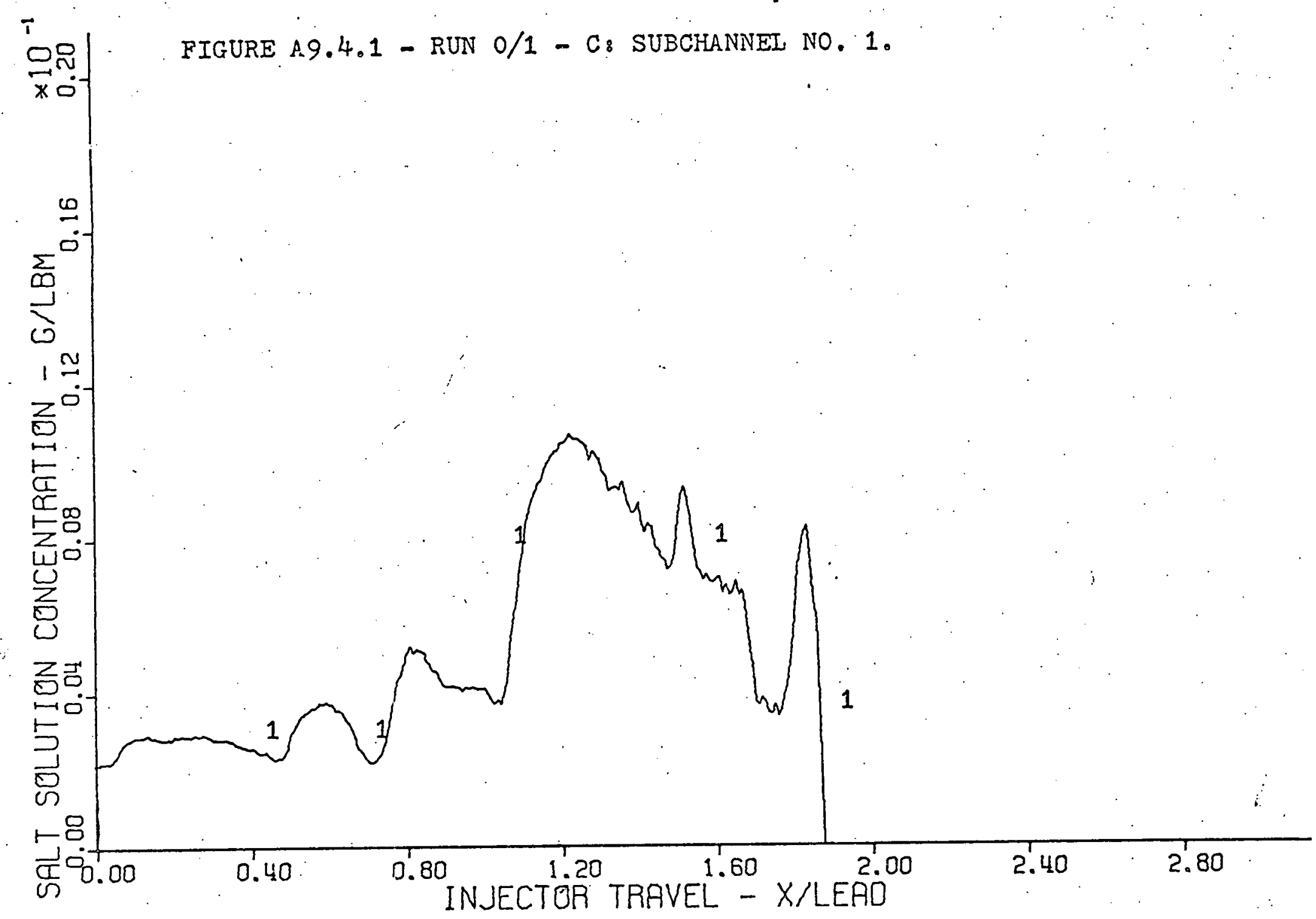




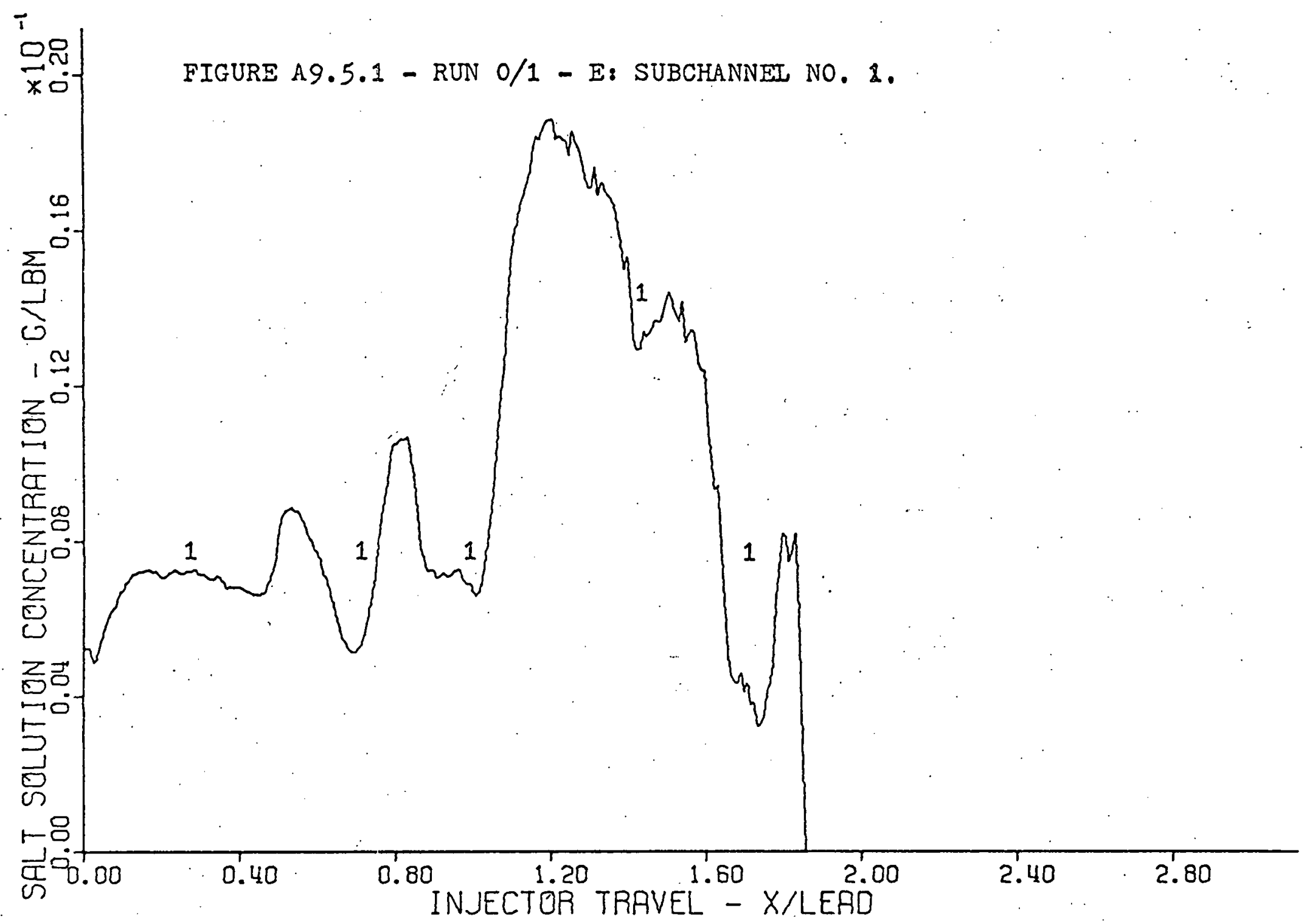




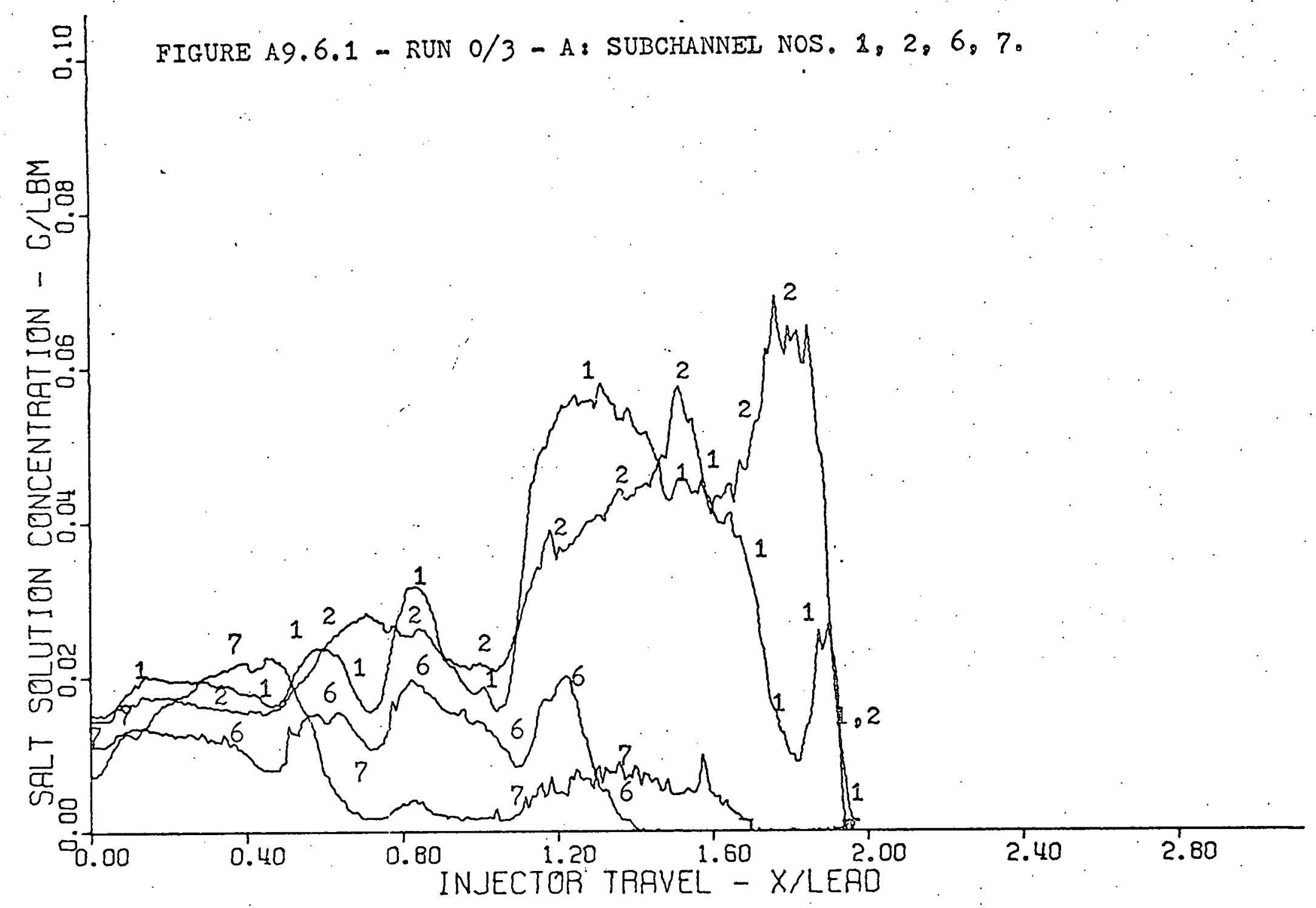




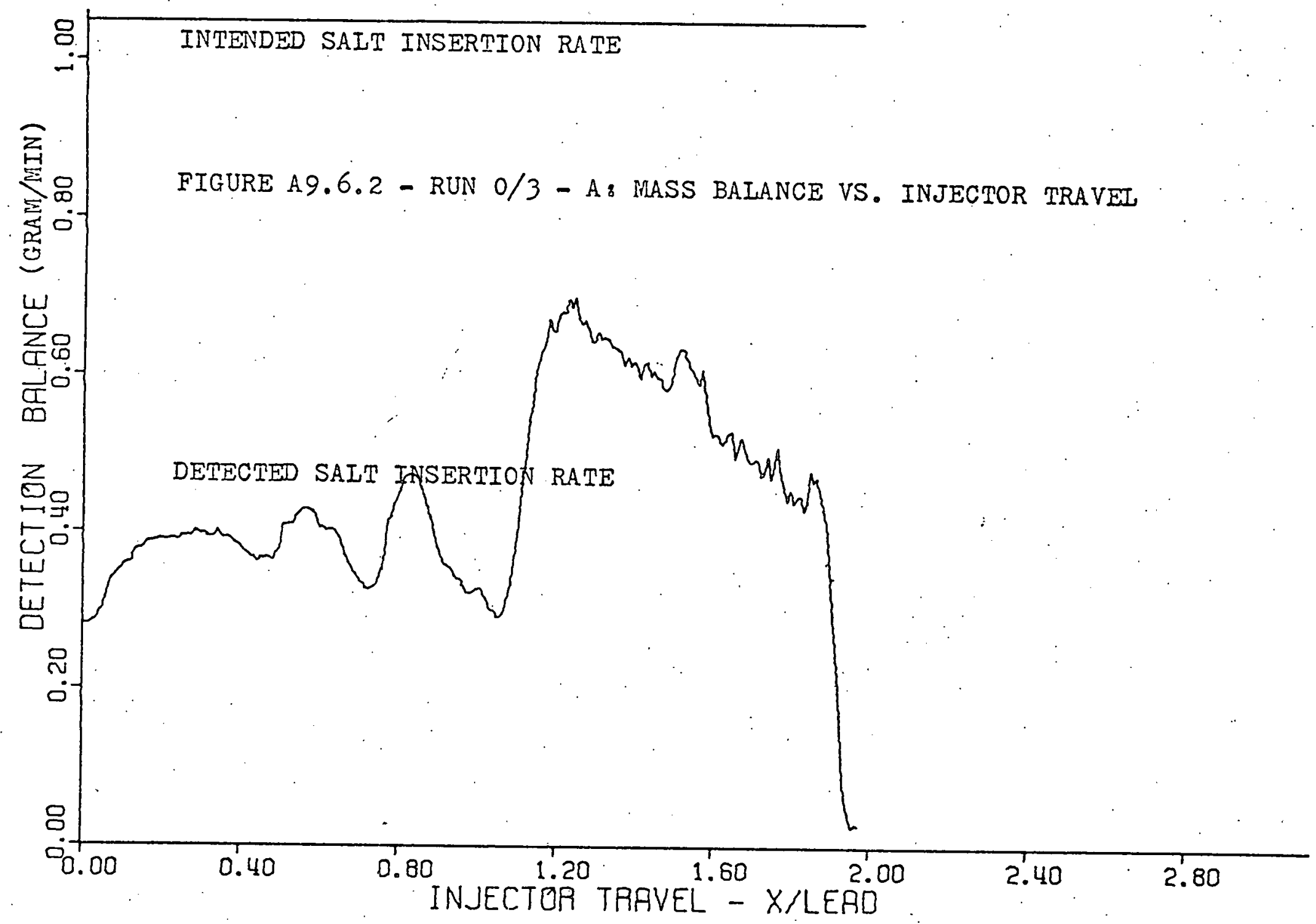




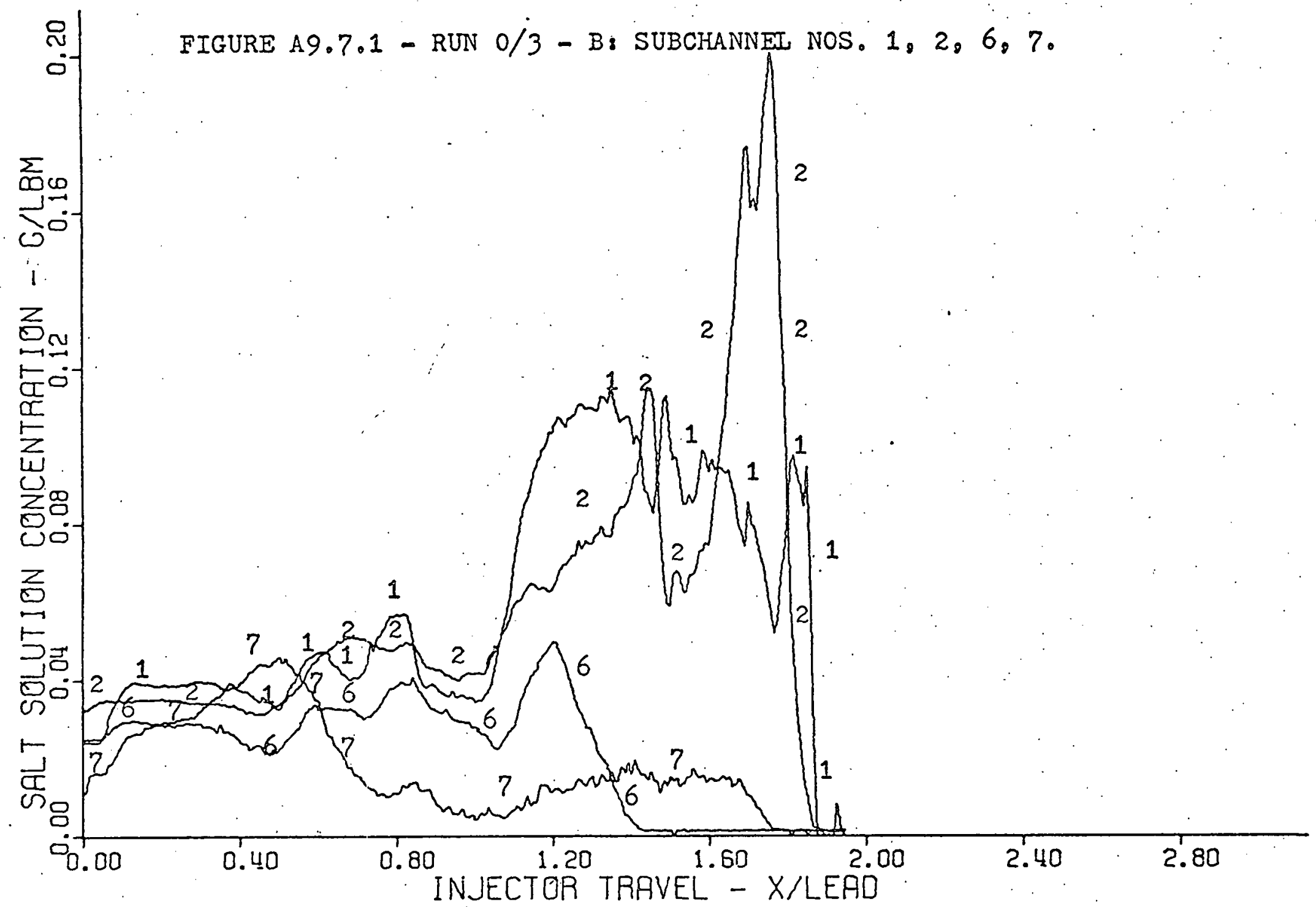




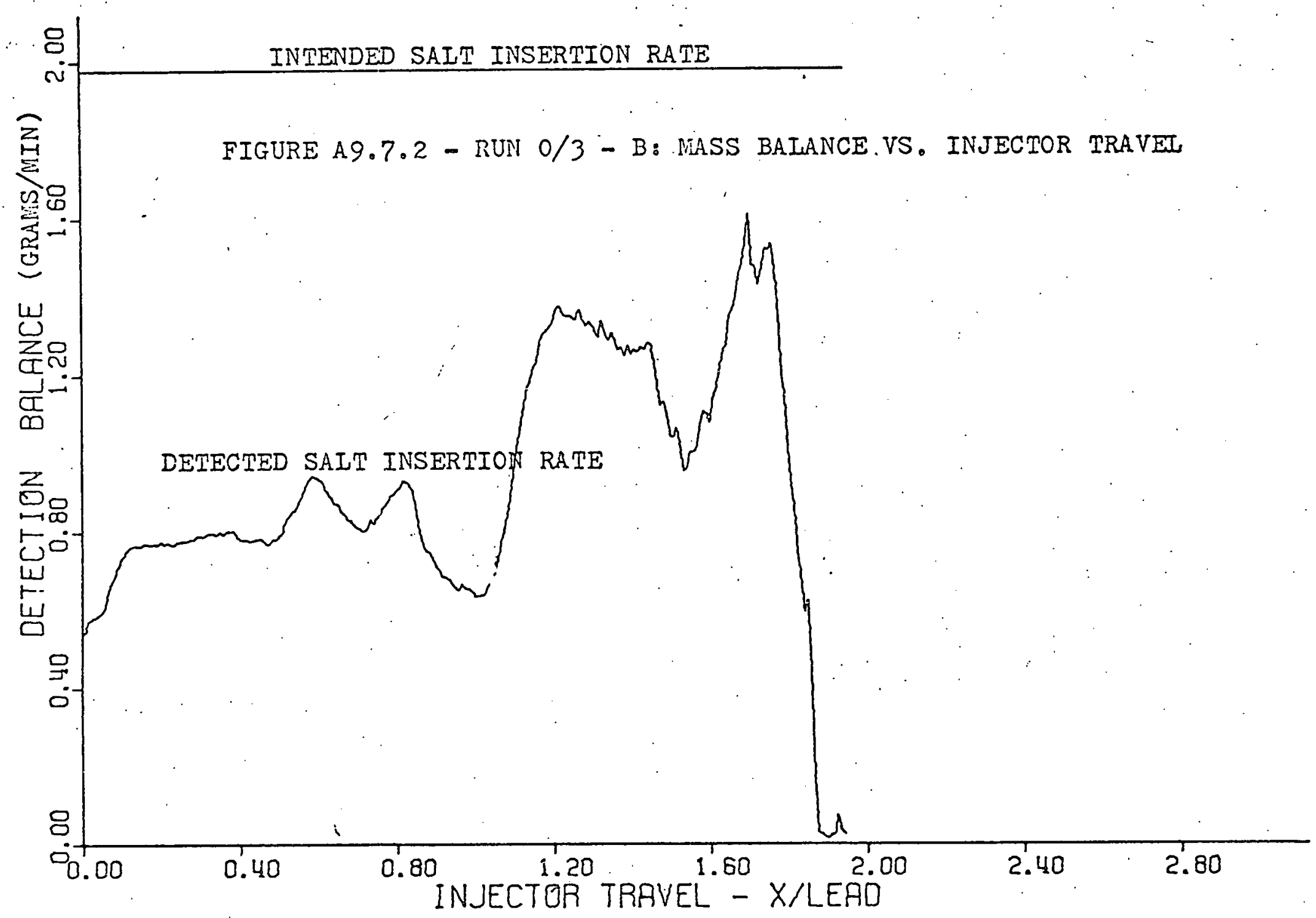




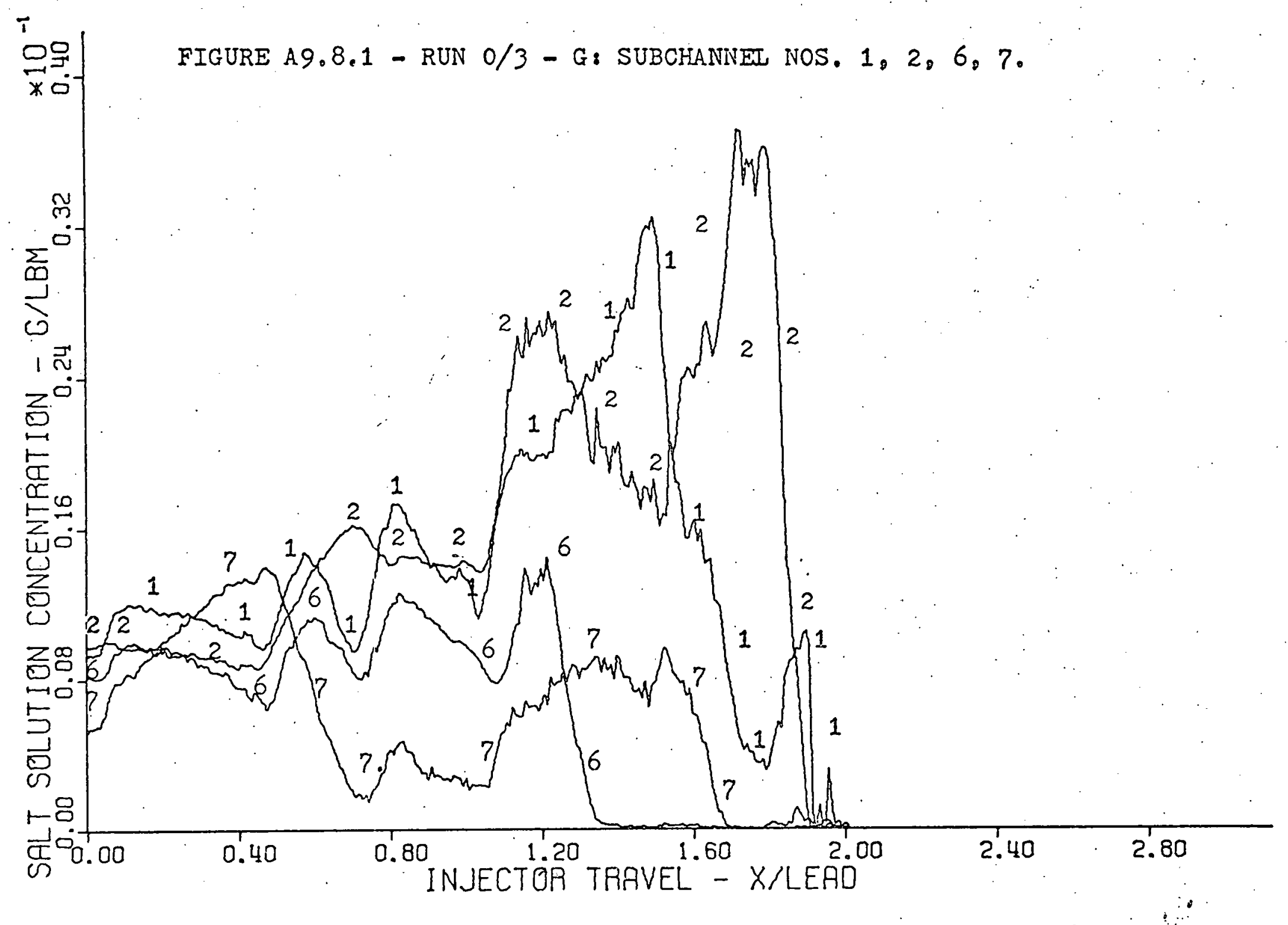




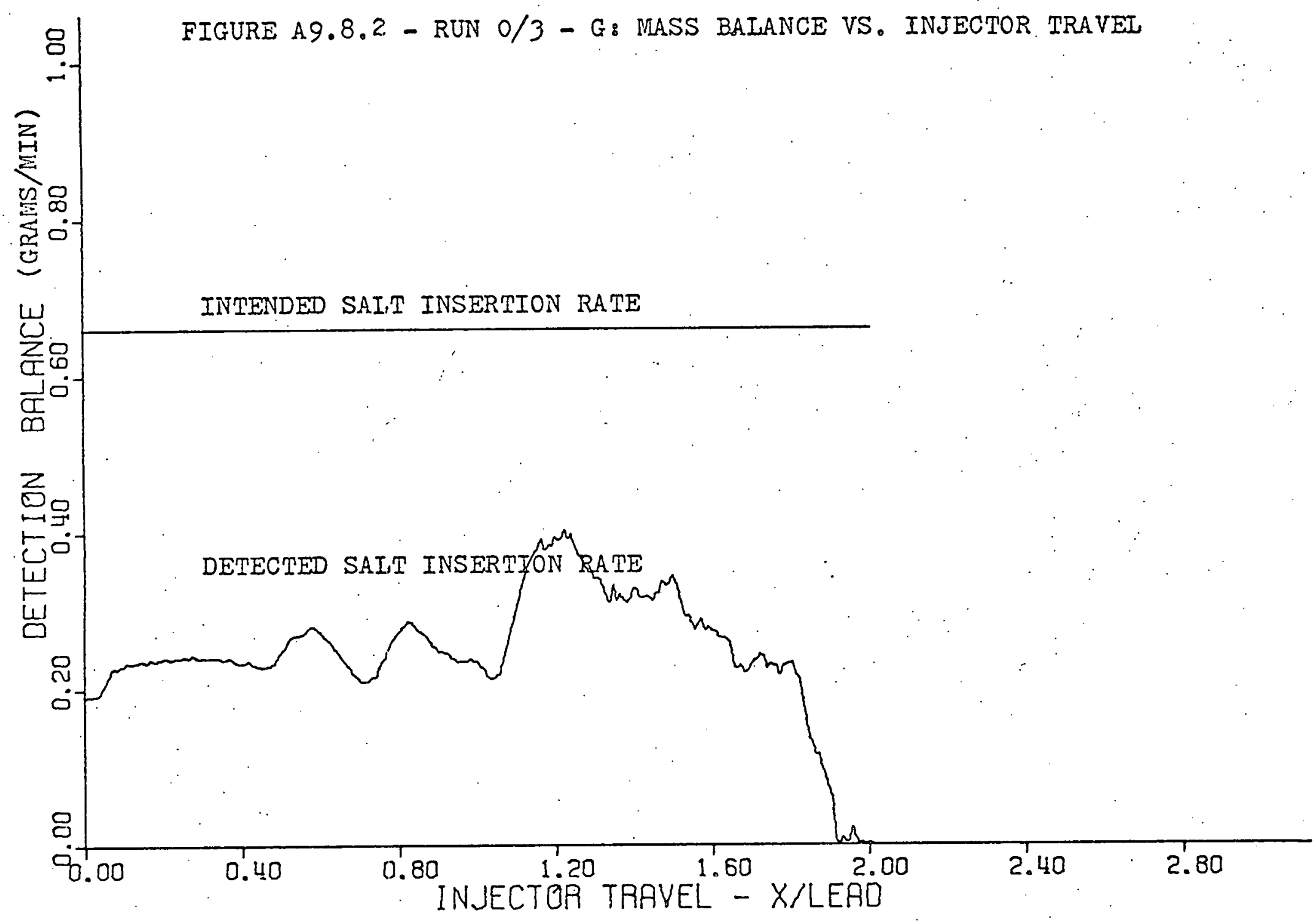




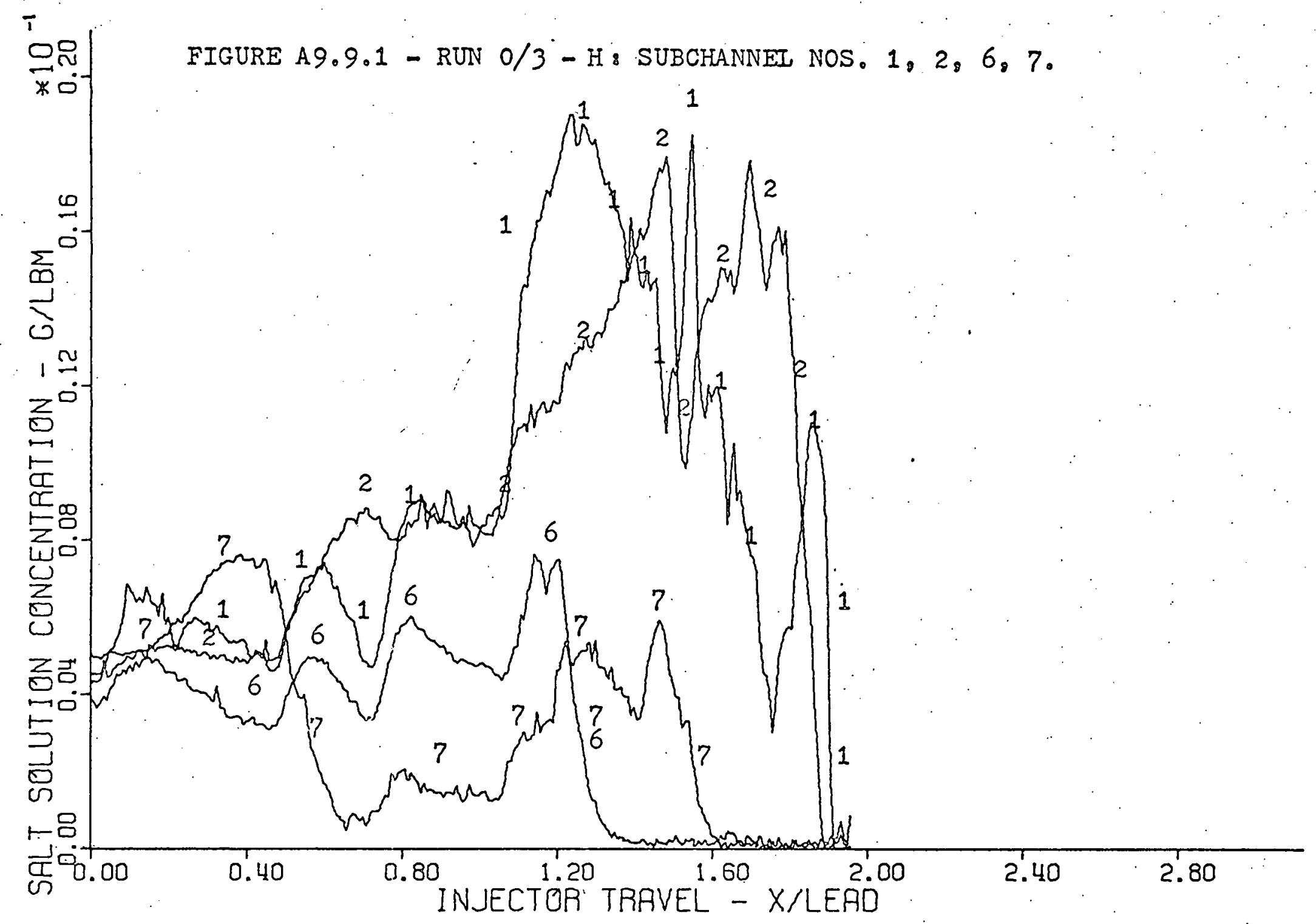




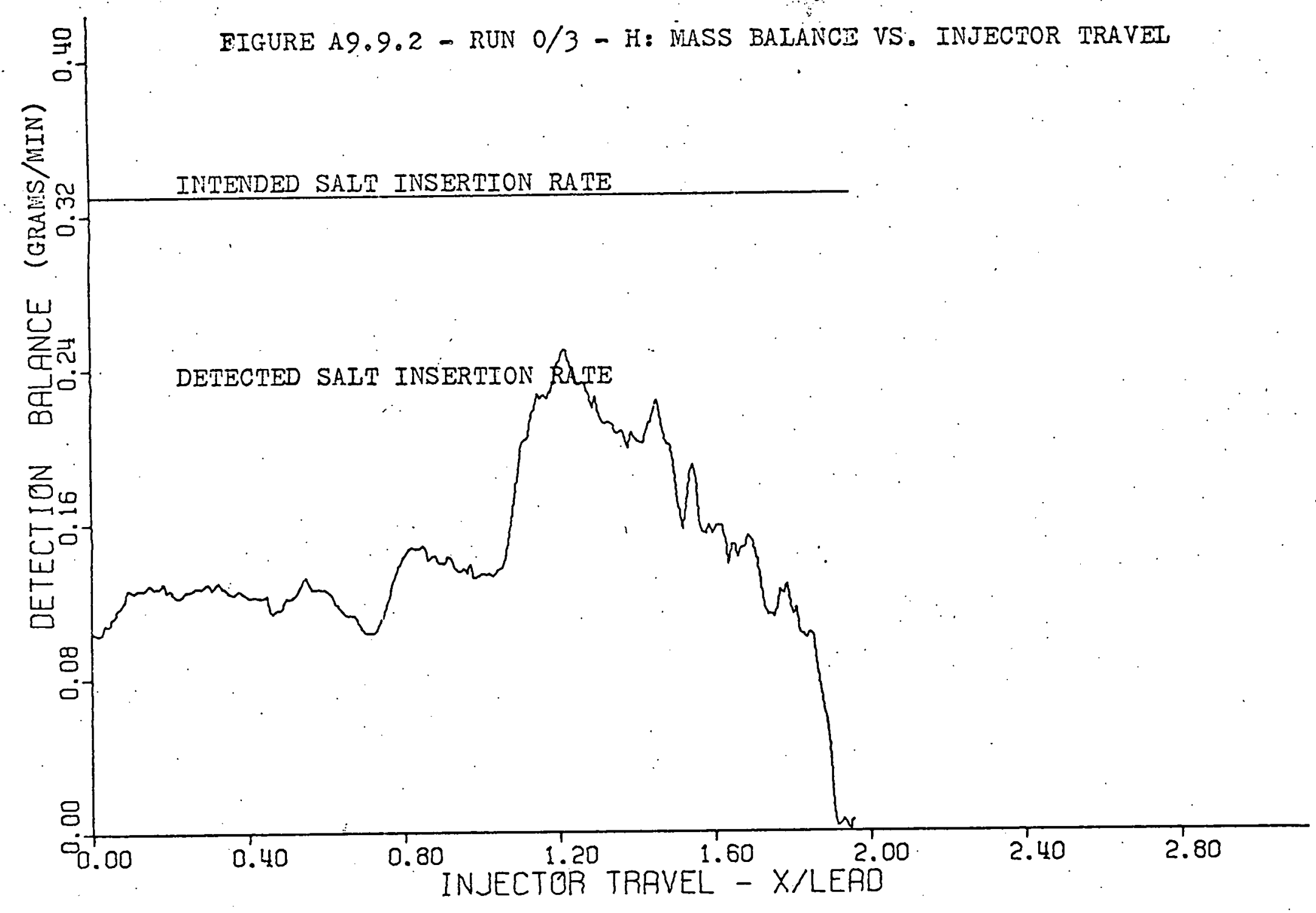




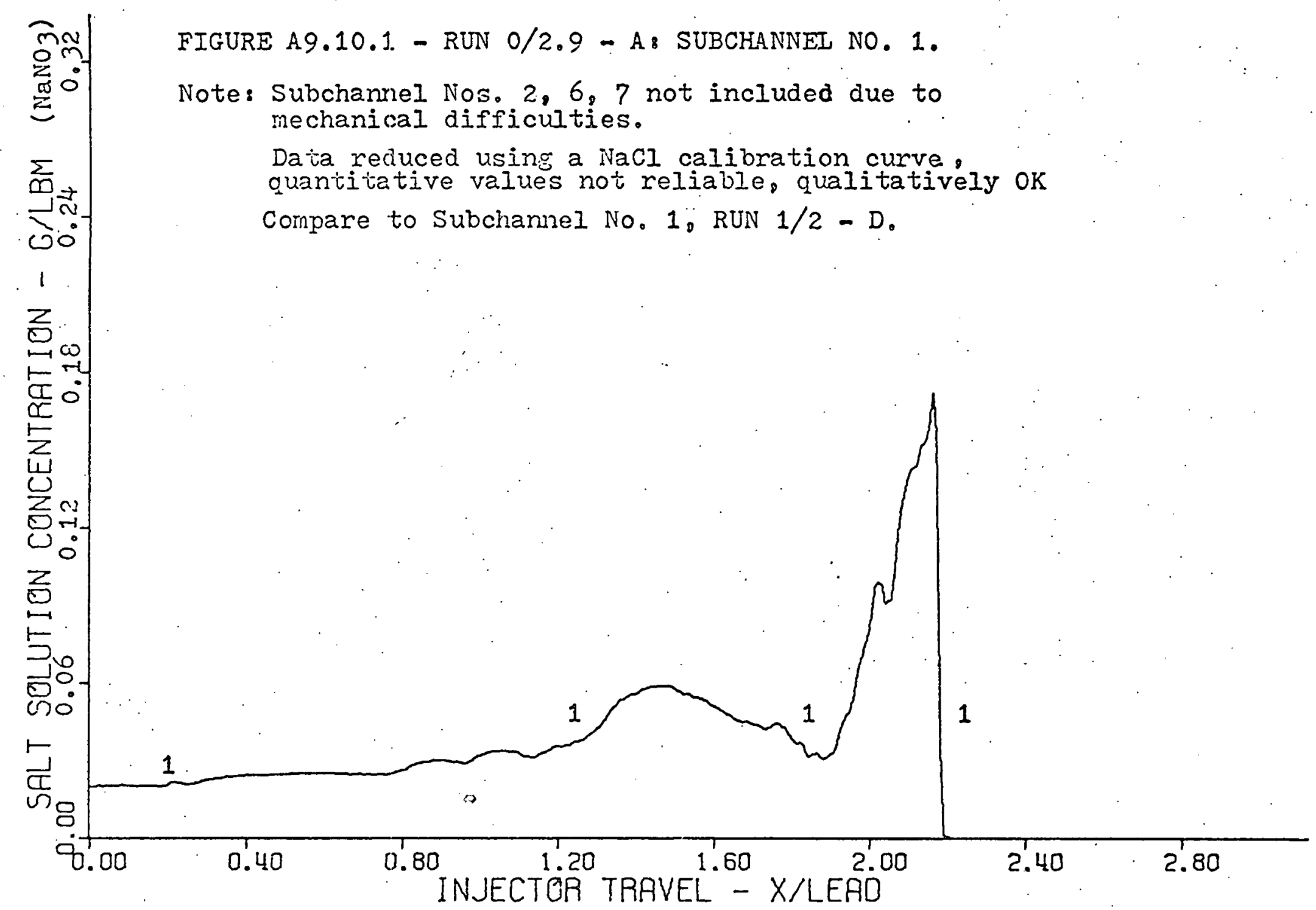




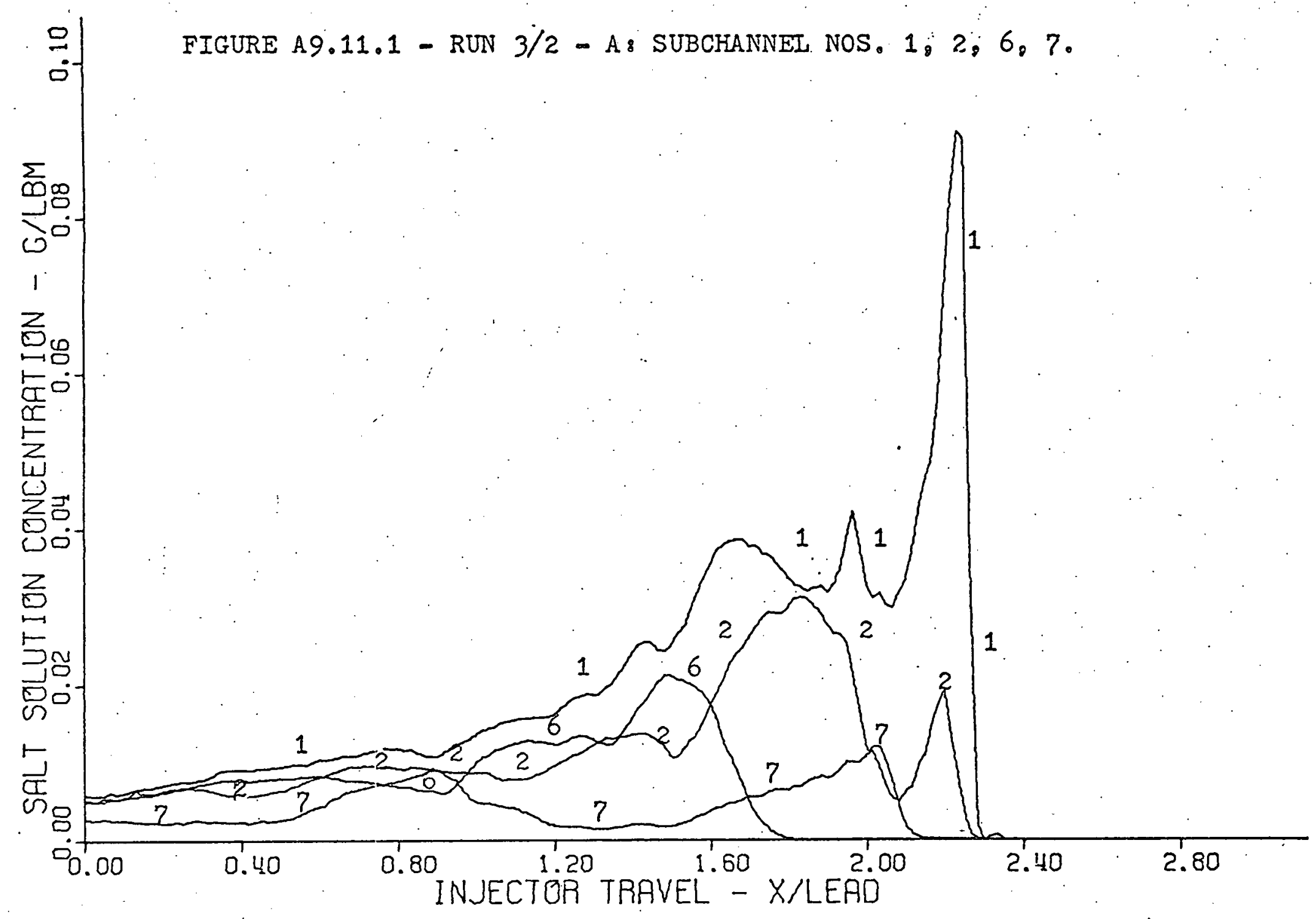




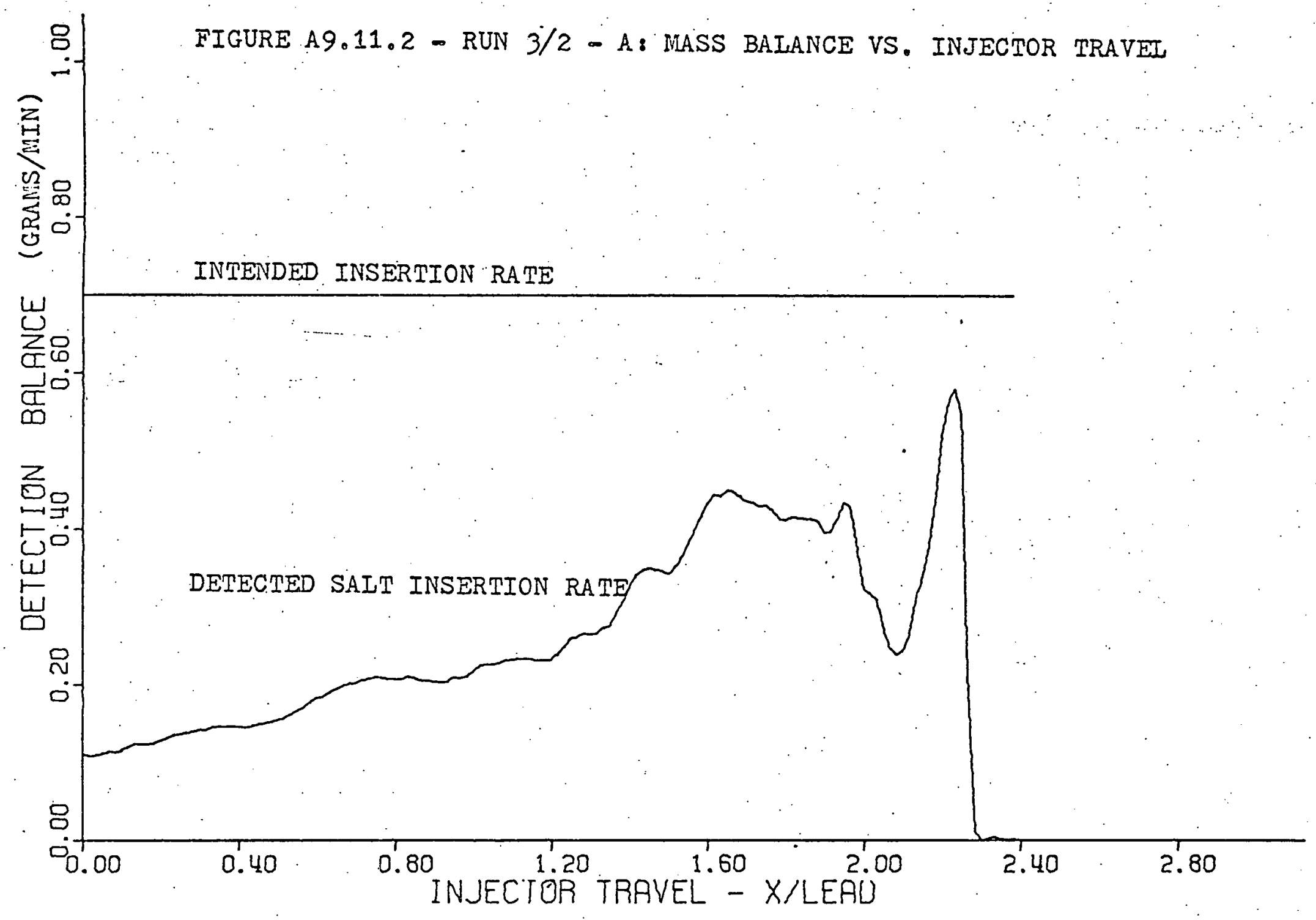




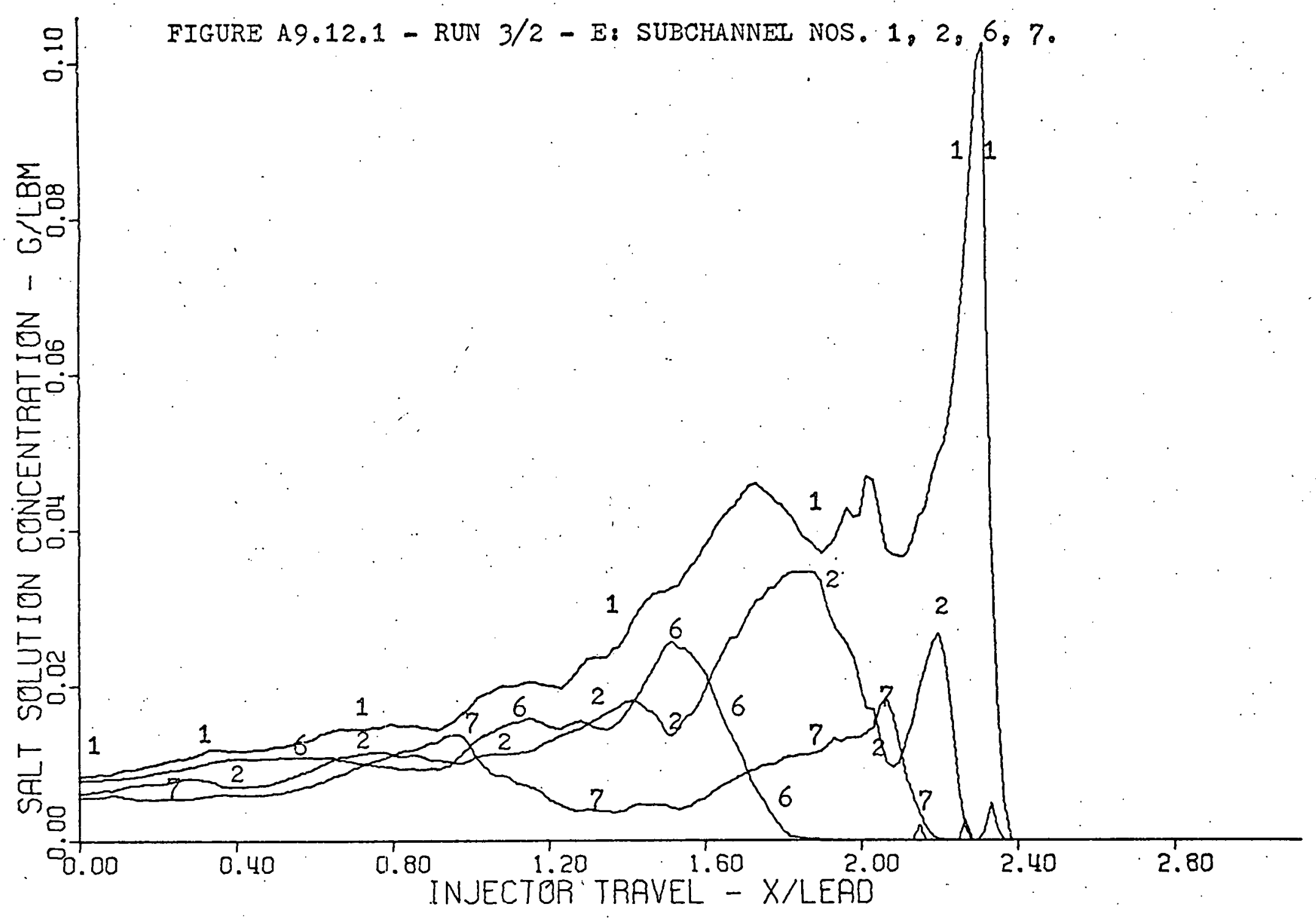




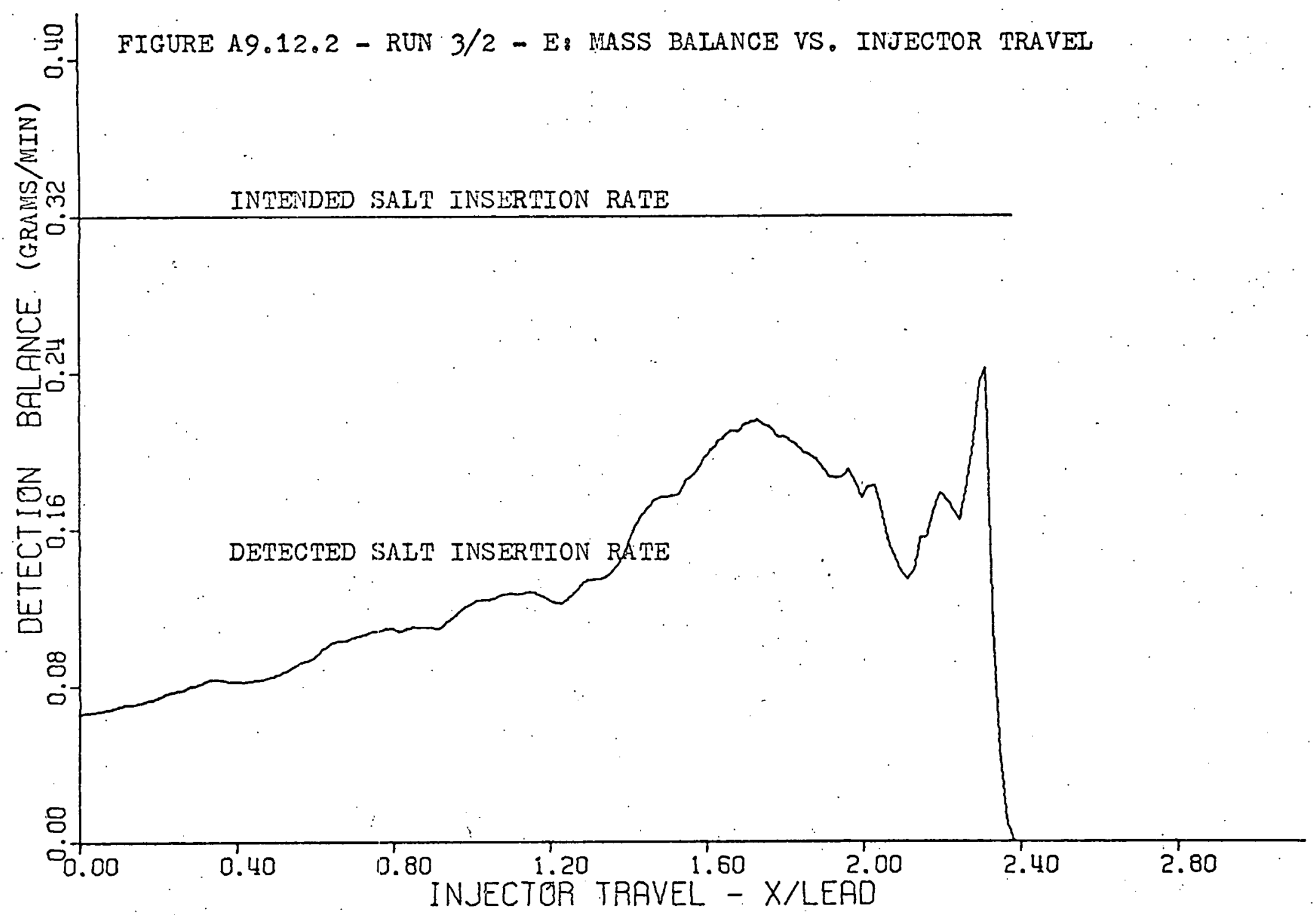




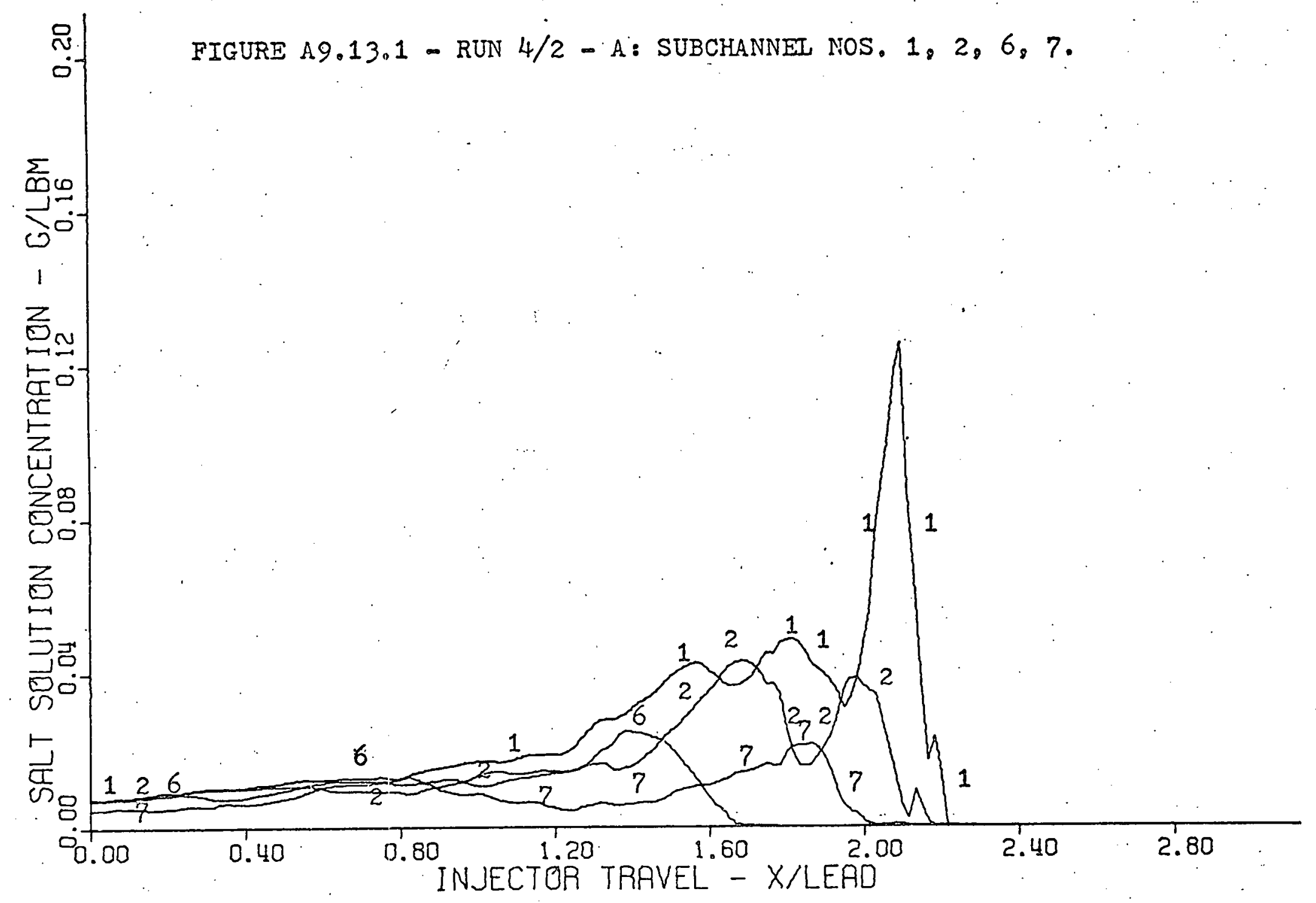




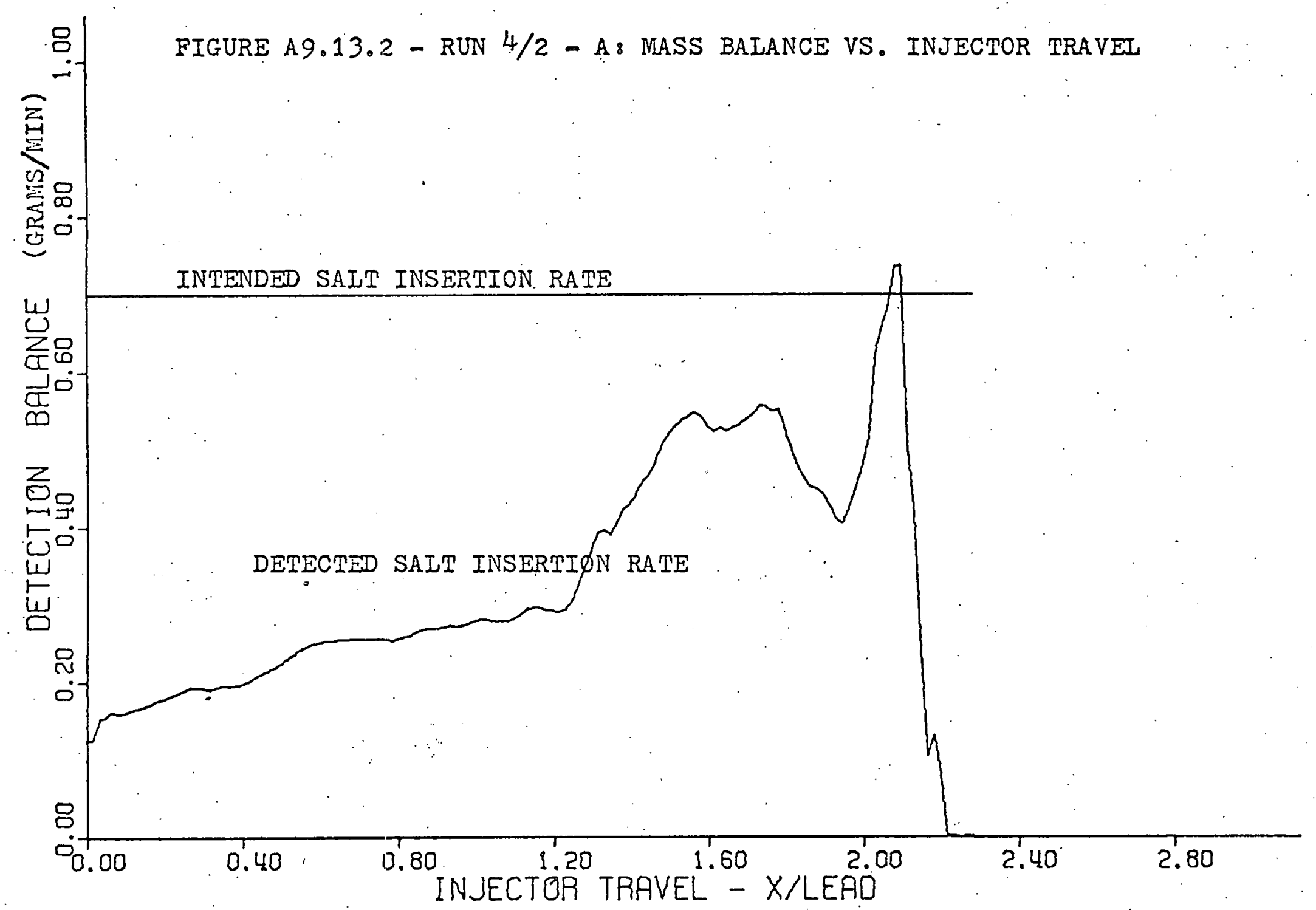




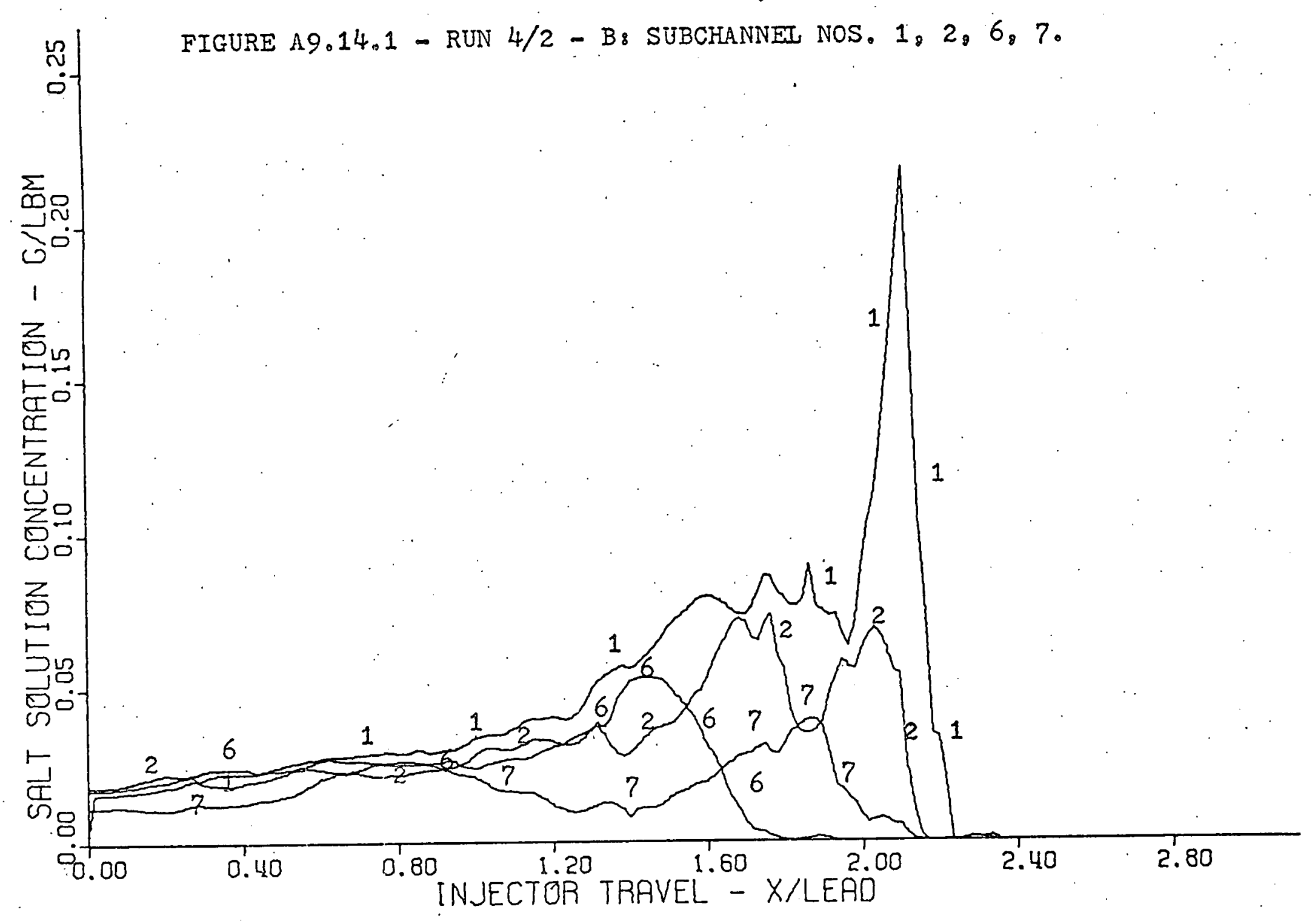




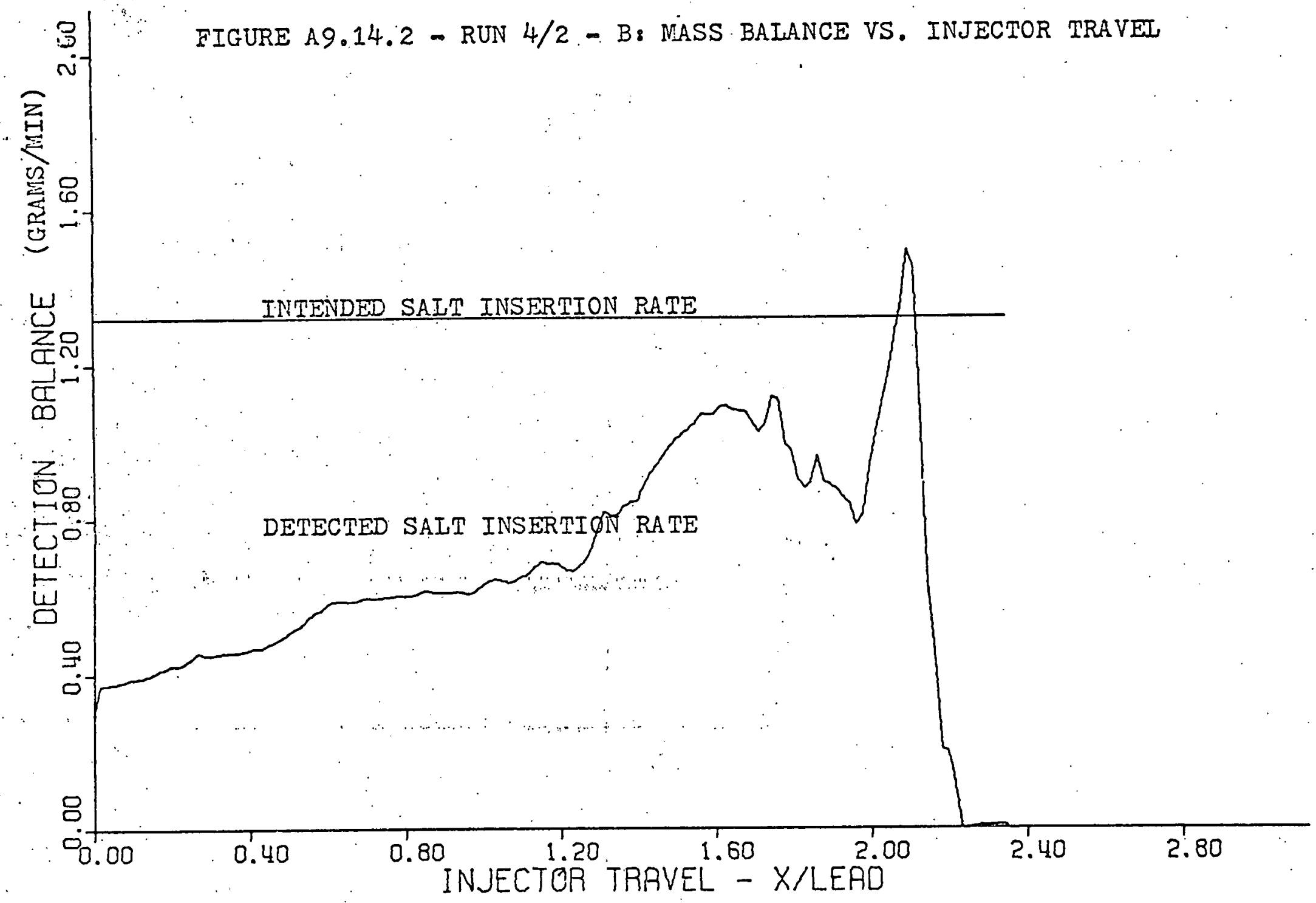




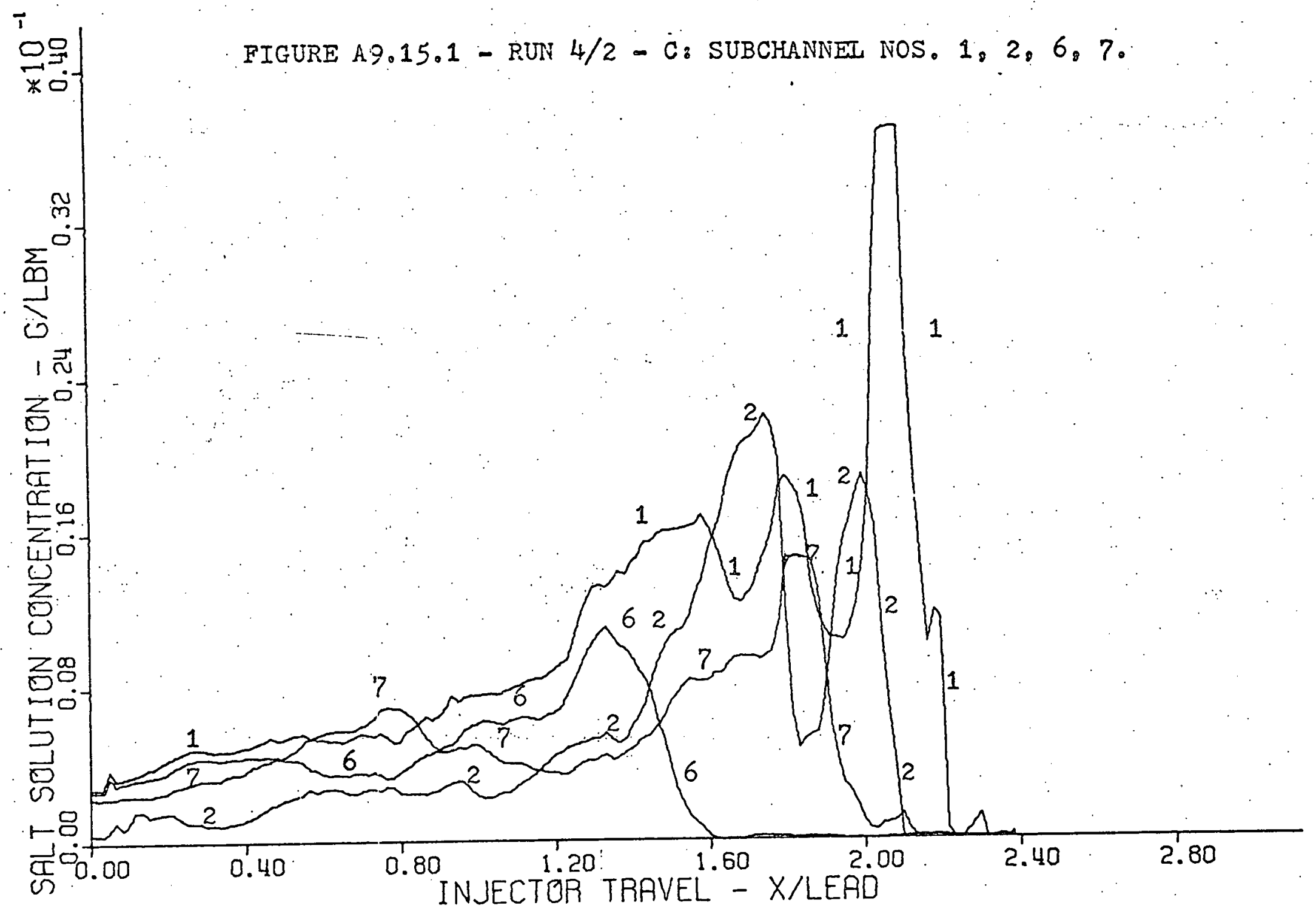




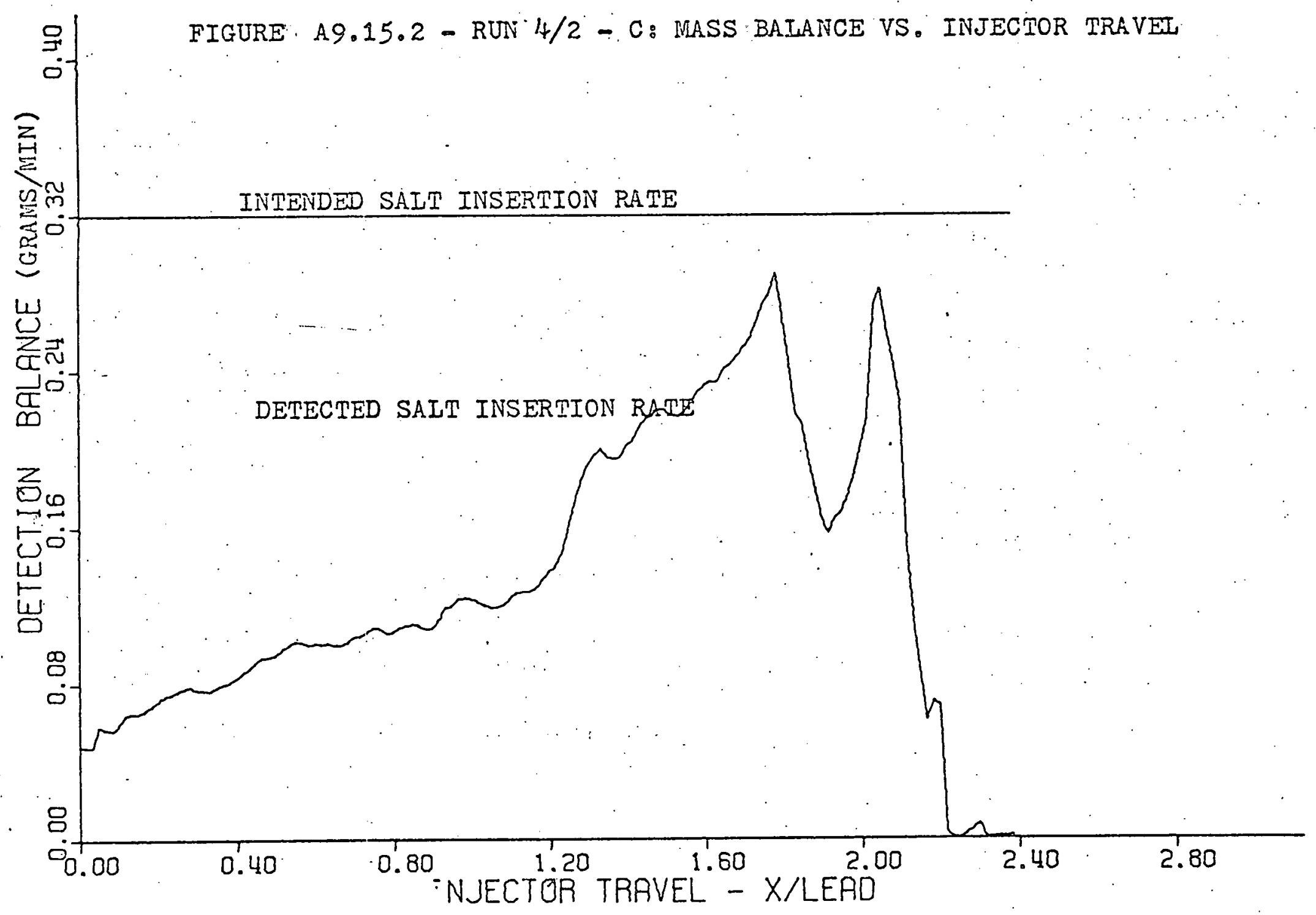




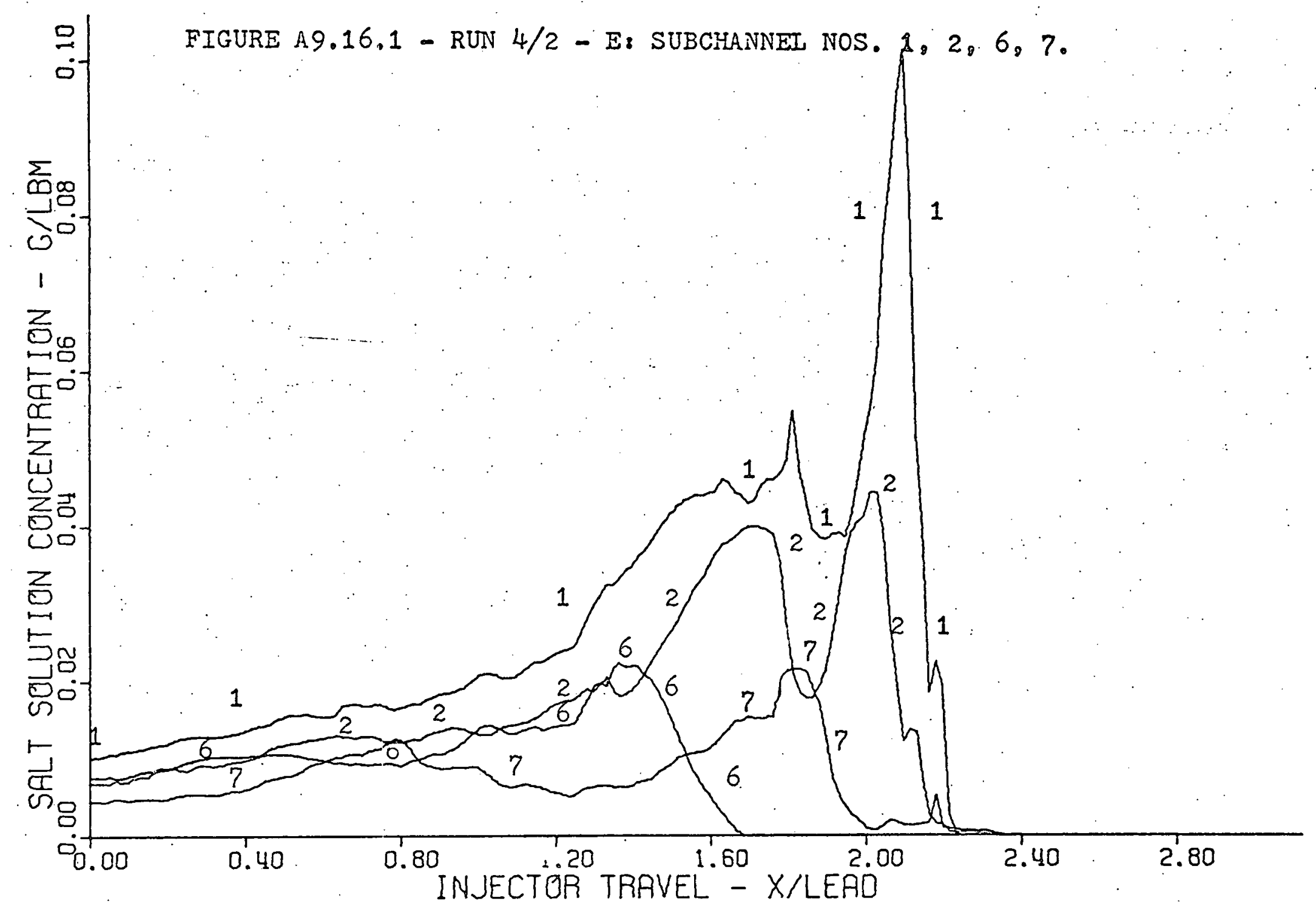




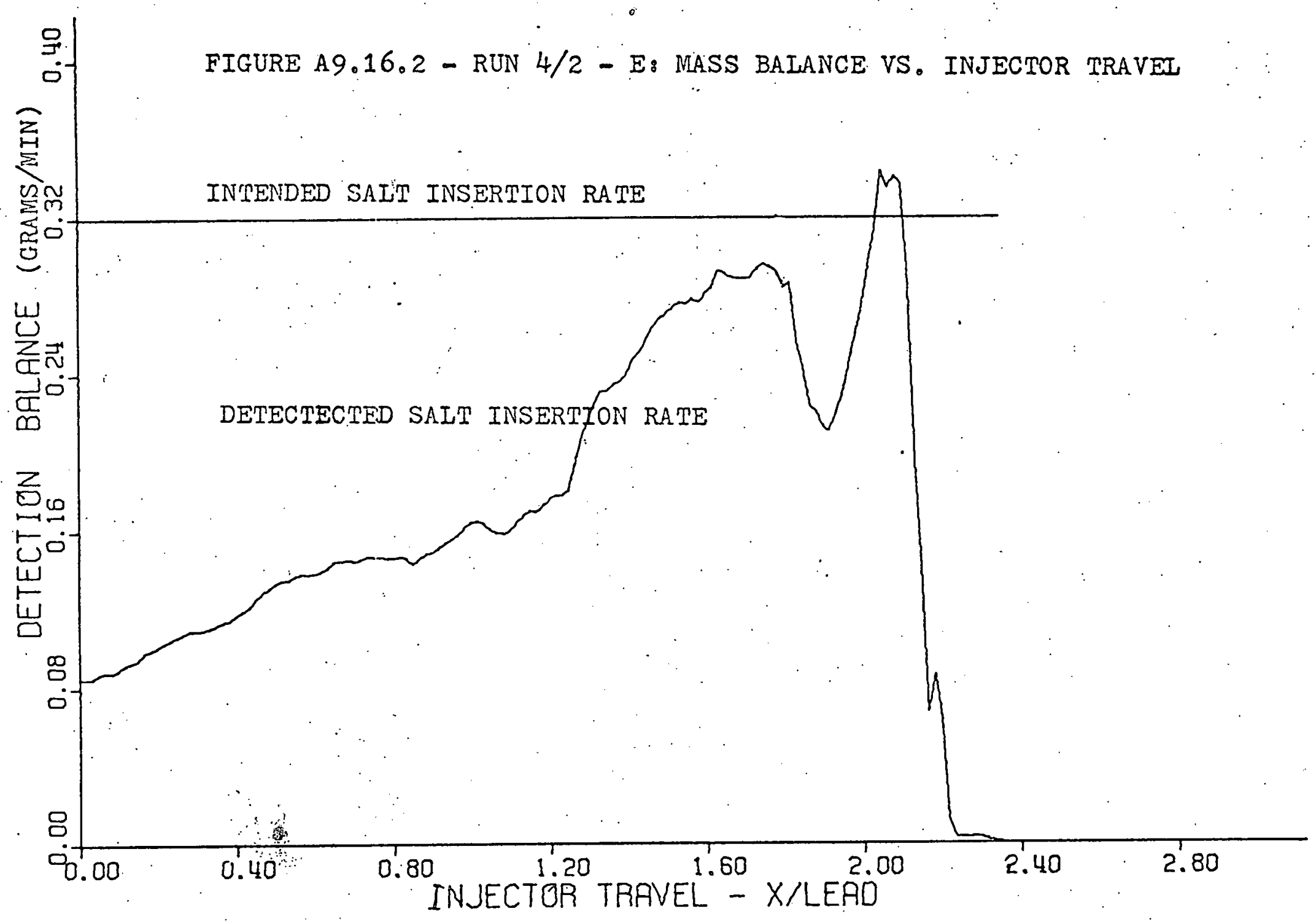




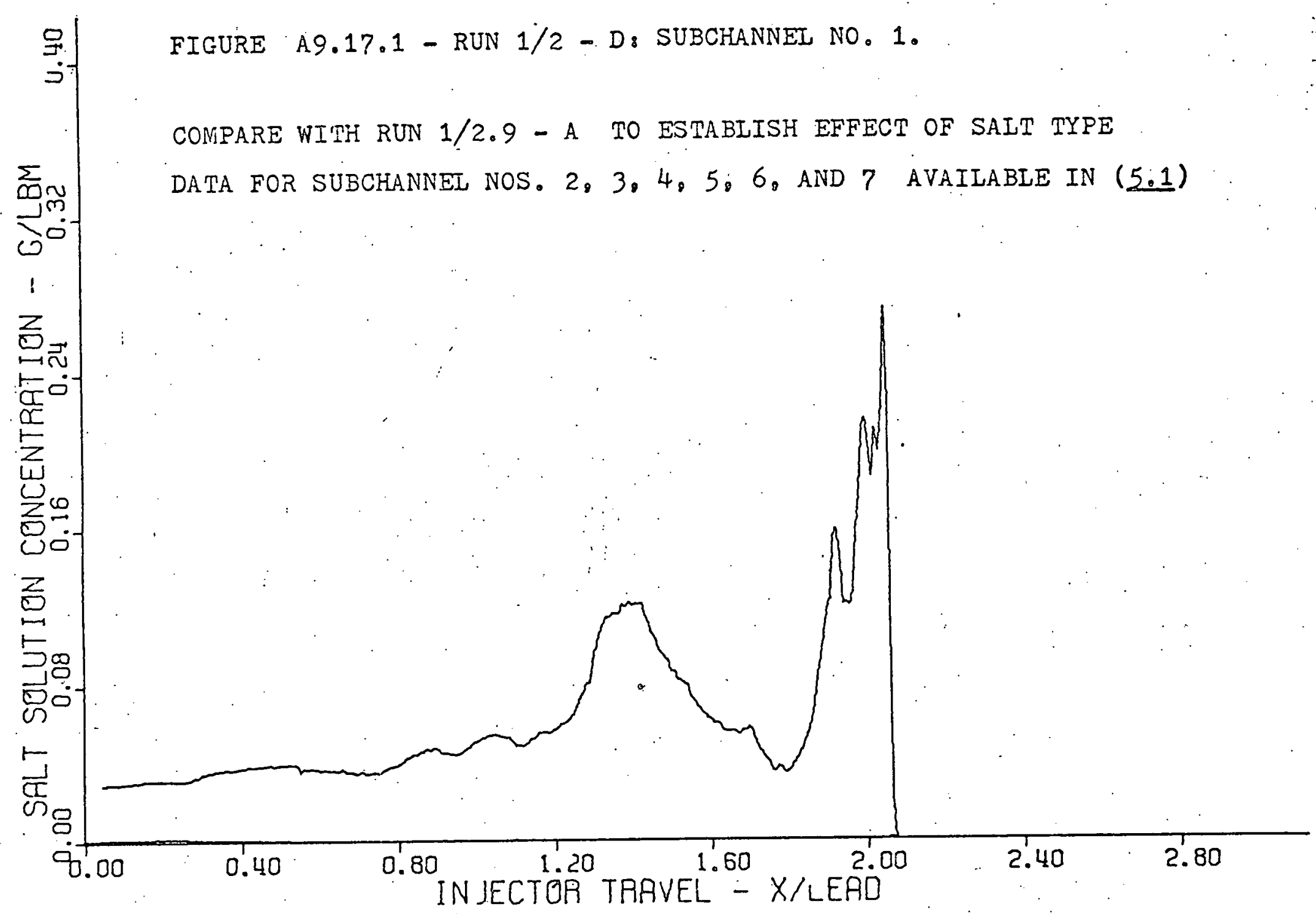




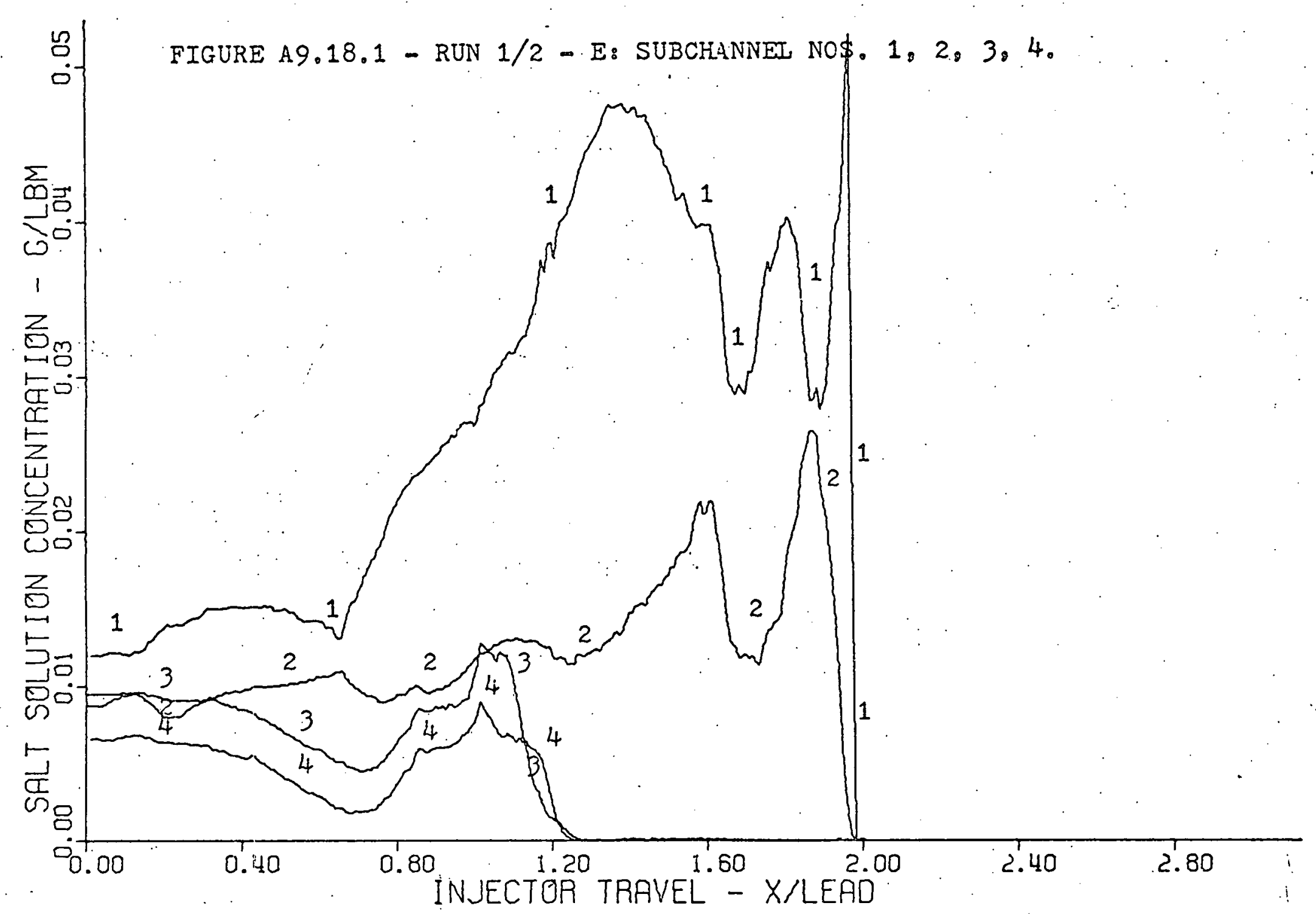




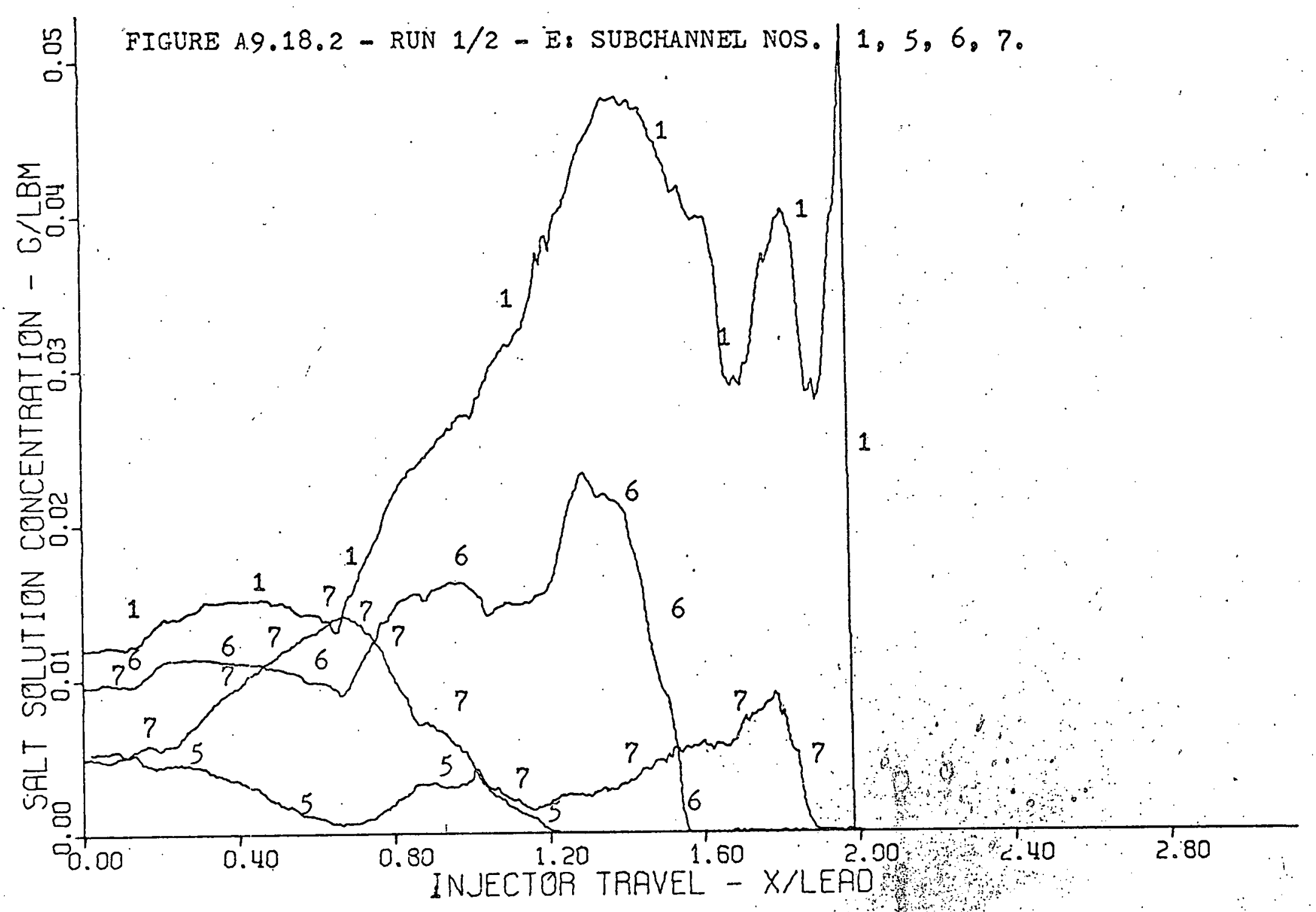




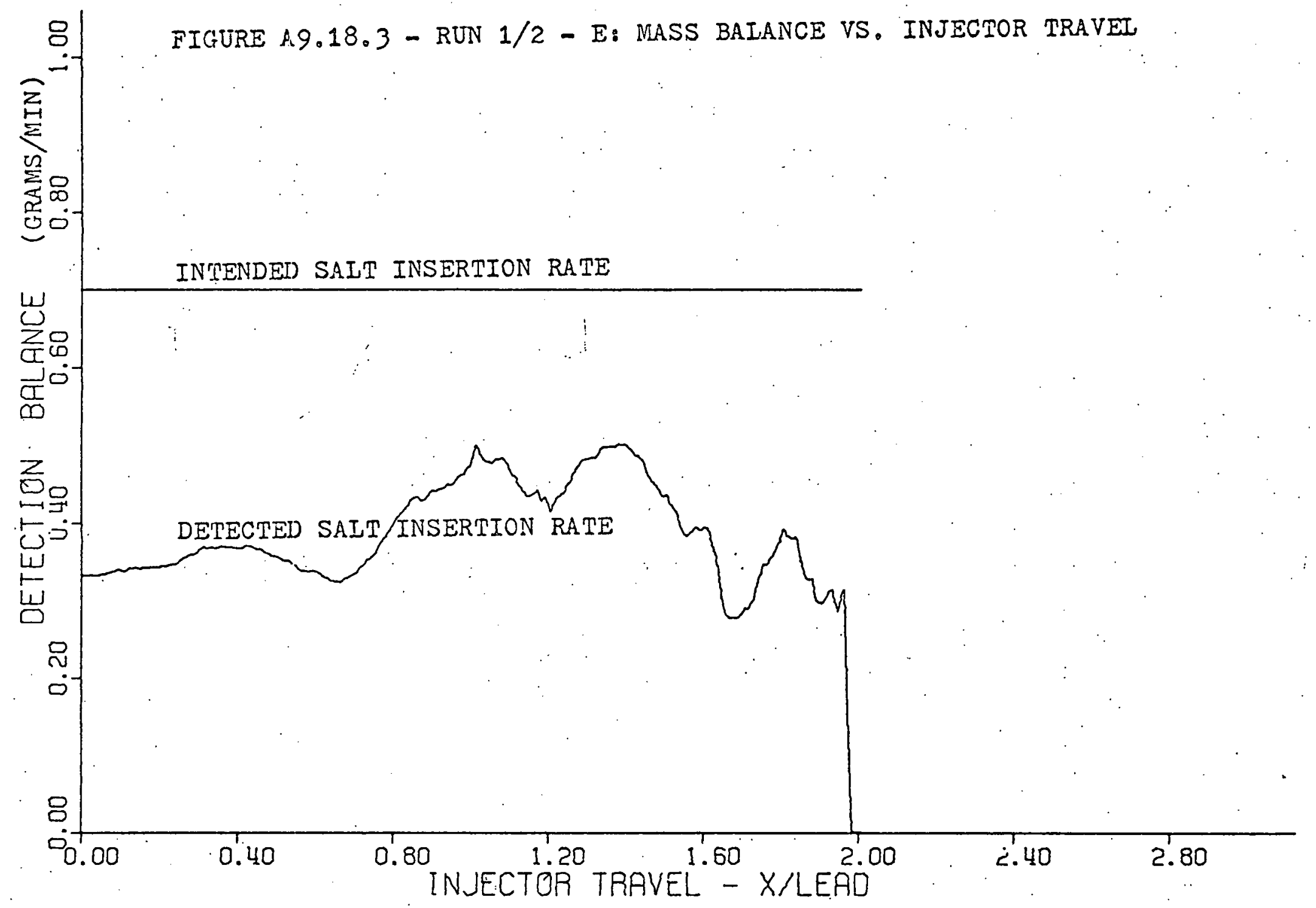




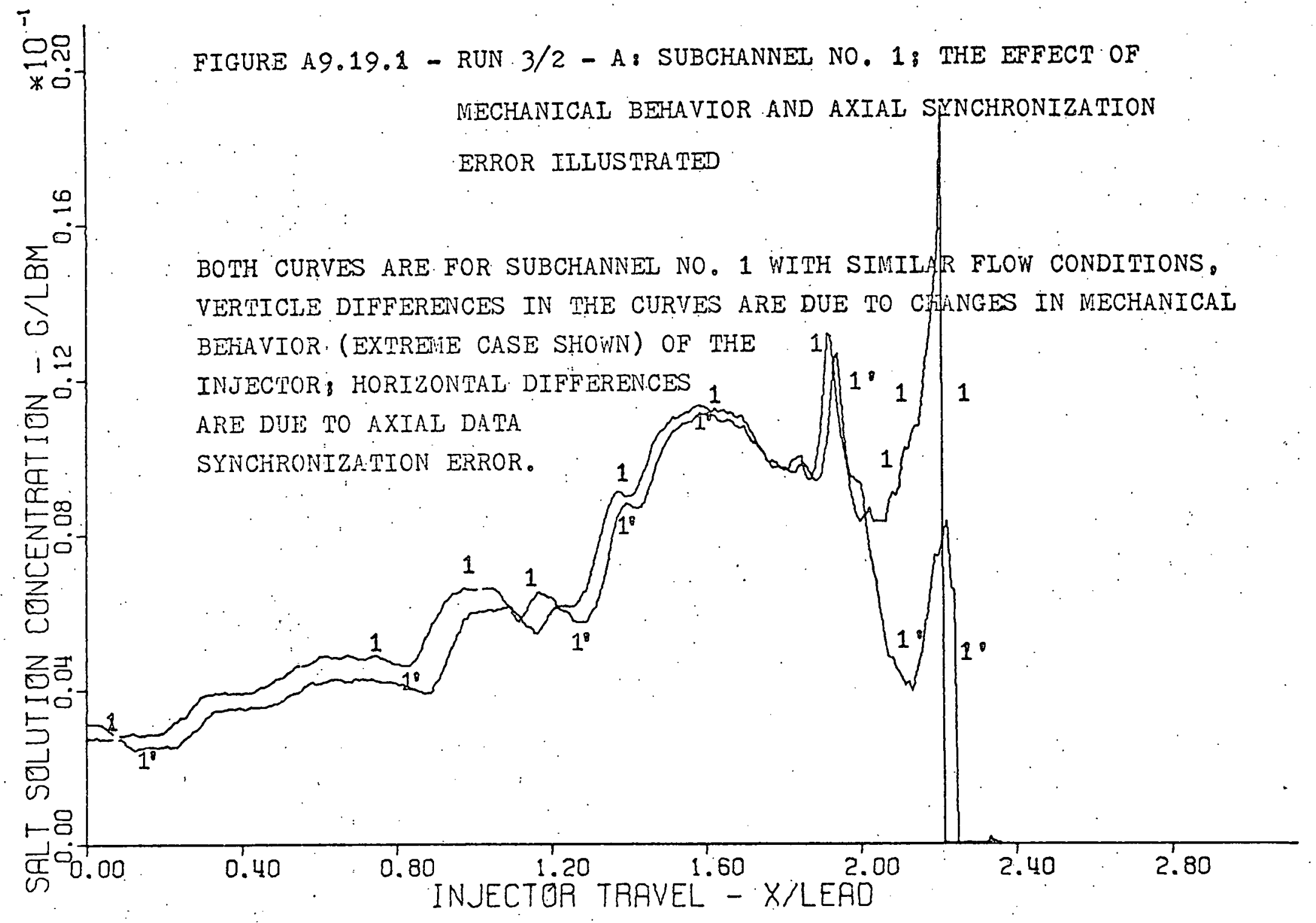




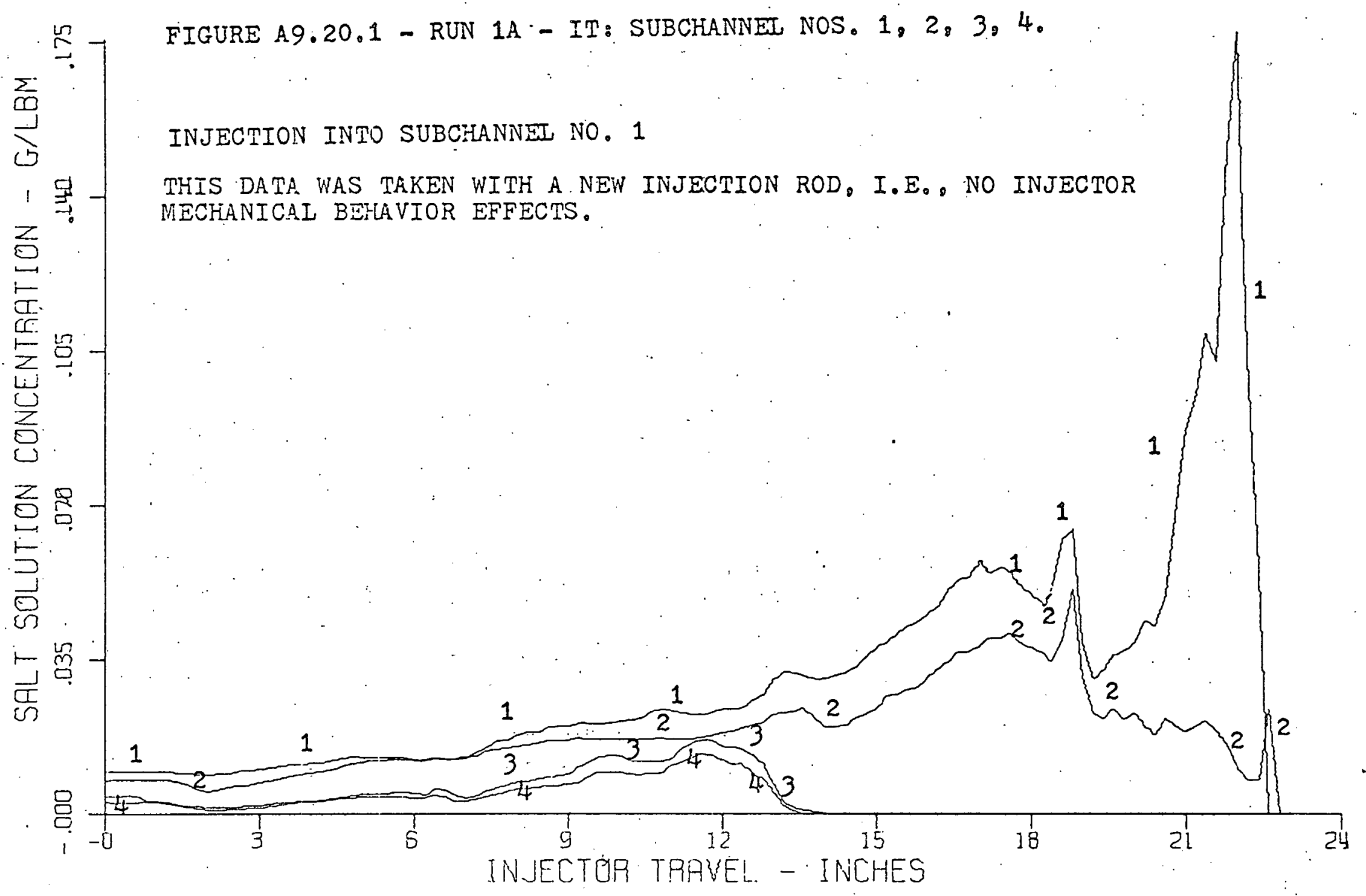




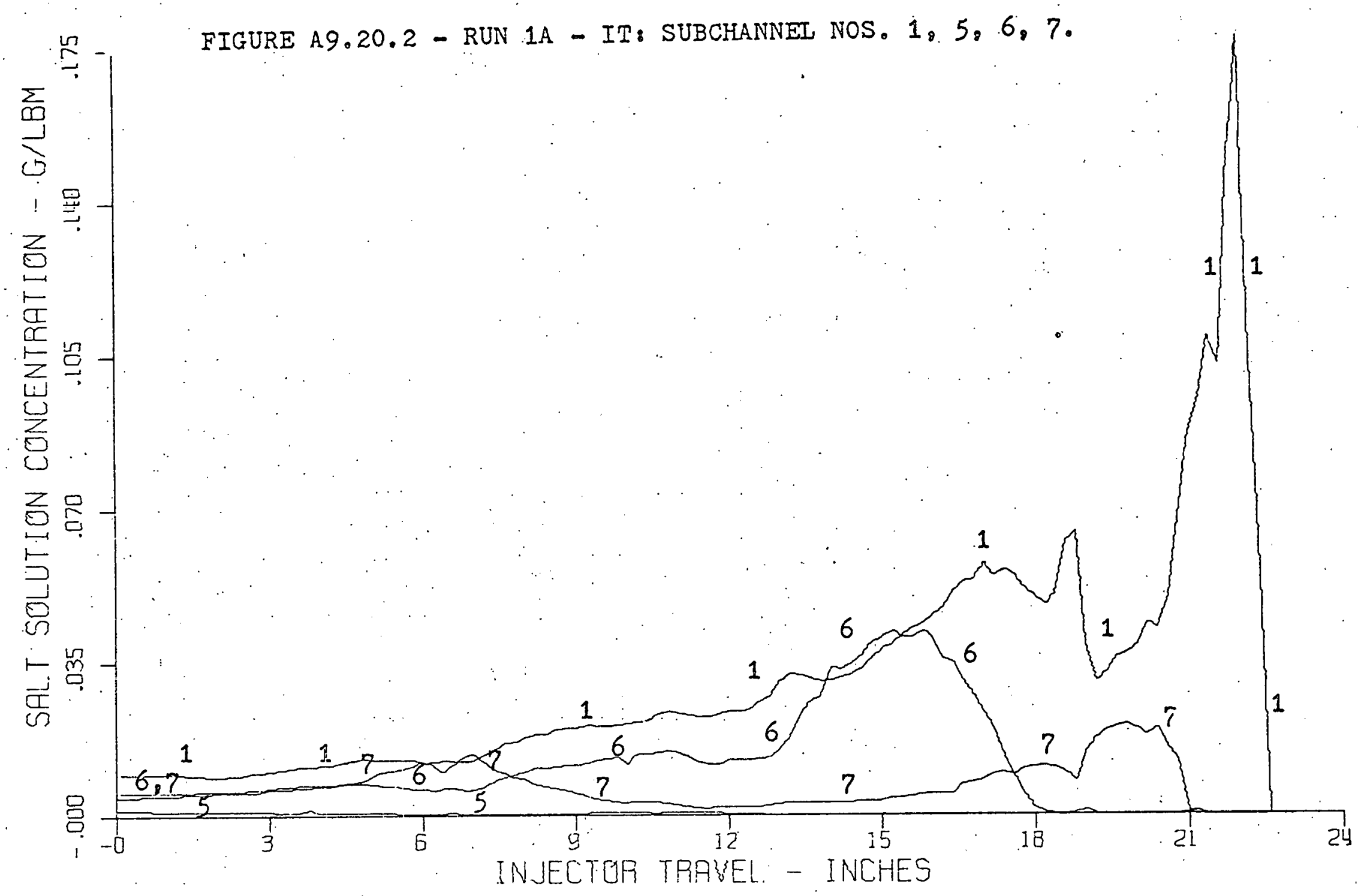

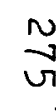




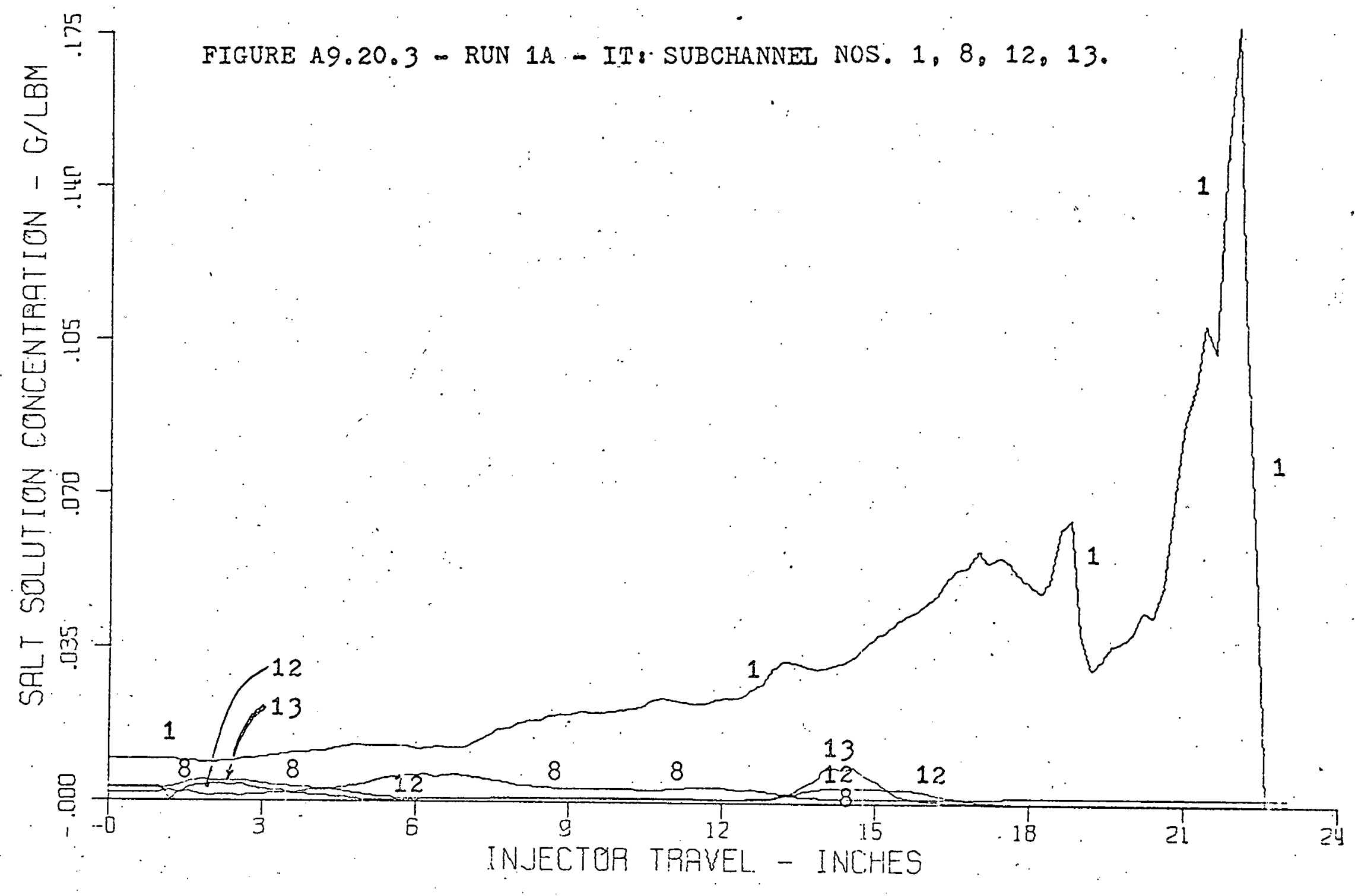




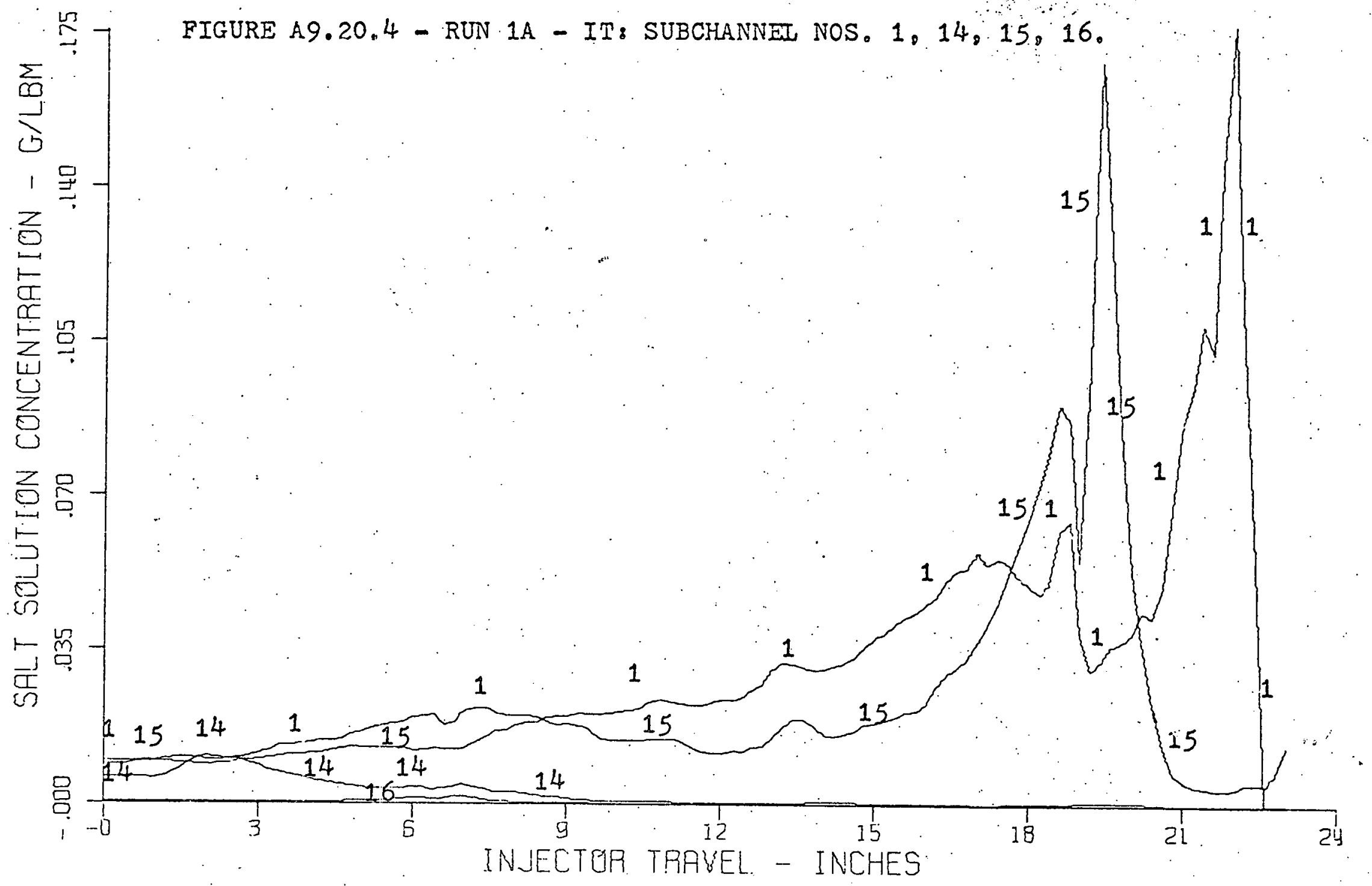




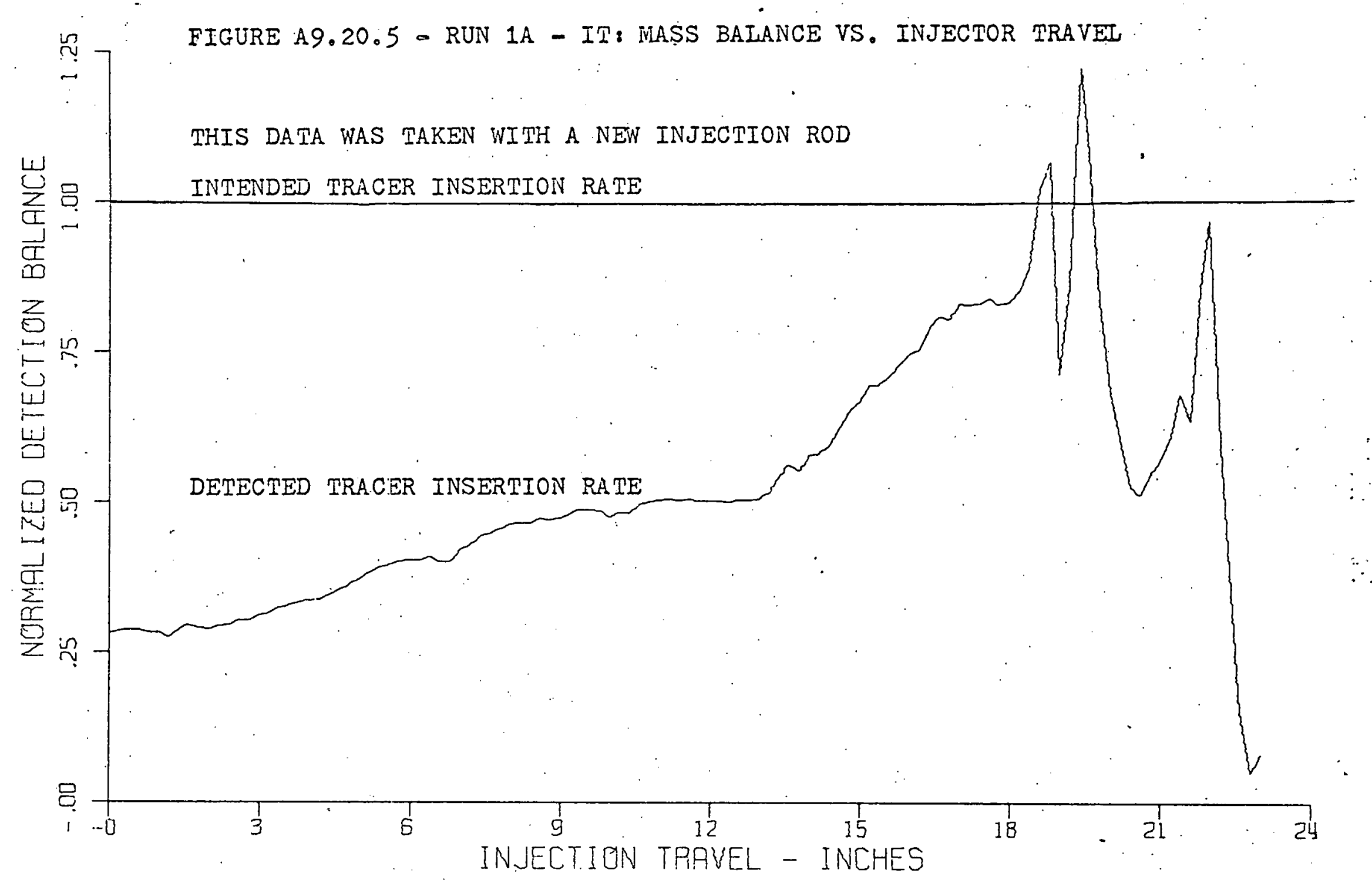

